\title{
DISMINUCIÓN DEL IMPACTO MEDIOAMBIENTAL DE PROCESOS DE MECANIZADO MEDIANTE COMBINACIÓN DE MICROPULVERIZACIÓN MQL Y REFRIGERACIÓN CRIOGÉNICA
}

Octavio M. Pereira Neto

Marzo 2017 

"Con paciencia y saliva..." 



\section{Agradecimientos}

Me gustaría aprovechar este apartado para agradecer a todas las personas que han estado implicadas de tal modo que han hecho posible la realización de esta tesis:

En primer lugar a mis directores de tesis, Joaquín y Anabel, por inculcarme "el veneno" de la investigación, que hace que ésta se haya convertido en mi modo de vida. También a Noberto, quien siempre tiene soluciones para cosas imposibles y a quien debo el gran salto de calidad que he realizado en estos últimos 4 años. No podría dejar aparte a Luis, Dani, Susana y Javi que en el inicio de este viaje fueron de gran ayuda. También a mis compañeros de despacho Egoitz, Iker y Rober con los cuales trabajar no sólo ha sido un placer, sino un honor (buenas risas nos hemos echado...). También a mis nuevos compis Exequiel y Haizea, algo me dice que grandes aventuras nos quedan por vivir. Además de ellos, también tengo unos compañeros de trabajo -más que compañeros son amigos- los cuales logran que cada día que paso aqui dentro sea especial. Entre ellos se encuentran (en orden alfabético) Aintzane, Amaia, Álvaro, Asier, Iñaki, Iñigo, Iván, Izaro, Gorka (Urbikain y Vidal), Leire, Magda, Mario, Silvia y Olatz, sin ellos el café de las 11 no hubiera sido lo mismo. Además, también quiero agradecer a los alumnos que han estado al pie del cañón como Marquitos, Oihane y Óscar; a los que están como Villén y Beretens; y a los que vienen: Mikel, Pablo y Ánder, el futuro es vuestro.

Por otra parte, me gustaría agradecer a mi familia por haberme criado y educado con todos los medios que han tenido a su disposición haciéndome sentir lo más especial del mundo mundial. A Ana por estar ahi desde pequeñitos a mi lado y a mi novia, cómo no, Esther gracias por aguantarme todo este tiempo! También me tengo que acordar de Iñaki, testigo de muchos de mis mitos y travesuras. Asimismo, tengo que tener en cuenta a mi eterna compañera de piso, Laura y mi casera, Mónica, así como Jairo, Nerea y Zeltia. Ellos han hecho que guarde muy buen recuerdo de mi estancia en León.

Por último, querría hacer especial mención a Adrián, el cual ha sido decisivo en la realización de esta tesis. En estos años ha sido mi gran apoyo. Siempre que lo he necesitado ha estado ahí, sabiendo qué decir en cada momento, haciéndome ver las cosas desde otra perspectiva y dispuesto a echar una mano siempre que lo he necesitado. Gracias, de verdad! ;) 



\section{Índice general}

I Introducción 1

1. Introducción 3

1.1. Contexto Industrial . . . . . . . . . . . . . . . . . . . . 3

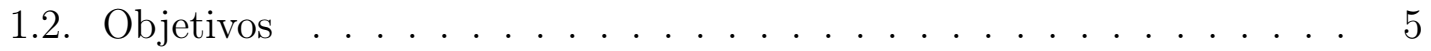

1.3. Organización de la memoria . . . . . . . . . . . . . 7

$\begin{array}{ll}\text { II Estado del arte } & 11\end{array}$

2. Estado del arte 13

2.1. Introducción . . . . . . . . . . . . . . . . . . . 13

2.2. Microlubricación mediante MQL . . . . . . . . . . . . . . 17

2.2.1. $\mathrm{I}+\mathrm{D}+\mathrm{i} \ldots \ldots \ldots \ldots \ldots$

2.2.2. Ámbito industrial . . . . . . . . . . . . . . . . 23

2.3. La refrigeración criogénica . . . . . . . . . . . . . . 27

2.3.1. $\mathrm{I}+\mathrm{D}+\mathrm{i} \ldots \ldots \ldots \ldots \ldots$

2.3.2. Ámbito industrial . . . . . . . . . . . . . . . . 35

2.4. Análisis de ciclo de vida . . . . . . . . . . . . . . . . . . . . . . 41

2.4.1. $\mathrm{I}+\mathrm{D}+\mathrm{i} \ldots \ldots \ldots \ldots \ldots 4 . \ldots \ldots \ldots$

2.5. Conclusiones . . . . . . . . . . . . . . . . . . . 46

III Desarrollo y adaptación de sistemas de inyección criogénicos

3. Desarrollo y adaptación de sistemas de inyección criogénicos $\quad 53$

3.1. Introducción . . . . . . . . . . . . . . . . . . . . 53 
3.2. Equipos de alimentación . . . . . . . . . . . . . 53

3.2.1. Equipo de regulación de $\mathrm{CO} 2 \ldots \ldots \ldots \ldots$

3.2.2. Equipo de almacenamiento de $\mathrm{LN} 2 \ldots \ldots \ldots$

3.2.3. Equipo de pulverización para MQL . . . . . . . . . . 57

3.3. Sistemas de inyección para $\mathrm{CO} 2 \ldots \ldots \ldots \ldots$

3.3.1. Simulación mediante CFD y validación del modelo matemático. Diámetro y velocidad óptima de salida . . . . . . . . . 59

3.3.2. Adaptación y desarrollo de los sistemas de inyección . . . . . . 67

3.4. Sistemas de inyección para LN2 . . . . . . . . . . . . . 70

3.5. Toberas "Plug \& Play" CryoMQL . . . . . . . . . . . . . . . . 71

3.6. Conclusiones . . . . . . . . . . . . . . . . . . . . . 75

$\begin{array}{lll}\text { IV Ensayos experimentales } & 77\end{array}$

4. Ensayos experimentales $\quad 79$

4.1. Introducción . . . . . . . . . . . . . . . . . . . . 79

4.2. Materiales, máquinas y equipos utilizados . . . . . . . . . . 79

4.3. Torneado de AISI 304L . . . . . . . . . . . . . . . . . 85

4.3.1. Introducción . . . . . . . . . . . . . . . . 85

4.3.2. Montaje y metodología experimental . . . . . . . . . . 87

4.3.3. Resultados . . . . . . . . . . . . . . . . . . . . . . 89

4.3.4. Discusión de los resultados - AISI 304L . . . . . . . . . 97

4.4. Torneado en duro de ASP23 . . . . . . . . . . . . . . . . 98

4.4.1. Introducción . . . . . . . . . . . . . . . . . . 98

4.4.2. Montaje y metodología experimental . . . . . . . . . . . 99

4.4.3. Resultados . . . . . . . . . . . . . . . . . . 100

4.4.4. Discusión de los resultados - ASP23 . . . . . . . . . . . 104

4.5. Fresado Inconel $718 \ldots \ldots$. . . . . . . . . . . . . . . 105

4.5.1. Introducción . . . . . . . . . . . . . . . . . . . 105

4.5.2. Montaje y metodología experimental . . . . . . . . . . 105

4.5.3. Resultados . . . . . . . . . . . . . . . . . . 107

4.5.4. Discusión de los resultados - Inconel 718 . . . . . . . . . 109

4.6. Taladrado Stacks Ti6Al4V-CFRP . . . . . . . . . . . . . 110

4.6.1. Introducción . . . . . . . . . . . . . . . . . . 110

4.6.2. Montaje y metodología experimental . . . . . . . . . . . 110 
4.6.3. Resultados . . . . . . . . . . . . . . . . . . 112

4.6.4. Discusión de los resultados - Ti6Al4V-CFRP . . . . . . . . 115

4.7. Conclusiones . . . . . . . . . . . . . . . . . . . 116

$\begin{array}{lll}\text { V Análisis de ciclo de vida } & 119\end{array}$

5. Análisis de ciclo de vida (ACV) 121

5.1. Introducción . . . . . . . . . . . . . . . . . . . . . . . 121

5.2. Definición y objetivo del alcance del ACV . . . . . . . . . . . . . 121

5.3. Análisis de inventario (ICV) . . . . . . . . . . . . . . . . . 126

5.4. Evaluación del impacto ambiental . . . . . . . . . . . . . . . . . . 128

5.5. Interpretación del ciclo de vida (ICV) . . . . . . . . . . . . . . . 129

5.6. Conclusiones . . . . . . . . . . . . . . . . . . . . . . . 131

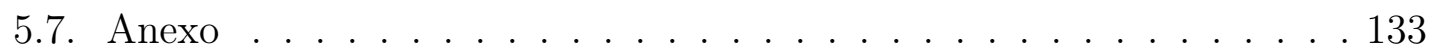

\section{Desarrollo y validación del equipo CryoMQL propues-}

to

6. Desarrollo y validación del equipo CryoMQL propuesto 147

6.1. Introducción . . . . . . . . . . . . . . . . . . . . . . . 147

6.2. Finalidad del equipo CryoMQL . . . . . . . . . . . . . . . . 147

6.3. Descripción de los sistemas que componen el equipo CryoMQL . . . . 148

6.3.1. El sistema criogénico . . . . . . . . . . . . . . . . . . 148

6.3.2. El sistema MQL . . . . . . . . . . . . . . . . . . 150

6.4. Composición y funcionamiento del Equipo . . . . . . . . . . . . . . . 151

6.5. Validación del equipo CryoMQL . . . . . . . . . . . . . . . . . 156

6.5.1. Montaje y metodología experimental . . . . . . . . . . . 156

6.5.2. Resultados . . . . . . . . . . . . . . . . . . . 159

6.5.3. Discusión de los resultados - Inconel 718 . . . . . . . . . . . . 162

6.6. Conclusiones . . . . . . . . . . . . . . . . . . . . . . . 162

VII Aportaciones y líneas futuras 165

7. Aportaciones y líneas futuras $\quad 167$

7.1. Introducción . . . . . . . . . . . . . . . . . . 167 
7.2. Aportaciones . . . . . . . . . . . . . . . . . 168

7.3. Publicaciones . . . . . . . . . . . . . . . . 171

7.3.1. Revistas indexadas . . . . . . . . . . . . . . . 171

7.3.2. Congresos y conferencias . . . . . . . . . . . . . 172

7.3.3. Patentes . . . . . . . . . . . . . . . . . . 172

7.3.4. Revistas técnicas . . . . . . . . . . . . . 173

7.4. Líneas futuras . . . . . . . . . . . . . . . . . . . . . . 174 


\section{Índice de figuras}

2.1. Clasificación de los fluidos de corte de origen mineral . . . . . . . . . 13

2.2. Esquema sistema MQL . . . . . . . . . . . . . . . . . . . . . . . . 18

2.3. Esquema tipos de sistemas MQL . . . . . . . . . . . . . . . . 19

2.4. Esquema sistema COD . . . . . . . . . . . . . . . . . 21

2.5. Esquema sistema CAMQL . . . . . . . . . . . . . . . . 22

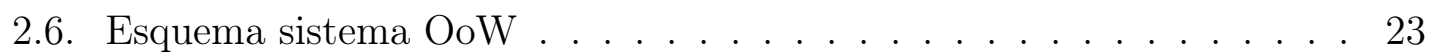

2.7. Esquema sistema MWD . . . . . . . . . . . . . . . . . 23

2.8. Sistema "Serv-O-Spray®" . . . . . . . . . . . . . . . . . . . . . 24

2.9. Gama equipos MQL de Steidle . . . . . . . . . . . . . . . . 25

2.10. Gama equipos MQL de Accu-Lube . . . . . . . . . . . . . . . 26

2.11. Componentes neumáticos encargados de regular el caudal de aceite en los sistemas MQL . . . . . . . . . . . . . . . . . . . . . 27

2.12. Estado del inserto tras 20 minutos torneado en AISI 304 . . . . . . . 30

2.13. Vida de herramienta durante el torneado de Ti6Al4V . . . . . . . . . 32

2.14. Microestructura y microdurezas obtenidas durante el torneado de Inconel $718 \ldots \ldots \ldots$. . . . . . . . . . . . . . . . . . . 34

2.15. Presentación de la línea Criogénica de MAG en EMO 2011 . . . . . . 36

2.16. Línea de productos criogénicos de CoolClean . . . . . . . . . . . . . 38

2.17. Línea de productos criogénicos de Rother . . . . . . . . . . . . . . . . 39

2.18. Funcionamiento de la línea "Walter Cryo Tec®" . . . . . . . . . . . 40

2.19. Resultados obtenidos en el ACV por Pusavec et al. 2010 . . . . . . . 44

2.20. Resultados obtenidos en el ACV por Fratila et al. 2010 . . . . . . . . 45

2.21. Etapas que conforman la tesis . . . . . . . . . . . . . . . . . 50

3.1. Diagrama de fases del CO2 . . . . . . . . . . . . . . 54

3.2. Sistema de regulación de $\mathrm{CO} 2 \ldots \ldots \ldots 55$

3.3. Diagrama de fases del LN2 . . . . . . . . . . . . . . . . 56 
3.4. Sistema de almacenamiento de LN2 . . . . . . . . . . . . . . . 57

3.5. Sistema de pulverización de aceite . . . . . . . . . . . . . . 58

3.6. Banco de ensayos para la validación de CFD . . . . . . . . . . . . 59

3.7. Diagrama de flujo del algoritmo de resolución PISO . . . . . . . . . . 64

3.8. Características de la malla utilizada . . . . . . . . . . . . . . . . . . . 64

3.9. Simulaciones realizadas de los diámetros analizados para salida de CO2 65

3.10. Resultados empíricos obtenidos para los diferentes orificios de salida de $\mathrm{CO} 2 \ldots \ldots \ldots \ldots 6 \ldots$

3.11. Comparación resultados reales con CFD . . . . . . . . . . . . 67

3.12. CO2 "stand alone" externo . . . . . . . . . . . . . . . . 68

3.13. CO2 "stand alone" interno . . . . . . . . . . . . . . . . . 68

3.14. CO2 "stand alone" interno . . . . . . . . . . . . . . . . . . . 69

3.15. CO2 "stand alone" en torneado . . . . . . . . . . . . . . . . 70

3.16. Adaptadores para inyección de CryoMQL . . . . . . . . . . . . . . 71

3.17. Características mallado de los adaptadores . . . . . . . . . . . . . . 72

3.18. Resultados obtenidos de las simulaciones mediante CFD . . . . . . . 74

3.19. Adaptador convergente CryoMQL aplicado al fresado . . . . . . . . . 74

4.1. Microestructura AISI 304L . . . . . . . . . . . . . . . . . 80

4.2. Microestructura ASP23 . . . . . . . . . . . . . . . . . . . . 81

4.3. Microestructura Inconel 718 . . . . . . . . . . . . . . . . . 82

4.4. Montaje experimental para el torneado de AISI 304L . . . . . . . . 88

4.5. Vida de herramienta durante torneado de AISI 304L . . . . . . . . . 89

4.6. Fuerzas de corte en torneado de AISI 304L . . . . . . . . . . . . . . . 91

4.7. Rugosidad obtenida durante el torneado de AISI 304L . . . . . . . . . 94

4.8. Topología superficial obtenida durante el torneado de AISI 304L . . . 95

4.9. Capa deformada en microestructura de AISI 304L . . . . . . . . . . 95

4.10. Dureza de AISI 304L después del torneado . . . . . . . . . . . . . . 96

4.11. Montaje experimental para el torneado en duro de ASP23 . . . . . . 100

4.12. Evolución del desgaste de herramienta al tornear en duro ASP23 . . . 101

4.13. Evolución de la rugosidad al tornear en duro ASP23 . . . . . . . . . . 102

4.14. Microestructuras obtenidas al tornear en duro ASP23 . . . . . . . . 103

4.15. Montaje experimental y geometría de la herramienta para el fresado de Inconel 718 . . . . . . . . . . . . . . . . . . . . . . . . 105

4.16. Evolución de vida de herramienta durante el fresado de Inconel 718 . 107 
4.17. Evolución del desgaste de las herramientas en la cara de incidencia durante el fresado de Inconel 718 . . . . . . . . . . . . . . . . . . . 108

4.18. Estado de los insertos después de 7 minutos mecanizados . . . . . . 108

4.19. Montaje experimental para el taladrado de composite CFRP-Ti6Al4V 111

4.20. Diámetros obtenidos durante el taladrado de stacks CFRP-Ti6Al4V . 112

4.21. Temperatura de la punta de herramienta al taladrar stacks CFRPTi6Al4V . . . . . . . . . . . . . . . . . 113

4.22. Imágenes de las brocas al taladrar stacks CFRP-Ti6Al4V . . . . . . 113

4.23. Altura de rebaba al taladrar stacks CFRP-Ti6Al4V . . . . . . . . . . 114

4.24. Potencia consumida por el husillo al taladrar stacks CFRP-Ti6Al4V . 114

4.25. Estado de la herramienta y el CFRP tras el taladrado de 160 agujeros 115

5.1. Límites del sistema . . . . . . . . . . . . . . . . . . . . . . 123

5.2. Diagrama de red resultados ACV . . . . . . . . . . . . . . 130

6.1. Esquema de montaje del sistema criogénico . . . . . . . . . . . . . . 149

6.2. Esquema de montaje sistema MQL . . . . . . . . . . . . . . . . 151

6.3. Equipo CryoMQL instalado en Ibarmia ZV-25 . . . . . . . . . . . . 152

6.4. Componentes externos del equipo CryoMQL . . . . . . . . . . . . . . 152

6.5. Componentes internos del equipo CryoMQL . . . . . . . . . . . . . 153

6.6. Conexiones del equipo CryoMQL . . . . . . . . . . . . . . . . 153

6.7. Algoritmo equipo CryoMQL . . . . . . . . . . . . . . . . . 154

6.8. Esquema de montaje del equipo CryoMQL . . . . . . . . . . . . . 156

6.9. Esquema de montaje experimental . . . . . . . . . . . . . . . . 157

6.10. Características del mallado utilizado . . . . . . . . . . . . . . . 158

6.11. Longitudes mecanizadas . . . . . . . . . . . . . . . . . . 159

6.12. Imágenes de los filos en su final de vida . . . . . . . . . . . . . . . . 159

6.13. Resultados de las simulaciones . . . . . . . . . . . . . . . . . 160

6.14. Imágenes de los filos en diferentes etapas de los ensayos . . . . . . . . 161 



\section{Índice de tablas}

2.1. Ventajas e inconvenientes de las emulsiones . . . . . . . . . . . . . . . 14

3.1. Características de los bloques de mallado . . . . . . . . . . . 73

4.1. Propiedades acero inoxidable AISI $304 \mathrm{~L} \ldots \ldots$. . . . . . . . . . 80

4.2. Propiedades acero ASP23 . . . . . . . . . . . . . . 81

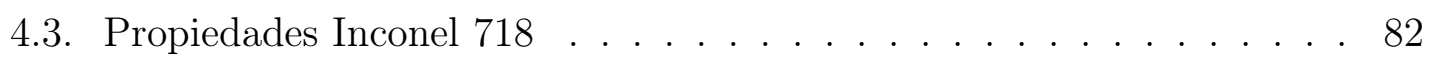

4.4. Propiedades CFRP . . . . . . . . . . . . . . . . . . . . . . 83

4.5. Propiedades Ti6Al4V solubilizado . . . . . . . . . . . . . . 83

4.6. Máquinas-herramienta utilizadas . . . . . . . . . . . . . . . . . 84

4.7. Equipos de medición utilizados . . . . . . . . . . . . . . . 85

4.8. Características de insertos, portaherramientas y condiciones de corte utilizadas . . . . . . . . . . . . . . . . 86

4.9. Técnicas de lubricación evaluadas en torneado . . . . . . . . . . . 87

4.10. Cálculo del intervalo de confianza (T-Student) . . . . . . . . . . . . . 92

4.11. Características técnicas de insertos y condiciones de corte . . . . . . . 99

4.12. Condiciones de corte para el fresado de Inconel 718 . . . . . . . . . . 106

4.13. Técnicas de lubricación evaluadas en torneado . . . . . . . . . . . 106

4.14. Características del composite y condiciones de corte utilizadas . . . . 111

5.1. Resumen de categorías de impacto utilizadas . . . . . . . . . . . . . . 124

5.2. Datos recopilados por la formación de $1 \mathrm{~kg}$ de taladrina . . . . . . . 133

5.3. Datos recopilados por la formación de $1 \mathrm{~kg}$ de LN2 . . . . . . . . . 133

5.4. Datos recopilados por la formación de $1 \mathrm{~kg}$ de diferentes aceites . . . 134

5.5. Datos derivados de la formación de $1 \mathrm{~kg}$ de gases criogénicos licuados 134

5.6. Datos recopilados por la formación de $1 \mathrm{~kg}$ de diferentes aceites . . . 135

5.7. Datos derivados del tratamiento de $1 \mathrm{~kg}$ de taladrina agotada . . . . 135

5.8. Consumos medios eléctricos registrados durante el mecanizado . . . . 136 
5.9. Porcentaje de mix energético a nivel nacional . . . . . . . . . . . . . 136

5.10. Datos derivados de la generación de $1 \mathrm{~kW}$ de energía eléctrica . . . . 137

5.11. Impacto ambiental derivado de la producción/generación de entradas al sistema estudiado . . . . . . . . . . . . . . . . . . . . . . . 138

5.12. Consumos de potencia y tiempos de mecanizado . . . . . . . . . . . 139

5.13. Energía total consumida durante los mecanizados . . . . . . . . . . 139

5.14. Impacto ambiental derivado del consumo energético . . . . . . . . . 140

5.15. Caudales y consumos de fluidos de corte para MQL y mecanizado criogénico . . . . . . . . . . . . . . . . . . . . . . . . . . . . 141

5.16. Consumo de taladrina en función del flujo de referencia . . . . . . . 141

5.17. Impacto ambiental producido por los fluidos de corte en función del flujo de referencia . . . . . . . . . . . . . . . . . . . . . . . . 142

5.18. Impacto total generado en función del fluido de corte utilizado . . . . 143 
CAPÍTULO 1

Introducción 



\section{CAPÍTULO 1 \\ Introducción}

\subsection{Contexto Industrial}

En la actualidad el aumento de la preocupación medioambiental es un hecho. Por ello, en los países industrializados cada vez se es más estricto con la normativa medioambiental llevando al sector industrial a buscar técnicas de eficiencia energética, el uso sostenible de los recursos naturales y reducción de los desechos derivados de la fabricación de sus productos. En esta senda se encamina el programa "Horizonte 2020" de la Unión Europea con sus objetivos "20-20-20" donde se pretende en el año 2020 haber reducido un $20 \%$ los gases de efecto invernadero; que un $20 \%$ del consumo energético sea proveniente de fuentes renovables; y que el aumento de la eficiencia energética sea también de un $20 \%$. Por otra parte, dada la alta competitividad existente se hace necesario estar en una continua mejora de los procesos de fabricación para poder competir con los reducidos costes de fabricación de países donde tanto las condiciones laborales como las legislaciones medioambientales y de salubridad son más permisivas.

De cara a aumentar la productividad del mecanizado y teniendo en cuenta la necesidad de mantener y/o mejorar la integridad superficial tras el proceso, es habitual el empleo de lubricantes y refrigerantes de origen mineral durante el proceso de mecanizado. El control de las técnicas de refrigeración y lubricación implica directamente un aumento de la productividad y una drástica reducción de coste y daños medioambientales, provocados estos por las taladrinas y aceites de corte actualmente utilizados durante el mecanizado de diferentes productos y materiales. Hay que tener en cuenta que el uso de fluidos de corte puede llegar a representar entre el $7 \%$ y $17 \%$ del coste de fabricación de una pieza, pudiendo llegar a oscilar entre el $20 \%$ y $30 \%$ en materiales de difícil maquinabilidad cuyo uso en el sector 
aeronáutico cada vez es más habitual [Shokrani et al., 2012] [Weinert et al., 2004] [Klocke and Eisenblatter, 1997]. Además, la cantidad de fluidos de corte utilizados en el mecanizado sólo en la Unión Europea asciende a 320.000 Toneladas/año y su tratamiento una vez terminada su vida útil supone un coste de entre 2 y 4 veces su precio de compra, de los cuales el $30 \%$ se pierden por fugas en los circuitos, por las partículas que quedan adheridas a la máquina en forma de suciedad, en la limpieza de las piezas, etc. [Lawal et al., 2012] [Shokrani et al., 2012] [Byrne et al., 2003]. Por lo que su utilización a día de hoy implica no sólo ser ineficiente medioambientalmente sino ser menos competitivo desde un punto de vista económico. Por todo ello y dada la importancia de los fluidos de corte dentro del sector del mecanizado, se hace necesaria la búsqueda de técnicas alternativas de refrigeración/lubricación que sean viables tanto desde un punto de vista ecológico como tecnológico, con el fin de sustituir las actuales emulsiones de aceite utilizadas en los talleres mecánicos.

Desde principios de este siglo, el movimiento hacia tecnologías alternativas de refrigeración/lubricación medioambientalmente eficientes es un hecho. En un principio se introdujeron los sistemas de lubricación MQL (mínima cantidad de la lubricación) en el día a día industrial. Con esta técnica se consigue una temperatura de corte más estable a la vez que se disminuye la utilización de aceites de corte con caudales que oscilan entre 10 y $100 \mathrm{ml} / \mathrm{h}$. Simultáneamente también se empezó a investigar el uso de la refrigeración criogénica con nitrógeno líquido (LN2) con fines industriales. No obstante, no es hasta la EMO de 2011 que la refrigeración criogénica se hace visible para el sector del mecanizado. Esta tecnología aporta beneficios al mecanizado como la drástica reducción de la temperatura de corte, lo que mitiga los efectos negativos que ésta produce sobre la herramienta. Por otra parte, el LN2 presenta principalmente problemas de almacenamiento debido a que se encuentra en estado líquido a $-198^{\circ} \mathrm{C}$, por lo que está en constante evaporación. Este fenómeno hace que desde un punto de vista económico, el dióxido de carbono líquido (CO2) sea más atractivo ya que puede ser almacenado en ese estado a temperatura ambiente y por tanto tiene mayor facilidad de inserción en el entorno industrial.

Sin embargo, aunque estas tecnologías por separado aportan beneficios para casos concretos, no llegan a ofrecer una solución "única" como para sustituir definitivamente a las emulsiones de aceite tradicionales. Por ejemplo, en materiales considerados de difícil maquinabilidad como las aleaciones de níquel, cuyo consumo en el sector 
de la turbomaquinaria aeronáutica ha experimentado un crecimiento exponencial, ninguna de estas dos alternativas llega a ser tecnológicamente viable. Esto se debe a que estas aleaciones presentan una elevada dureza junto a una gran ductilidad y una alta tendencia al endurecimiento mecánico debido a su matriz austenítica que se traduce en un desgaste de herramienta derivado no sólo de efectos mecánicos sino térmicos. En esta situación, el MQL es capaz de lubricar y la refrigeración criogénica enfriar, pero no las dos cosas simultáneamente. Consecuentemente, se ha comenzado a investigar procesos de mecanizado donde se aplican ambas tecnologías de tal modo que se lubrique y refrigere a la vez.

Aparentemente este parece ser el camino a seguir en cuanto a técnicas de refrigeración/lubricación se refiere. De hecho, actualmente ya existen diversas empresas que tienen como una de sus actividades el desarrollo de equipos ya no sólo de MQL, sino también criogénicos y de CryoMQL (unión de las dos tecnologías). Sin embargo, estos últimos aún son costosos y necesitan de un acondicionamiento previo de las máquinas-herramientas ya existentes para poder operar con ellos, lo que se traduce en una alta inversión inicial. Además, tanto la tecnología criogénica como CryoMQL no está realmente validada y no existen sistemas de inyección propiamente dichos, basándose su oferta en una simple tobera con la que aplicar el fluido de corte de forma externa a la herramienta sin tener en cuenta la naturaleza del proceso a realizar. Por último, se habla de que estas tecnologías son medioambientalmente respetuosas y que por tanto, no tienen impacto ambiental. Sin embargo, a día de hoy nadie ha realizado un análisis de ciclo de vida exhaustivo que verifique esta afirmación.

\subsection{Objetivos}

En este contexto, con esta tesis lo que se pretende aportar es una solución a esta situación analizando no sólo desde un punto vista técnico, sino también medioambiental, el uso de fluidos de corte alternativos a los actuales derivados del petróleo, mediante la aplicación de las tecnologías de refrigeración criogénicas y por microlubricación con aceites biodegradables (MQL). Para ello, como objetivo general se establece:

El desarrollo y validación de una tecnología de refrigeración/lubricación alterna- 
tiva al uso de taladrinas que combine la criogenia con la microlubricación MQL y que además de medioambientalmente eficiente sea tecnológicamente viable su implantación en las máquinas-herramienta actuales durante los procesos de mecanizado más habituales en el sector industrial como son el torneado, fresado y taladrado.

Para conseguir este objetivo general, se plantean los siguientes objetivos particulares:

- Identificar los antecedes en cuanto a técnicas de refrigeración y lubricación medioambientalmente sostenibles se refiere tanto desde un punto de vista científico como industrial.

- Desarrollar diversos sistemas de inyección de gases criogénicos que además de poder ser utilizados en modo "stand alone" puedan ser aplicados de forma combinada con los sistemas de inyección de MQL actuales.

- Implementar la tecnología desarrollada en los procesos de mecanizado más habituales, como son el torneado, fresado y taladrado. Dicha implementación podrá ser aplicada de forma externa o interna a la herramienta.

- Analizar y validar el uso de la tecnología desarrollada mediante su uso en diferentes materiales y procesos de mecanizado, comprobando su efecto sobre la vida de herramienta y la integridad superficial y microestructural de la pieza mecanizada.

- Estudiar la viabilidad medioambiental de la tecnología propuesta mediante la realización de un análisis de ciclo de vida (ACV) en el que se comparan los diferentes fluidos de corte utilizados habitualmente.

- Desarrollar y validar un equipo CryoMQL "Plug \& Play" que tenga la capacidad de utilizar tanto la refrigeración criogénica como la lubricación MQL tanto de forma combinada como en modo "stand alone" en función de las necesidades del mecanizado. 


\subsection{Organización de la memoria}

Este documento ha sido estructurado en cinco capítulos además del capítulo de introducción. A continuación describe brevemente el contenido de cada uno de estos capítulos:

El capítulo 1, sirve de introducción al documento. Se comienza analizando el contexto industrial en el que se desarrolla este trabajo. A continuación se define el objetivo global de la investigación llevada a cabo, así como los objetivos particulares que han sido necesarios para llegar a éste. Finalmente, en este capítulo se hace un resumen de cada uno de los capítulos que componen esta tesis.

En el capítulo 2, se procede a la revisión del estado del arte en aspectos relacionados con las tecnologías de refrigeración y lubricación aplicadas a los procesos de mecanizado desde un punto de vista técnico y medioambiental. Para ello, en primer lugar se presentan los principales inconvenientes del uso de taladrinas durante el mecanizado y posteriormente se analizan las principales alternativas de refrigeración/lubricación que se pueden encontrar en la actualidad. A continuación se hace una revisión más exhaustiva relacionada con la lubricación mediante técnicas MQL y con la refrigeración criogénica no sólo desde un punto de vista científico, sino también industrial. Por último, se realiza una revisión sobre los análisis de ciclo de vida aplicados al mecanizado.

En el capítulo 3, se aborda el desarrollo y adaptación de los diferentes sistemas de inyección criogénicos para poder aplicar la tecnología al mecanizado. El capítulo se divide en dos partes con diversos apartados. La primera parte hace referencia a los equipos de alimentación utilizados para poder utilizar la refrigeración criogénica y MQL con los sistemas de inyección propuestos. En la segunda parte, se exponen los diferentes sistemas de inyección desarrollados. Para ello se han utilizado elementos comerciales junto con otros de fabricación propia. Cabe destacar que con el fin de optimizar el uso de CO2 se ha estudiado mediante CFD (Computer Fluid Dynamics) su comportamiento con diferentes diámetros de salida. Además se han validado los modelos utilizados empíricamente con el fin de aplicarlos durante el desarrollo de los adaptadores CryoMQL. 
En el capítulo 4, se recogen los diferentes ensayos realizados para la validación de la tecnología propuesta. El capítulo consta de cinco apartados donde en el primer apartado se hace una introducción de los materiales mecanizados, máquinasherramienta utilizadas así como los equipos utilizados en cada uno de los ensayos. En el segundo y tercer apartado se abarcan los procesos de torneado sobre el acero inoxidable austenítico AISI 304L y acero templado ASP23 (64 HRc), respectivamente. En ellos se ha analizado vida de herramienta, esfuerzos y potencias de corte, así como su integridad superficial. En el cuarto apartado se ha procedido al análisis de la evolución del desgaste de la herramienta a lo largo de su vida útil en el proceso de fresado de Inconel 718. En el quinto apartado se procede a describir los ensayos de taladrado en stacks de fibra de carbono (CFRP) y titanio (Ti6Al4V) en los cuales se ha analizado además de la vida de herramienta, la temperatura de corte y medida nominal de los taladros realizados.

En el capítulo 5, se refleja el análisis de ciclo de vida (ACV) realizado con el fin de validar desde un punto de vista medioambiental el uso de las principales técnicas de refrigeración/lubricación existentes actualmente. Este capítulo consta de cinco apartados en los que primeramente se define el objetivo y el alcance del ACV. Posteriormente se procede al análisis de inventario donde se recopilan los datos necesarios para efectuar el ACV. En el tercer apartado se realiza la evaluación del impacto del ACV donde se calcula el impacto ambiental producido durante el mecanizado por cada una de las tecnologías de refrigeración/lubricación analizadas. En el cuarto apartado se procede a la interpretación del ACV donde se discute y compara el impacto ambiental producido por las tecnologías de refrigeración/lubricación estudiadas. Este capítulo finaliza con un Anexo donde se recogen todas las tablas con los datos utilizados y calculados para llevar a cabo el ACV.

En el capítulo $\boldsymbol{6}$, se ha desarrollado y validado un equipo CryoMQL con el fin de lograr implantar la tecnología CryoMQL en las máquinas-herramienta ya existentes de una forma totalmente "Plug \& Play". De este modo no se requiere de una instalación previa ni grandes inversiones iniciales para poder introducir esta tecnología en el entorno industrial. Este capítulo se divide en cinco apartados y unas conclusiones. En el primer apartado se describe el equipo desarrollado. En el segundo apartado se describen los dos sistemas de los que está compuesto el equipo. En el tercer apartado se reflejan los componentes que conforman el equipo y la forma de funcionamiento 
de éste. Finalmente en el último apartado se valida el equipo utilizándolo durante unos ensayos de recanteado de Inconel 718.

En el capítulo 7, se reflejan las aportaciones derivadas de la realización de esta tesis y las posibles líneas futuras en las que seguir investigando. 

CAPÍTULO 2

Estado del arte 



\section{CAPÍTULO 2 \\ Estado del arte}

\subsection{Introducción}

El mecanizado de metales es un proceso altamente agresivo donde los esfuerzos mecánicos junto con la temperatura de corte puestos en juego son muy elevados. Esto hace que tanto la herramienta como la pieza a mecanizar estén sometidas a un estrés térmico y mecánico que provocan daños tanto en sus integridades superficiales como microestructurales. Por ello, de cara a aumentar la productividad del mecanizado y teniendo en cuenta la necesidad de mantener y/o mejorar la integridad superficial de la pieza tras el proceso, es habitual el empleo de lubricantes y refrigerantes durante la ejecución de las distintas operaciones. Estos lubricantes/refrigerantes, conocidos como fluidos de corte, son derivados del petróleo y generalmente se dividen atendiendo a si son miscibles en agua o no, es decir, emulsiones y soluciones, o aceites puros. En la Figura 2.1 se muestra en detalle la clasificación de éstos [Debnath et al., 2014].

\section{Lubricantes refrigerantes derivados del petróleo}

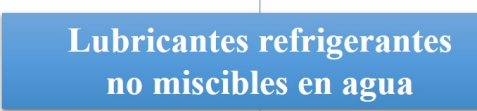

Aceites puros

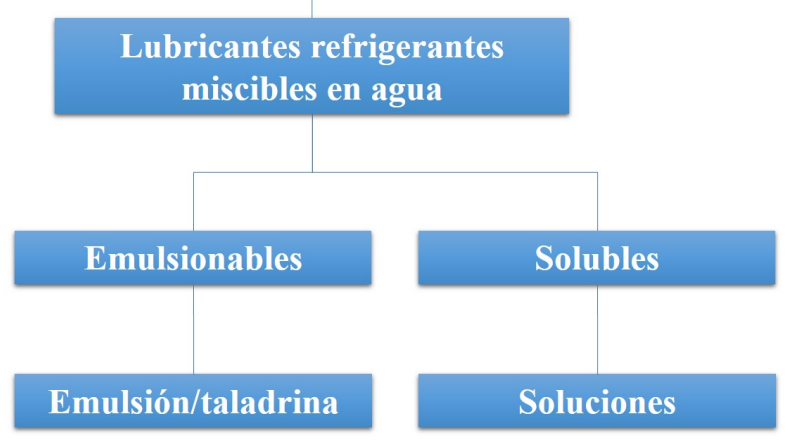

Soluciones

Figura 2.1: Clasificación de los fluidos de corte de origen mineral 
En el mecanizado por arranque de viruta principalmente se utilizan 3 tipos de emulsiones como fluidos de corte. Una de de ellas es la emulsión de aceite con base mineral donde el aceite está en una concentración mayor al $40 \%$. Después se encuentran las emulsiones de base semi-sintética donde la concentración de aceite está por debajo de esa cifra llegando hasta el 2,5\%. Finalmente se encuentran las emulsiones sintéticas las cuales no contienen aceite mineral, pero sí aditivos. El precio de éstas últimas es 4 veces mayor que el de las emulsiones de base mineral, lo que hace que su uso en la industria sea relativamente reducido. En la Tabla 2.1 se resumen las ventajas y desventajas de cada una de los tipos de emulsiones.

\begin{tabular}{|c|c|c|c|}
\hline & $\begin{array}{l}\text { Emulsiones } \\
\text { minerales }\end{array}$ & $\begin{array}{c}\text { Emulsiones } \\
\text { semi-sintéticas }\end{array}$ & $\begin{array}{l}\text { Emulsiones } \\
\text { sintéticas }\end{array}$ \\
\hline \multirow[t]{5}{*}{ Ventajas } & Buena lubricación & Buena refrigeración & Excelente refrigeración \\
\hline & Buena refrigeración & $\begin{array}{l}\text { Buen control de } \\
\text { oxidación }\end{array}$ & $\begin{array}{c}\text { Excelente control } \\
\text { bacteriano }\end{array}$ \\
\hline & & Buen control bacteriano & No inflamable \\
\hline & & & $\begin{array}{c}\text { Buen control de la } \\
\text { corrosión }\end{array}$ \\
\hline & & & $\begin{array}{c}\text { Reducción de los } \\
\text { problemas de formación } \\
\text { de nieblas y espuma }\end{array}$ \\
\hline \multirow[t]{3}{*}{ Inconvenientes } & $\begin{array}{c}\text { Problema de control de } \\
\text { óxido }\end{array}$ & $\begin{array}{l}\text { Facilidad de formar } \\
\text { espuma }\end{array}$ & Pobre lubricación \\
\hline & Crecimiento bacterial & $\begin{array}{l}\text { Estabilidad afectada por } \\
\text { la dureza del agua }\end{array}$ & $\begin{array}{l}\text { Facilidad de ser } \\
\text { contaminada por otros } \\
\text { fluidos de las máquinas }\end{array}$ \\
\hline & $\begin{array}{l}\text { Pérdidas por } \\
\text { evaporación }\end{array}$ & $\begin{array}{l}\text { Facilidad de ser } \\
\text { contaminada por otros } \\
\text { fluidos de las máquinas }\end{array}$ & Coste relativamente alto \\
\hline
\end{tabular}

Tabla 2.1: Ventajas e inconvenientes de las emulsiones [Kuram et al., 2013]

En cuanto a los aditivos, actualmente están presentes en los tres tipos de emulsiones. Estos tienen como finalidad mejorar las propiedades de estas emulsiones y a la vez alargar su vida útil. Generalmente estas emulsiones contienen agentes para la neutralización; inhibidores de corrosión y óxido; aditivos lubricantes antidesgaste y de presión extrema (EP) como el azufre, cloro y aditivos químicos con base fósforo; 
biocidas y fungicidas; y antiespumantes [Kuram et al., 2013].

Sin embargo, la problemática del uso de estas emulsiones, coloquialmente conocidas como taladrinas, radica en su insalubridad e impacto que tienen en el coste de fabricación final. Como ya se indicó en el capítulo 1, sólo en la Unión Europea se estima que se utilizan $320.000 \mathrm{Tm} /$ año [Lawal et al., 2012], de las cuales el $30 \%$ se pierden por fugas en los circuitos, por las partículas que quedan adheridas a la máquina en forma de suciedad, en la limpieza de las piezas, etc.[Byrne et al., 2003]. Además, según el NIOSH (National Institute of Occupational, Safety and Health) hay alrededor de 1,2 millones de trabajadores en el mundo expuestos a sus efectos nocivos entre los que se encuentran la irritación de la piel, acné, pérdida de la función pulmonar, neumonía e incluso cáncer de piel o pulmón [Sharma and Sidhu, 2014] [Cetin et al., 2011] [Park et al., 2010] [Khan et al., 2009]. Económicamente, el uso de este tipo de fluidos de corte repercute hasta en un $17 \%$ del coste de fabricación de la pieza [Klocke and Eisenblatter, 1997], pudiendo aumentar hasta el $30 \%$ en materiales de difícil maquinabilidad [Shokrani et al., 2012].

Por ello, una de las apuestas de la Unión Europea es la fabricación limpia o "Green manufacturing" en cuanto a sus objetivos "20-20-20", es decir, reducir los gases de efecto invernadero en un $20 \%$, conseguir que el consumo de energía proveniente de fuentes renovables sea del $20 \%$ y aumentar un $20 \%$ la eficiencia energética [Pusavec et al., 2014]. En este sentido, a día de hoy han surgido diferentes alternativas de refrigeración/lubricación como puede ser el mecanizado con lubricantes sólidos, taladrina a alta presión, mínima cantidad de lubricación (MQL), cold-gun, o la refrigeración criogénica. Los principios generales en los que se basa cada una de estas técnicas se exponen en la siguiente lista:

- El mecanizado con lubricantes sólidos consiste en utilizar herramientas con recubrimientos laminares como son el disulfuro de molibdeno $\left(M o S_{2}\right)$ o grafito cuya función es disminuir el rozamiento entre la viruta y herramienta reduciéndose la temperatura de corte y las fuerzas de corte. El inconveniente de utilizar herramientas con este tipo de recubrimientos es que se pierde la función refrigerante y de evacuación de viruta que sí se tiene con las taladrinas. Cuando se trata de mecanizar materiales que tienen tendencia a la formación de filo recrecido o cuando se requiere mecanizar piezas con elevada precisión dimensional en materiales de baja conductividad térmica, el uso de fluidos se 


\subsection{Introducción}

hace indispensable. Por otro lado, cuando se trata de realizar operaciones de taladrado, roscado o mandrinado es fundamental el uso de fluidos de corte para facilitar la evacuación de viruta. Por tanto, se pone de manifiesto, que el uso de lubricantes sólidos no es una solución que cubra todas las aplicaciones. Además, estas herramientas tienen un coste superior a las herramientas habituales y esto se traduce en un aumento del coste de fabricación sin añadir valor al producto final.

- El mecanizado con taladrina a alta presión se basa en la inyección de un chorro de taladrina a más de 30 bares, normalmente en la cara de desprendimiento de la herramienta. Gracias a esto el contacto entre herramienta-viruta es mucho menor y se consigue un menor desgaste de la herramienta además de controlar la direccionalidad de la viruta. Aunque el caudal utilizado es mucho menor que con la taladrina convencional se siguen utilizando fluidos de origen mineral, lo que la hace medioambientalmente ineficiente.

- El mecanizado con $M Q L$ consiste en utilizar un aerosol formado por micropartículas de aceite - generalmente biodegradable - . Con esta técnica hay una reducción drástica del uso de fluidos de corte (se utilizan entre 10 y 100 $\mathrm{ml} / \mathrm{h}$ frente a los $7 \mathrm{l} / \mathrm{min}$ usados tradicionalmente con la taladrina), un aumento de la higiene industrial, las virutas salen completamente limpias, y se puede llegar a conseguir una lubricación superior a la obtenida con las taladrinas [Sharma et al., 2009] [Byrne et al., 2003]. Por contrapartida, al utilizar tan poca cantidad de aceite en forma de aerosol se pierde toda la capacidad refrigerante que sí se logra con las emulsiones. Por ello en mecanizados donde las condiciones de corte son agresivas, como materiales de difícil maquinabilidad, puede resultar ineficiente ya que las temperaturas alcanzadas hacen que las micropartículas de aceite se volatilicen antes de llegar a la zona de corte.

- El mecanizado con cold-gun consiste en utilizar un tubo vórtex de RanqueHilsch [Lofton, 1990] por cuyo interior se centrifuga el aire de tal forma que las partículas más frías se separan de las calientes, proyectando estas primeras hacia la zona de corte. En el caso más favorable se pueden alcanzar temperaturas de $-37^{\circ} \mathrm{C}$. Con esta técnica se consigue una cierta capacidad de refrigeración en comparación con las técnicas anteriores, pero ésta sigue siendo insuficiente para materiales de difícil maquinabilidad debido al escaso caudal proyectado sobre la zona de corte. 
- Por último, el mecanizado criogénico consiste en asistir el mecanizado mediante la disminución de la temperatura de corte con la ayuda de gases licuados. La utilización de estos gases se traduce en una menor temperatura de corte, mayor limpieza en los puestos de trabajo y piezas totalmente limpias. Esa reducción drástica de temperatura hace que en el mecanizado a alta velocidad de materiales, como es el caso de las aleaciones de titanio, donde el efecto térmico predomina como mecanismo de desgaste de la herramienta, se obtengan resultados similares, o incluso mejores, al mecanizado con taladrinas [Kramer et al., 2013].

Como se observa, aunque son varias las técnicas alternativas al uso de taladrinas, sólo la lubricación mediante MQL y la refrigeración criogénica parecen tener largo recorrido. Concretamente, el interés industrial como científico mostrado día a día por estas dos tecnologías, tanto en modo "stand alone" como "combinado", se debe a que en determinados casos se llega a reducir el impacto ambiental a la vez que se aumenta la productividad en el mecanizado. Por ello, a continuación se exponen los avances existentes hasta la fecha en ambas tecnologías y los estudios realizados en cuanto a impacto ambiental se refiere.

\subsection{Microlubricación mediante MQL}

La lubricación mediante sistemas MQL (minimum quantity lubrication) consiste, como se indicó anteriormente, en la pulverización de un aerosol formado por micropartículas de aceite - generalmente biodegradable - en la zona de corte con un caudal de aceite que dependiendo del material a mecanizar oscila entre 10 y 100 $\mathrm{ml} / \mathrm{h}$. Generalmente las partes principales que componen un sistema MQL son un compresor de aire, un depósito de aceite, un sistema de control del caudal y un sistema de inyección para la micropulverización del aceite en la zona de corte. En la Figura 2.2 se muestra un esquema de un sistema de microlubricación por MQL con los componentes anteriormente mencionados.

La microlubricación mediante MQL puede ser aplicada de forma externa a la herramienta, como se ha hecho tradicionalmente con la taladrina, o aplicarlo de forma interna en donde el aerosol circula por el interior de ésta. La inyección externa es la más indicada para las operaciones de serrado, planeado y fresados de acabado. Tam- 


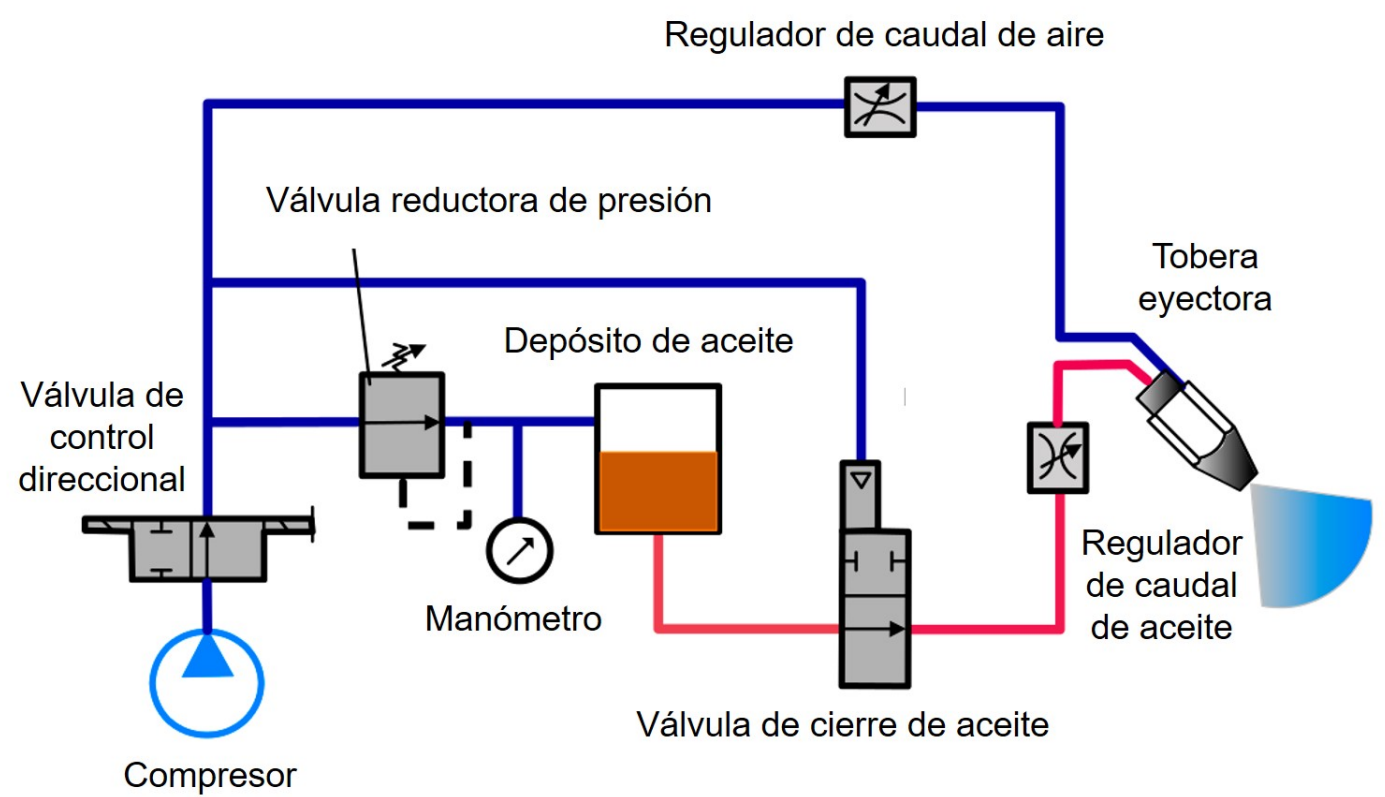

Figura 2.2: Esquema de un sistema genérico de microlubricación por MQL

[Astakhov, 2009]

bién puede ser aplicada en operaciones de taladrado, escariado y roscado siempre y cuando se tenga en consideración que la longitud del agujero no supere en tres veces el diámetro de éste $(\mathrm{L} / \mathrm{D}<3)$. Esto se debe a que el aerosol en ese caso no es capaz de penetrar correctamente en la zona de interacción entre el extremo de la herramienta y el material. En cambio la inyección del aerosol por el interior de la herramienta es especialmente recomendado además de para operaciones de fresado, torneado y para operaciones de taladrado, escariado y roscado donde L/D >3 [Weinert et al., 2004].

En los equipos MQL la micropulverización del aceite puede ser obtenida mediante dos técnicas diferentes basadas en el efecto Venturi. Una donde la pulverización se obtiene en la salida del sistema de inyección y otra donde la pulverización se genera en un atomizador anterior al sistema de inyección [Sharma et al., 2016]. Los equipos que utilizan la primera técnica se conocen como "equipos $M Q L$ de dos canales" debido a que el aceite y el aire circulan por conductos separados hasta el sistema de inyección. En cambio los equipos que utilizan la segunda técnica se denominan "equipos MQL de un canal" debido a que el aerosol ya formado es conducido hacia la zona de corte por un solo conducto [Attanasio et al., 2006]. En la Figura 2.3 se puede ver sus representaciones gráficas. 


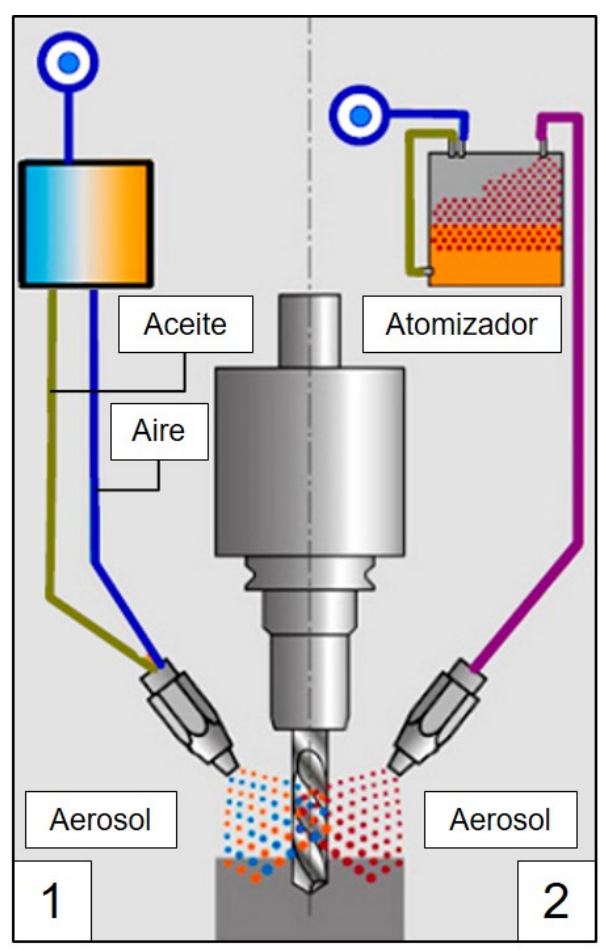

Figura 2.3: Representación gráfica de los tipos de sistemas MQL

[1] Sistema de dos canales - [2] Sistema de un canal

[Astakhov, 2009]

Entre las ventajas de la lubricación mediante MQL frente al uso de taladrinas cabe destacar la disminución del uso de fluidos de corte; la reducción de costes; el aumento de la higiene industrial; la posibilidad de utilizar aceites biodegradables; la consecución de una mejor lubricación y estabilidad térmica debido a que existe una mejor penetración de las partículas de aceite en la intercara herramienta/viruta; y la obtención de virutas prácticamente limpias. La aplicación de la lubricación mediante MQL en materiales como el aluminio o aceros al carbono por lo general resulta satisfactoria.

En el caso del mecanizado de aluminio cabe destacar la investigación llevada a cabo en [de Lacalle et al., 2006]. En esos ensayos se analizó el efecto del uso de MQL como técnica de lubricación durante el fresado de la aleación de aluminio 5083-H112 a una velocidad de corte de casi $1000 \mathrm{~m} / \mathrm{min}$ y $5000 \mathrm{~mm} / \mathrm{min}$ de avance. La herramienta utilizada fue una fresa de acero rápido (HSS) con un $8 \%$ de cobalto de $12 \mathrm{~mm}$ de diámetro y dos labios. Al comparar la lubricación mediante MQL durante el mecanizado a alta velocidad frente al uso de taladrina se observó cómo con la 
lubricación MQL se conseguía una mayor productividad gracias al aumento de la velocidad de corte en combinación con un menor desgaste de la herramienta debido a la mejor penetración de las micropartículas de aceite en el filo de corte frente a la taladrina.

En referencia a los aceros al carbono, cabe destacar una investigación publicada en Journal of Materials Technology en 2009 donde se tornea con un inserto de metal duro sin recubrir un acero AISI 9310. En dicha investigación se concluyó que al utilizar la lubricación mediante MQL se reduce el desgaste en un $60 \%$ después de 45 minutos de mecanizado frente al uso de taladrina gracias a la mejor penetración de las micropartículas de aceite en la intercara herramienta/viruta [Khan et al., 2009].

Por contrapartida, la tecnología MQL no elimina de forma eficiente la viruta generada de la zona de corte a la vez que se hace necesario una campana extractora que absorba la neblina formada en el interior de la máquina-herramienta. Además, como se indició en la introducción de este capítulo, principalmente la microlubricación mediante MQL tiene una pobre capacidad refrigerante, lo que en la mayoría de los casos hace inviable su utilización en el mecanizado de materiales de difícil maquinabilidad debido a que este tipo de materiales presentan generalmente una combinación de una alta dureza con alta ductilidad, lo que se traduce en la generación simultánea de grandes esfuerzos mecánicos y térmicos durante el corte.

\subsection{1. $\quad \mathrm{I}+\mathrm{D}+\mathrm{i}$}

Con el fin de intentar suplir esta falta de refrigeración inherente a la tecnología MQL, son varias las investigaciones realizadas desde principios de este siglo. Sin embargo, los primeros datos documentados donde se aplica la lubricación MQL propiamente dicha al mecanizado parten de 1964. En ese año se patenta un sistema MQL de un canal, el cual incorpora una cámara de mezcla y dos llaves de paso para el control del caudal de aire y aceite, respectivamente [Vega and Walker, 1964]. En cambio no es hasta cinco años después, en 1969, cuando se patenta un sistema MQL de dos canales [Eckardt and Stirling, 1969]. Dicho sistema consta de dos depósitos de aceite que son activados mediante la presión del aire del sistema con el fin de lograr el caudal de aceite deseado de forma uniforme. Finalmente en 1973 se patenta un sistema MQL del que cabe destacar que es activado en su totalidad neumáticamente, sin necesidad de electroválvulas solenoides [Izumi and Katsushika-ku, 1973]. 
A día de hoy, las investigaciones realizadas se han basado principalmente en la modificación de alguno de estos dos parámetros:

- La variación de la temperatura del aerosol.

- La modificación del aire como gas portador.

Para variar la temperatura del aerosol se han desarrollado diversos sistemas que reducen de algún modo la temperatura del aire portador de las micropartículas de aceite. En este sentido cabe destacar a [Obikawa et al., 2006] donde se trabajó en un sistema denominado "sistema $\boldsymbol{C O D}$ " ("controled oil mist direction"). En este sistema se modifica la tobera de salida del aerosol con el fin de producir una expansión adiabática y disminuir así la temperatura de éste hasta $0^{\circ} \mathrm{C}$ a la vez que se logra controlar de forma más eficiente la dirección del aerosol. En la Figura 2.4 se detalla el esquema de su funcionamiento. Con este sistema se logra un menor desgaste de la herramienta a la vez que se reduce el consumo de aceite en un $65 \%$ en comparación con la lubricación MQL convencional.

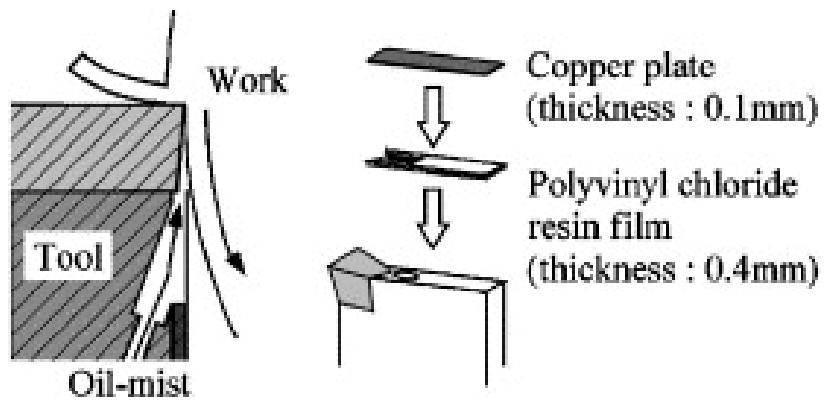

Figura 2.4: Esquema funcionamiento Sistema COD. [Obikawa et al., 2006]

Por otra parte, en [Su et al., 2007] se optó por desarrollar una máquina frigorífica compuesta por un intercambiador de calor simple, un sistema de vapor-compresión convencional y un sistema de refrigeración semiconductor, que junto a un sistema MQL tradicional forma lo que se denomina "sistema CAMQL" ("Cooling Air and Minimal Quantity Lubrication"). En la Figura 2.5 se muestra el esquema de dicho sistema. Su funcionamiento se basa en la reducción de la temperatura del aire en dos etapas. En una primera etapa el aire es refrigerado en el intercambiador de calor simple para posteriormente, en una segunda etapa, volver a disminuir su temperatura mediante efecto Peltier gracias a las termopilas del sistema de refrigeración 
semiconductor. En ambas etapas se utiliza agua para evacuar el calor intercambiado con el aire, la cual es refrigerada en el sistema de vapor-compresión convencional. Para poder controlar la temperatura del aerosol basta con regular la tensión de alimentación de las termopilas, las cuales son alimentadas mediante corriente continua. Gracias a esta técnica se logra reducir la temperatura del aerosol hasta $-20^{\circ} \mathrm{C}$ y se aumenta la vida de herramienta en un $124 \%$ frente al mecanizado en seco.

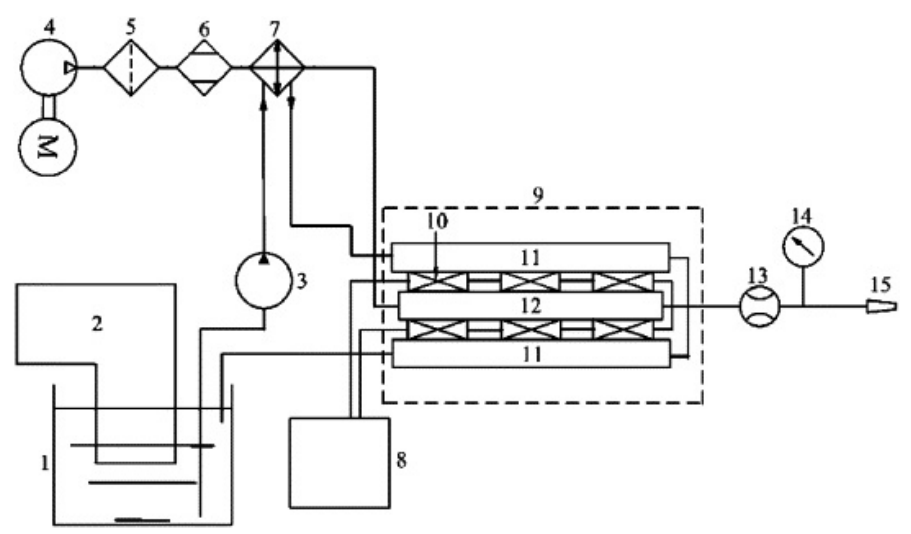

Figura 2.5: Esquema funcionamiento Sistema CAMQL.

(1)Depósito de agua. (2) Sistema refrigerador vapor-compresión. (3) Bomba de agua. (4) Compresor. (5) Filtro. (6) Secador. (7) Intercambiador de calor. (8) Caja de control. (9) Sistema refrigerador semiconductor. (10) Termopila. (11) Absorbedor de calor. (12) Enfriador. (13) Caudalímetro. (14) Manómetro. (15) Sistema MQL.

[Su et al., 2007]

En cuanto a la modificación del aire como gas portador de las micropartículas de aceite en [Min et al., 2005] se encuentra una de las primeras referencias en esta dirección. En dicha investigación, asistido por una cámara atmosférica, se sustituyó el aire utilizado de forma habitual en el sistema MQL por nitrógeno y oxígeno. Los resultados al comparar los tres gases pusieron de manifiesto como al mecanizar con oxígeno la fuerza de corte se redujo un $17 \%$ y un $35 \%$ la fuerza de avance, además de mejorar el acabado superficial. En cambio, un método más práctico en el que se modificó éste parámetro fue el desarrollado por [Itoigawa et al., 2006] y [Wakabayashi et al., 2007]. En dichas investigaciones se utilizó agua como portador del aceite, en otras palabras, se creó un aerosol formado por micropartículas de agua recubiertas de aceite. Ambas investigaciones difieren en el método para la obtención de dicho aerosol. El primero se denomina "sistema Oo $\boldsymbol{W}^{\prime \prime}$ ("Oil on Water") y es obtenido por medio de una tobera de tres canales como se observa en la Figura 2.6 en la cual mediante efecto Venturi en dos etapas se recubren las micropartículas de 
agua con aceite en primer lugar y posteriormente se vuelven a pulverizar con aire.
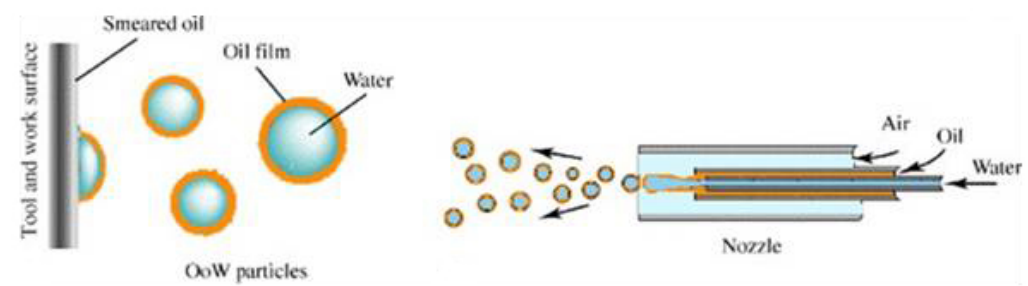

Figura 2.6: Esquema de funcionamiento "sistema OoW" [Itoigawa et al., 2006]

En cambio, el otro método es mediante el sistema denominado "sistema $\boldsymbol{M W D}$ " ("Micro Water Droplets"). Con este método se hace necesario un depósito presurizado para vaporizar agua. Seguidamente este vapor es liberado en el fondo de un tanque de aceite a presión atmosférica donde se condensa y se forman por tanto las micropartículas de agua recubiertas de aceite, como se muestra en la Figura 2.7.

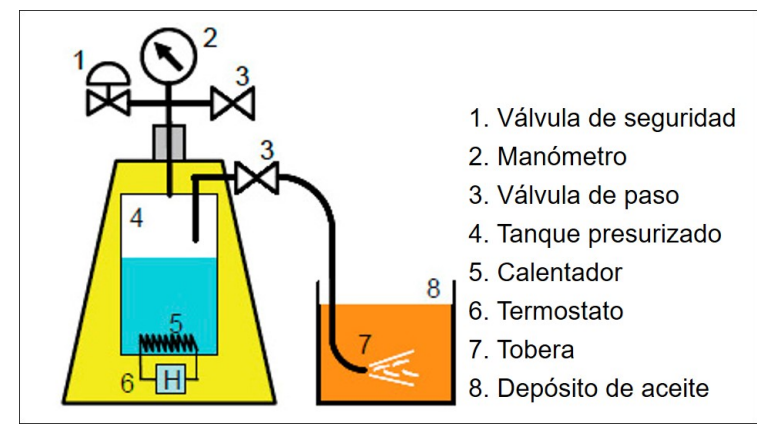

Figura 2.7: Esquema de funcionamiento "sistema MWD" [Wakabayashi et al., 2007]

\subsection{2. Ámbito industrial}

A nivel industrial, a pesar de que la tecnología de microlubricación mediante MQL es conocida desde hace más de 50 años, en Europa no despierta prácticamente interés hasta la década de los 90. Es entonces cuando nacen nuevas empresas europeas con el fin de ofrecer la tecnología MQL como fluido de corte. Sin embargo, no es hasta 10 años después que las empresas ya existentes especializadas en la venta de fluidos de corte convencionales comienzan a ofrecer este tipo de tecnología para satisfacer la creciente demanda, surgiendo así el apogeo de la tecnología MQL. 
Una de las empresas pioneras en utilizar los sistemas de lubricación mediante MQL fue la empresa americana Unist. Fundada en 1957, su negocio inicial fue utilizar pistolas de pintura por microlubricación [Siefen, 1959] y ya en 1971 patentaba un sistema específico para sistemas MQL en el cual se conectan el conducto que transporta el aire y el depósito de aceite con el fin de controlar el caudal de aceite mediante la presión del aire [Boelkins, 1971]. Ese mismo año también la empresa aeronáutica Boeing patentó un sistema similar en el que gracias al efecto Venturi generado en una cámara de succión se consigue reducir la temperatura del aerosol a $-25^{\circ} \mathrm{C}$. Dicho sistema fue diseñado para la realización de taladros y no se tiene constancia de que alguna vez se llegase a comercializar [Visser, 1971]. En cambio, la empresa Unist sí lo hizo y actualmente ofrece un sistema denominado "Serv-OSpray®" compuesto por un equipo MQL de dos canales. Inicialmente este producto está diseñado para su uso de modo externo a la herramienta y en caso de ser necesaria su utilización de forma interna, a ésta se debe añadir una junta rotativa que adapte la entrada de la refrigeración interna de la máquina-herramienta a este sistema. En la Figura 2.8 se muestra un esquema del sistema y la junta rotativa antes mencionada.

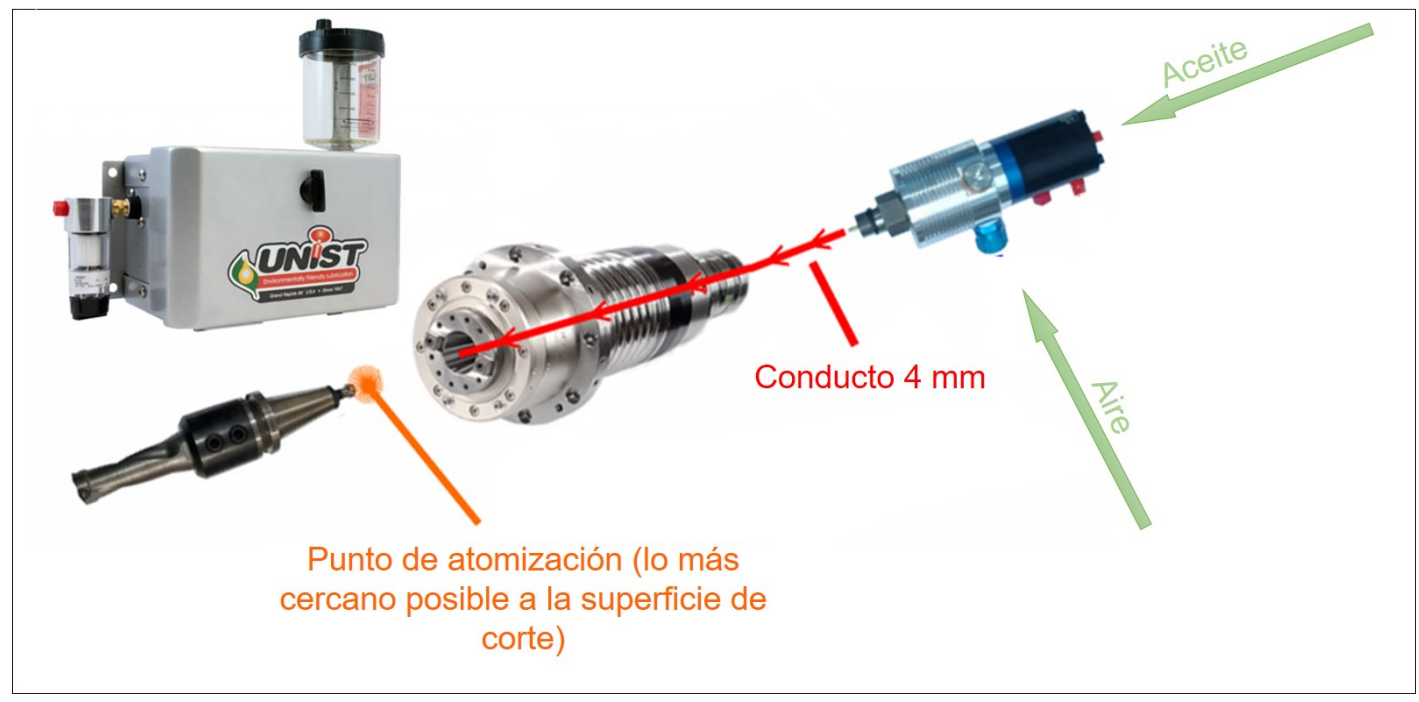

Figura 2.8: Sistema lubricación mediante MQL "Serv-O-Sprayß" de Unist

En Europa, a diferencia de las compañías americanas, las primeras empresas nacen específicamente para ofrecer principalmente productos de lubricación mediante MQL. Concretamente las pioneras fueron Steidle, fundada en 1978, que a principios de los 80 ofrecía productos de microlubricación y Accu-Lube, fundada 10 años después, cuya primera patente parte de 1991 en la que se registra un equipo MQL 
de un canal, similar a los dispositivos de lubricación de instalaciones neumáticas, y que mediante la utilización de conductos de diámetro uniforme se logra transportar el aerosol sin peligro de que las micropartículas se condensen antes de llegar a la zona de corte [Swift, 1991]. Accu-Lube además de tener patentado su propio equipo MQL, en 1995 y 1999 patentó un posicionador automático de las toberas de inyección en función de la longitud de la herramienta y una junta rotativa que permite el cambio de herramienta automático cuando se hace necesario introducir el aerosol por el interior de ésta [Chambers, 1995] [Kwok, 1999]. Actualmente ambas empresas ofrecen sus equipos MQL como lubricación interna o externa a la herramienta en diversas gamas. En el caso de Steidle, cuyos sistemas son mostrados en la Figura 2.9, cabe destacar su sistema básico "Pulsomat" $®$; el utilizado para refrigeración interna "Centermat@"; y el de uso general "Lubrimat@".
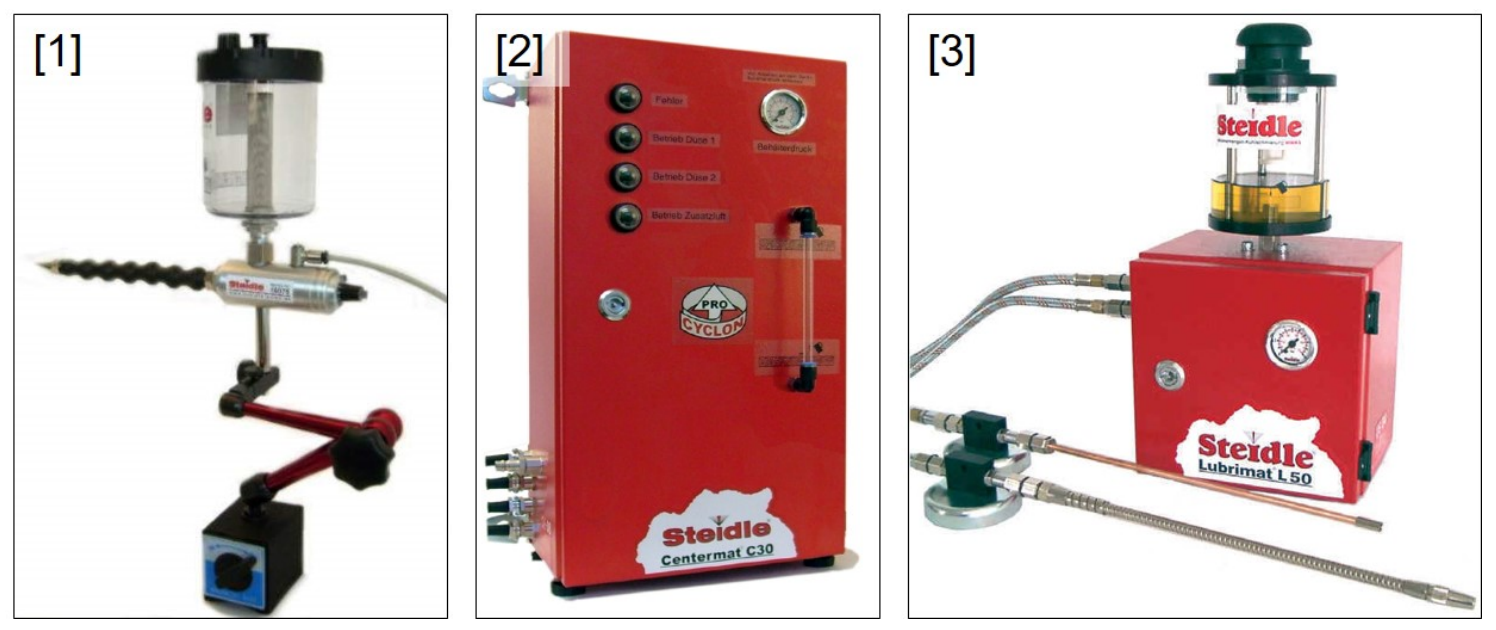

Figura 2.9: Gama equipos MQL de Steidle [1] Sist. básico, [2] Sist. de lubricación interna, [3] Sist. uso general

En cambio Accu-Lube ofrece además del sistema básico otro sistema de uso general que puede ser adaptado para lubricación interna o externa a la herramienta. Por otra parte cabe destacar que ofrece la posibilidad de tener en un mismo sistema simultáneamente tanto lubricación interna como externa. En la Figura 2.10 se muestran los equipos MQL desarrollados por Accu-Lube.

Finalmente a finales del año 2000, y en pleno auge de lo que se conoce hoy como fabricación sostenible, diversas empresas se posicionaron bajo esta filosofía ofreciendo productos para la microlubricación mediante MQL. Un ejemplo es SFK, 

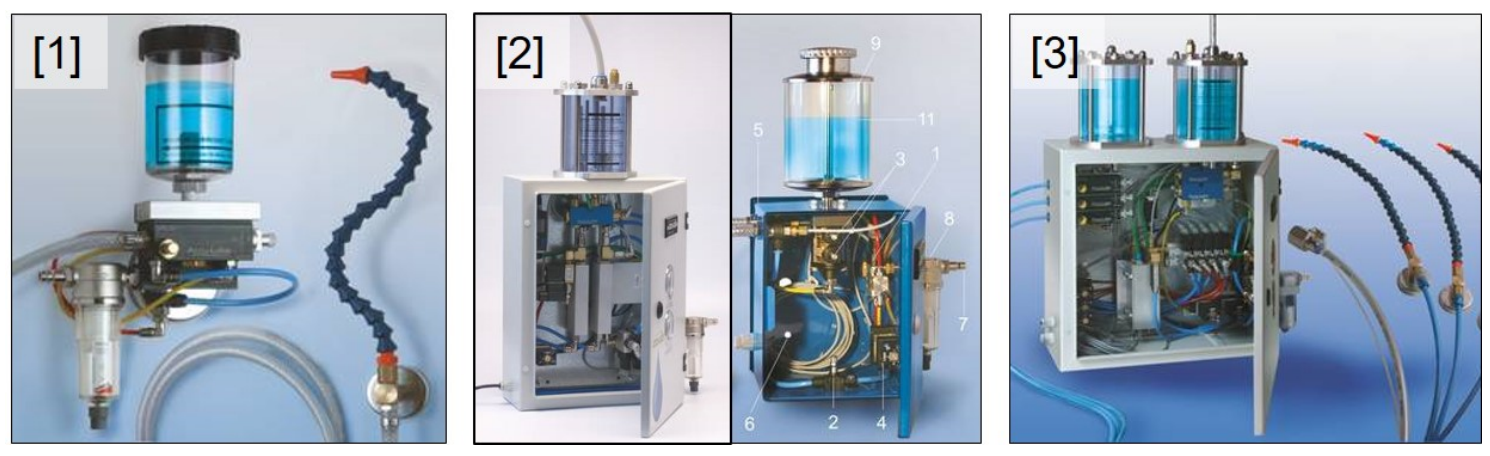

Figura 2.10: Gama equipos MQL de Accu-Lube [1] Sist. básico, [2] Sist. uso general, [3] Sist. lubric. interna y externa simultáneo

multinacional dedicada a la venta de productos para la automatización de procesos, que adquiere Vogel en 2004, la cual estaba especializada en la tecnología de los sistemas MQL desde 2003 [Spiess, 2003]. Otras empresas como Bielomatik que inicialmente se dedicaba en los años 50 al diseño de máquinas para procesar papel, a lo largo de estos años se ha diversificado en diferentes sectores, entre ellos los de la lubricación y concretamente entrando en la lubricación mediante MQL en 2005 [Bolz, 2005].

Cabe destacar que aunque son diversas las empresas que ofrecen sistemas MQL, todos los equipos tienen algo en común y es que el control del caudal de aceite se realiza neumáticamente. Consecuentemente para adecuar el caudal de aceite a las necesidades del material a mecanizar el operario debe manipular el "frecuenciómetro neumático" y la "válvula de paso" mostrados en la Figura 2.11. El frecuenciómetro neumático es el encargado de la creación de pulsos para controlar la intermitencia de la apertura y cierre de la válvula de paso. Por otra parte, con la regulación de la válvula de paso se consigue aumentar o disminuir la capacidad de apertura del orificio de salida del depósito de aceite. De este modo se logra el caudal deseado en cada momento. Sin embargo, este método además de ser tedioso para el operario crea una incertidumbre inherente a los sistemas analógicos que hace que el caudal de aceite no sea controlado estrictamente, lo que se traduce en no optimizar al máximo la lubricación que aporta al mecanizado esta tecnología. Por todo ello, la búsqueda de un método que controle de forma más exhaustiva el caudal de aceite de los sistemas MQL a la vez que sea más confortable para la manipulación del operario es uno de los objetivos de esta tesis. 


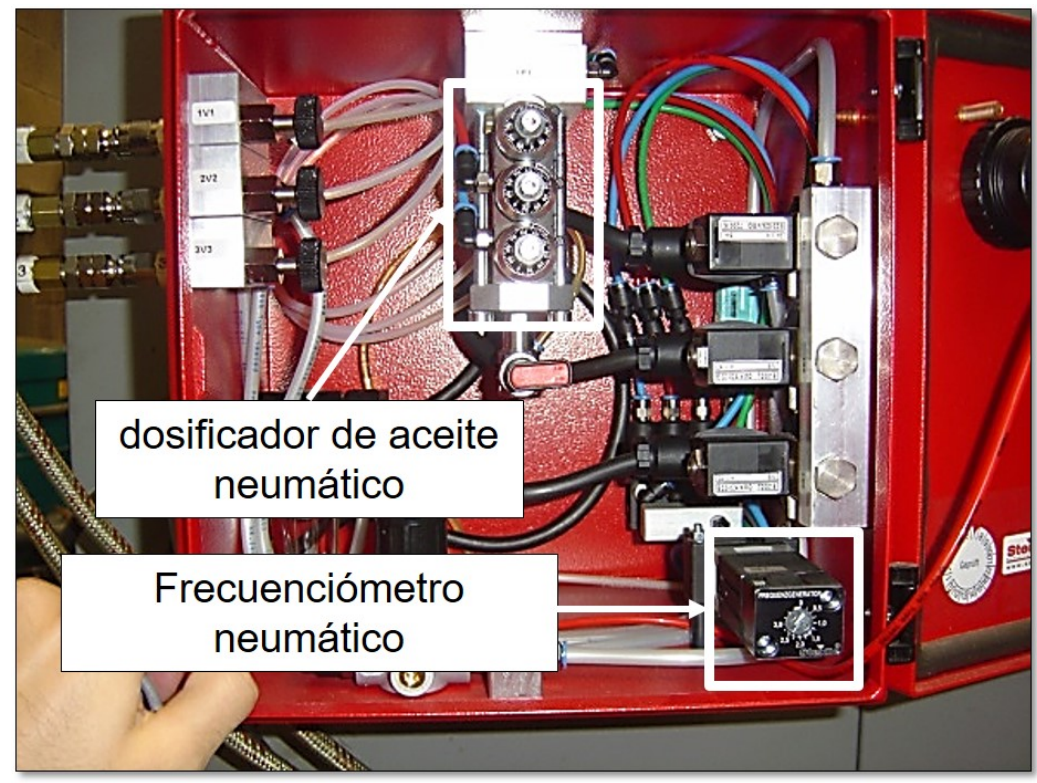

Figura 2.11: componentes neumáticos encargados de regular el caudal de aceite en los sistemas MQL

\subsection{La refrigeración criogénica}

La primera vez que se utilizó en operaciones de mecanizado un gas criogénico como fluido de corte fue en 1919, utilizando dióxido de carbono licuado (CO2) [Shaw and Smith, 1956]. Debido al alto coste que tenía la obtención de gases licuados frente a otros fluidos de corte no es hasta nuestros días que se vuelve una alternativa factible. Esto se debe, además de a la toma de conciencia medioambiental, al aumento del precio para la obtención de las materias primas para la formación de emulsiones y el coste de su gestión una vez terminada su vida útil. Además, en todos estos años se han perfeccionado las técnicas de licuación de gases, así como abaratado sus costes, por lo que la refrigeración criogénica parece la solución ideal debido a que su utilización combina el tándem ecología y economía, es decir, se logra una fabricación ecoeficiente. Entre las ventajas de la refrigeración criogénica cabe decir que es una tecnología limpia, segura y medioambientalmente respetuosa; se consigue un aumento del ratio de material eliminado (MRR) sin provocar mayor desgaste en la herramienta, lo que se traduce en menores tiempos muertos por cambio de herramienta, es decir, una mayor productividad; se obtiene una mayor vida de herramienta debido a una menor abrasión y desgaste químico; y se mantiene la integridad superficial de la pieza debido a la ausencia de una degradación superficial 


\subsection{La refrigeración criogénica}

química o mecánica del material [Sharma et al., 2016] [Kopac, 2009].

Los gases que normalmente se utilizan para inyectar en la zona de corte son el nitrógeno líquido (LN2) o dióxido de carbono líquido (CO2). Estos gases son utilizados desde hace años en otros sectores por otras empresas. Concretamente Articubeß, cuya matriz es una empresa vitoriana de matricería, utiliza el CO2 para refrigeración de platos y copas, Cool-Clean (Minnneapolis) utiliza hielo seco de CO2 para la limpieza de fachadas o el Grupo Horeca (Málaga) ofrece utensilios para cocinar con LN2.

Las razones por las cuales se utiliza el LN2 como fluido de corte es debido a que es un gas inerte que se encuentra en grandes cantidades en la atmósfera, tiene una alta capacidad refrigerante $\left(-196^{\circ} \mathrm{C}\right)$ y no se necesitan sistemas de aspiración adicionales. Por otra parte, es de difícil almacenamiento debido a que el LN2 está en continua ebullición, por lo que en los recipientes se genera una sobrepresión que una vez alcanza un determinado valor acciona una válvula de seguridad que permite evacuar nitrógeno en forma de escape para evitar cualquier riesgo de explosión por sobrepresión de éste. En cambio el CO2, aunque tiene una capacidad refrigerante menor $\left(-78^{\circ} \mathrm{C}\right)$, puede ser almacenado a temperatura ambiente en recipientes presurizados a 55-60 bares y además se podría disolver en aceites cuando está en estado supercrítico. Como contrapartida, al utilizar CO2 se necesita un equipo de regulación especial para evitar la formación de hielo seco en los conductos del sistema antes de su expansión en la salida de éste. Finalmente, cabe destacar que el CO2 utilizado es obtenido de un proceso primario, es decir, se le da un segundo uso en lugar de ser expulsado a la atmósfera directamente como residuo. De este modo se conserva el nulo impacto medioambiental inherente a los sistemas criogénicos basados en LN2. El uso de los gases criogénicos de forma aislada para asistir a los procesos de mecanizado no resuelve el problema por completo. Cuando se trata de mecanizar materiales donde el desgaste de la herramienta no sólo está influenciado por la temperatura de corte sino también por los esfuerzos mecánicos, los gases criogénicos no aportan la suficiente lubricación y por ello una opción es su combinación con micropartículas de aceite biodegradable. Los aceites son obtenidos a partir de plantas como la colza, canola, girasol o soja. Con ellos se consigue aportar al poder refrigerante de los gases criogénicos la lubricación proveniente del aceite, logrando así eliminar dicha barrera, alcanzando un gran abanico de materiales a mecanizar y sin llegar a aumentar de forma efectiva el impacto ambiental derivado de su utilización. Esta unión recibe el 
nombre de CryoMQL. Con esta técnica también cabe utilizar tanto el LN2 como el CO2. Sin embargo, en el caso del LN2 al no ser miscible en aceite, simplemente se utiliza simultáneamente un equipo de MQL y LN2 convencional. En cambio, el CO2 en estado supercrítico, como sí lo es, cabría la posibilidad de disolverlo con el aceite antes de ser inyectado en la zona de corte.

\subsection{1. $\quad \mathrm{I}+\mathrm{D}+\mathrm{i}$}

La refrigeración criogénica en sus distintas modalidades ha sido investigada en los últimos 15 años por diversos estudios que se han centrado fundamentalmente en materiales de difícil maquinabilidad, como aceros inoxidables, aceros templados, aleaciones de titanio o aleaciones de níquel. Por ello, en este apartado se realiza un análisis de las diferentes investigaciones realizadas hasta la fecha en función de estos materiales.

\section{Aceros inoxidables}

En el caso del mecanizado sobre aceros inoxidables en [Khan and Ahmed, 2008] se utiliza LN2 para tornear AISI 304. En dicho ensayo cabe destacar que en vez de inyectar el LN2 directamente sobre la zona de corte lo que se hizo fue modificar el portaherramientas para que éste se expanda justo en la parte anterior del inserto, convirtiéndolo así en un intercambiador de calor, al igual que [Hong and Ding, 2001]. Gracias a ello se aumentó la vida de herramienta hasta 4 veces frente al uso de taladrina. En la Figura 2.12 se muestran los insertos utilizados en dichos ensayos. Como se observa después de 20 minutos de mecanizado, el inserto utilizado durante el mecanizado criogénico apenas tiene desgaste de flanco ni signos de abrasión. En cuanto al uso de CO2 en [Jerold and Kumar, 2012] se torneó AISI 316L obteniendo con ello una reducción de las fuerzas de corte en un $35 \%$ frente al uso de taladrina, lo que conlleva un menor desgaste de herramienta y mejor acabado superficial.

Por otra parte, en [Chiffre et al., 2007] no sólo se utilizó CO2 en procesos de roscado y ranurado, sino que también se combinó con aceite biodegradable. De los ensayos concluyó que con $6 \mathrm{~g} / \mathrm{s}$ se consigue un caudal óptimo para el roscado en AISI 316L. En cambio a la hora de ranurar AISI 304L aparte de CO2 es necesario combinarlo con un caudal de aceite de $10 \mathrm{ml} / \mathrm{h}$. Gracias a esta combinación se aumenta 


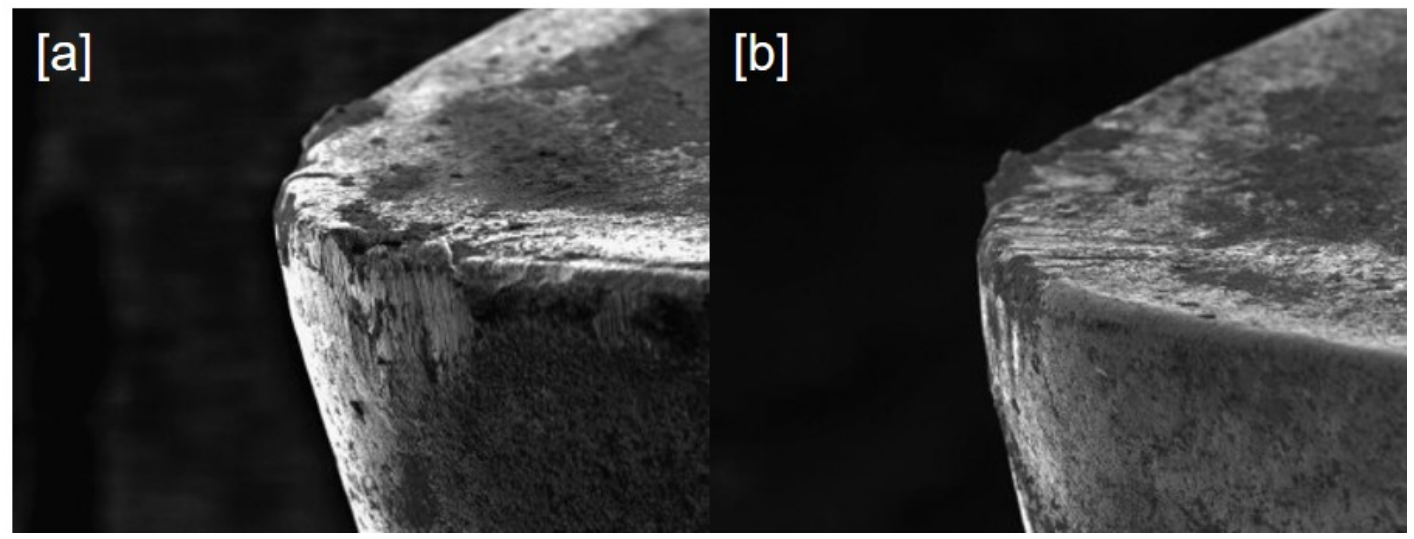

Figura 2.12: Estado del inserto tras 20 minutos torneado en AISI 304 [a] Taladrina. [b] LN2

[Khan and Ahmed, 2008]

un $82 \%$ la durabilidad de la herramienta frente a la taladrina.

\section{Aceros templados}

En cuanto al mecanizado de aceros templados, actualmente hay una tendencia de sustitución de los procesos de rectificado que llevan asociados las piezas de este tipo de materiales por torneado en duro. Éstos deben de ser realizados en seco dado que por lo general se utilizan plaquitas de nitruro de boro cúbico (CBN), material con el que se deben de evitar los choques térmicos producidos por los fluidos de corte convencionales.

Los estudios en esta dirección aplicando la refrigeración criogénica son pocos, pero cabe resaltar dos. En el primer caso, en [Bicek et al., 2012], se torneó AISI 52100 con LN2 y como consecuencia se redujo la degradación térmica de la superficie mecanizada. En el segundo caso, en [Abele and Schramm, 2008], se marcó como objetivo conseguir mecanizar GJV-500 (249HV) con insertos de diamante policristalino (PCD) a pesar de la gran afinidad del PCD con los materiales ferrosos por encima de $700^{\circ} \mathrm{C}$. Para ello se sirvió de la combinación del tamaño de grano de la plaquita y la refrigeración criogénica con CO2. Concretamente se utilizó un tamaño de grano de 50 micrómetros y un caudal de CO2 de 20kg/h. De este modo se consigue el equilibrio para que el PCD no reaccione con el material. 


\section{Aleaciones de titanio}

Para el mecanizado de aleaciones de titanio en la literatura se encuentran sobretodo estudios de torneado con refrigeración criogénica mediante LN2. En dichos artículos se busca la manera más eficiente de aplicar la técnica, ya sea reduciendo el caudal del LN2 o aumentando el MRR.

En [Hong and Ding, 2001], por ejemplo, se utilizaron diferentes métodos para aplicar LN2 al tornear Ti6Al4V, desde utilizar la plaquita como intercambiador de calor - como se indicó anteriormente - hasta inyectar el LN2 por las diferentes caras de la plaquita. De dicho estudio se obtuvo que lo más efectivo es inyectar LN2 por la cara de desprendimiento e incidencia simultáneamente. De este modo se consiguió reducir las temperaturas de corte por debajo de $500^{\circ} \mathrm{C}$ y se logró doblar la velocidad de corte frente al mecanizado con taladrina. Además, en otro estudio de [Hong et al., 2001] se demostró que éste es el método más eficiente de inyección de LN2 ya que se mecaniza sin enfriar innecesariamente otras zonas que no sean las de corte y que si se desea utilizar las mismas velocidades de corte que con la taladrina es suficiente con inyectar LN2 por la cara de desprendimiento del inserto.

Un año después, en [Hong et al., 2002] se quiso demostrar las propiedades lubricantes del LN2 en el torneado de titanio. En el estudio se justifica que aunque la combinación del nitrógeno con el titanio a alta temperatura genera nitruro de titanio (TiN), sustancia de bajo rozamiento, no se espera su formación debido a que la temperatura de corte producida no es lo suficientemente alta como para que este gas deje de seguir siendo inerte. Lo que realmente provoca la propiedad lubricante del LN2 en este material es la presión estática de inyección y por tanto para maximizar dicho efecto hidrostático el LN2 debe de ser aplicado tan cerca como sea posible de la zona de contacto.

Cinco años más tarde, en [Hong, 2007] se demuestra que dicha presión estática produce un film hidrodinámico entre la herramienta-viruta-pieza que produce coeficientes de fricción muy bajos, independientemente de los materiales de la herramienta y pieza. Estos dos últimos estudios están en sintonía con los realizados en [Klocke et al., 2012] y [Kramer et al., 2013]. En ellos se hizo un estudio más exhaustivo del efecto del LN2 en la zona de contacto entre la viruta y la herramienta. Se indicó que al tornear Ti6Al4V con taladrina se consiguen 246 metros mecanizados, 
mientras que con 1111 metros de mecanizado con LN2 la plaquita sólo muestra un ligero desgaste [Klocke et al., 2012]. Esto es debido a que hay una reducción del contacto entre la viruta y la herramienta, lo que se traduce en una menor temperatura de corte. Este efecto es demostrado mediante la teoría del "Vapour bubble". Ésta se basa en que el fluido de corte al bullir forma una burbuja firme de vapor cercana a la cara de corte, aislando la zona de corte del fluido de corte frío. Por lo tanto la presión de vapor al bullir se opone a la presión mecánica del chorro de LN2 que actúa sobre la burbuja de vapor. De este modo quedó demostrado que un aumento de presión reduce la temperatura de la herramienta en mayor proporción que un aumento del caudal [Kramer et al., 2013].

En estos mismos estudios, también se analiza el efecto de la vida de herramienta al utilizar CO2 al tornear Ti6Al4V. Aunque no se obtiene la misma vida de herramienta que si se utiliza LN2, sí se obtiene un desgaste mucho menor en comparación con la taladrina. En la Figura 2.13 se muestran la vida de herramienta obtenidas con los tres fluidos de corte utilizados [Klocke et al., 2012].
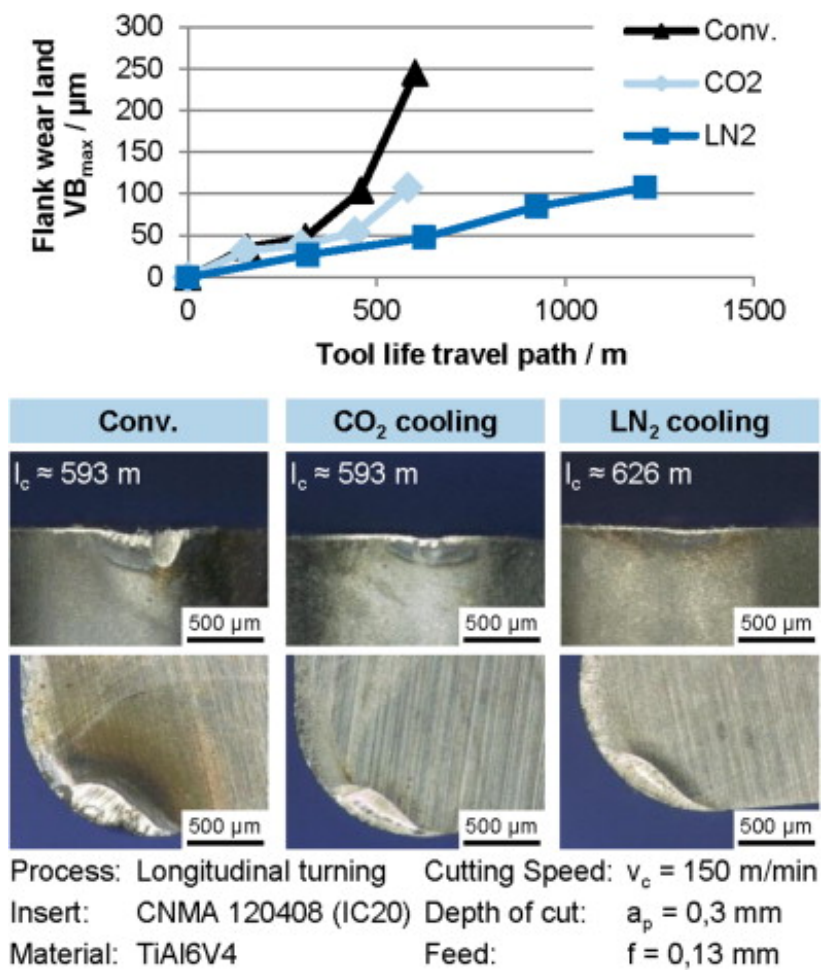

Figura 2.13: Vida de herramienta durante el torneado de Ti6Al4V [Klocke et al., 2012] [Kramer et al., 2013] 
En esta línea, en [Supekar et al., 2012] se comprobó la efectividad del CO2 en estado supercrítico (scCO2) y su combinación con dos caudales distintos de micropartículas de aceite de soja también torneando Ti6Al4V, entre otros materiales. Para conseguir una mezcla homogénea del scCO2 con las micropartículas se sirvió de un depósito presurizado con aceite en su interior. En dicho depósito se introdujo CO2 líquido y posteriormente se aportó calor al depósito para llevar el CO2 por encima de su punto triple para que éste sea soluble en aceite. Una vez realizado este proceso simplemente la mezcla es dirigida mediante unos conductos hacia la zona de corte. A raíz de estos ensayos, se concluyó que en las técnicas donde el scCO2 es utilizado como fluido de corte se logra una mejor refrigeración/lubricación en comparación con la taladrina o el MQL bajo condiciones industriales de producción. Por tanto el potencial de eliminación de calor o lubricación basado solamente en sus propiedades físicas no es necesariamente correlativo con la eficacia con la que elimina el calor o lubrica realmente el proceso de mecanizado, sino que la penetración del fluido en la zona de corte también es importante a la hora de refrigerar/lubricar la zona de corte; siendo esto acorde con lo publicado tanto por Hong en sus diferentes artículos como por Klocke y Krammer. De este modo, con esta combinación se logra un aumento de vida de herramienta a la vez que se aumenta el MRR frente a la utilización de taladrina o MQL.

En cuanto a vida de herramienta se refiere, en [Strano et al., 2013] se realizan estudios más concretos al tornear Ti6Al4V y [Machai et al., 2013] al ranurar titanio beta (Ti-10V-2Fe-3Al). Del primero se concluyó que a igualdad de condiciones con el LN2 se consigue un aumento de vida de herramienta del $40 \%$ frente a la utilización de taladrina [Strano et al., 2013] y en el segundo como conclusión se desprendió que si se inyecta $\mathrm{CO} 2$ en el flanco se obtiene un menor desgaste frente al uso de taladrina [Machai et al., 2013].

\section{Aleaciones de níquel}

En referencia al mecanizado de aleaciones de níquel hay menos cantidad de estudios en comparación con los referentes a las aleaciones de titanio. El desgaste predominante en este tipo de aleaciones, como el Inconel 718, es principalmente producido por problemas de lubricación y las altas temperaturas generadas en la zona de corte, es decir, el desgaste de herramienta aparte de producirse por mo- 
tivos térmicos también entran en juego los esfuerzos mecánicos [Sadik et al., 2016] [Kopac, 2009]. Esto es debido a que este tipo de aleaciones presenta una alta dureza combinada con una alta ductilidad. Además, en el caso concreto del Inconel 718, éste posee una matriz austenítica que provoca una alta tendencia al endurecimiento mecánico.

Para poder combatir estos dos inconvenientes en [Pusavec et al., 2011] se torneó Inconel 718 combinando LN2 con micropartículas de aceite. En el estudio no se dan datos sobre la vida de herramienta o aumento de productividad, pero se concluyó que con esta combinación se consigue una mejora de la integridad superficial en comparación con el uso de la criogenia o MQL en modo "stand alone". Concretamente, se lograron rugosidades medias menores, las tensiones residuales a compresión fueron mayores y a la vez se obtuvo una mayor microdureza en distancias próximas a la superficie de la pieza. En la Figura 2.14 se muestran las microestructuras y microdurezas obtenidas en este ensayo.

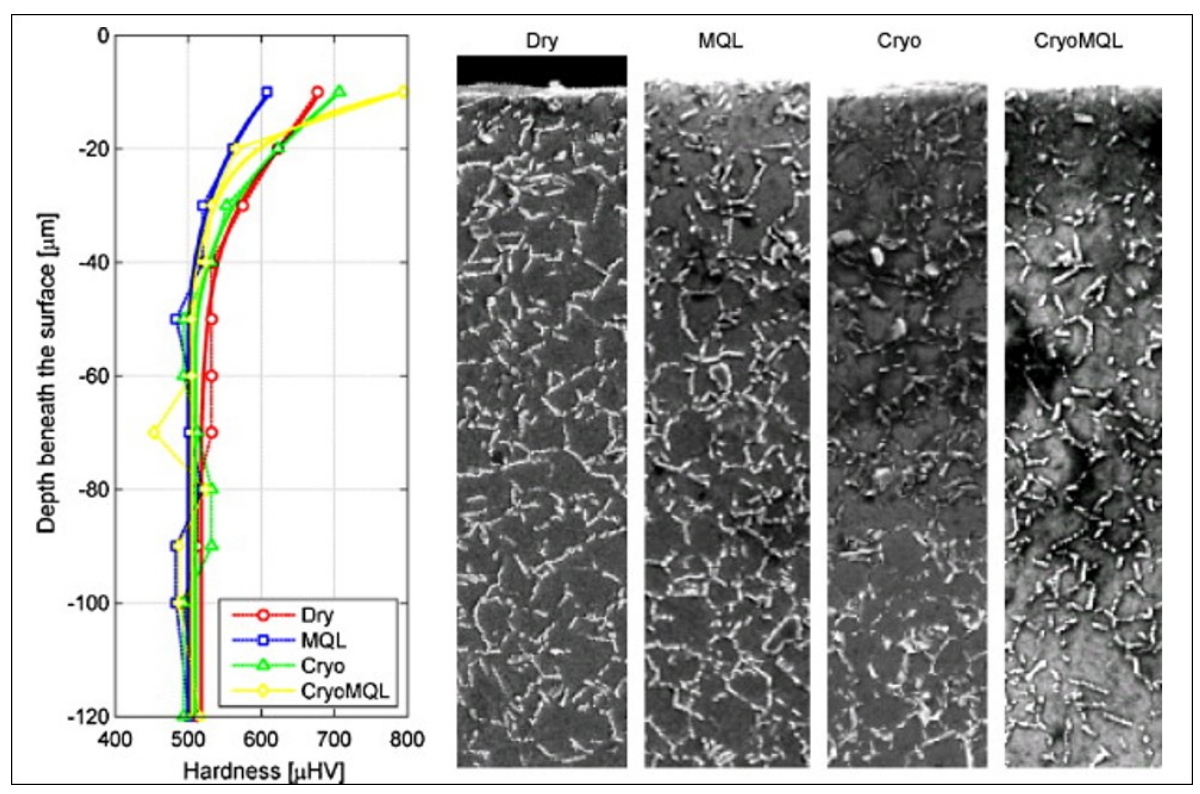

Figura 2.14: Microestructura y microdurezas obtenidas durante el torneado de Inconel 718 [Pusavec et al., 2011]

Tres años después, en [Pusavec et al., 2014] se estudió con mayor concreción los efectos del LN2 y MQL. Estos se utilizaron en modo "stand alone" y combinado, siendo inyectados en las diferentes caras de la plaquita, respectivamente. La selección del uso del LN2 frente al CO2 se basó, a pesar de los estudios anteriores, principalmen- 
te en la menor capacidad refrigerante de éste último frente al LN2. En concreto, se calculó que la capacidad total refrigerante del CO2 es de $347 \mathrm{~kJ} / \mathrm{kg}$ frente a los 428 $\mathrm{kJ} / \mathrm{kg}$ del LN2, es decir, éste último tiene un $20 \%$ más de capacidad de refrigerante, lo que se traduce en un menor consumo. A raíz de los resultados mostrados se concluyó que la combinación del LN2 con el MQL es una alternativa real frente a las otras dos técnicas debido a una disminución del desgaste de herramienta, una disminución de las fuerzas de corte y una mejora de la rugosidad superficial al tornear Inconel 718.

En [Stephenson et al., 2014] sí se optó por utilizar un "CryoMQL" con aceite de soja para tornear Inconel 750. El sistema para lograr la correcta mezcla de ambos fluidos fue el mismo que se utilizó en [Supekar et al., 2012] al tornear Ti6Al4V. Con dicha técnica logra ratios de MRR superiores entre un 25 y $45 \%$ frente al torneado con taladrina con un caudal que ronda los $450 \mathrm{~g} / \mathrm{min}(27 \mathrm{~kg} / \mathrm{h})$ de CO2 y 15ml/h de aceite.

Un caso en el que se ahorran costes de mecanizado gracias a un aumento del MRR pese a un mayor desgaste de herramienta es el presentado en [Truesdale and Shin, 2009]. En este estudio se fresó Udimet 720 y se comparó la utilización de LN2 e inyección de taladrina a alta presión. En este estudio se observó que al utilizar la taladrina a alta presión, la velocidad de corte está limitada por la deformación estructural del material a 10m/min, mientras que al utilizar LN2 esta limitación se encuentra a $120 \mathrm{~m} / \mathrm{min}$. Esto lleva a una disminución del coste de mecanizado total de un $90 \%$ por el aumento del MRR a pesar del aumento de los costes de cambio de herramienta en un $84 \%$.

\subsection{2. Ámbito industrial}

A pesar de que el mercado de las tecnologías limpias emergió en 2007 con un incremento de un 11,8\% por año hasta alcanzar un valor total de 2 trillones de euros en la actualidad [Pusavec et al., 2014], no es hasta la $\boldsymbol{E M O}$ de 2011 cuando se dio un paso real al frente y el grupo alemán $\boldsymbol{M A G}$ decidió lanzar una línea completa de máquinas-herramienta con refrigeración criogénica mediante LN2, como se muestra en la Figura 2.15. Además de sus máquinas "All in one", MAG con el fin de ampliar su abanico de clientes, también lanzó un portaherramientas capaz de soportar las temperaturas criogénicas producidas por el LN2 en su interior y así lograr una adaptación de las máquinas ya existentes a su tecnología. 

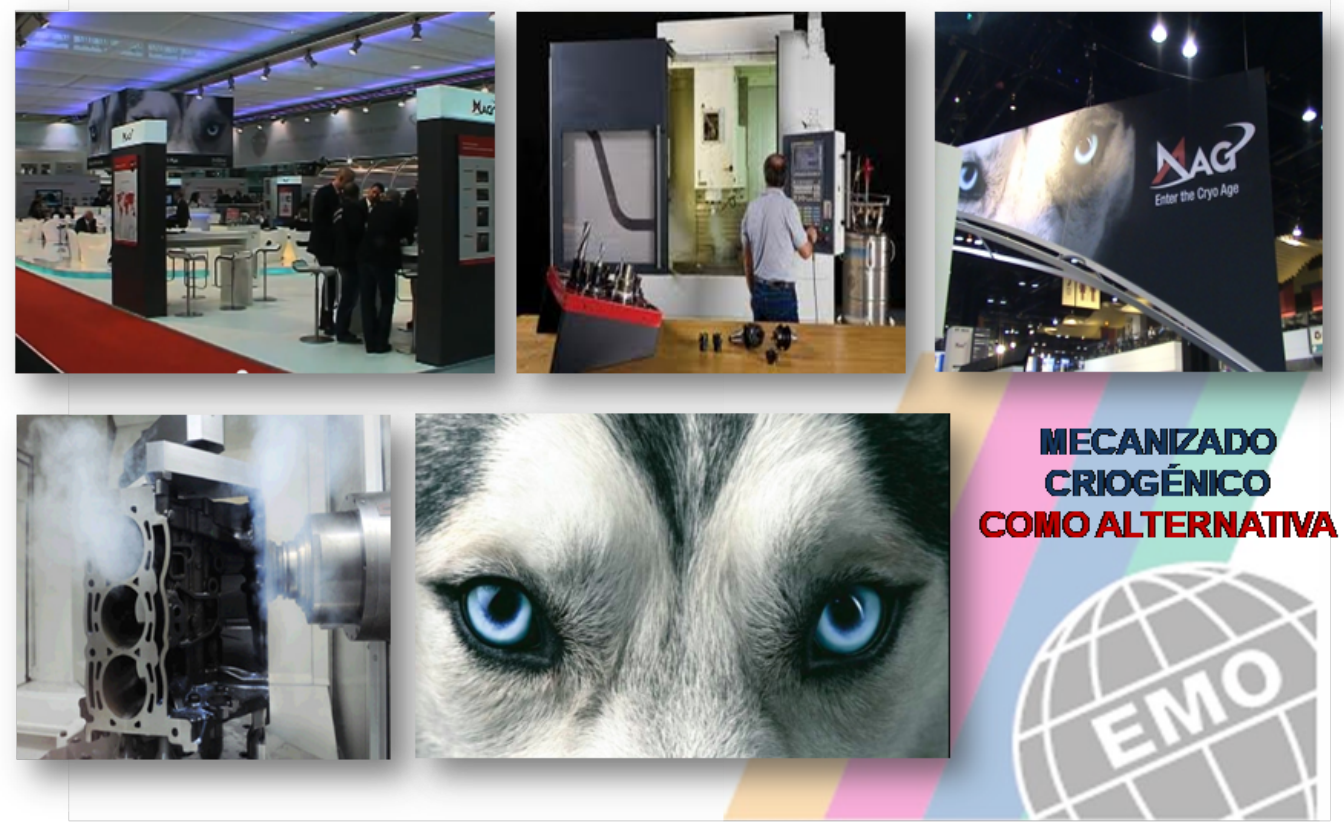

Figura 2.15: Presentación de la línea Criogénica de MAG en EMO 2011

Pese a que este fue el primer hito mundial desde el punto de vista empresarial que marcó el camino a seguir al resto, ya en Estados Unidos IceFly tenía desde 2001 patentado un equipo para la aplicación de LN2 de forma externa a la máquina para el mecanizado. Este sistema se basa en la utilización de tubos de polímeros capaces de doblarse al estar a $-196^{\circ} \mathrm{C}$. A diferencia de MAG, esta no es una solución realmente desarrollada para el mundo de la máquina-herramienta sino para poder transvasar LN2 entre recipientes y aparatos de laboratorio [Zurecki et al., 2003], lo que ha supuesto una debilidad a la hora de implantar su tecnología en el sector del mecanizado.

Después de esa demostración de MAG, la realidad es que los derroteros de la refrigeración criogénica desde un punto de vista industrial y práctico han ido por otros caminos, en concreto con el uso de $\mathrm{CO} 2$ como gas refrigerante. Cierto es que el LN2 desde el mundo científico ha sido el más estudiado ya que es inerte, tiene una gran capacidad refrigerante, es de fácil utilización y han sido más que probadas sus propiedades lubricantes; pero por contrapartida tiene cuatro grandes inconvenientes a la hora de su aplicación en el día a día de una empresa. El primero es que para ciertos materiales se corre el riesgo de sobreenfriar la pieza y con ello aumentar su dureza de forma considerable hasta el punto de disminuir la vida de herramienta 
[Hong et al., 1999] o sacar fuera de tolerancias dimensionales la pieza mecanizada. El segundo es que una vez liberado se expande hasta 700 veces su volumen inicial, desplazando el oxígeno y provocando riesgo de asfixia en el operario. El tercero es que está en constante ebullición, es decir, no se puede almacenar indefinidamente ya que tiene pérdidas constantes. Por último su precio es relativamente caro. En la otra cara de la moneda se encuentra el CO2 que tiene una menor capacidad de refrigeración que el LN2, pero hay que tener en cuenta que la eficacia de la refrigeración también depende en gran medida de la presión estática a la que es inyectado el gas en la zona de corte para poder penetrar de forma más eficaz en la zona de interacción entre el material y la herramienta, como se vio anteriormente en diversas referencias. En este sentido el LN2 se suele inyectar a 1,5 bares, mientras que el CO2 se inyecta normalmente entre 6 y 15 bares, en función de las necesidades. Además, su capacidad de expansión sólo es de 550 veces su volumen inicial. Por último, éste puede ser almacenado a temperatura ambiente sin ningún tipo de pérdida y tiene un precio relativamente inferior al del LN2.

Por estas razones, todo el mercado de la refrigeración criogénica se ha posicionado en ofrecer soluciones en las que se incluye el CO2 como gas refrigerante. Incluso MAG, que en 2011 presentaba en la EMO su línea criogénica de LN2, ese mismo año ya trabajaba en el desarrollo de husillos para adaptar sus máquinas a la utilización de CO2. Prueba de ello es su patente US2011/0166692 A1 en la que registró un método para refrigeración y lubricación de la zona de corte mediante un husillo en el que por su interior se combina CO2 y MQL en un mismo conducto para su posterior pulverización en los orificios de fresas con refrigeración interna [Horn et al., 2011].

Uno de los primeros en apostar por el CO2 como fluido de corte fue la empresa norteamericana CoolClean, la cual fue fundada en 2001 y cuya actividad principal era la limpieza de superficies mediante chorros con micropartículas de hielo seco. En 2008 patentó una boquilla en la que se combina micropartículas de aceite con CO2, consiguiendo así un sistema de inyección CryoMQL para aplicación externa en procesos de corte. Dicha boquilla está dotada de tres conductos de entrada y dos salidas, una en su extremo y otra en la parte central de su cuerpo. La característica principal de esta boquilla es que las micropartículas de aceite formadas en su interior recorren las paredes externas de ésta por efecto coanda hasta alcanzar su extremo donde por electrospraying se combinan con el CO2 [Jackson, 2008]. CoolClean, a la 
vista de la línea marcada por MAG, dos meses después de la EMO 2011 también patentó su propio equipo de regulación de $\mathrm{CO} 2$ para máquinas-herramienta, tanto externamente con la boquilla de efecto coanda, como interiormente mediante la introducción de éste por los husillos de las máquinas-herramienta [Jackson, 2011]. A raíz de este hito CoolClean lanzó su línea de refrigeración criogénica "Chil Aire®" en la cual se ofrecen tres gamas diferentes del equipo patentado que permite desde la inyección de CO2 en modo "stand alone" hasta su combinación con micropartículas de aceite en modo CryoMQL en la gama más alta. En la Figura 2.16 se muestran el esquema de la boquilla con efecto coanda así como la gama de productos "Chil Aire(R)".

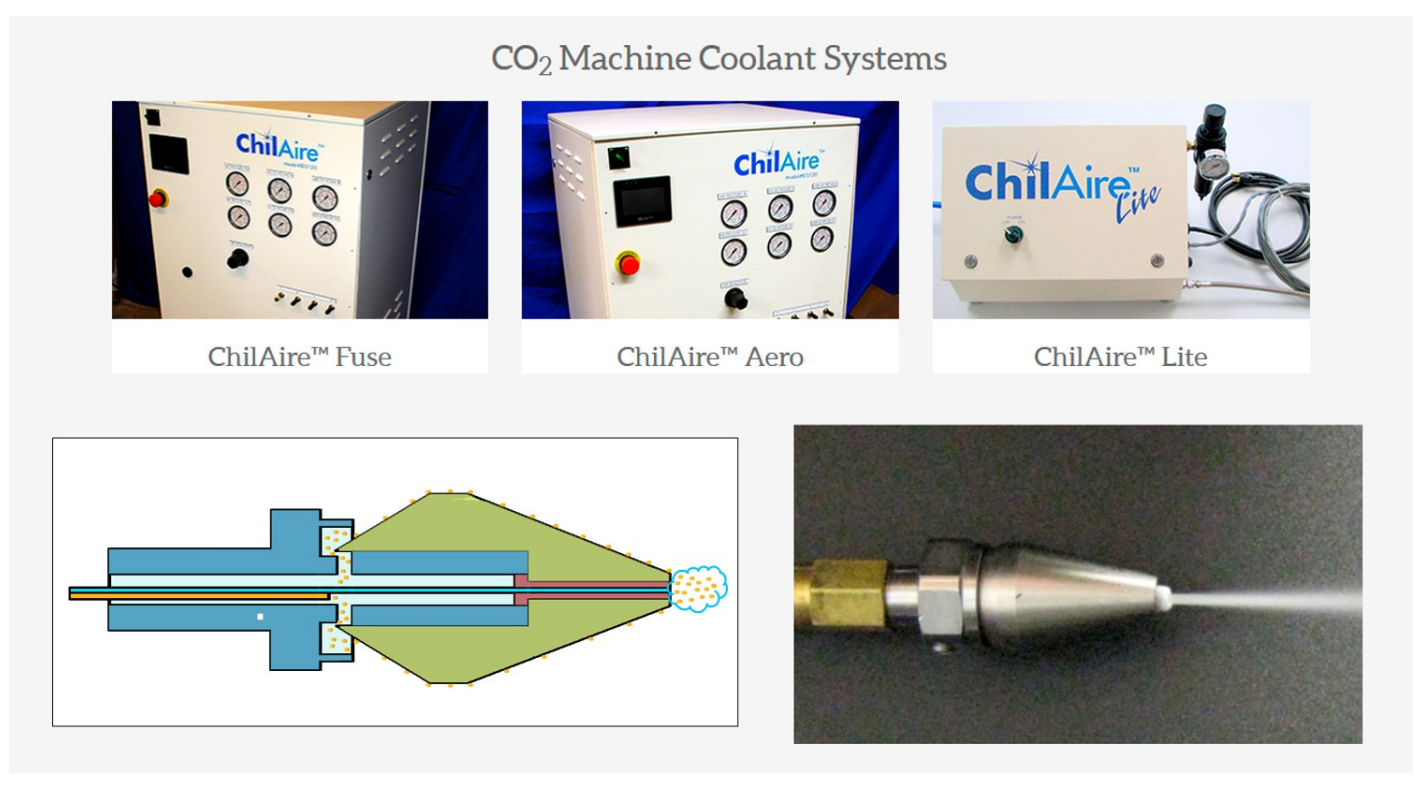

Figura 2.16: Línea de productos criogénicos de CoolClean

Otra de las empresas que se ha decantado por ofrecer la refrigeración criogénica es la alemana Rother technologies. Esta empresa de más de treinta años especializada en ofrecer soluciones adaptadas al cliente en cuanto a lubricantes, ensamblajes de máquinas, herramientas, etc., ha centrado el eje de su estrategia comercial en la refrigeración criogénica con CO2. En Junio 2011 patentó su primer equipo de regulación CryoMQL [Rother, 2010], es decir, cuatro meses antes que CoolClean lo hiciera. Este sistema diseñado por Rother principalmente se basa en hacer independiente la producción del aerosol del sistema de inyección de éste. Así se pueden tener con un mismo equipo varias líneas de CryoMQL independientes. Para ello se tiene un tanque con aceite depositado en su interior. Dicho aceite es recirculado a través de una válvula que se encuentra en la parte superior del tanque. Esta válvula es un 
micropulverizador por la que también se introduce CO2 y por efecto Venturi lo que se hace es formar un aerosol compuesto por micropartículas de aceite y CO2 en el interior del tanque. Además, éste tiene un sistema de control que se encarga de mantener constante la presión deseada en su interior con el fin de evitar la solidificación del CO2 al ser abiertas las válvulas para la liberación del aerosol a través del sistema de inyección. De este modo se evitan posibles taponamientos por la formación de hielo seco. Cabe destacar que a diferencia tanto de CoolClean como de MAG, Rother no patentó hasta 2013 una solución para poder introducir el aerosol por el interior del husillo de una máquina, así como el diseño de las herramientas necesarias para poder aplicarlo en las máquinas-herramienta [Rother, 2012a] [Rother, 2012b]. En el caso de Rother, la línea de refrigeración criogénica se denomina "Aerosol Master@" y consta al igual que CoolClean de tres gamas, como se puede observar en la Figura 2.17 .

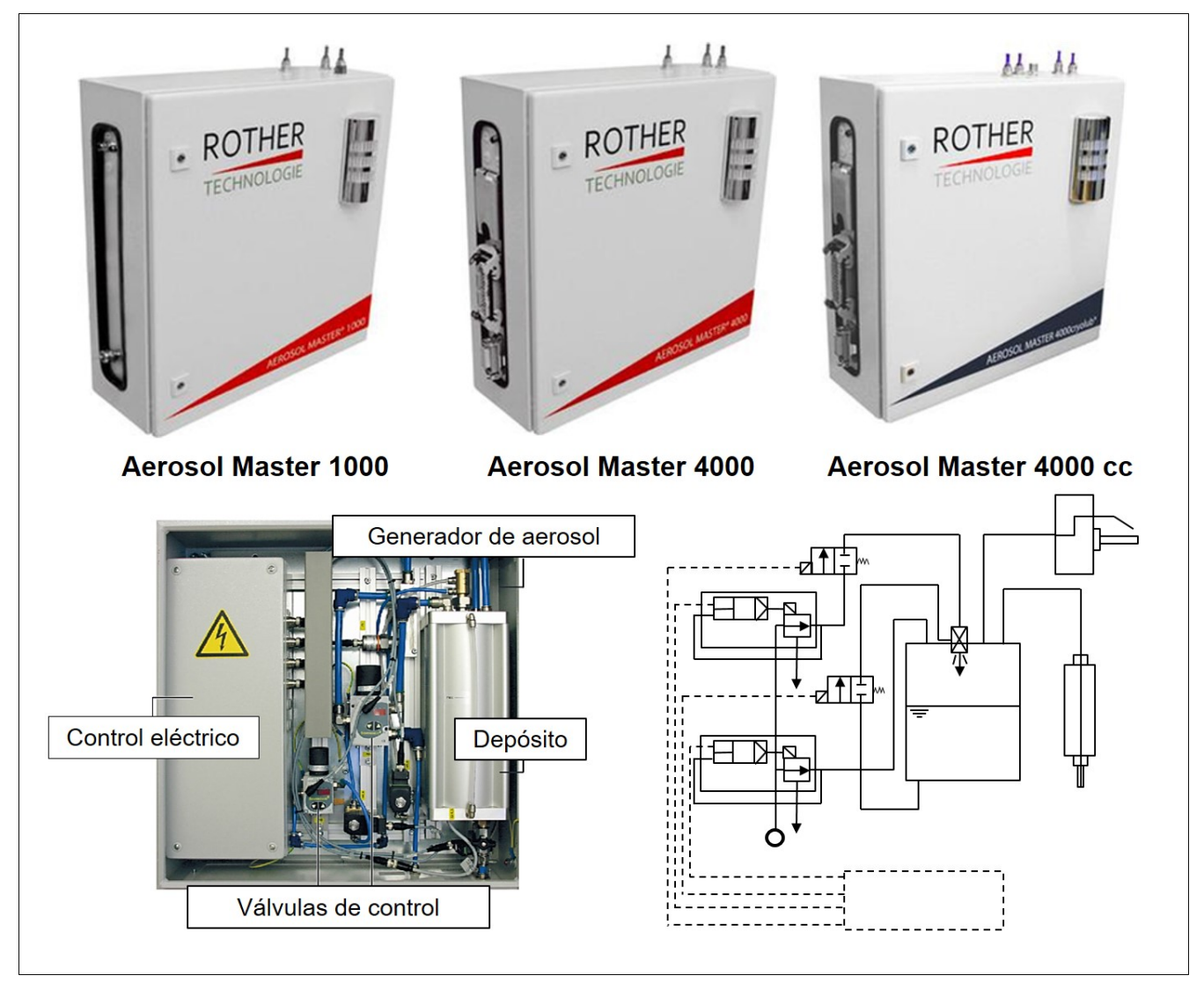

Figura 2.17: Línea de productos criogénicos de Rother

En el caso de multinacionales, como Starrag y Walter, en lugar de ofrecer una solución integral al igual que Rother, lo que han hecho es aunar esfuerzos para 
lograr ofrecer al consumidor un servicio completo de refrigeración criogénica con el fin de no quedarse fuera del mercado. Starrag, fabricante de máquinas-herramienta, se encargó de lograr conducir el CO2 sin problemas de congelación/solidificación por el interior de los husillos de sus máquinas-herramienta y Walter, fabricante de herramientas, adaptó uno de sus platos de plaquitas intercambiables patentado en 2011 [Bonnarang and Guerardelle, 2011]. Como resultado de esta unión, en la EMO 2013 presentaron una fresadora con refrigeración criogénica mediante CO2 con la que obtuvieron el premio "MM Award for Innovation" al mecanizar palas de turbina a escala con dicha fresadora. Actualmente, se encuentran en fase de lanzamiento de su línea "Walter Cryo-tec®". Esta línea se basa en un husillo con dos conductos concéntricos en su interior por los que circula el aerosol de micropartículas de aceite y el CO2. Después mediante un portaherramientas HSK estos conductos comunican con otro par de conductos existentes en el plato de insertos intercambiables los cuales acaban inyectando ambos fluidos en la cara de desprendimiento de los insertos. Con esta línea es posible utilizar el CO2, aire o MQL en modo "stand alone" o combinar el CO2 con cualquiera de las otras dos opciones [Cordes et al., 2014]. En la Figura 2.18 se detalla la esencia del funcionamiento de esta línea de trabajo.

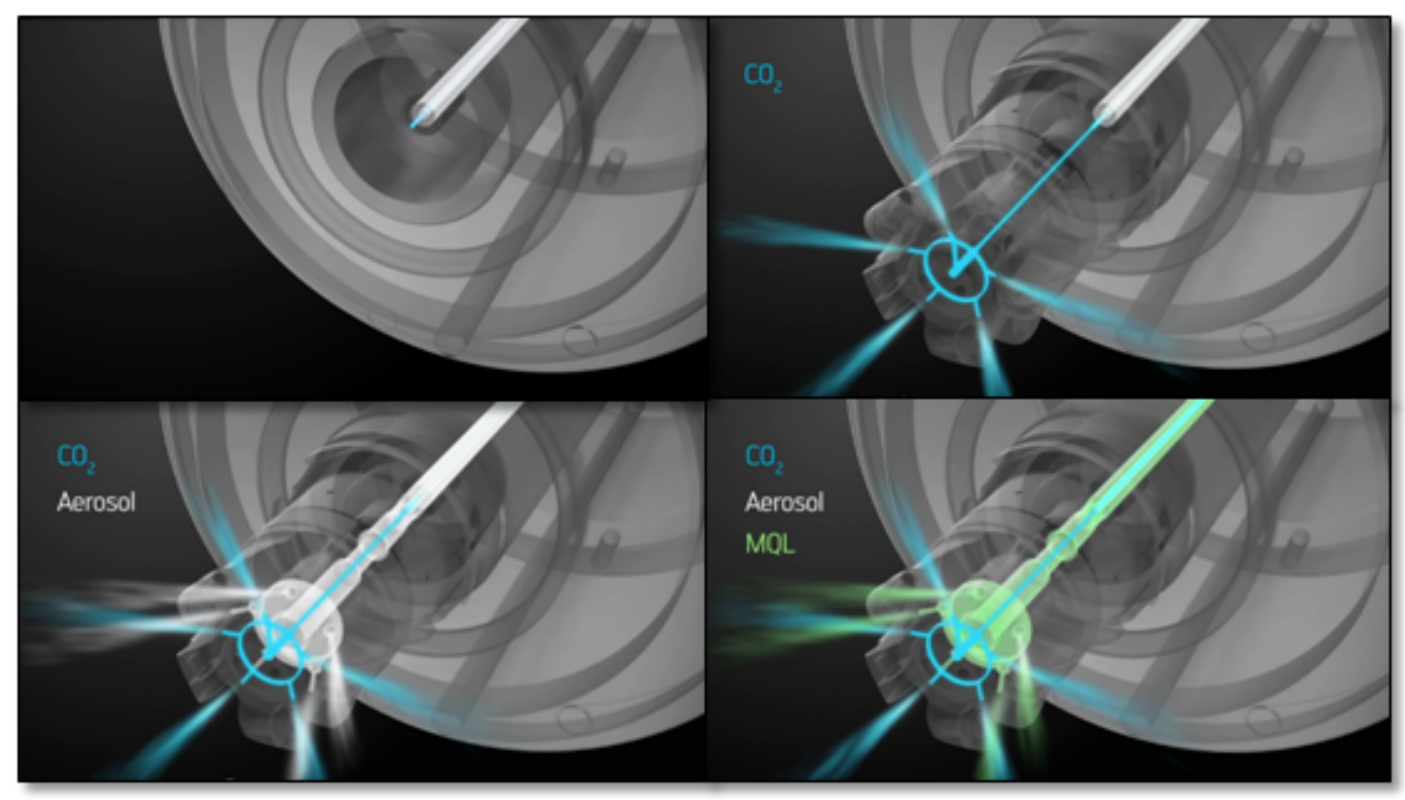

Figura 2.18: Funcionamiento de la línea "Walter Cryo Tec®"

Como se observa, la refrigeración criogénica presenta en la actualidad un nicho de mercado en el que diversas empresas están invirtiendo recursos. Sin embargo, a 
día de hoy las soluciones propuestas son para situaciones concretas, es decir, están enfocadas para dar solución a un tipo de problema determinado pero no para ser utilizadas como tecnología de refrigeración/lubricación para cualquier tipo de operación de mecanizado. Por ejemplo, se han desarrollado sistemas de inyección de CO2 aplicables a materiales donde la temperatura de corte tiene mayor peso en el desgaste de la herramienta que los esfuerzos mecánicos, pero estos no tienen utilidad en materiales donde se dé la situación contraria. Además, estos sistemas requieren acondicionar la máquina-herramienta para poder ser utilizados, lo que conlleva una inversión inicial aparte de la propia compra de los equipos. Por otra parte, la mayor parte ofrecen sólo la posibilidad de refrigeración externa. En caso de necesitar refrigerar de forma interna la herramienta en procesos de fresado no existe una solución para las máquinas ya existentes con las que el CO2 pueda atravesar el husillo sin dañar los rodamientos o cualquier otro componente móvil que pueda existir.

Por ello, con esta tesis además de validar, caracterizar los parámetros adecuados de funcionamiento e incrementar la eficiencia de la tecnología criogénica/CryoMQL con CO2, se busca desarrollar un equipo que no sólo sea capaz de utilizar la técnica CryoMQL como fluido de corte, sino que también sea posible utilizar el CO2 y el aerosol de micropartículas de aceite de forma independiente según las necesidades del material a mecanizar. Además con este sistema se busca abarcar no sólo una solución específica para una operación de mecanizado en concreto sino que el sistema se ha diseñado de tal modo que pueda ser adaptado para las principales operaciones de mecanizado como son el fresado, torneado y taladrado. Asimismo, se busca que el equipo sea totalmente portátil de tal manera que pueda ser utilizado en las diferentes máquinas-herramienta sin necesidad de realizar una instalación previa para su correcto funcionamiento.

\subsection{Análisis de ciclo de vida}

Con las alternativas de refrigeración/lubricación consideradas ecoeficientes se pretende alcanzar lo que se conoce actualmente como fabricación sostenible, es decir, se busca combinar la viabilidad técnica y medioambiental de éstas durante los procesos de mecanizado. Por ello, se hace necesario valorar el impacto ambiental producido por cada una de las principales técnicas de refrigeración/lubricación de forma cuantitativa. De este modo, se puede conocer de forma objetiva el impacto 
real que tienen sobre el medioambiente los fluidos de corte.

Gracias a los "Análisis de ciclo de vida" (ACV) se puede evaluar el impacto ambiental producido por los procesos de refrigeración/lubricación mediante la cuantificación del uso de recursos utilizados y emisiones ambientales producidas por éstos. Hay que tener en cuenta que en los ACV se utilizan varios criterios de corte para decidir los parámetros que se analizan. Por otra parte además, un ACV debe no sólo hacer un estudio comparativo sino también una interpretación de dichos resultados. Para ello debe utilizarse metodologías equivalentes en el análisis de cada técnica de refrigeración/lubricación.

Los análisis de ciclo de vida, según la norma UNE-EN-ISO 14044:2006, deben constar de las siguientes fases:

- Definición del objetivo y el alcance del ACV.

- Análisis de inventario.

- Evaluación del impacto ambiental.

- Interpretación del ACV.

En la "definición del objetivo y alcance" se debe especificar sin ambigüedad las razones para la realización del estudio, el público para el que es destinado el $\mathrm{ACV}$, etc. Además es necesario definir claramente el sistema que está bajo estudio, la unidad funcional, el flujo de referencia, los límites del sistema, los procedimientos de asignación, la metodología seguida, las suposiciones, los juicios de valores y los requisitos de calidad de los datos.

En la fase de "análisis del inventario" se debe realizar la recopilación de los datos necesarios para llevar a cabo el ACV. Además se deben realizar los cálculos necesarios en función del flujo de referencia con el fin de obtener dichos datos de forma cuantitativa y deben ser verificados una vez terminada dicha fase.

Los elementos de la "evaluación del impacto ambiental" deben reflejar las categorías de impacto, los indicadores de categoría, o los modelos de caracterización existente. Además es necesario asignar los resultados generados en el análisis de inventario a las categorías de impacto seleccionadas. Por último, en la evaluación del 
impacto ambiental se debe de calcular los resultados de cada indicador de categoría.

Finalmente, en la fase de "interpretación del $\boldsymbol{A} \boldsymbol{C} \boldsymbol{V}^{\text {" }}$ se deben de identificar los asuntos significativos basados en los resultados de las fases previas. En ella se deben verificar los análisis de integridad, sensibilidad y coherencia de los resultados obtenidos. Asimismo debe contener las conclusiones y limitaciones del ACV.

\subsection{1. $\quad \mathrm{I}+\mathrm{D}+\mathrm{i}$}

Respecto a los análisis de ciclo de vida realizados con el fin de cuantificar el impacto ambiental producido por los fluidos de corte cabe destacar principalmente dos artículos cuyo objetivo principal es intentar analizar el impacto ambiental producido por las técnicas de refrigeración sometidas a estudio. En el primer estudio realizado por [Pusavec et al., 2010] se llevo a cabo un ACV con el fin de comparar el impacto ambiental derivado de la utilización de taladrina convencional, taladrina a alta presión (HPJAM) y el LN2 como fluidos de corte para el torneado de Inconel 718. Para realizar el análisis se consideró el impacto ambiental provocado por la producción y uso de los fluidos de corte. Además, en el caso de la taladrina también se consideró a mayores su recirculación en el sistema, su cambio de dos veces por año y las emisiones derivadas de su secado y posterior incineración una vez terminada su vida útil. También se asumió que la energía consumida durante el torneado es la misma para todas las tecnologías y que para la obtención del LN2 se utilizan fuentes de energía renovables. Utilizando estos datos se obtuvo una comparación de las tres técnicas basándose en los marcadores de [Benedetto and Klemeš, 2009], como se muestra en la Figura 2.19. Los resultados muestran como al utilizar LN2 como fluido de corte tiene nulo impacto en todos los marcadores salvo en el uso de energía. Sin embargo, tanto el uso de HPJAM como taladrina convencional destacan por el uso de agua y residuo sólido derivados de su elaboración y tratamiento terminada su vida útil, respectivamente. Por tanto, de este ACV se concluye que el LN2 es la opción que más ventajas ofrece desde el punto de vista ambiental.

Por otro lado, en [Fratila, 2010] tomando como referencia el mecanizado con taladrina convencional se analizó el impacto ambiental producido por la lubricación con MQL al fresar 16MnCr5. En este ACV se dejó fuera de los límites del sistema el uso de las herramientas a pesar del alto coste energético que supone la deposición 


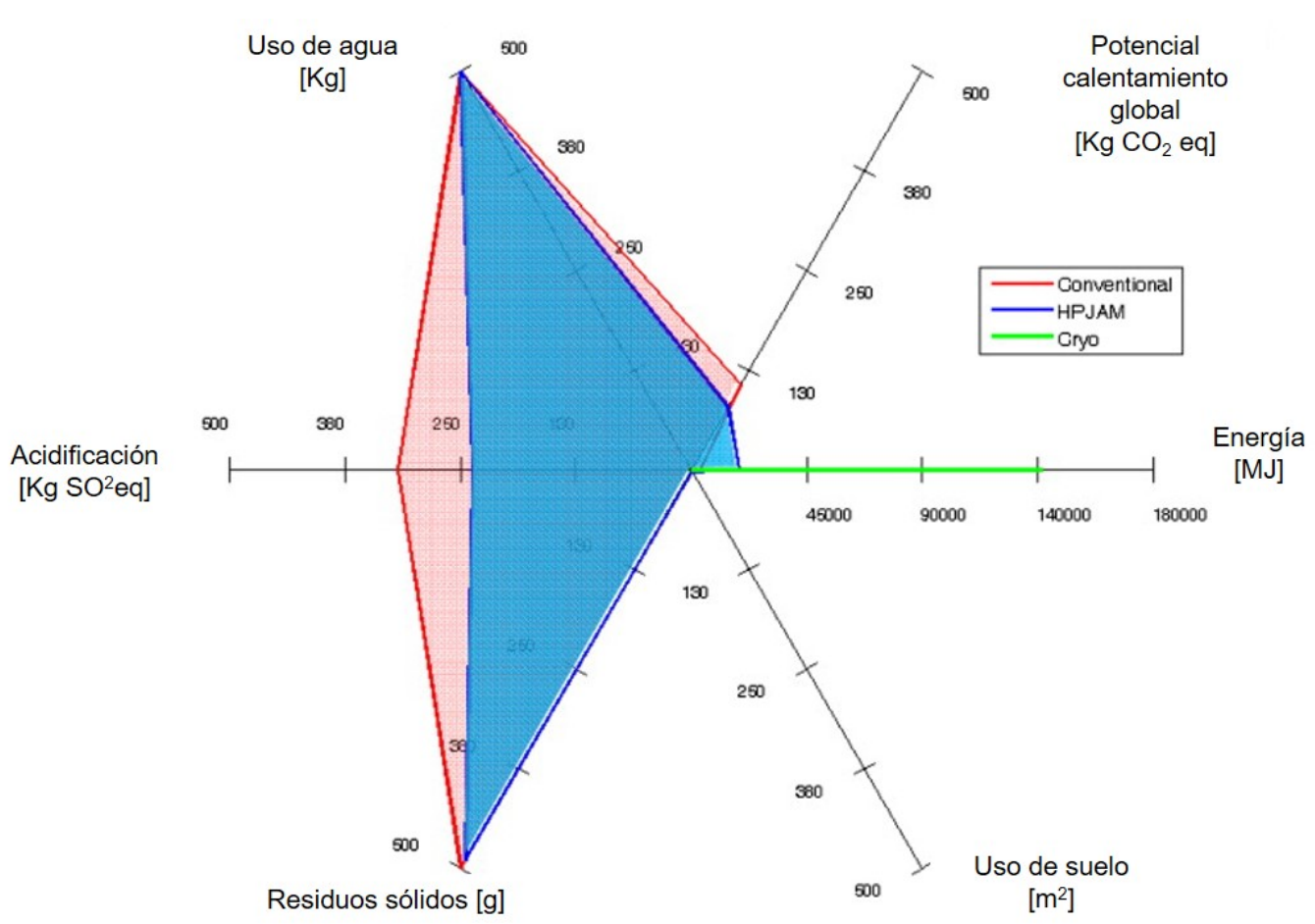

Figura 2.19: Resultados obtenidos en el ACV por Pusavec et al. 2010 [Pusavec et al., 2010]

de los recubrimientos sobre éstas. Esto es debido a que dicho consumo de energía es repartido a lo largo de la vida útil de las herramientas, lo que se traduce en un bajo impacto ambiental en el cómputo final. Además, se asumió que con lubricación con MQL las virutas no necesitan ser sometidas a un proceso de limpieza debido a la ínfima cantidad de aceite inyectado y que las emisiones de los fluidos de corte durante el mecanizado no tienen impacto ambiental en base a un estudio realizado con un Multigas MonitorType 1301 hecho en [Fratila, 2009]. Los resultados obtenidos se muestran en la Figura 2.20. En este caso, se tomó como referencia la utilización de la taladrina asignándole el $100 \%$ del impacto ambiental de tal modo que el análisis de ciclo de vida es cualitativo. Concretamente, en los marcadores estudiados se observa que la lubricación MQL es más eficiente medioambientalmente como mínimo en un $15 \%$ salvo en el uso de recursos minerales.

Por contrapartida, hay dos investigaciones que muestran las debilidades de los ACV y aunque en la práctica no han tenido gran repercusión, desde un punto de vista científico deben ser mencionadas con el fin de resaltar las limitaciones inherentes a los ACV. La primera es la realizada en [Benedetto and Klemeš, 2009] en 


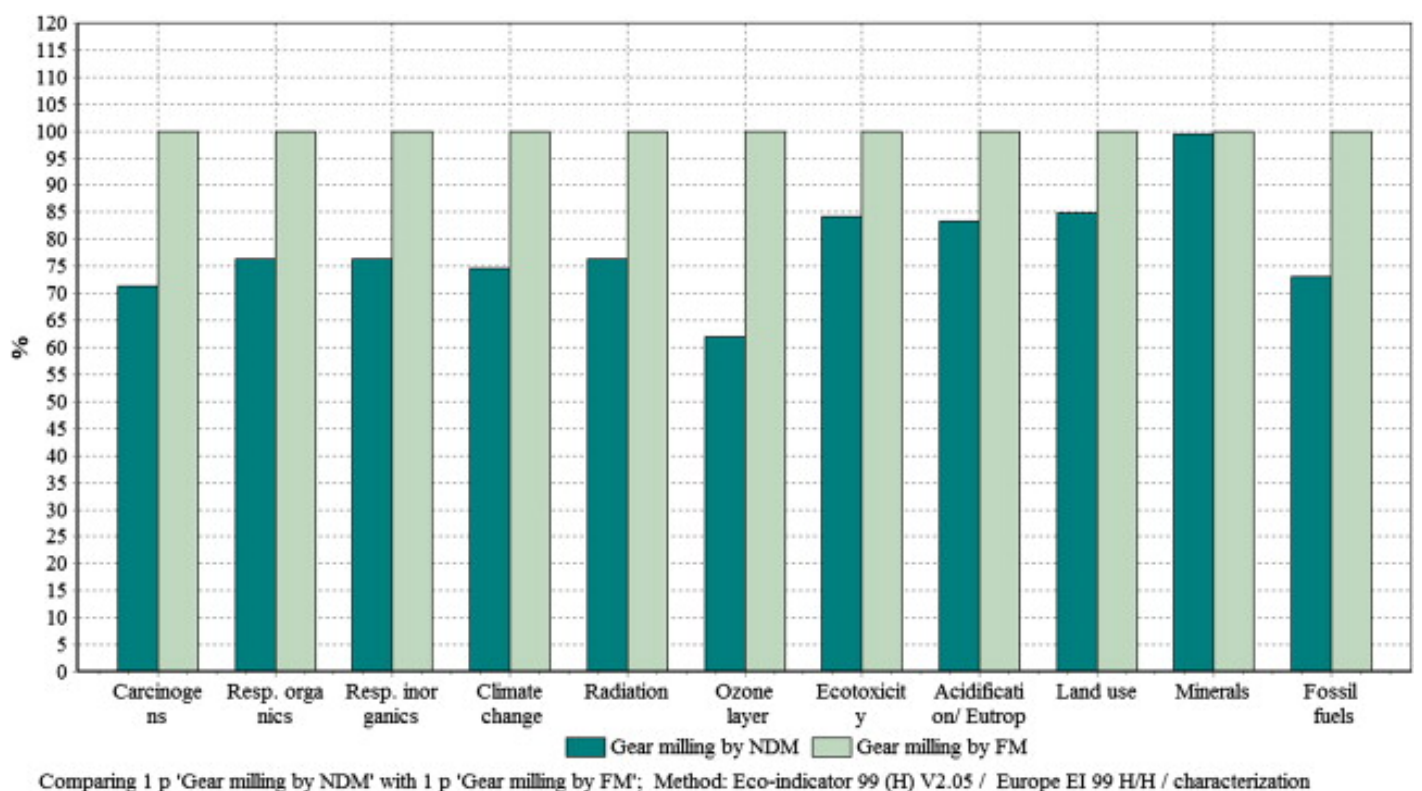

Figura 2.20: Resultados obtenidos en el ACV por Fratila et al. 2010

[Fratila, 2010]

la que se critica que la norma ISO14040 no describe en detalle ni en profundidad las herramientas relacionadas con el ACV y no especifica qué metodología debe ser utilizada en cada fase. Por ello, en el trabajo se desarrollaron unos marcadores para poder analizar el impacto de un producto de forma más concreta. Una vez definidos, el procedimiento a seguir se muestra con el ejemplo de una fábrica de fertilizantes que emite 52.000 Tm anuales de CO2 a la atmósfera. Para ello una vez analizados los marcadores, éstos fueron normalizados utilizando los metros cuadrados $\left(\mathrm{m}^{2}\right)$ necesarios de suelo para la regeneración del daño producido y así comparar todos los marcadores y determinar el más influyente. Esta normalización es denominada como SEPI (Sustainable Environmental Performance Indicator).

Otra investigación realizada en esta línea es la realizada en [Löfgren et al., 2011] donde se advierte que la naturaleza holística de los ACV, lleva al analista a definir unos objetivos muy amplios con el fin de reducir el impacto ambiental olvidando que una sola decisión del fabricante no influye a todo el ciclo vida del producto. También pone de manifiesto que la disminución de la fuente contaminante no implica una disminución proporcional del impacto ambiental lo que puede llegar a ser desalentador, según los autores. Por ello, el objetivo principal de esta investigación fue sobreponer esas deficiencias desarrollando un nuevo método de interpretación 
basado en "life-cycle thinking", es decir, realizar el ACV pensando en el radio de acción del fabricante en lugar de utilizar "entradas y salidas" con el fin del que ACV sea realmente útil.

En definitiva, como se ha podido observar, no existen estudios exhaustivos que cuantifiquen el impacto ambiental generado por los fluidos de corte desde su proceso de producción hasta su tratamiento final una vez terminada su vida útil. En los análisis de ciclo de vida expuestos se observa cómo en las suposiciones realizadas en uno de ellos se simplifica considerablemente el problema de tal modo que se limita a resaltar las bondades de la refrigeración criogénica desde un punto de vista ecológico. En cambio, el otro ACV es una simple comparación cualitativa tomando como referencia el uso de taladrina sin llegar a cuantificar realmente el impacto producido por la lubricación MQL. Además, ambos ACV utilizan marcadores diferentes lo que hace imposible su comparación. Por ello se hace necesario un análisis de ciclo de vida que compare las principales técnicas de refrigeración/lubricación existentes hasta el momento de tal modo que se cuantifique de forma normalizada el impacto ambiental generado por cada una ellas en su producción, su utilización durante el mecanizado y su disposición final una vez terminada su vida útil, es decir, un análisis de ciclo de vida que evalúe el impacto ambiental producido en cada una de sus etapas desde "la cuna hasta la tumba" ("from cradle to grave"). Es aquí donde en esta tesis se dedica un capítulo a resolver esta cuestión de tal modo que se cuantifique y compare cada una de las técnicas de refrigeración/lubricación.

\subsection{Conclusiones}

La necesidad desde el entorno industrial de alcanzar procesos de mecanizado más eficientes medioambientalmente ha llevado a la búsqueda de alternativas al uso de taladrinas como fluidos de corte. En este capítulo se han mostrado los avances y debilidades de las principales alternativas de refrigeración/lubricación ecosostenibles. Las técnicas que actualmente posibilitan suprimir el uso total de aceites derivados del petróleo son la lubricación MQL, la refrigeración criogénica, y la combinación de ambas (CryoMQL). Con el fin de realizar un estado del arte lo más completo posible se ha procedido a la exposición de cada una de estas técnicas desde un punto de vista científico e industrial, respectivamente. En él se han recopilado las principales investigaciones realizadas así como los equipos existentes para posibilitar su aplicación. 
Por otra parte, esta revisión se ha centrado en la aplicación de estas alternativas de refrigeración/lubricación en materiales de difícil maquinabilidad. Concretamente se ha analizado su uso en aceros inoxidables, aceros templados, la aleación de titanio Ti6Al4V y la aleación de níquel Inconel 718. La razón ha sido la demanda existente de estos materiales en sectores estratégicos como el de la turbomaquinaria aeronáutica, ya que la previsión realizada por los fabricantes de aeronaves Airbus y Boeing es la de duplicar la flota de aviones en el período de 2012-2032. Además, a esto hay que sumarle el constante aumento de los precios del combustible, de la energía y de los impuestos relativos a la protección medioambiental. Por ello, construir turbopropulsores más eficientes es una tarea estratégica para dicho sector.

En estas circunstancias la optimización del uso de fluidos de corte durante los procesos de mecanizado de los componentes de los turbopropulsores toma especial relevancia. Como se ha expuesto en este capítulo, su aplicación en este tipo de materiales puede suponer entre un 20-30 \% del precio de fabricación. Por tanto, sustituir el uso de taladrinas por alguna de las alternativas propuestas implica no sólo volverse económicamente más competitivo sino también reducir el impacto ambiental producido por los procesos de mecanizado.

Sin embargo, como se ha ido desglosando a lo largo de este capítulo, la aplicación de estas alternativas industrialmente aún presenta ciertas reticencias. Por ejemplo, los equipos actuales encargados de pulverizar el aceite en la lubricación MQL no proporcionan un control exhaustivo de caudal de aceite utilizado, quedando éste generalmente a merced de la pericia del operario. Además, el aerosol generado pierde casi toda la capacidad refrigerante que se espera de un fluido de corte, por lo que aplicarlo en materiales de difícil maquinabilidad implica menores vida de herramienta que hace su utilización inviable en estas situaciones. Como se ha expuesto, aunque recientemente se han desarrollado diferentes alternativas con lubricación MQL que intentan suplir esta carencia no se ha llegado a crear una alternativa real.

En cambio, la refrigeración criogénica sí aporta la capacidad refrigerante que no aporta la lubricación MQL. Varias investigaciones con LN2 además han demostrado su capacidad lubricante. Sin embargo, el LN2 tiene poco interés industrial debido a las pérdidas generadas durante su almacenamiento en depósitos aislados térmica- 
mente. Por ello, el CO2 resulta más atractivo a la hora de aplicar la refrigeración criogénica dado que aunque tiene una capacidad refrigerante menor, éste se mantiene en estado líquido en depósitos presurizados a temperatura ambiente sin producir ningún tipo de pérdida. Pese a ello, actualmente la inyección de CO2 como fluido de corte está lejos de ser utilizada como alternativa a la taladrina. En primer lugar, se hace necesario el desarrollo de sistemas de inyección que optimicen su utilización en los principales procesos de mecanizado (fresado, torneado y taladrado) ya que a día de hoy se limita a ser utilizado con una simple tobera convergente análoga a las de taladrina. Por otro, la capacidad lubricante del CO2 es nula. En esta tesitura es donde entra en juego la combinación de la lubricación MQL y refrigeración criogénica (CryoMQL) ya que se consigue aunar las sinergias de ambas tecnologías lubricando a la vez que se refrigera. Sin embargo, esta tecnología está prácticamente dando sus primeros pasos. Además, la optimización idónea sería disponer de un equipo que tuviera la capacidad de proporcionar la lubricación MQL y refrigeración criogénica con CO2 tanto en modo "stand alone" o combinada (CryoMQL) en función de las necesidades del material a mecanizar. Esto facilitaría su inclusión en los actuales procesos de mecanizado, relegando la taladrina a un papel testimonial. Sin embargo, este tipo de equipos no han sido desarrollados en la actualidad ya que los diferentes equipos encontrados y expuestos en este capítulo son equipos "stand alone" que proporcionan únicamente una de las tres tecnologías descritas (MQL, CO2 o CryoMQL).

Además de la necesidad de desarrollar sistemas de inyección y equipos que sean capaces de optimizar la utilización de estas tres tecnologías, se necesita evaluar su impacto en los principales materiales de difícil maquinabilidad con el fin de dar una respuesta completa a las necesidades del sector. Aunque han sido diversos los ensayos realizados, la mayoría no han aplicado de forma eficiente estas tecnologías hasta la fecha.

Por ejemplo, en el caso de los aceros inoxidables austeníticos sólo se ha comparado la refrigeración criogénica con el uso de taladrina sin tener en cuenta la naturaleza del material. Este tipo de aceros inoxidables tienden al endurecimiento por acritud debido a su matriz austenítica, lo que implica someter a la herramienta de corte a esfuerzos térmicos y mecánicos con los que la refrigeración criogénica no puede tratar en condiciones industriales. 
En el caso antagónico se encuentran los aceros templados. Debido a la gran dureza que presentan (hasta 64HRc) deben ser mecanizados en seco con herramientas de nitruro de boro cúbico policristalino $(\mathrm{PCBN})$ o de diamante policristalino (PCD). En esta situación se ha aplicado la refrigeración criogénica consiguiendo que la superficie no se degrade térmicamente en un caso o que el PCD no reaccione con el material en otro. Sin embargo, uno de los principales problemas que se presentan en este tipo de materiales es la aparición de la denominada "capa blanca" en la subsuperficie del material. Este fenómeno puede reducir la vida útil a fatiga del componente mecanizado considerablemente. Por ello debe ser tenida en cuenta en cualquier tipo de ensayo realizado en este tipo de material.

En cuanto al Ti6Al4V, ha sido estudiado ampliamente observando la viabilidad de su mecanizado con la tecnología CryoMQL. Sin embargo, cuando el Ti6Al4V es utilizado junto con la fibra de carbono en forma de stacks en componentes estructurales de las aeronaves la utilización de aceite está contraindicado. Una de las operaciones que más se realizan y mayor problemática presenta en este tipo de material compuesto son los taladrados. Por ello, su estudio con refrigeración criogénica sin la utilización de ningún fluido de corte líquido debe ser analizado con el fin de optimizar el proceso.

Por último, en cuanto a las aleaciones de níquel se ha analizado el comportamiento de la tecnología CryoMQL en procesos de torneado, utilizando la refrigeración criogénica de forma externa. Sin embargo, no ha sido evaluado su comportamiento en procesos de fresado con refrigeración externa o interna a la herramienta. Este tipo de procesos tienen una importancia vital en componentes críticos de la turbomaquinaria aeronáutica como impellers o blisks. Además, aparte del alto valor añadido de los componentes, se debe tener en cuenta el alto coste que tienen las herramientas de acabado en estos procesos de fresado. Por eso, evaluar el comportamiento de las diferentes alternativas a la taladrina en operaciones de acabado durante el fresado de este tipo de material es un factor a tener en cuenta.

Por todo ello, en esta tesis se ha procedido al estudio en profundidad de la refrigeración criogénica, MQL y CryoMQL. Con su realización se ha intentado dar respuesta a la necesidad de aumentar la competitividad de los procesos de meca- 
nizado y simultáneamente disminuir el impacto ambiental derivado del uso de los fluidos de corte. Para ello se han desarrollado diferentes sistemas de inyección criogénicos y CryoMQL que aporten unas soluciones robustas capaces de ser utilizadas en un entorno industrial. Posteriormente se ha procedido a la aplicación de estas tecnologías en materiales de difícil maquinabilidad con el fin de determinar la idoneidad de cada técnica de refrigeración/lubricación en cada caso. Además, con el fin de determinar no sólo la viabilidad técnica de estas tecnologías sino también ecológica, se ha realizado un exhaustivo ACV con el fin de determinar el impacto que tienen los diferentes fluidos de corte en el medioambiente. Por último, una vez evaluada tanto la viabilidad técnica como medioambiental se ha procedido al desarrollo y validación de un equipo CryoMQL totalmente "Plug \& Play" capaz de satisfacer las necesidades industriales del entorno en los principales procesos de fabricación como el fresado, torneado y taladrado. En la Figura 2.21 se muestra un resumen con las etapas que han conformado esta tesis.

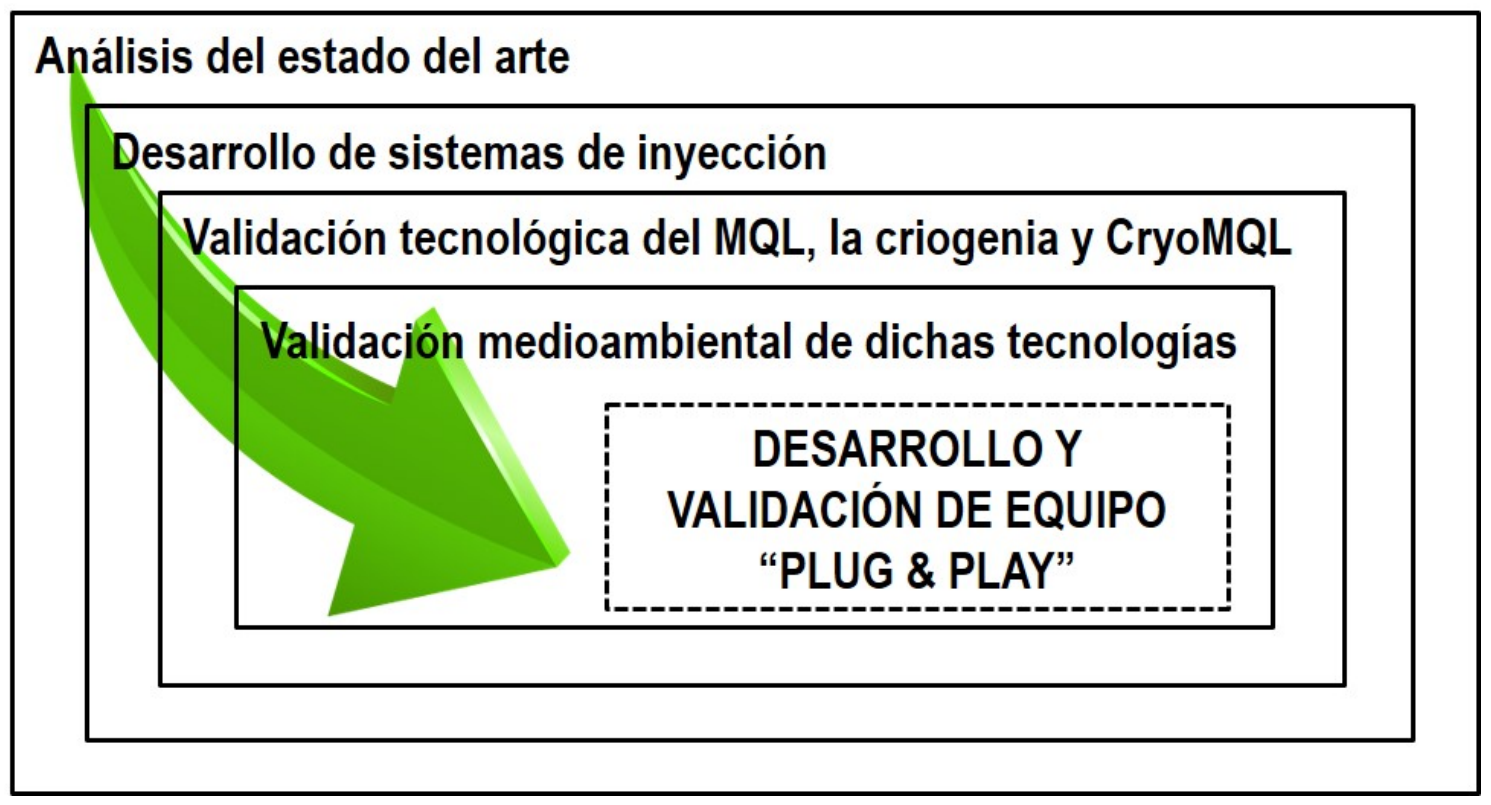

Figura 2.21: Etapas que conforman esta tesis 
CAPÍTULO 3

Desarrollo y adaptación de sistemas de inyección criogénicos 



\section{Desarrollo y adaptación de sistemas de inyección criogénicos}

\subsection{Introducción}

En base al análisis realizado en el estado del arte y con el objetivo claro de aplicar tanto la refrigeración criogénica en modo "stand alone" como su combinación con la lubricación MQL (CryoMQL) en los principales procesos de mecanizado se ha optado por desarrollar y adaptar en una primera instancia diversos sistemas de inyección. Los desarrollos y adaptaciones propuestos están destinados principalmente al uso de CO2 debido a las razones expuestas en el capítulo anterior. Sin embargo, también se ha dedicado un apartado de este capítulo a la descripción de los sistemas de inyección que posibilitan la utilización del LN2.

Con el fin de poder utilizar los sistemas de inyección propuestos durante el mecanizado se hace necesario disponer de diferentes equipos de alimentación en función del fluido de corte utilizado. Por ello, este capítulo está dividido en dos partes principales: la primera hace referencia a los tres tipos de equipos de alimentación utilizados inicialmente en esta tesis y en la segunda parte se exponen los desarrollos y adaptaciones realizados de los diferentes sistemas de inyección.

\subsection{Equipos de alimentación}

Con el fin de alimentar los sistemas de inyección se adaptaron 3 equipos distintos en función del fluido de corte a utilizar. En el caso del CO2 se necesita un equipo de regulación que evite la formación de hielo seco. En cambio, para poder 
almacenar el LN2 se hace imprescindible un equipo de almacenamiento aislante que evite que se evapore en la medida de lo posible. Por último, para pulverizar el aceite en micropartículas (MQL) se dispuso de un sistema neumático por pulsos. En los siguientes puntos se exponen las características y particularidades de cada sistema de alimentación:

\subsubsection{Equipo de regulación de $\mathrm{CO} 2$}

En el caso concreto del CO2, como se expuso en el anterior capítulo, se puede almacenar en depósitos presurizados a 55-60 bares a temperatura atmosférica sin provocar ningún tipo de fuga. Sin embargo, para su inyección se hace necesario la utilización de un sistema de regulación con el fin de evitar la formación de hielo seco en los conductos previos al sistema de inyección y consecuentemente el taponamiento del circuito. Como se muestra en el diagrama de fases de la Figura 3.1, esta formación de hielo seco se debe a que si el CO2 almacenado en dichos depósitos se expande a presión atmosférica sin ningún tipo de regulación atraviesa la "zona de sólido" provocando la formación de hielo seco.

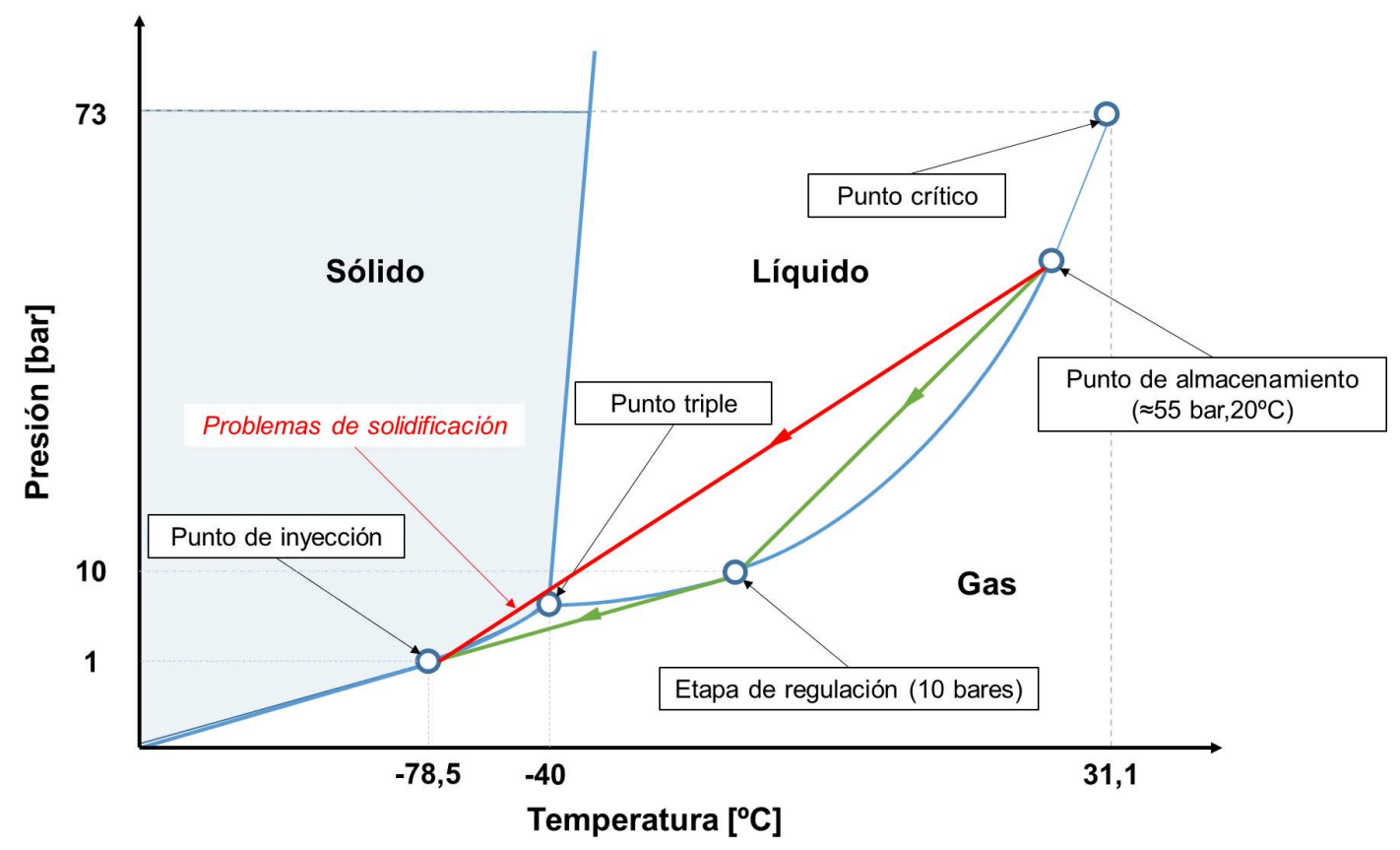

Figura 3.1: Diagrama de fases del CO2 
El equipo de regulación de CO2 utilizado se muestra en la Figura 3.2. Este equipo introduce en todo el circuito una presión de 10-14 bares para evitar que la presión del CO2 esté por debajo del punto triple $\left(5,11\right.$ bares y $\left.-56,4^{\circ} \mathrm{C}\right)$ hasta que sea expandido en la zona de corte. Para ello, antes de la inyección del CO2 en estado líquido propiamente dicho, el equipo inyecta $\mathrm{CO} 2$ en estado gaseoso para presurizar todos los conductos por encima de dicho punto (10 bares). Una vez todos los conductos están presurizados, el equipo de regulación da paso al CO2 líquido que circula a 14 bares para barrer el CO2 gaseoso de las conducciones hasta que es expandido en la zona de corte donde se transforma en estado gaseoso con micropartículas sólidas a $-78^{\circ} \mathrm{C}$. Este sistema es común a cualquier aplicación en la que se desee refrigerar la zona de corte con $\mathrm{CO} 2$ durante el mecanizado.

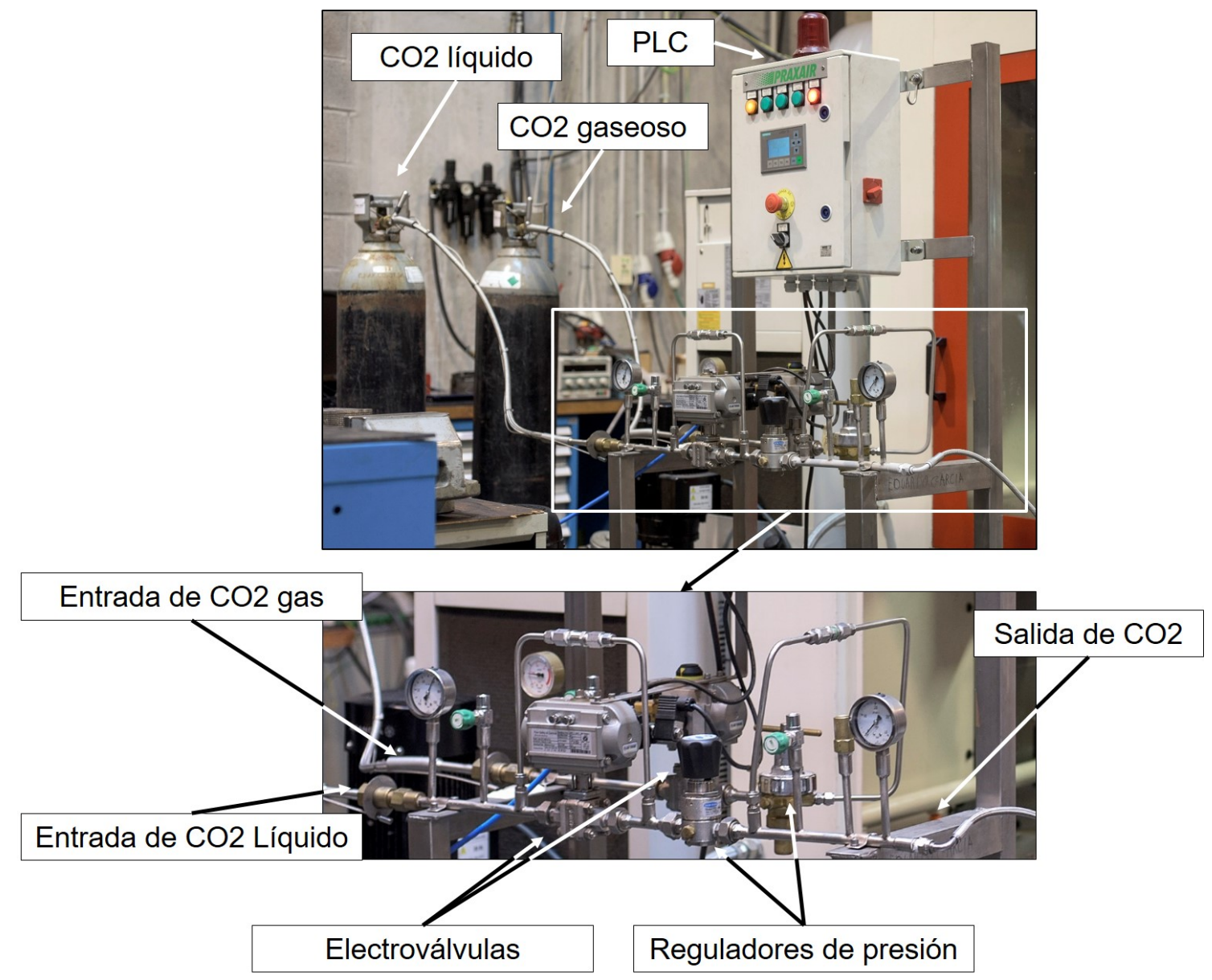

Figura 3.2: Sistema de regulación de CO2 


\subsubsection{Equipo de almacenamiento de LN2}

A diferencia del CO2, el LN2 no necesita un equipo de regulación para poder aplicarlo en los procesos de mecanizado debido a que es mantenido en estado líquido por temperatura como se puede apreciar en el diagrama de fases mostrado en la Figura 3.3.

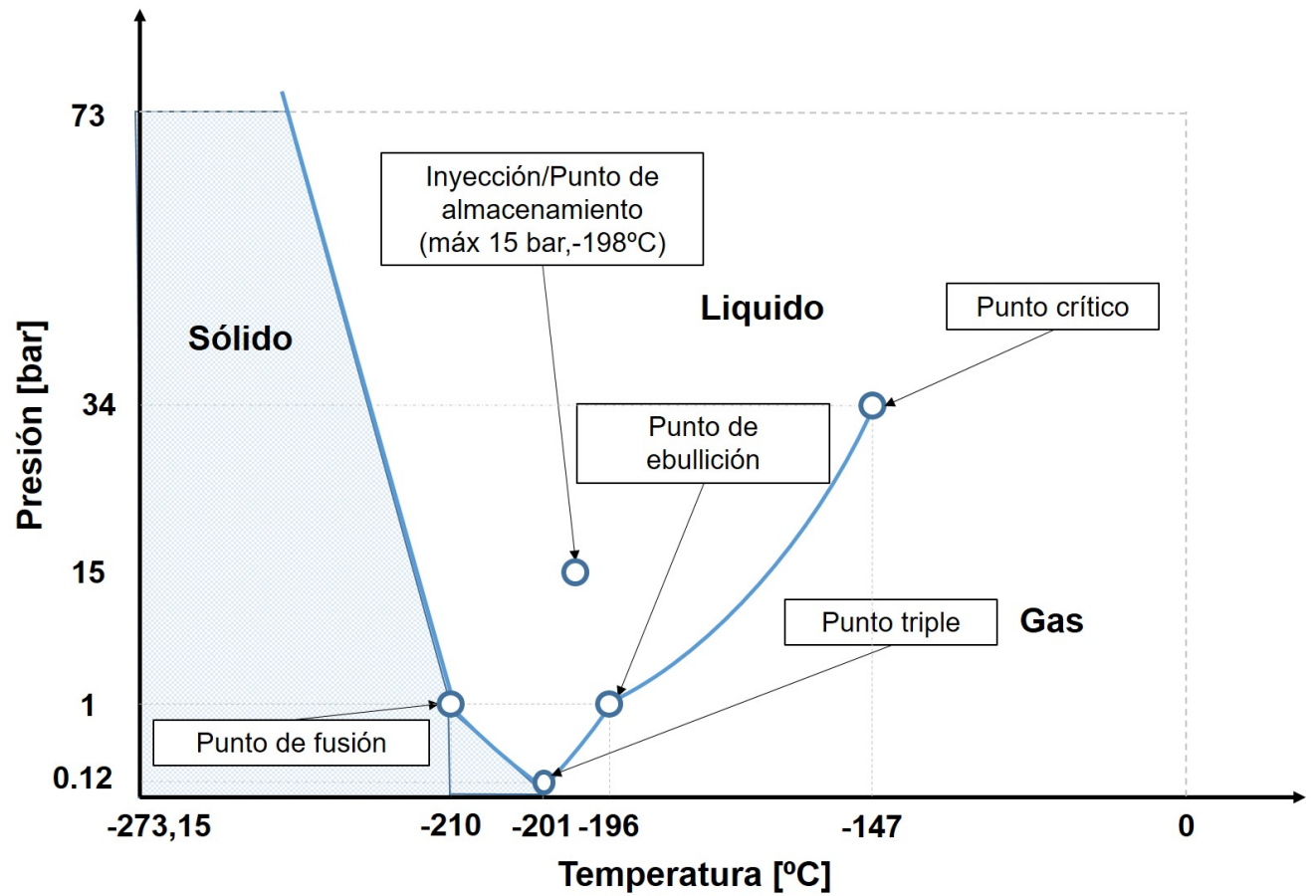

Figura 3.3: Diagrama de fases del LN2

En este caso el LN2 se encuentra en un recipiente aislado en dicho estado a $198^{\circ} \mathrm{C}$ y presión atmosférica. Estos equipos de almacenamiento son conocidos como "PGS" o "Deward" y como se observa en la Figura 3.4 además de mantener en su interior el LN2 están provistos con diferentes elementos de conexión. Entre dichas conexiones caben destacar la válvula de salida de LN2 -a la cual se conectan los diferentes sistemas de inyección- y la válvula de seguridad. Esta última se hace imprescindible debido a que el LN2 está en continua ebullición, por lo que en el interior de éste se genera una sobrepresión que debe ser eliminada una vez alcanza un valor de 15 bares. Una vez dicho valor es sobrepasado, ésta se activa y deja salir el nitrógeno gaseoso en forma de escape con el fin de evitar cualquier riesgo de explosión. 

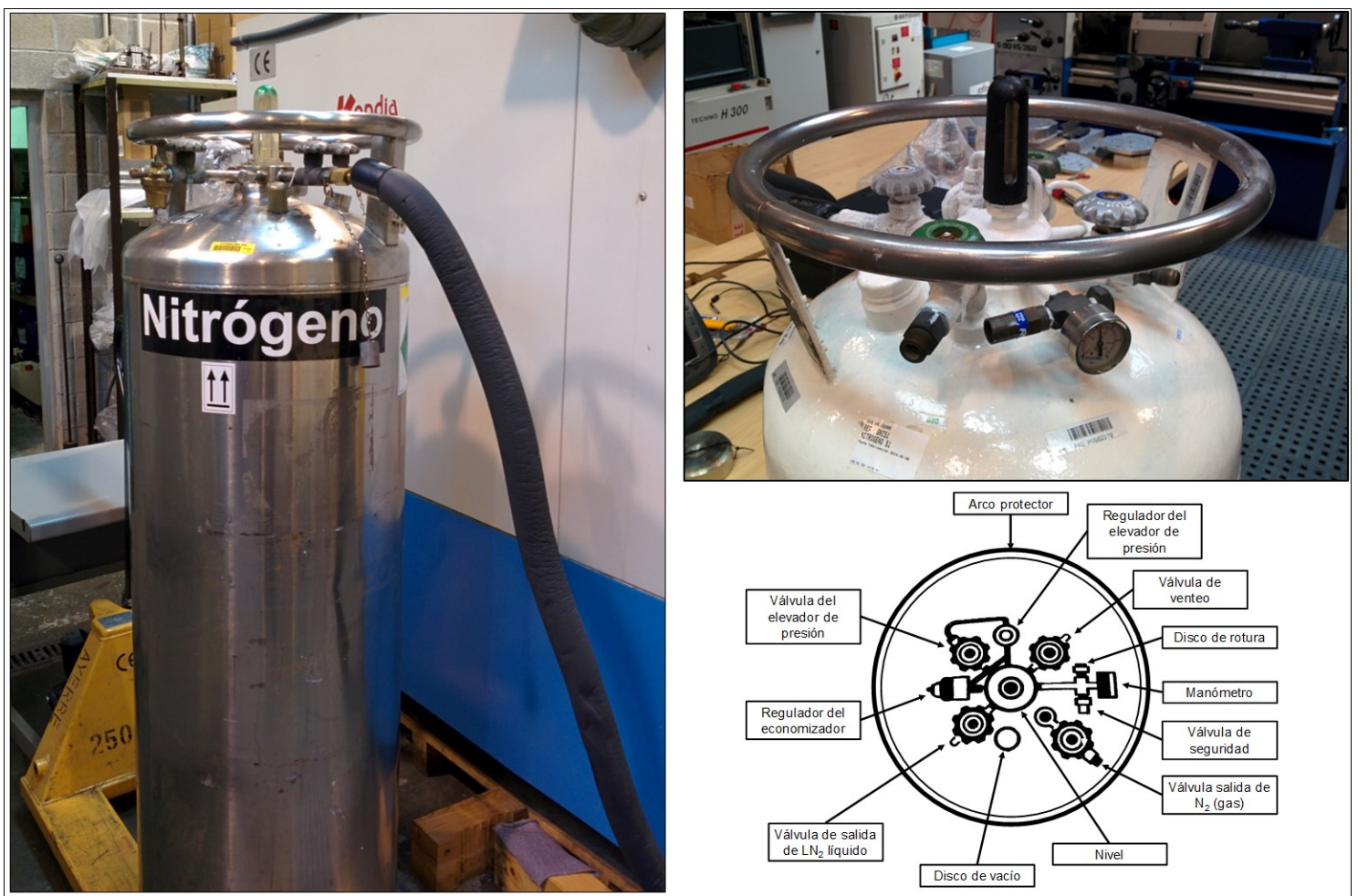

Figura 3.4: Sistema de almacenamiento de LN2

\subsubsection{Equipo de pulverización para MQL}

El equipo de pulverización de aceite utilizado para la aplicación de la lubricación MQL durante el mecanizado consiste en un sistema MQL externo como el mostrado en la Figura 3.5. Para el control del caudal de aceite este equipo está provisto de un dosificador neumático gobernado por un frecuenciómetro. Éste genera unos pulsos que abren y cierran la válvula del dosificador que está alimentada de aceite por el depósito situado en la parte superior del equipo MQL. De este modo se forman gotas de aceite que son transportadas hacia el extremo de la tobera de dos canales gracias al efecto Venturi producido en ésta y la energía potencial derivada de la altura a la que se encuentra el sistema MQL respecto a la tobera. Por otra parte, el sistema está provisto de un regulador de presión que además de controlar la presión de salida del aire cuando las electroválvulas de paso están abiertas, alimenta a los diferentes elementos de los que está compuesto el sistema. Por último, cabe destacar que la unión coaxial de la que está provisto sirve para combinar los conductos de aire y aceite concéntricamente en una manguera, que es la que comunica con la tobera. 


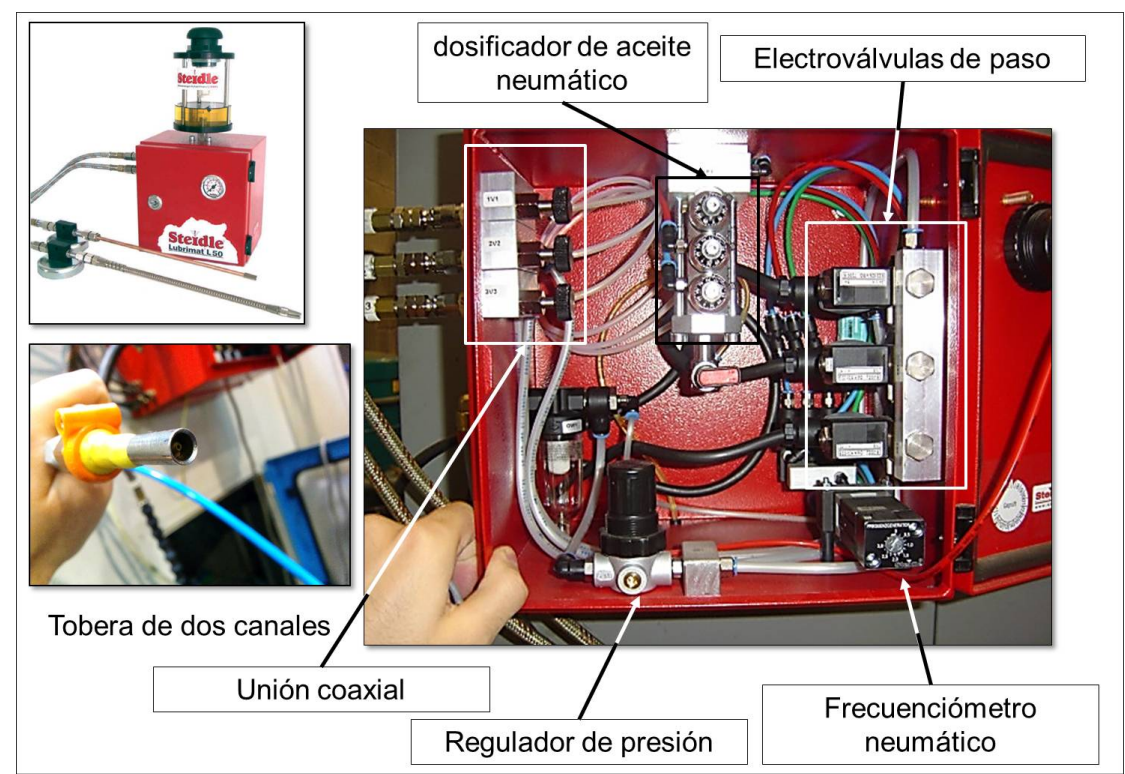

Figura 3.5: Sistema de pulverización de aceite

\subsection{Sistemas de inyección para $\mathrm{CO} 2$}

Como cualquier fluido de corte el $\mathrm{CO} 2$ puede ser inyectado de forma externa o interna a la herramienta. Cuando es utilizado de forma externa, éste es inyectado en la zona de corte de forma análoga a como se inyecta la taladrina. Sin embargo, si es utilizado de forma interna a la herramienta caben dos modalidades de uso en función del diámetro de los orificios de salida. La primera es que sea inyectado hacia la cara de desprendimiento de la herramienta de forma semejante a la taladrina a alta presión, y la segunda es que sea expandido en el interior de la herramienta provocando que ésta trabaje como intercambiador de calor. En el caso concreto del fresado este efecto se ha logrado gracias a las matrices de "micro-orificios" que poseen las herramientas con refrigeración interna los cuales actúan como simples orificios de escape. De este modo se relega la inyección del CO2 en la zona de corte a un segundo plano y consecuentemente se reduce considerablemente su consumo.

Por tanto, un factor clave a la hora de diseñar los diferentes sistemas de inyección es el diámetro de salida de los canales por los que circula el CO2. Su optimización conduce a un mayor control del consumo de CO2 durante los procesos de mecanizado. Esto se traduce en procesos viables desde el punto de vista técnico y económico. Para determinar el diámetro mínimo útil, en primer lugar se ha procedido a la simulación del comportamiento del $\mathrm{CO} 2$ con diferentes diámetros de salida mediante 
dinámica de fluidos computacional (CFD). Además, con el fin de validar dichos modelos y obtener la velocidad óptima de inyección de CO2 para su posterior uso en simulaciones más complejas realizadas para el desarrollo de sistemas de inyección CryoMQL, estos fueron comparados mediante pruebas empíricas realizadas en un banco de ensayos dotado de una cámara de alta velocidad. Por último y teniendo en cuenta los resultados obtenidos, se procedió al desarrollo y adaptación de diversos sistemas de inyección para los diferentes procesos de fabricación.

\subsubsection{Simulación mediante CFD y validación del modelo ma- temático. Diámetro y velocidad óptima de salida}

Los diámetros de salida estudiados con el propósito de optimizar el gasto de CO2 durante los procesos de mecanizado fueron tres. Específicamente se estudiaron salidas de $0,5 \mathrm{~mm}, 1 \mathrm{~mm}$ y $1,5 \mathrm{~mm}$. Las simulaciones fueron realizadas con la ayuda del software Fluent@. Una vez realizadas, los resultados obtenidos fueron validados en un banco de ensayos como el mostrado en la Figura 3.6. Dicho banco de ensayos está compuesto por un tablero dividido en sectores cuadráticos de 20x20 mm para posibilitar la medida de distancias en las imágenes tomadas; una cámara de alta velocidad Olympus i-speed LT; unos parámetros de adquisición de 1500 frames/segundo; y cinco focos de tungsteno de $1000 \mathrm{~W}$ de potencia cada uno.

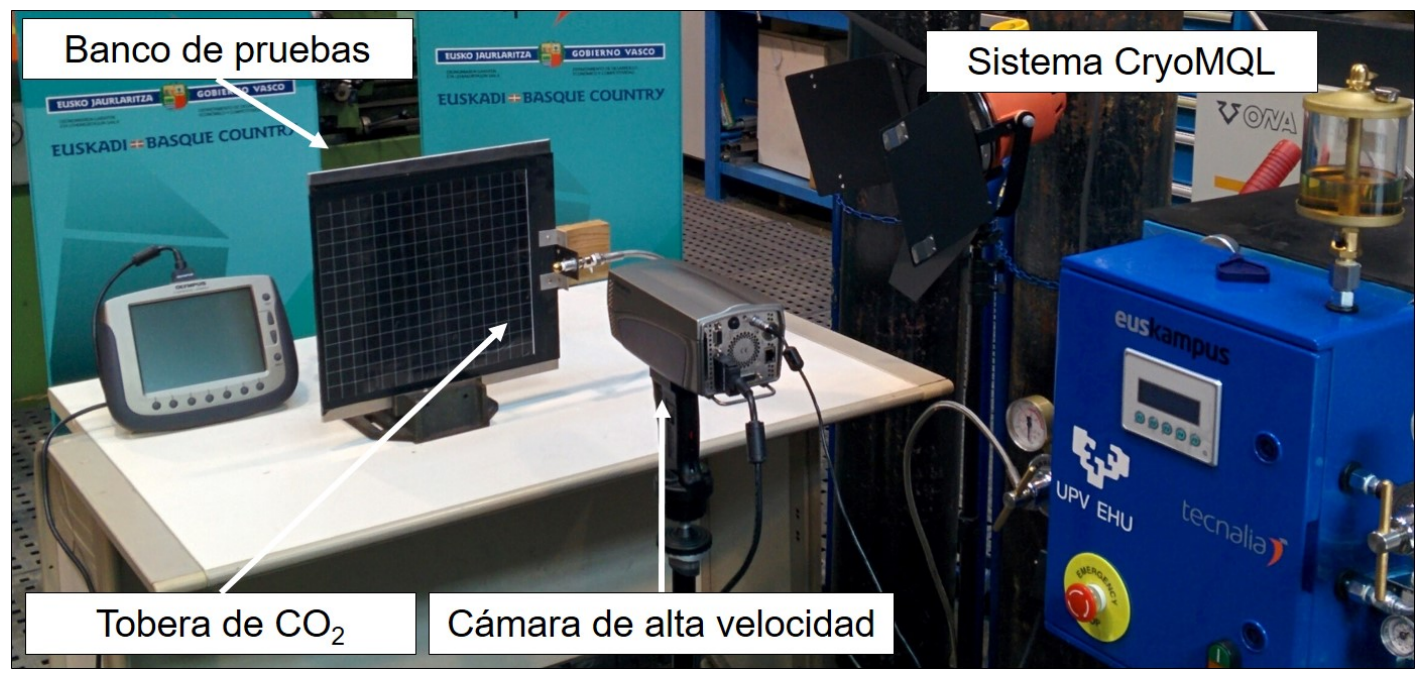

Figura 3.6: CO2 Banco de ensayos para la validación de CFD 


\section{Base matemática de los modelos utilizados}

El modelo utilizado fue el conocido como "Volume of fluid" (VOF) o volumen de fluido. Este modelo se caracteriza por tener la capacidad de poder modelar dos o más fluidos inmiscibles. Se seleccionó este modelo porque es el recomendado cuando existen dos o más fluidos que sean interpenetrantes y se desplacen a velocidades diferentes. Como particularidad de este modelo los volúmenes de control deben estar definidos por una fase simple de fluido o combinación de varios, es decir, no puede haber nodos sin masa. A diferencia de otros modelos en los que se resuelven las ecuaciones de conservación de la masa, de la cantidad de movimiento y de conservación de la energía, en el modelo VOF la ecuación de conservación de la masa es sustituida por la ecuación de la fracción de volumen en cada nodo modelizado. Por lo tanto para una fase $q$ cuya fracción de volumen en el nodo sea $\alpha_{q}$, existen tres situaciones posibles:

- $\alpha_{q}=0$, el nodo está vacío del fluido $q$.

- $\alpha_{q}=1$, el nodo contiene únicamente al fluido $q$.

- $0<\alpha_{q}<1$, el nodo contiene fluido $q$ y uno o más fluidos hasta que la suma de sus fracciones formen la unidad.

Con este modelo las propiedades y variables son asignadas en cada volumen de control del dominio basándose en el valor local $\alpha_{q}$. La ecuación de la fracción de volumen está representada en la Ecuación 3.1. En el primer miembro $\rho_{q}$ y $v_{q}$ son la densidad y velocidad de la fase $q$. En cambio, en el segundo miembro $\dot{m}_{q p}$ y $\dot{m}_{p q}$ son la transferencia de masa desde la fase $q$ a la fase $p$ y viceversa. $S_{\alpha_{q}}$ es una constante para incrementar la masa de la fase $q$ (generalmente cero).

$$
\frac{1}{\rho_{q}} \cdot\left[\frac{\partial}{\partial t}\left(\alpha_{q} \rho_{q}\right)+\nabla \cdot\left(\alpha_{q} \rho_{q} \overrightarrow{v_{q}}\right)=S_{\alpha_{q}}+\sum_{p=1}^{n}\left(\dot{m}_{p q}-\dot{m}_{q p}\right)\right]
$$

En cuanto a la ecuación de la cantidad de movimiento (o momento) mostrada en la Ecuación 3.2, ésta es resuelta en todo el dominio y el campo de velocidades resultante es repartido entre todas las fases en función de su fracción másica como refleja la Ecuación 3.3. En este caso, $g$ es la aceleración de la gravedad y $\vec{F}$ representa la fuerza derivada de los efectos de la tensión superficial. Como se puede observar, la 
ecuación de la cantidad de movimiento es dependiente de las fracciones de volumen de todas las fases a través de la densidad $(\rho)$ y la viscosidad $(\mu)$ ya que estas dos propiedades son calculadas en función de la fracción presente de cada fase en cada nodo como se muestran en las Ecuaciones 3.4 y 3.5 .

$$
\begin{gathered}
\frac{\partial}{\partial t}(\rho \vec{v})+\nabla \cdot(\rho \vec{v} \vec{v})=-\nabla p+\nabla \cdot[\mu(\nabla \vec{v}+\nabla \vec{v})]+\rho \vec{g}+\vec{F} \\
v=\frac{\sum_{q=1}^{n} \alpha_{q} \rho_{q} v_{q}}{\rho} \\
\rho=\sum_{q=1}^{n} \alpha_{q} \rho_{q} \\
\mu=\sum_{q=1}^{n} \mu_{q} \rho_{q}
\end{gathered}
$$

En la Ecuación 3.6 se muestra la ecuación de la conservación de la energía, la cual también es distribuida una vez calculada entre todas las fases del dominio. Los términos $k_{\text {eff }}$ y $S_{h}$ son la conductividad térmica efectiva y una variable para tener en cuenta la radiación así como otras fuentes de calor volumétrico, respectivamente. En este caso, al igual que la velocidad, la energía $(E)$ y la temperatura $(T)$ son calculadas en función de la masa media de cada nodo como muestran las Ecuaciones 3.7 y 3.8 .

$$
\begin{gathered}
\frac{\partial}{\partial t}(\rho E)+\nabla(\vec{v}(\rho E+p))=\nabla \cdot\left(k_{e f f} \nabla T\right)+S_{h} \\
E=\frac{\sum_{q=1}^{n} \alpha_{q} \rho_{q} E_{q}}{\rho} \\
T=\frac{\sum_{q=1}^{n} \alpha_{q} \rho_{q} T_{q}}{\rho}
\end{gathered}
$$

En cuanto a los modelos de turbulencia, se utilizó un modelo " $K-\varepsilon$ ". Este modelo de turbulencia es un modelo RANS (Reynolds Average Navier-Stokes) basado en los modelos de vorticidad viscosa de 2 ecuaciones. En este modelo se necesitan condiciones iniciales y/o de frontera como parámetros de entrada. Este modelo está aceptado 
y plenamente validado por numerosas investigaciones relacionadas con procesos de mecanizado ([Duchosal et al., 2015], [Cotas et al., 2015], [Obikawa et al., 2006]). De

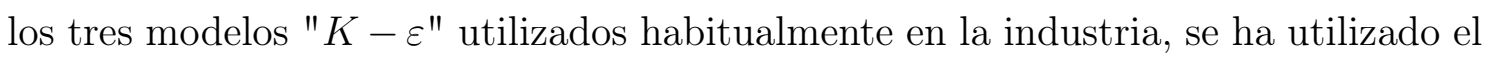

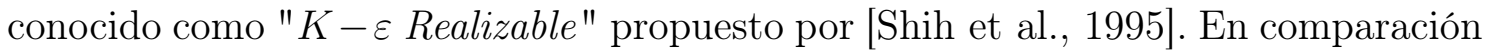
con otros modelos, presenta mejoras en las características de flujo - incluyendo una gran curvatura aerodinámica - e impide la producción de componentes de energía negativas. Su ecuación de energía cinética de transporte de turbulencia es mostrada en la Ecuación 3.9, la cual no difiere de la desarrollada en el modelo " $K-\varepsilon$ " original. En ella $\frac{\partial}{\partial t}(\rho k)$ es la tasa de cambio de la energía cinética media $(\mathrm{K}) ; \frac{\partial}{\partial x_{j}}\left(\rho k u_{j}\right)$ es el trasporte de K por convección; $\frac{\partial}{\partial x_{j}}\left[\left(\mu+\frac{\mu_{t}}{\sigma_{k}} \frac{\partial k}{\partial x_{j}}\right)\right]$ es el transporte de K por difusión, donde $\sigma_{k}$ es 1,0; $P_{k}$ es la generación de $\mathrm{K}$ debida al gradiente de la velocidad media; $P_{b}$ es la generación de $\mathrm{K}$ debido a la flotabilidad; $\rho \varepsilon$ es la tasa de disipación de $\varepsilon$ (tasa de disipación de energía cinética); $Y_{M}$ representa la contribución de la dilatación fluctuante en la turbulencia compresible a la tasa global de disipación.

$$
\frac{\partial}{\partial t}(\rho k)+\frac{\partial}{\partial x_{j}}\left(\rho k u_{j}\right)=\frac{\partial}{\partial x_{j}}\left[\left(\mu+\frac{\mu_{t}}{\sigma_{k}} \frac{\partial k}{\partial x_{j}}\right)\right]+P_{k}+P_{b}-\rho \varepsilon-Y_{M}
$$

Sin embargo, este modelo difiere del original por presentar una ecuación de la tasa de disipación de energía cinética $(\varepsilon)$ modificada la cual está basada en una ecuación exacta para el transporte de la fluctuación cuadrática media de la vorticidad. La nueva ecuación desarrollada en este modelo se refleja en la Ecuación 3.10, donde $\frac{\partial}{\partial t}(\rho \varepsilon)$ es la tasa de cambio de $\varepsilon ; \frac{\partial}{\partial x_{j}}\left(\rho \varepsilon u_{j}\right)$ es el transporte de $\varepsilon$ por convección; $\frac{\partial}{\partial x_{j}}\left[\left(\mu+\frac{\mu_{t}}{\sigma_{\varepsilon}}\right) \frac{\partial \varepsilon}{\partial x_{j}}\right]$ es el transporte de $\varepsilon$ por difusión, donde $\sigma_{\varepsilon}$ is 1,$2 ; \rho C_{1} S \varepsilon-$ $\rho C_{2} \frac{\varepsilon^{2}}{k+\sqrt{v \varepsilon}}$ es la ecuación de la tasa de disipación de $\varepsilon$, donde $C_{1}$ es gobernado por la Ecuación 3.11 y $C_{2}$ es 1,$9 ;$ y $C_{1 \varepsilon} \frac{\varepsilon}{k} C_{3 \varepsilon} P_{b}$ es la ecuación de la generación de $\varepsilon$ es 1,44.

$$
\frac{\partial}{\partial t}(\rho \varepsilon)+\frac{\partial}{\partial x_{j}}\left(\rho \varepsilon u_{j}\right)=\frac{\partial}{\partial x_{j}}\left[\left(\mu+\frac{\mu_{t}}{\sigma_{\varepsilon}}\right) \frac{\partial \varepsilon}{\partial x_{j}}\right]+\rho C_{1} S \varepsilon-\rho C_{2} \frac{\varepsilon^{2}}{k+\sqrt{v \varepsilon}}+C_{1 \varepsilon} \frac{\varepsilon}{k} C_{3_{\varepsilon}} P_{b}
$$

$$
\begin{gathered}
C_{1}=\max \left[0,43, \frac{\eta}{\eta+5}\right] \quad \text { donde, } \\
\eta=S \frac{k}{\varepsilon} \quad S=\sqrt{2 S_{i j} S i j} \quad S_{i j}=\frac{1}{2}\left[\frac{\partial u_{j}}{\partial x_{i}}+\frac{\partial u_{i}}{\partial x_{j}}\right]
\end{gathered}
$$


Además, se ha desarrollado una ecuación para gobernar la viscosidad de turbulencia en lugar de considerarla constante. Dicha ecuación se muestra en la Ecuación 3.12. Esta ecuación introduce una variable inicialmente propuesta por [Reynolds, 1987] y después desarrollada por [Shih and Zhu, 1994], $C_{\mu}$, cuya ecuación se refleja en la Ecuación 3.13. En esta ecuación, el flujo principal $\left(U^{*}\right)$ está definido en la Ecuación 3.14 que tiene en cuenta la velocidad de deformación anisótropa $S_{i j}$ y la tasa de rotación media vista desde el sistema de referencia que gira $\left(\widetilde{\Omega}_{i j}\right)$; el coeficiente $A_{s}$, que depende del tipo de deformación, es definido por la Ecuación 3.15; y el valor de $A_{0}$ es 4,04 con el fin de producir un nivel adecuado de tensión de corte en el flujo de tensiones.

$$
\begin{gathered}
\mu_{t}=\rho C_{\mu} \frac{k^{2}}{\varepsilon} \\
C_{\mu}=\frac{1}{A_{0}+A_{S} U \cdot \frac{k}{\varepsilon}} \\
U^{*} \equiv \sqrt{S_{i j} S_{i j}+\widetilde{\Omega}_{i j} \widetilde{\Omega}_{i j}} \quad d o n d e, \\
\widetilde{\Omega}_{i j}-2 \varepsilon_{i j k} \omega_{k} \quad \Omega_{i j}=\bar{\Omega}_{i j}-\varepsilon_{i j k} \omega_{k} \\
A_{S}=\sqrt{6} \cos \phi \quad d o n d e, \\
\phi=\frac{1}{3} \operatorname{arc} \cos (\sqrt{6} W) \quad W=\frac{S_{i j} S_{j k} S_{k i}}{\widetilde{S^{3}}} \quad \widetilde{S}=\sqrt{S_{i j} S_{i j}}
\end{gathered}
$$

Por último, el algoritmo de resolución para llevar a cabo las iteraciones seleccionado fue el método PISO (Pressure Implicit with Splitting of Operators). Este algoritmo es un procedimiento de cálculo de presión-velocidad desarrollado originalmente para la computación no-iterativa de flujos inestables compresibles. Sin embargo, ha sido adaptado para soluciones iterativas para fluidos inestables tanto compresibles como incompresibles. Para ello el algoritmo PISO involucra un paso indicador/predictor y dos pasos correctores para una convergencia de la solución más rápida. En la Figura 3.7 se muestra un diagrama de flujo con los pasos seguidos por este algoritmo de resolución.

En cuanto a las características de la malla utilizada para cada diámetro de salida se realizó una malla 2D cuadrática simétrica por el eje central como la mostrada 


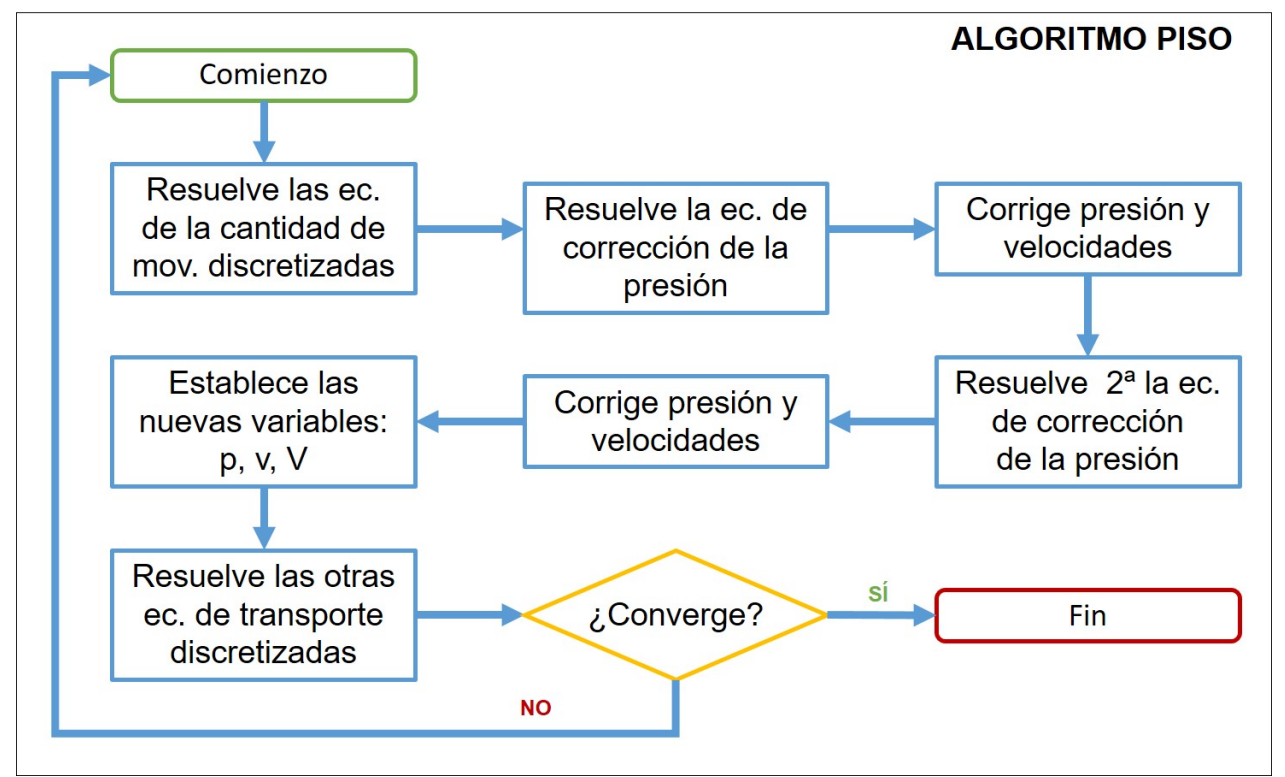

Figura 3.7: Diagrama de flujo del algoritmo de resolución PISO

en la Figura 3.8. La longitud total de cada una de las mallas fue de $350 \mathrm{~mm}$ con un espaciado exponencial para los nodos de $0,2 \mathrm{~mm}$ para el eje vertical y $0,3 \mathrm{~mm}$ para el horizontal. Sin embargo, en la zona del diámetro de salida el espaciado fue uniforme con un valor de $0,1 \mathrm{~mm}$.

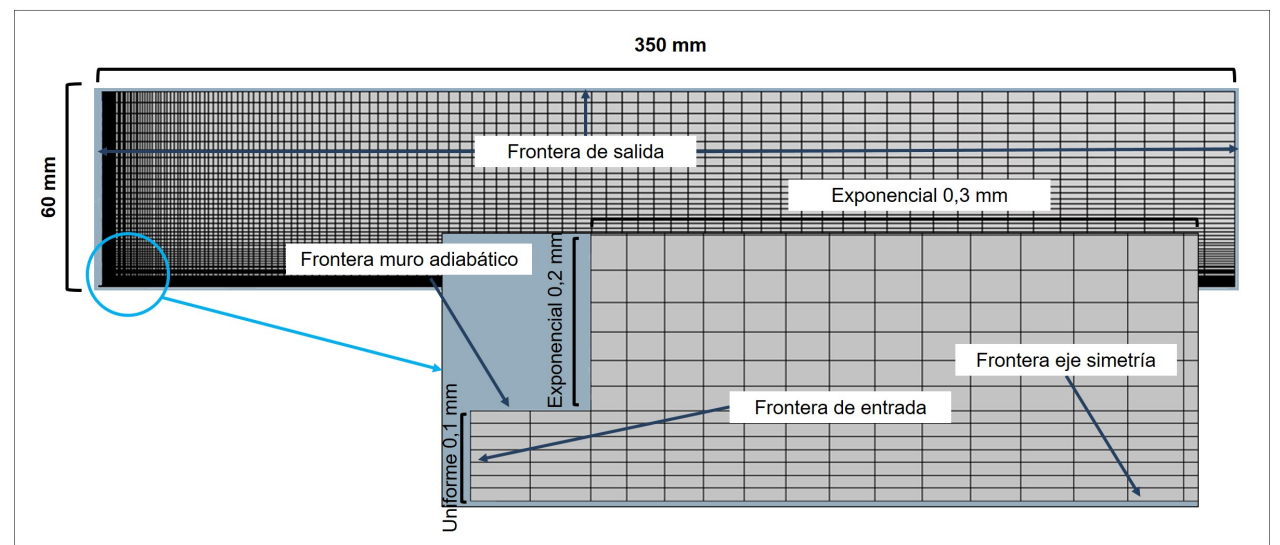

Figura 3.8: Características de la malla utilizada

Las condiciones frontera utilizadas fueron: para la entrada de $\mathrm{CO} 2$ se utilizó una presión constante de 14 bares y una intensidad de turbulencia del 10\%; las paredes de la salida de CO2 se consideraron adiabáticas; y las restantes fronteras de la malla fueron consideradas como salidas con presión atmosférica, una intensidad de reflujo 
turbulento del $2 \%$ y una escala del reflujo turbulento basado en la Ecuación 3.16, donde L es el diámetro hidráulico.

$$
l=0,07 L
$$

\section{Resultados}

En la Figura 3.9 se muestran un gráfico con las velocidades medias obtenidas en las respectivas simulaciones realizadas para cada uno de los diámetros analizados. Como se observa, en los primeros $20 \mathrm{~mm}$ la velocidad media descendió hasta 6 veces con el diámetro de $0,5 \mathrm{~mm}$ y 3 veces con el diámetro de $1 \mathrm{~mm}$. Sin embargo, con el diámetro de 1,5 mm solamente se reduce a la mitad, es decir, la velocidad se mantiene a $600 \mathrm{~m} / \mathrm{s}$ en este punto. Hay que destacar que, como es obvio, el CO2 tiende a dispersarse en el ambiente. Esto provoca una disipación de su velocidad que provoca la inutilización del CO2 para asistir los procesos de mecanizado como fluido de corte. De acuerdo con esto el CO2 inyectado con una salida de diámetro de 1,5 $\mathrm{mm}$ alcanzó los $30 \mathrm{~mm}$ de distancia con $400 \mathrm{~m} / \mathrm{s}$.

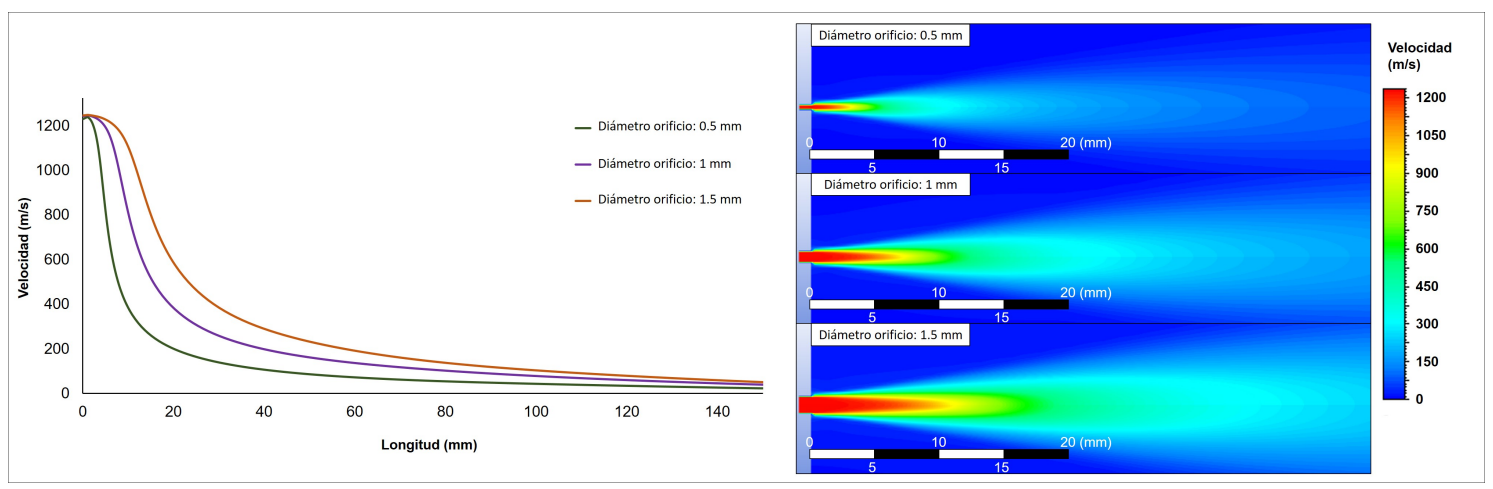

Figura 3.9: Simulaciones realizadas de los diámetros analizados para salida de CO2

Una vez realizadas las simulaciones se procedió a la realización del análisis empírico con los mismos diámetros de salida. Los resultados obtenidos muestran principalmente la propagación/esparcimiento del CO2 en el ambiente como se observa en la Figura 3.10. Con los diámetros de salida de 0,5 mm y $1 \mathrm{~mm}$, el CO2 alcanzó una distancia de $10 \mathrm{~mm}$ y $18 \mathrm{~mm}$, respectivamente. En cambio al utilizar la salida con un diámetro de 1,5 mm se alcanzaron los $40 \mathrm{~mm}$ de distancia. 

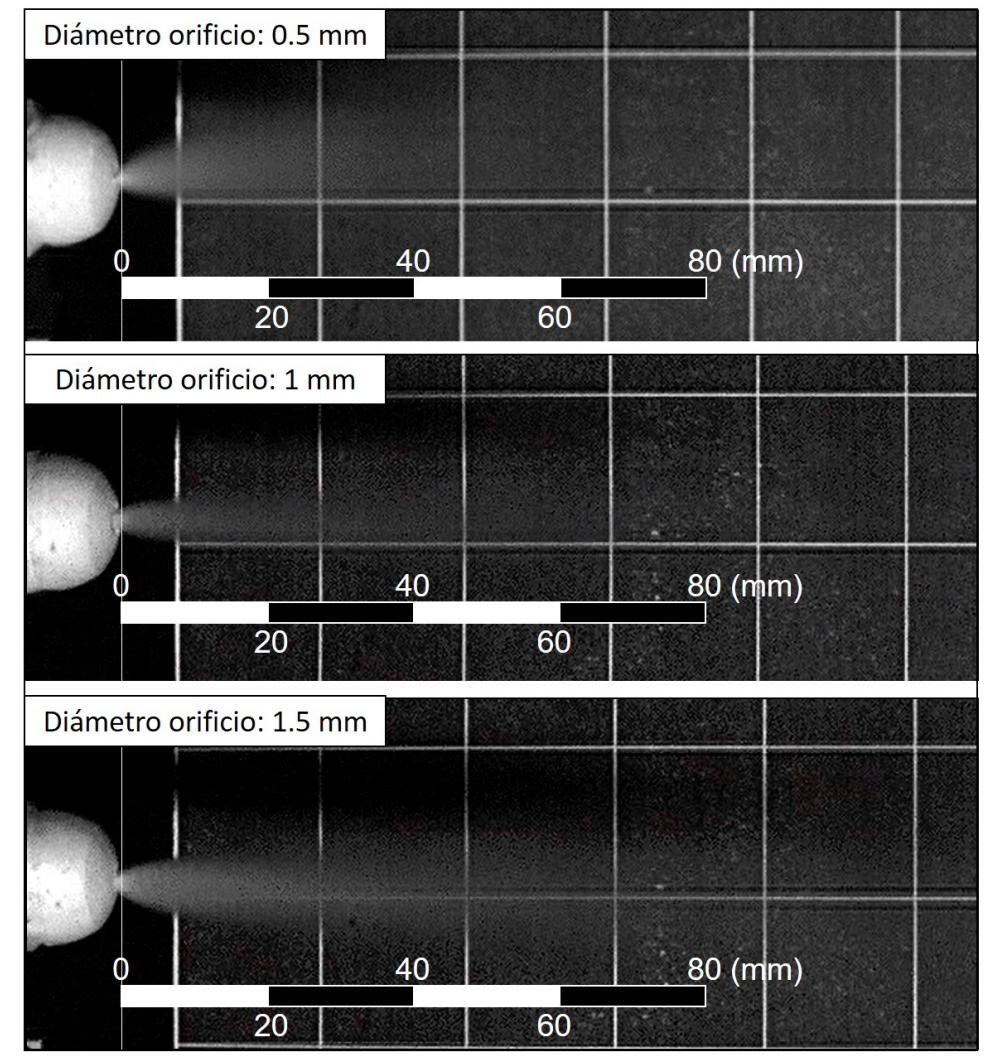

Figura 3.10: Resultados empíricos obtenidos para los diferentes orificios de salida de $\mathrm{CO} 2$

\section{Validación}

Para validar los modelos matemáticos elegidos y así posteriormente también aplicarlos en el desarrollo del sistema de inyección de CryoMQL se compararon los resultados obtenidos con las simulaciones mediante CFD y con el banco de ensayos. Dicha comparación se refleja en la Figura 3.11. Ambos resultados en cuanto a extensión del CO2 son similares, lo que indica la validez de los modelos utilizados en el software de CFD. Además, esta comparación muestra la velocidad útil a la que debe ser inyectado en la zona de corte. Basándose en ella, la velocidad se estableció en $325 \mathrm{~m} / \mathrm{s}$. De acuerdo con el diámetro seleccionado dicho valor es alcanzado en diferentes distancias. Concretamente para el diámetro de 0,5 $\mathrm{mm}$ se alcanzó a los $11 \mathrm{~mm}$, para el diámetro de $1 \mathrm{~mm}$ se alcanzó a los $24 \mathrm{~mm}$ y a los $35 \mathrm{~mm}$ para el diámetro de 1,5 mm. Por lo tanto, de cara a los desarrollos y adaptaciones realizados para los diferentes sistemas de inyección se tuvo en cuenta éste diámetro para los canales de salida por los que vaya a circular el CO2. 


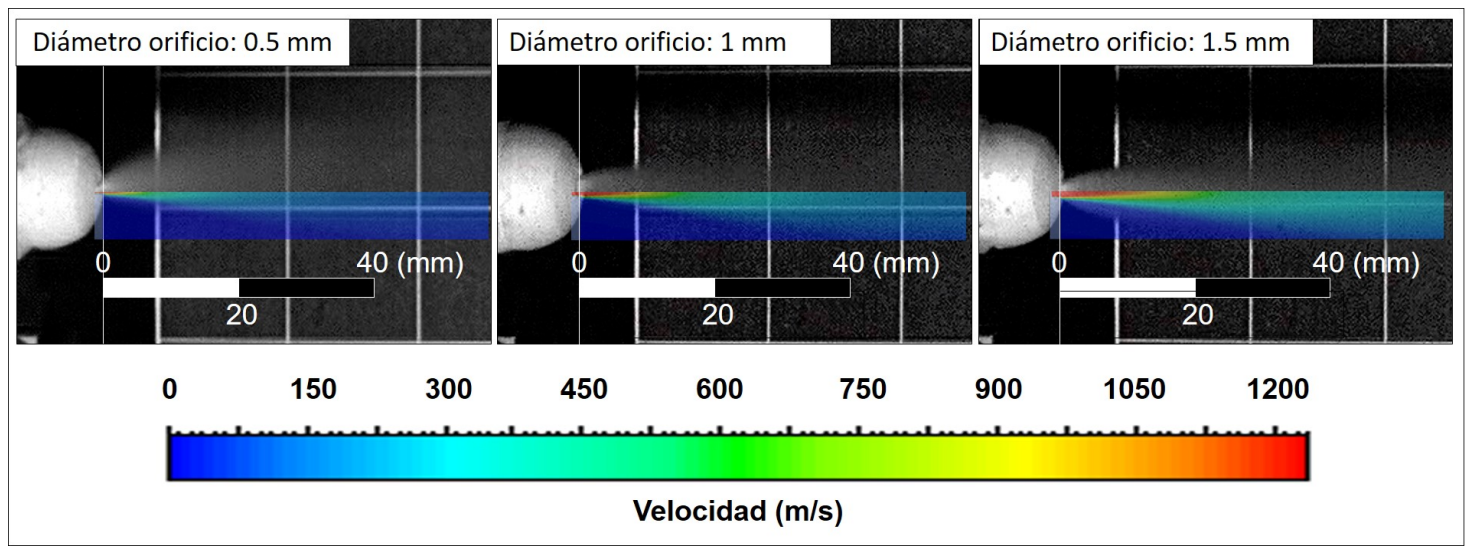

Figura 3.11: Comparación resultados reales con CFD

\subsubsection{Adaptación y desarrollo de los sistemas de inyección}

Partiendo del diámetro óptimo de salida calculado con el cual el CO2 es inyectado correctamente en la zona de corte, se ha procedido al desarrollo y adaptación de diferentes sistemas de inyección de CO2. Estos sistemas fueron aplicados en los principales procesos de mecanizado, es decir, fresado, taladrado y torneado. Cabe destacar que se ha tenido en cuenta tanto la capacidad de aplicar la refrigeración criogénica con CO2 de forma externa a la herramienta como interna.En los siguientes puntos se muestran los desarrollos y adaptaciones realizados para la aplicación de la criogenia con $\mathrm{CO} 2$ en los diferentes procesos de mecanizado:

\section{Fresado/Taladrado}

Para aplicar el CO2 como fluido de corte externo a la herramienta tanto en procesos de fresado como de taladrado se han utilizado toberas similares a las utilizadas con la taladrina como las mostradas en la Figura 3.12. Sin embargo, a diferencia de las toberas y conductos convencionales, estos deben de ser metálicos con el fin de soportar las presiones a las que son sometidos y tener un diámetro de salida de 1,5 mm.

Para poder utilizar el CO2 interiormente durante el fresado y taladrado, como se muestra en la Figura 3.13, se hace necesario modificar la junta rotativa de la fresadora mediante un adaptador que permita la entrada del CO2 sin dañarla ni dañar los rodamientos del husillo; hermetizar los portaherramientas a utilizar para evitar despresurizaciones que provoquen descensos drásticos de temperatura en el 


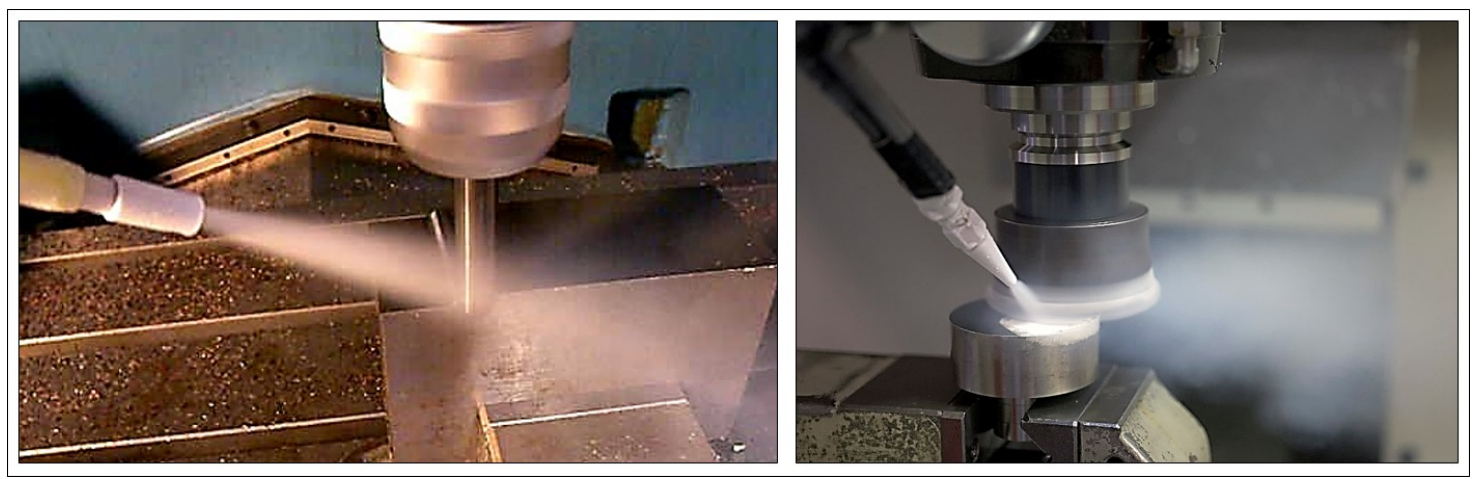

Figura 3.12: CO2 "stand alone" externo

interior del husillo; y por último utilizar herramientas comerciales de alta presión con refrigeración interna.

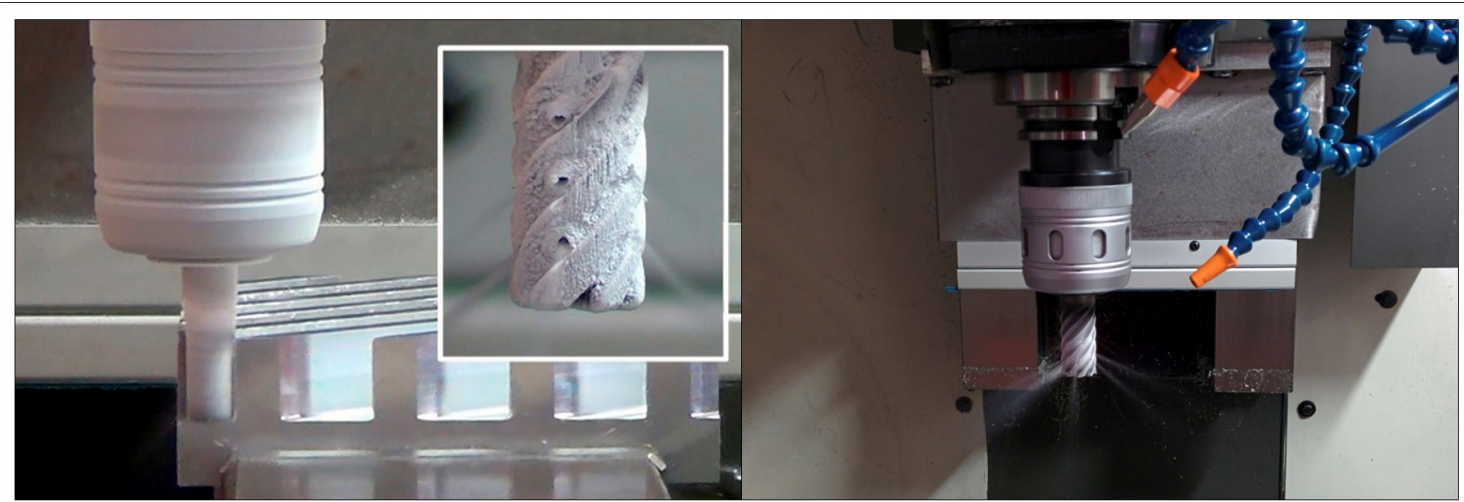

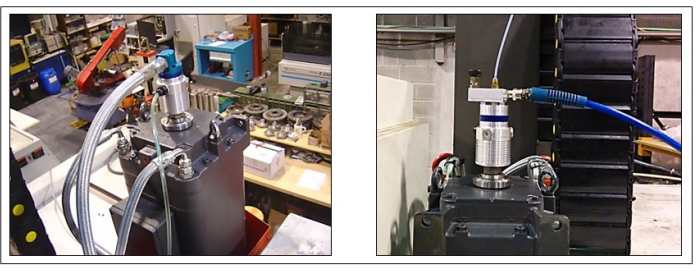

Modificación de la junta rotativa

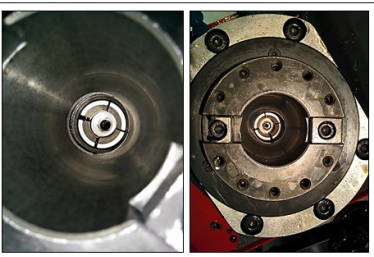

Modificación del portapinzas

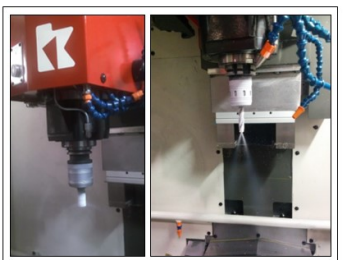

Modificación del portahtas

Figura 3.13: CO2 "stand alone" interno

Por otra parte para las operaciones de taladrado, además de las técnicas expuestas en el párrafo anterior, existe una tercera opción para poder aplicar el CO2 internamente en caso de no tener un conducto en el interior del husillo por el cual conducirlo. Para ello simplemente es necesario adecuar un adaptador coaxial como 
el mostrado en la Figura 3.14, utilizado generalmente para aplicar taladrina o MQL. En este adaptador el CO2 entra de forma radial a una cámara presurizada en su interior que está provista de unos orificios que permiten la entrada de éste al interior de la herramienta. Sin embargo, este adaptador debe estar provisto de unos rodamientos que sean capaces de trabajar en seco a grandes velocidades de rotación ya que si contienen algún tipo de lubricante, al introducir el CO2, éste congelará dicha grasa provocando el fallo de éstos.

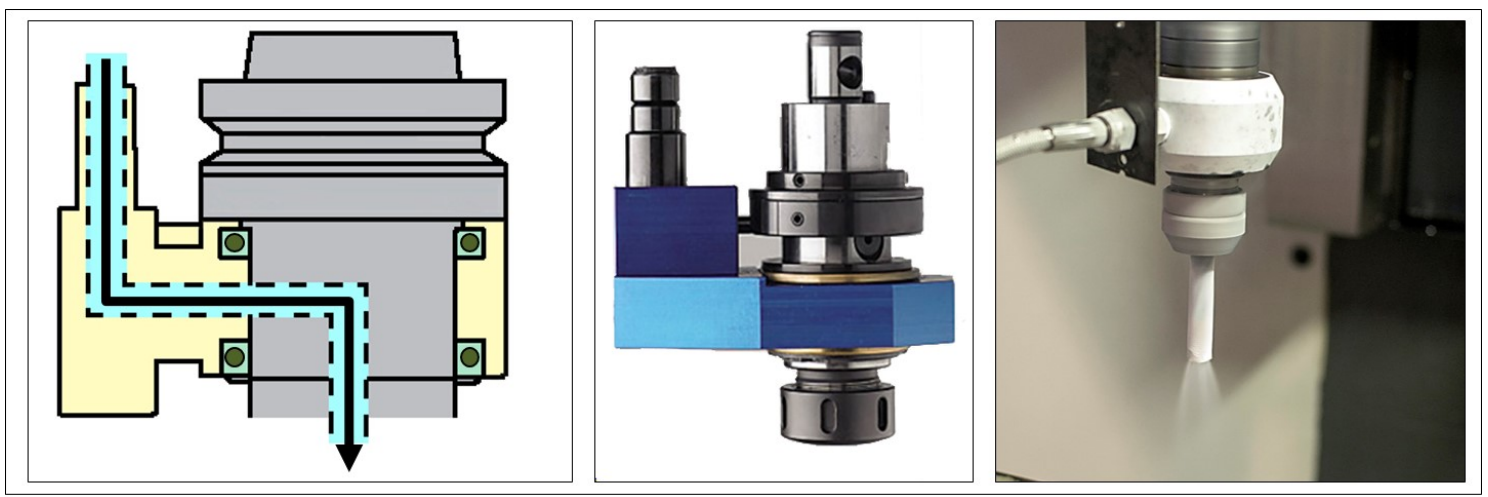

Figura 3.14: CO2 "stand alone" interno (Taladrado)

\section{Torneado}

Por último, para su aplicación en operaciones de torneado el CO2 puede ser utilizado externamente como se utiliza habitualmente la taladrina, o en caso de desear una aplicación más precisa y eficiente, utilizar portaherramientas con refrigeración interna para taladrina a alta presión, como el mostrado en la Figura 3.15. Este tipo de portaherramientas por lo general poseen dos salidas dirigidas hacia la cara de desprendimiento e incidencia, respectivamente. Gracias a este tipo de portaherramientas y la inyección del CO2 por ambas caras se consiguen principalmente tres efectos. El primero es que se reduce la temperatura de corte por la inyección del CO2 en la cara de incidencia; el segundo que se consigue controlar la dirección de la viruta además de volverla más frágil al inyectar CO2 en la cara de desprendimiento; y por último se logra convertir la plaquita en un intercambiador de calor, lo que se traduce en un menor desgaste por efectos térmicos. 


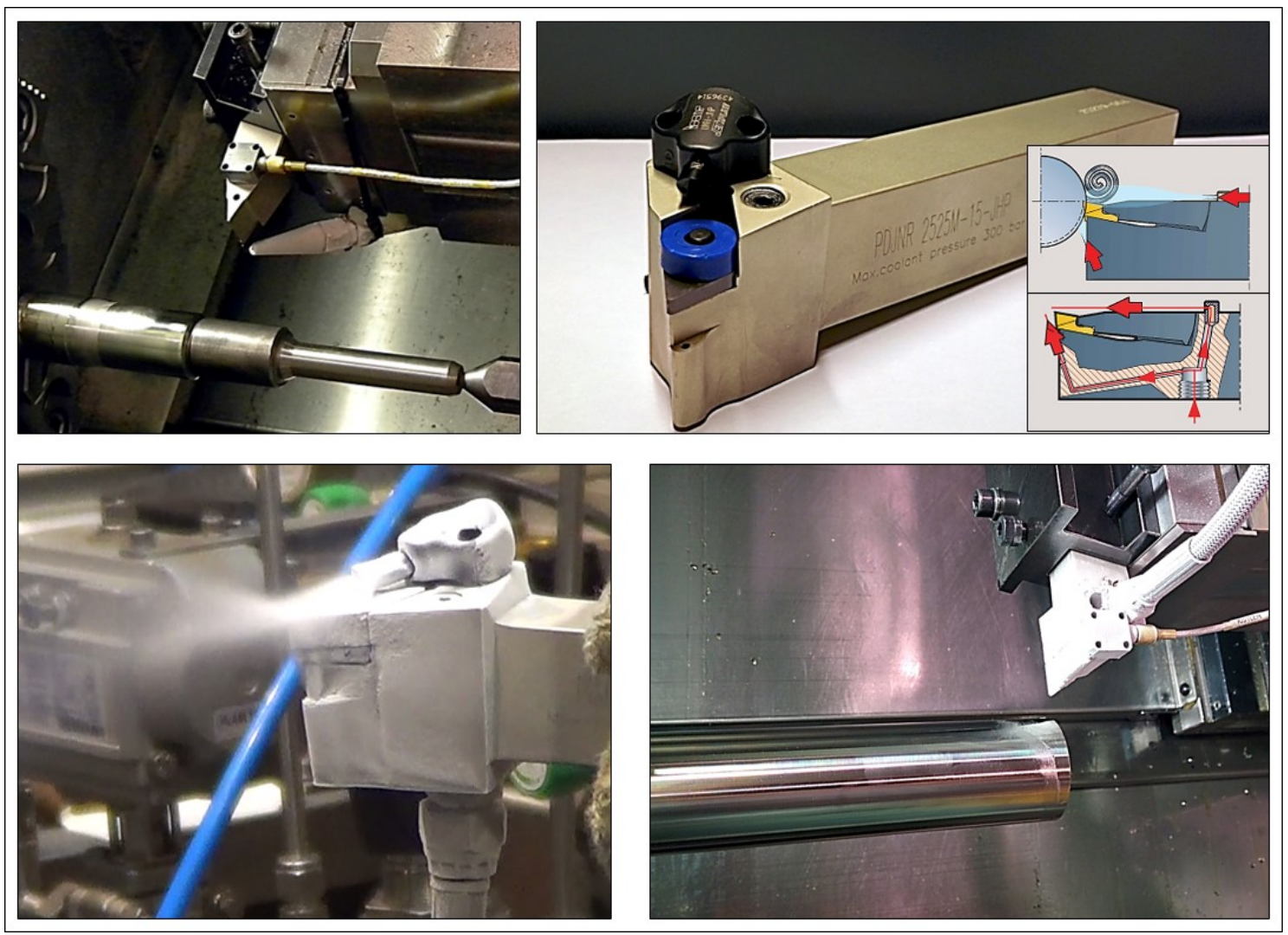

Figura 3.15: CO2 "stand alone" en torneado

\subsection{Sistemas de inyección para LN2}

Los sistemas de inyección para la aplicación del LN2 como fluido de corte son análogos a los expuestos en el punto anterior. Sin embargo, éste no puede ser introducido a través de elementos móviles debido a la baja temperatura que circula por el interior de los conductos. Esto desde un punto de vista técnico limita la aplicación del LN2 con los diversos sistemas de inyección desarrollados para CO2 en máquinasherramienta ya existentes. Específicamente no se ha encontrado un método fiable para introducir el LN2 por la junta rotativa de los husillos de los centros de mecanizado o por los adaptadores de entrada radial para procesos de taladrado sin que entrañe riesgo alguno para dichos elementos. Sin embargo, tanto en los casos de ser utilizado de forma externa a la herramienta como internamente en herramientas de torneado, al no existir elementos móviles en su transcurso hasta la zona de corte, los resultados han sido satisfactorios. 


\subsection{Toberas "Plug \& Play" CryoMQL}

Para combinar la refrigeración criogénica junto con la lubricación MQL (CryoMQL) se ha optado por el desarrollo de toberas externas fabricadas mediante "rapid prototyping" como sistemas de inyección. Estas toberas han sido diseñadas para combinar los equipos MQL tradicionales de dos canales y la tecnología criogénica con un formato "Plug \& Play", es decir, se parte de los equipos MQL ya existentes comercialmente y se les coloca la tobera en forma de adaptador a sus boquillas de forma totalmente personalizada para que posibilite el uso de CO2.

Inicialmente se desarrollaron dos tipos de adaptadores que aunque en esencia siguen la misma filosofía difieren en la forma de inyección del CO2 sobre el aerosol de micropartículas de aceite. La idea es obtener la mayor velocidad de inyección posible en la zona de interacción del flujo del MQL con el CO2 para que el aerosol de micropartículas criogenizadas alcance la zona de corte de la forma más eficiente. Por ello una versión ha sido diseñada con unos orificios de salida para el CO2 formando una tobera convergente ya que de este modo, según la dinámica de fluidos tradicional, una menor sección implica una mayor velocidad del fluido. En la otra versión, teniendo en cuenta la dinámica de fluidos compresibles, se han modificado los conductos en el adaptador para formar una tobera convergente-divergente (tobera de Laval), de este modo el fluido es capaz de superar la velocidad del sonido. El diseño de ambas toberas se muestra en la Figura 3.16.

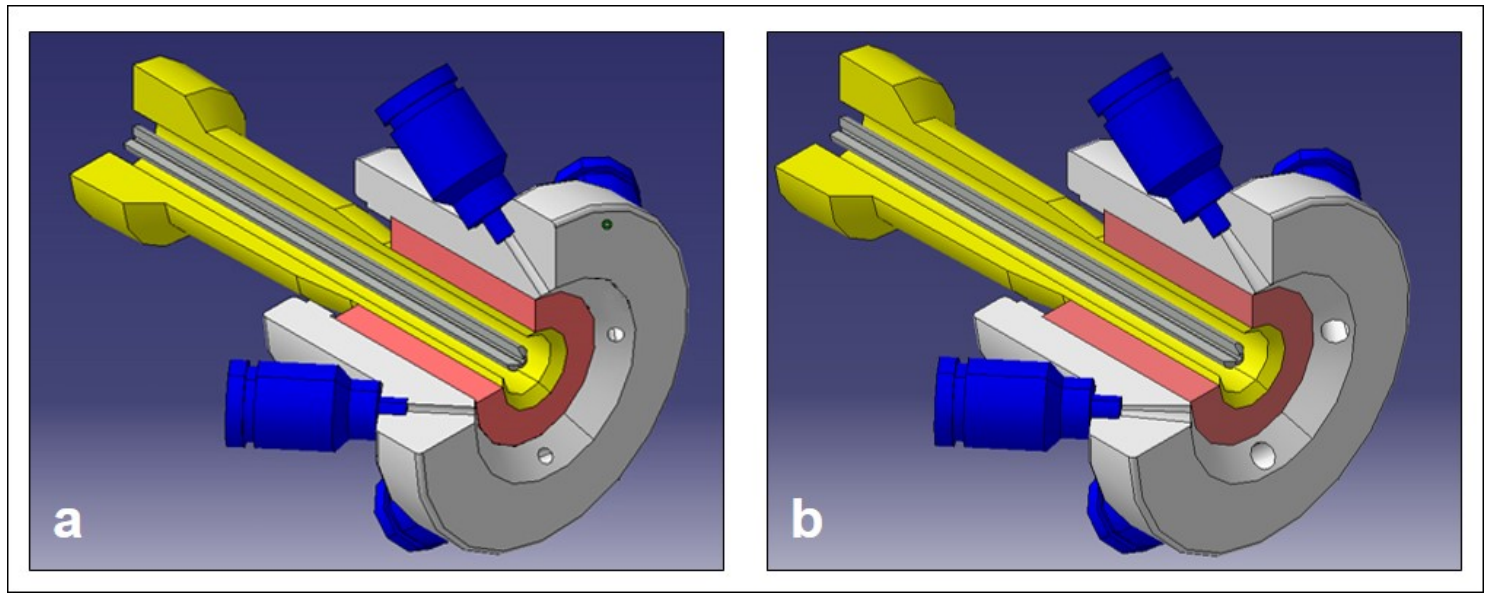

Figura 3.16: Adaptadores para inyección de CryoMQL. a) Adaptador con salidas de CO2 convergentes. b) Adaptador con salidas de CO2 convergentes-divergentes 
El comportamiento de ambos adaptadores fue simulado mediante CFD con los mismos modelos matemáticos expuestos anteriormente. Además, también se ha utilizado una malla simétrica por el eje central como se muestra en la Figura 3.17. Sin embargo, en lugar de utilizar un incremento espacial uniforme para la situación de los nodos, la malla ha sido dividida en 5 bloques con diferentes tamaños y espaciados. En la Tabla 3.1 se detalla las características utilizadas para el mallado en cada bloque. En ambas simulaciones se han utilizado las mismas condiciones frontera que en la simulación anterior, es decir: para la salidas de CO2 se ha establecido una presión constante de 14 bares; todas las paredes de los adaptadores se supusieron adiabáticas; y las salidas se establecieron con presión atmosférica, una intensidad de reflujo turbulento del $5 \%$ y una escala del reflujo turbulento basado en la ecuación 3.16. Sin embargo, como en este caso también se ha introducido el flujo proveniente del MQL, se ha establecido para la entrada de aire una presión constante de 6 bares y una velocidad constante de $1,418 \cdot 10^{-6} \mathrm{~m} / \mathrm{s}$ (caudal de $100 \mathrm{ml} / \mathrm{h}$ ) para el aceite.

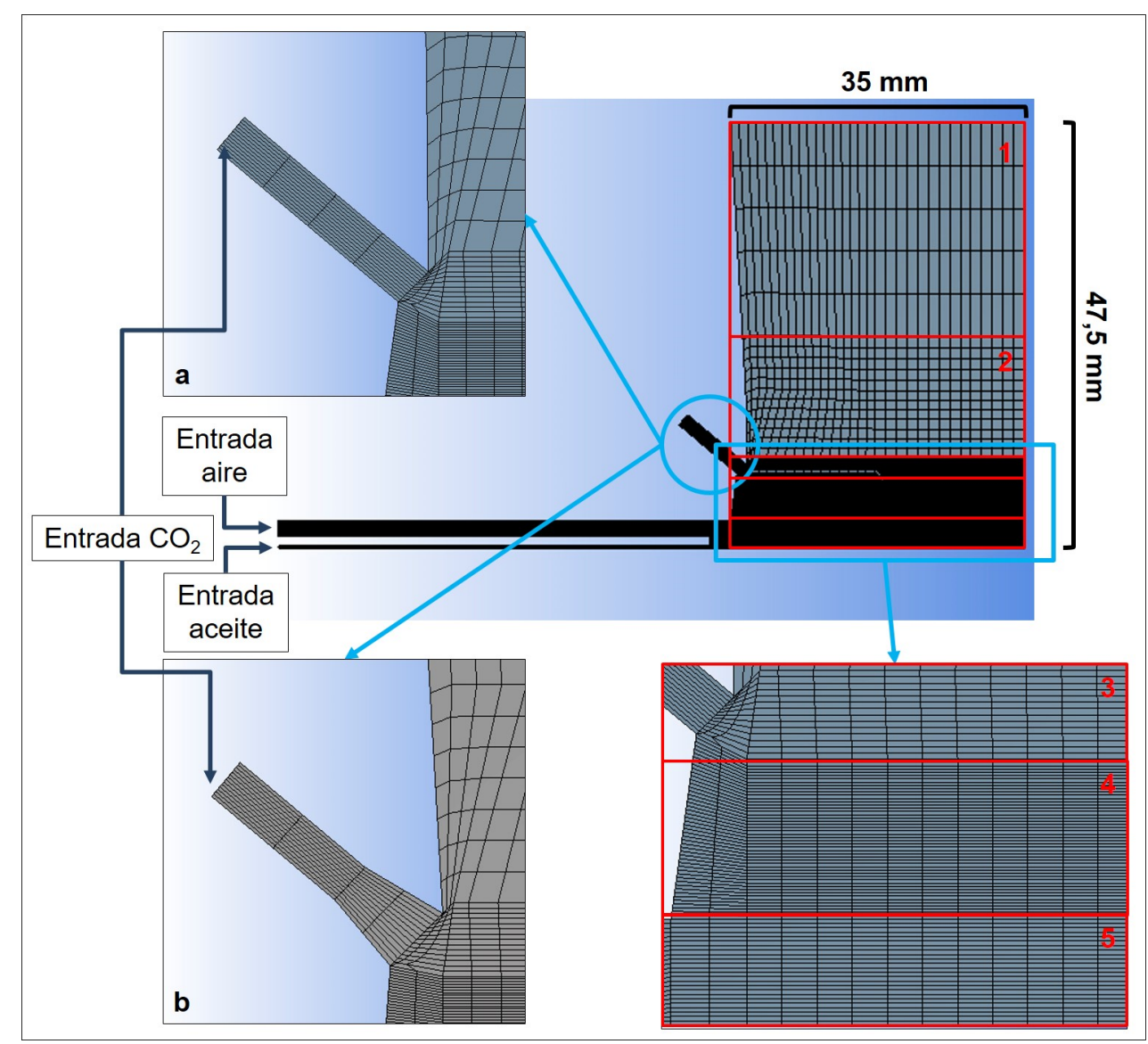

Figura 3.17: Características mallado de los adaptadores 
Capítulo3. Desarrollo y adaptación de sistemas de inyección criogénicos

\begin{tabular}{ccccc}
\hline & \multicolumn{2}{c}{ Horizontal } & \multicolumn{2}{c}{ Vertical } \\
Zonas & $\begin{array}{c}\text { Longitud } \\
(\mathrm{mm})\end{array}$ & $\begin{array}{c}\text { Espaciado } \\
(\mathrm{mm})\end{array}$ & $\begin{array}{c}\text { Longitud } \\
(\mathrm{mm})\end{array}$ & $\begin{array}{c}\text { Espaciado } \\
(\mathrm{mm})\end{array}$ \\
\hline 1 & 35 & 33 & 23,68 & 6 \\
2 & 31,134 & 33 & 13,32 & 14 \\
3 & 30 & 30 & 2,5 & 50 \\
4 & 30,36 & 30 & 4,5 & 25 \\
\hline
\end{tabular}

Tabla 3.1: Características de los bloques de mallado

En la Figura 3.18 se muestran por un lado las simulaciones obtenidas con ambos adaptadores y por otro una gráfica con las velocidades medias obtenidas a lo largo de su eje de simetría desde la punta de los adaptadores. Según las simulaciones anteriormente realizadas, la velocidad mínima necesaria para que el CO2 sea aplicado correctamente en los procesos de corte es de $325 \mathrm{~m} / \mathrm{s}$. Este valor es alcanzado para el adaptador convergente-divergente a los $9 \mathrm{~mm}$ y a los $14 \mathrm{~mm}$ para el convergente. Desde dichas distancias las velocidades fueron incrementándose hasta alcanzar los $475 \mathrm{~m} / \mathrm{s}$ a los $22 \mathrm{~mm}$ para el adaptador convergente-divergente y $400 \mathrm{~m} / \mathrm{s}$ a los 23 $\mathrm{mm}$ para el convergente. Sin embargo, se debe destacar que aunque con el adaptador convergente-divergente se han alcanzado mayores velocidades, el esparcimiento del aerosol es mayor. De hecho, la focalización del adaptador convergente-divergente a $35 \mathrm{~mm}$ abarca un diámetro de $\approx 15 \mathrm{~mm}$, mientras que con la tobera convergente ese diámetro es de $\approx 9 \mathrm{~mm}$. Esto supone una concentración 1,7 veces mayor del aerosol cuando se utiliza el adaptador con salidas convergentes. Por lo tanto, en función de los resultados simulados se deduce que el diseño apropiado es el adaptador con salidas de CO2 convergente. En la Figura 3.19 se muestra su aplicación durante un proceso de fresado. 


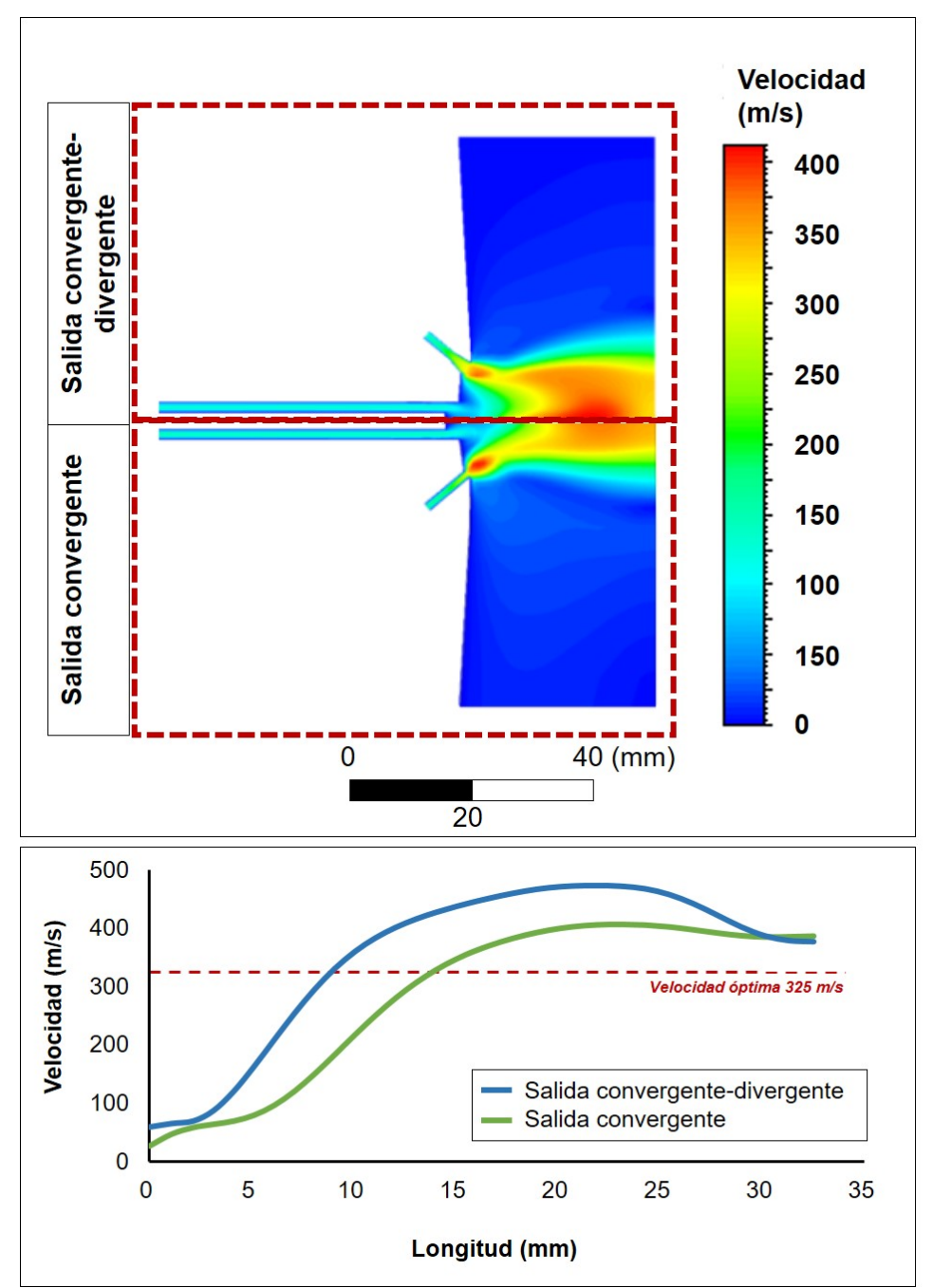

Figura 3.18: Resultados obtenidos de las simulaciones mediante CFD

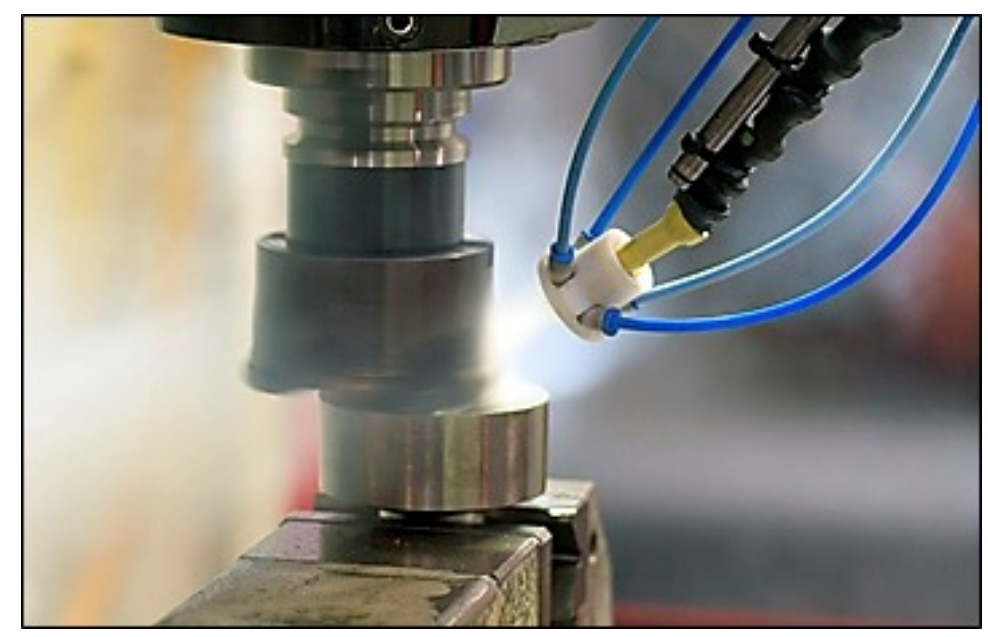

Figura 3.19: Adaptador convergente CryoMQL aplicado al fresado 


\subsection{Conclusiones}

En este capítulo se han expuesto los diferentes sistemas de inyección desarrollados en esta tesis para la aplicación de la refrigeración criogénica así como su combinación con la microlubricación MQL. Debido a su utilidad industrial, se ha primado la utilización del CO2 sobre LN2. Con los sistemas de inyección propuestos se ha tenido en cuenta la aplicación de la refrigeración criogénica tanto de forma externa como interna a la herramienta. Además, con el fin de utilizar la refrigeración criogénica de un modo eficiente y por tanto minimizar el consumo de $\mathrm{CO} 2$, se ha calculado el diámetro de salida óptimo en el cual se utiliza el caudal mínimo necesario para asistir los principales procesos de mecanizado (fresado, taladrado y torneado). Para ello se han comparado los resultados obtenidos durante la simulación de diversos diámetros de salida con los obtenidos empíricamente en un banco de ensayos. De dicha comparación también se ha deducido la velocidad óptima con la que el CO2 sigue teniendo utilidad para aplicarlo durante el mecanizado. Por último, basándose en los datos anteriores se ha desarrollado un adaptador "Plug \& Play" para combinar la refrigeración criogénica y los equipos MQL ya existentes.

Por lo tanto, con los diferentes sistemas de inyección desarrollados a lo largo de este capítulo se ha dado respuesta a la utilización de la refrigeración criogénica y CryoMQL de un modo eficiente en el que se ha posibilitado su utilización no sólo en máquina-herramienta nueva sino en la ya existente en el entorno industrial. 

CAPÍTULO 4

Ensayos experimentales 



\section{Ensayos experimentales}

\subsection{Introducción}

En el presente capítulo se ha procedido al análisis y evaluación de las diferentes tecnologías de refrigeración/lubricación desde un punto de vista técnico apoyándose en los sistemas de inyección propuestos en el capítulo anterior. Para ello se han llevado a cabo diferentes ensayos experimentales en los principales procesos de mecanizado, es decir, torneado, fresado y taladrado. El capítulo consta de 5 apartados en los que concretamente se expondrán los materiales, máquinas y equipos utilizados así como los ensayos realizados durante el torneado de AISI304L, torneado duro de ASP23, fresado de Inconel 718 y taladrados de stacks de Ti6Al4V-CFRP. A continuación se procede a describir los materiales, máquinas y equipos utilizados así como los ensayos realizados con cada uno de los procesos de mecanizado.

\subsection{Materiales, máquinas y equipos utilizados}

En relación a los materiales utilizados en cada uno de los ensayos se ha optado por la utilización de materiales de difícil maquinabilidad debido al incremento de demanda sufrido en los últimos años de este tipo de materiales, sobretodo en el sector aeronáutico. Concretamente los materiales utilizados fueron:

- Acero inoxidable AISI 304L: Este tipo de aceros inoxidables, cuya microestructura es mostrada en la Figura 4.1, son utilizados en sectores como el químico, aeroespacial, automovilístico, industria alimentaria o implantes médicos. Este tipo de material presenta ventajas como una alta resistencia a la tracción, alta ductilidad, alta resistencia a la fractura, un endurecimiento por deformación, una alta resistencia a la corrosión, una alta resistencia a la fatiga, 
una alta capacidad calorífica y una baja conductividad térmica. Su composición química así como sus propiedades mecánicas se plasman en la Tabla 4.1.

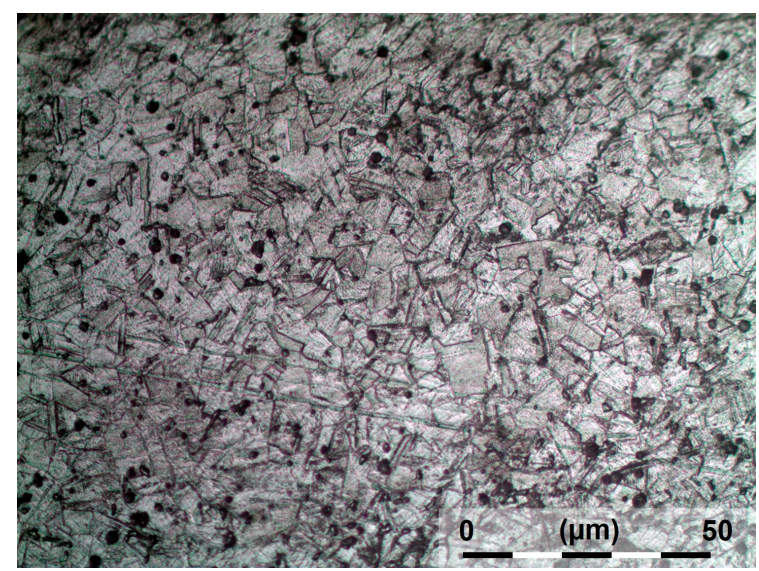

Figura 4.1: Microestructura AISI 304L

\begin{tabular}{|c|c|c|c|c|c|c|c|c|c|c|c|}
\hline \multicolumn{12}{|c|}{ Composición química } \\
\hline$\% \mathrm{C}$ & $\% \mathrm{P}$ & $\% \mathrm{~S}$ & $\% \mathrm{Si}$ & $\% \mathrm{Mn}$ & $\% \mathrm{Cr}$ & $\% \mathrm{Ni}$ & $\% \mathrm{Mo}$ & $\% \mathrm{Ti}$ & $\% \mathrm{~N}$ & $\% \mathrm{Cu}$ & $\% \mathrm{Fe}$ \\
\hline 0,024 & 0,033 & 0,027 & 0,240 & 1,466 & 17,924 & 8,208 & 0,234 & 0,003 & 0,065 & 0,271 & 71,505 \\
\hline \multicolumn{12}{|c|}{ Propiedades mecánicas } \\
\hline \multicolumn{2}{|c|}{ Tensión fluencia } & \multicolumn{3}{|c|}{ Límite tracción } & \multicolumn{2}{|c|}{ Elongación } & \multicolumn{3}{|c|}{ Conductividad térmica } & \multicolumn{2}{|c|}{ Dureza } \\
\hline \multicolumn{2}{|c|}{$210 \mathrm{MPa}$} & \multicolumn{3}{|c|}{$564 \mathrm{MPa}$} & \multicolumn{2}{|c|}{$58 \%$} & \multicolumn{3}{|c|}{$14 \mathrm{~W} / \mathrm{m}-\mathrm{K}$} & \multicolumn{2}{|c|}{$201 \mathrm{HB} / 15 \mathrm{HRc}$} \\
\hline
\end{tabular}

Tabla 4.1: Propiedades acero inoxidable AISI 304L

- Acero templado ASP23: Éste es un acero rápido pulvimetalúrgico (HSS High Speed Steel) sin cobalto aleado con cromo, molibdeno, tungsteno, vanadio que ha sido templado 3 veces a $560^{\circ} \mathrm{C}$ durante una hora para aumentar su dureza hasta 64 HRc. Su microestructura es la mostrada en la Figura 4.2. Este tipo de aceros es utilizado para la fabricación de herramientas de corte de alto rendimiento debido a su alta resistencia al desgaste, alta resistencia a la compresión, su buena tenacidad y buena estabilidad dimensional al someterlo a tratamientos térmicos para su utilización. En la Tabla 4.2 se muestra su composición química y principales características mecánicas. 


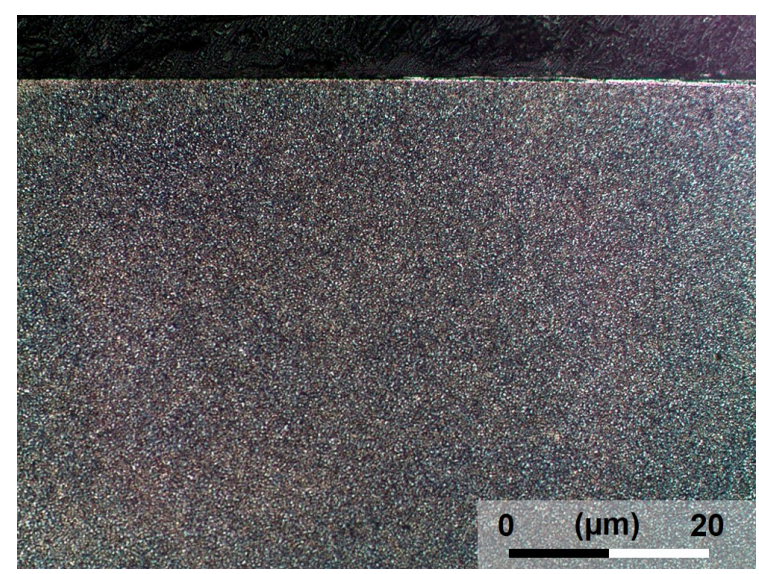

Figura 4.2: Microestructura ASP23

\begin{tabular}{|c|c|c|c|c|c|}
\hline \multicolumn{6}{|c|}{ Composición química } \\
\hline$\% \mathrm{C}$ & $\% \mathrm{Cr}$ & $\% \mathrm{Mo}$ & $\% \mathrm{~W}$ & $\% \mathrm{~V}$ & $\% \mathrm{Fe}$ \\
\hline 1,28 & 4,2 & 5 & 6,4 & 3,1 & 80,02 \\
\hline \multicolumn{6}{|c|}{ Propiedades mecánicas } \\
\hline \multicolumn{2}{|c|}{ Tensión fluencia a flexión } & \multicolumn{2}{|c|}{ Límite rotura a flexión } & Elongación & Dureza \\
\hline \multicolumn{2}{|c|}{$3500 \mathrm{MPa}$} & \multicolumn{2}{|c|}{$5000 \mathrm{MPa}$} & $10 \%$ & $64 \mathrm{HRc}$ \\
\hline \multicolumn{6}{|c|}{ Conductividad térmica } \\
\hline \multicolumn{2}{|c|}{$24 \mathrm{~W} / \mathrm{m}-\mathrm{K}$} & & & & \\
\hline
\end{tabular}

Tabla 4.2: Propiedades acero ASP23

- Inconel 718: Esta aleación de hierro-níquel es una de las superaleaciones más utilizadas cuando se requieren temperaturas de trabajo extremas. En la Figura 4.3 se muestra su microestructura. Concretamente el Inconel 718 tiene una temperatura de servicio de hasta $600^{\circ} \mathrm{C}$ durante largos tiempos de exposición, lo que supone una capacidad de trabajo en condiciones de hasta un 0,85\% de su temperatura de fusión. Este material es utilizado principalmente para la fabricación de componentes críticos presentes en la turbomaquinaria aeronáutica como los álabes de turbinas, entre otros. Esto es debido a que este material exhibe una alta dureza gracias a sus precipitados coherentes $\gamma^{\prime \prime}$ BCT (tetragonal centrada en el cuerpo) con la matriz $\gamma^{\prime}$, la cual aporta al material gran resistencia al creep. Por otra parte, gracias a su alto contenido en cromo tiende a formar cascarillas ricas en $\mathrm{Cr}_{2} \mathrm{O}_{3}$ que restringen la tasa de difusión de elementos metálicos hacia el exterior y de elementos agresivos o de la at- 
mósfera mientras el componente se encuentra sometido a altas temperaturas de trabajo. En la Tabla 4.3 se resume su composición química y propiedades mecánicas.

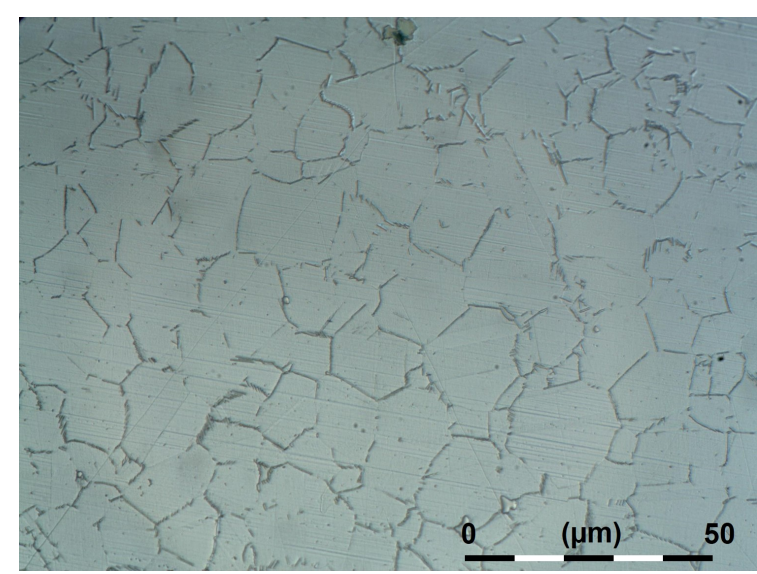

Figura 4.3: Microestructura Inconel 718

\begin{tabular}{ccccc}
\hline Composición quimica & & & & \\
$\% \mathrm{Ni}$ & $\% \mathrm{Cr}$ & $\% \mathrm{Co}$ & $\% \mathrm{Fe}$ & $\% \mathrm{Nb}$ \\
52,5 & 19 & 1 & 17 & 5 \\
$\% \mathrm{Mo}$ & $\% \mathrm{Ti}$ & $\% \mathrm{Al}$ & $\% \mathrm{~B}$ & 0,08 \\
3 & 1 & 0,6 & 0,01 & \\
$\% \mathrm{Mn}$ & $\% \mathrm{Si}$ & & \\
0,35 & 0,35 & 1,79 & & Dureza \\
\hline \multirow{2}{*}{ Propiedades mecánicas } & & & & \\
\hline Tensión fluencia & Límite tracción & Elongación & Conductividad térmica & \\
$1100 \mathrm{MPa}$ & $1375 \mathrm{MPa}$ & $25 \%$ & $11,4 \mathrm{~W} / \mathrm{m}-\mathrm{K}$ & $45 \mathrm{HRc}$ \\
\hline
\end{tabular}

Tabla 4.3: Propiedades Inconel 718

- Stacks Ti6Al4V-CFRP: Desde 2010 el uso de los composites en el sector aeronáutico está sufriendo un crecimiento exponencial con el fin de hacer estructuras más ligeras y resistentes. De hecho, este tipo de materiales suponen alrededor del $50 \%$ del peso total de las aeronaves que se construyen en la actualidad. Este tipo de materiales se comportan de forma distinta a los materiales metálicos debido a que no son homogéneos. Uno de los composites más utilizados son los formados por una matriz de titanio reforzada con fibra 
de carbono (Stacks CFRP-Ti6Al4V). En las Tablas 4.4 y 4.5 se muestran las composiciones químicas y principales características mecánicas del CFRP y Ti6Al4V, respectivamente:

\begin{tabular}{ccc}
\hline Composición química & & \\
\hline Densidad fibra & Diámetro filamento & Contenido carbono \\
$1,98 \mathrm{~g} / \mathrm{cm}^{3}$ & $7 \mu m$ & $>95 \%$ \\
\hline Propiedades mecánicas & & \\
\hline Límite de tracción a rotura & Elongación & Módulo de elasticidad \\
$3800 \mathrm{MPa}$ & $1,5 \%$ & $240 \mathrm{GPa}$ \\
\hline
\end{tabular}

Tabla 4.4: Propiedades CFRP

\begin{tabular}{|c|c|c|c|c|c|c|c|c|}
\hline \multicolumn{9}{|c|}{ Composición química } \\
\hline$\% \mathrm{Al}$ & $\% \mathrm{C}$ & $\% \mathrm{H}$ & $\% \mathrm{Fe}$ & $\% \mathrm{~N}$ & $\% \mathrm{O}$ & $\% \mathrm{~V}$ & $\% \mathrm{Ti}$ & $\%$ Otros \\
\hline 6 & 0,08 & 0,0125 & 0,25 & 0,03 & 0,13 & 4 & 89,1 & 0,4 \\
\hline \multicolumn{9}{|c|}{ Propiedades mecánicas } \\
\hline \multicolumn{2}{|c|}{ Tensión de fluencia } & \multicolumn{2}{|c|}{ Límite tracción } & \multicolumn{2}{|c|}{ Elongación } & \multicolumn{2}{|c|}{ Conductividad térmica } & Dureza \\
\hline \multicolumn{2}{|c|}{$790 \mathrm{MPa}$} & \multicolumn{2}{|c|}{$860 \mathrm{MPa}$} & \multicolumn{2}{|c|}{$15 \%$} & \multicolumn{2}{|c|}{$6,7 \mathrm{~W} / \mathrm{m}-\mathrm{k}$} & $35 \mathrm{HRc}$ \\
\hline
\end{tabular}

Tabla 4.5: Propiedades Ti6Al4V solubilizado

Los ensayos fueron realizados en el taller mecánico de la Escuela Técnica Superior de Ingenieros de Bilbao (UPV/EHU) con la combinación de los equipos de medida de ésta y la Escuela de Ingenierías Industrial, Informática y Aeronáutica de León (ULE). Para los procesos de torneado se utilizó un centro de torneado CMZ modelo TC25BTY. Para el proceso de fresado la máquina-herramienta utilizada fue un centro de mecanizado de alta velocidad Kondia HS1000. Finalmente para el proceso de taladrado la máquina-herramienta utilizada fue un centro de mecanizado Kondia A6. En la Tabla 4.6 se detallan las características tecnológicas de cada una de las máquinas-herramienta mencionadas.

Para la medida de los diferentes parámetros tanto de integridad superficial de las piezas mecanizadas como de monitorización de los ensayos se utilizaron los equipos descritos en la Tabla 4.7. 


\begin{tabular}{cccc}
\hline Equipo & Marca & Modelo & Características \\
\hline Centro de torneado & CMZ & TC25BTY & $\begin{array}{c}\text { Máx. } 4.000 \mathrm{rpm}, \\
\text { Máx. } \phi 300 \mathrm{~mm}\end{array}$ \\
& & & 3 ejes, $18 \mathrm{~kW}$, \\
Centro de & Kondia & HS1000 & Máx. $24.000 \mathrm{rpm}$, \\
mecanizado & & Máx. $20 \mathrm{~m} / \mathrm{min}$ \\
& & & 3 ejes, $7,9 \mathrm{~kW}$, \\
Centro de & Kondia & A6 & Máx. $12.000 \mathrm{rpm}$, \\
mecanizado & & Máx. $30 \mathrm{~m} / \mathrm{min}$ \\
& &
\end{tabular}

Tabla 4.6: Máquinas-herramienta utilizadas

Desde un punto de vista técnico el análisis de integridad superficial ayuda a controlar las posibles alteraciones producidas en las capas superficiales durante la fabricación de un componente. De este modo se pueden observar los efectos producidos por el proceso de fabricación sobre las propiedades del material y su alteración en cuanto al comportamiento de la superficie en servicio. Concretamente en este trabajo, en función de los ensayos realizados, se han analizado rugosidades y durezas superficiales así como las durezas subsuperficiales; se han obtenido topografías tridimensionales de las superficies mecanizadas; y finalmente se ha realizado un análisis metalográfico de las microestructuras en busca de la capa blanca y la cuantificación de la capa deformada. Por otra parte, en cuanto a la monitorización de ensayos se refiere, se han registrado los datos de potencia consumida, desgaste de herramientas y temperatura y/o fuerzas de corte en función de la prueba realizada. 


\begin{tabular}{|c|c|c|c|c|}
\hline Equipo & Marca & Modelo & Características & Aplicación \\
\hline Rugosímetro & $\begin{array}{l}\text { Taylor } \\
\text { Hobson }\end{array}$ & $\begin{array}{l}\text { Surtronic } \\
\text { Duo }\end{array}$ & $\mathrm{Ra}, \mathrm{Rz}$ & $\begin{array}{l}\text { Obtención de los } \\
\text { parámetros de } \\
\text { rugosidad }\end{array}$ \\
\hline $\begin{array}{c}\text { Microscopio } \\
\text { óptico confocal }\end{array}$ & Leica & DCM-3D & $\begin{array}{l}\text { 5x/150x, } \\
\text { confocal, } \\
\text { Resolución de } \\
0,1 \mu m\end{array}$ & $\begin{array}{c}\text { Obtención de } \\
\text { topografías 3D sin } \\
\text { contacto y } \\
\text { medición precisa } \\
\text { de parámetros de } \\
\text { rugosidad }\end{array}$ \\
\hline $\begin{array}{l}\text { Microscopio } \\
\text { óptico }\end{array}$ & Nikon & OptipHot 100 & $\begin{array}{l}\text { Máx aumento } \\
\text { 100x }\end{array}$ & $\begin{array}{l}\text { Obtención de } \\
\text { metalografías }\end{array}$ \\
\hline $\begin{array}{l}\text { Microscopio } \\
\text { óptico }\end{array}$ & Nikon & SMZ-2T & $\begin{array}{l}\text { Máx aumento } \\
\text { 20x }\end{array}$ & $\begin{array}{l}\text { Medida de } \\
\text { desgaste de filo de } \\
\text { herramienta }\end{array}$ \\
\hline $\begin{array}{l}\text { Durómetro } \\
\text { superficial }\end{array}$ & $\begin{array}{l}\text { Time } \\
\text { Group }\end{array}$ & HLN-11A & $\begin{array}{c}\text { 30-700HBN, } \\
\mathrm{HBN} / \mathrm{HRc} / \mathrm{HV}\end{array}$ & $\begin{array}{l}\text { Medición de } \\
\text { dureza superficial }\end{array}$ \\
\hline $\begin{array}{c}\text { Micro } \\
\text { durómetro }\end{array}$ & $\begin{array}{l}\text { Future } \\
\text { Tech }\end{array}$ & FM-800 & $\begin{array}{c}\text { 20x,50x, } \\
\mathrm{HV} / \mathrm{HK} / \mathrm{HRc}, \\
2-2000 \mathrm{gf}\end{array}$ & $\begin{array}{l}\text { Medición de la } \\
\quad \text { dureza } \\
\text { subsuperficial }\end{array}$ \\
\hline Potenciómetro & Vydas & UPC-E-120V & $\begin{array}{c}3 \mathrm{~kW} \ldots .93 \mathrm{~kW}, \\
3 \mathrm{~Hz}-1 \mathrm{KHz}\end{array}$ & $\begin{array}{l}\text { Registro de } \\
\text { potencia } \\
\text { consumida }\end{array}$ \\
\hline $\begin{array}{c}\text { Termopar data } \\
\text { logger }\end{array}$ & Lascar & EL-USB-TC & $\begin{array}{l}\text { Termopar tipo } \\
\quad \mathrm{K} \\
-200 \ldots 1300^{\circ} \mathrm{C}\end{array}$ & $\begin{array}{l}\text { Registro de } \\
\text { temperaturas }\end{array}$ \\
\hline $\begin{array}{l}\text { Dinamómetro } \\
\text { multicomponen- } \\
\text { te }\end{array}$ & Kistler & $9257 \mathrm{~B}$ & $\begin{array}{l}\text { Medida } \\
\text { Fx, Fy, Fz, } \\
-5 \ldots 10 \mathrm{kN}\end{array}$ & $\begin{array}{l}\text { Registro de fuerzas } \\
\text { de corte }\end{array}$ \\
\hline
\end{tabular}

Tabla 4.7: Equipos de medición utilizados

\subsection{Torneado de AISI 304L}

\subsubsection{Introducción}

Con el fin de evaluar las diferentes tecnologías ecológicas de refrigeración/lubricación durante el proceso de torneado se procedió al cilindrado de AISI 304L con unas condiciones de corte constantes. El inserto seleccionado fue un DNMG-150608 de carburo recubierto de TiN con calidad GC2025 y un portaherramientas con refrigeración interna para alta presión el cual inyecta el fluido de corte simultáneamente 
por la cara de incidencia y desprendimiento. La razón por la que se ha utilizado un portaherramientas de alta presión es debido a que gracias a él no sólo se logra penetrar de forma más eficiente en la intercara herramienta-material, sino que además se consigue direccionar la viruta de tal modo que permanezca en contacto con la cara de desprendimiento de la herramienta el menor tiempo posible y por tanto alargando su vida útil al mitigar la formación de cráter en dicha cara. En la Tabla 4.8 se detallan las condiciones de corte así como las características del inserto utilizado y su portaherramientas.

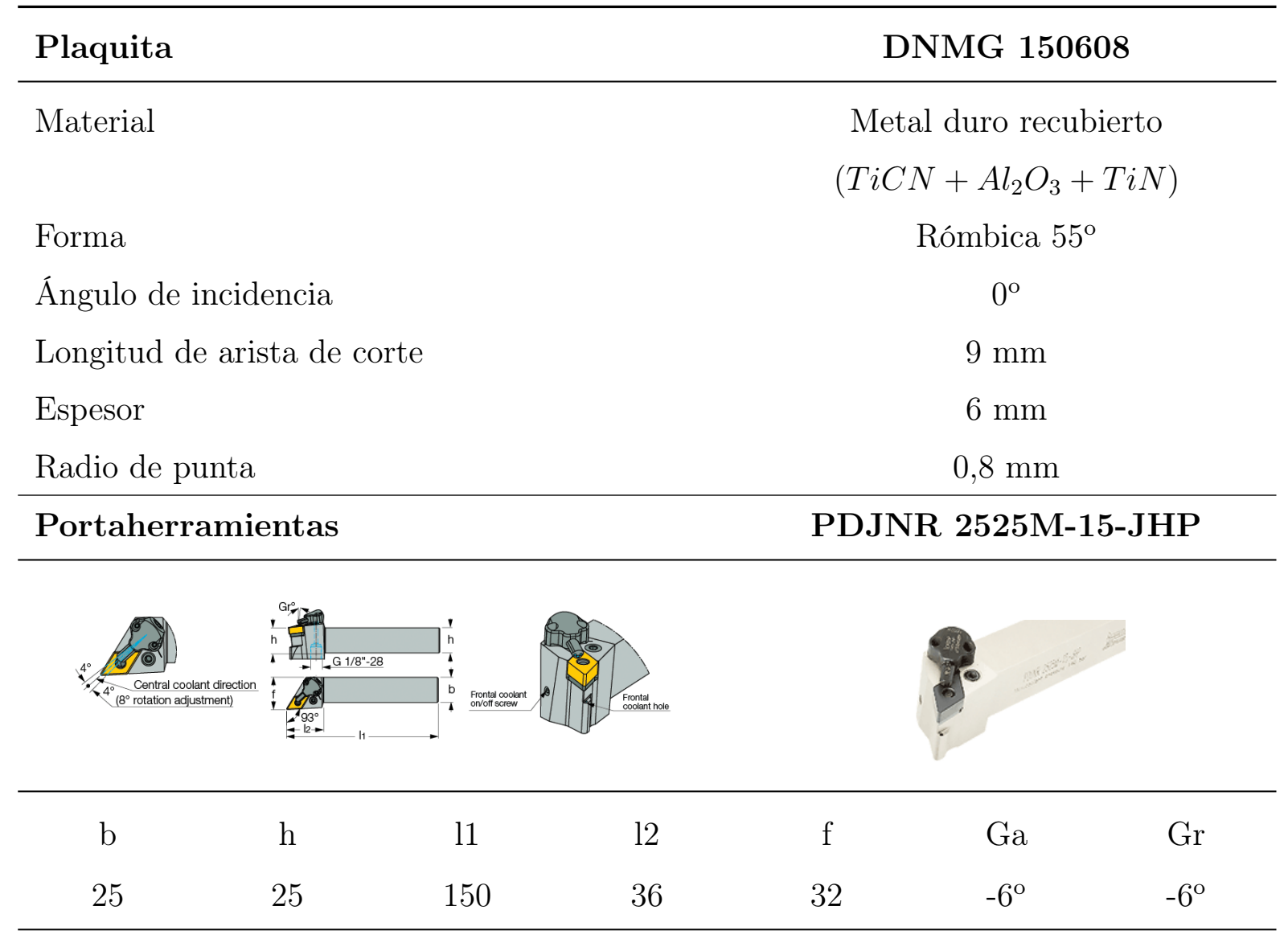

Condiciones de corte

Velocidad de corte $225 \mathrm{~m} / \mathrm{min}$

Profundidad de corte

$$
1,5 \mathrm{~mm}
$$

Avance

$0,25 \mathrm{~mm} / \mathrm{rev}$

Longitud de corte

$150 \mathrm{~mm}$

Tabla 4.8: Características de insertos, portaherramientas y condiciones de corte utilizadas 


\subsubsection{Montaje y metodología experimental}

Las pruebas fueron realizadas en el torno CMZ TC25BTY con 45 KVA de potencia instalada y $35 \mathrm{~kW}$ de potencia en el motor del plato. Para la homogenización de cada uno de los ensayos una vez montada la pieza se procedió a su preparación mediante un refrentado y cilindrado hasta dejarla con un diámetro de $59 \mathrm{~mm}$ con el fin de que en cada test se mecanizase la misma cantidad de material. La longitud mecanizada en cada pasada fue de $150 \mathrm{~mm}$. En los ensayos el montaje varía según el tipo de refrigeración/lubricación utilizada. En el caso del mecanizado con MQL se acopla de forma externa una boquilla pulverizadora, que es la encargada de dirigir el aerosol con micropartículas de aceite hacia la zona de corte. Por otra parte si el refrigerante utilizado es la taladrina o un gas criogénico, éste es conducido mediante los conductos internos del portaherramientas hasta la cara de incidencia y desprendimiento del inserto. En total la combinación de técnicas de refrigeración/lubricación asciende hasta 6 posibilidades. En la Tabla 4.9 se muestran de forma detallada las técnicas de refrigeración/lubricación utilizadas con sus respectivas combinaciones.

\begin{tabular}{cc}
\hline $\begin{array}{c}\text { Técnicas de } \\
\text { refrigeración/Lubricación }\end{array}$ & Características y descripción \\
\hline Mecanizado en seco & No hay lubricantes \\
MQL & Aceite de colza $\left(0,92 \mathrm{~g} / \mathrm{cm}^{3}\right)$, \\
& Caudal $=100 \mathrm{ml} / \mathrm{h}$, \\
& Presión neumática $=6$ bares \\
LN2 & Nitrógeno líquido \\
& $\left(15\right.$ bares, $\left.-196^{\circ} \mathrm{C}\right)$ \\
$\mathrm{CO} 2$ & Dióxido de carbono \\
& $\left(15\right.$ bares, $\left.-78^{\circ} \mathrm{C}\right)$ \\
CryoMQL $(\mathrm{LN} 2)$ & $\mathrm{MQL}+\mathrm{LN} 2$ \\
& $\left(100 \mathrm{ml} / \mathrm{h}+14\right.$ bar, $\left.-196^{\circ} \mathrm{C}\right)$ \\
CryoMQL $(\mathrm{CO} 2)$ & $\mathrm{MQL}+\mathrm{CO} 2$ \\
& $\left(100 \mathrm{ml} / \mathrm{h}+14\right.$ bar, $\left.-78^{\circ} \mathrm{C}\right)$ \\
\hline
\end{tabular}

Tabla 4.9: Técnicas de lubricación evaluadas en torneado 
Se consideró como final de vida de herramienta el alcance de un desgaste de flanco $\left(V_{b} \max \right)$ de $0,3 \mathrm{~mm}$ según establece la norma ISO 3685, o hasta que se produzca el fallo catastrófico. Durante el proceso se registraron las tres componentes de las fuerzas de corte utilizando el dinamómetro piezoeléctrico Kistler 9257B y la potencia consumida por todos los servomotores utilizando medidores de potencia Vydas UPC-E. Además, en el transcurso de los ensayos se realizaron paradas para medir la tendencia descrita por el desgaste de herramienta con el microscopio Nikon SMZ-2T y medir la rugosidad superficial (Ra y Rz) con el rugosímetro Taylor Hobson. Una vez finalizadas las pruebas se analizó la integridad superficial, en la que se midió la dureza superficial y subsuperficial con los durómetros Time Group y Future Tech, respectivamente; se obtuvo la topografía 3D superficial con el microscopio confocal Leica; y finalmente se evaluó el tamaño de la capa deformada con el microscopio Nikon Optiphot 100. En la Figura 4.4 se muestra el montaje experimental realizado para la ejecución de estos ensayos.

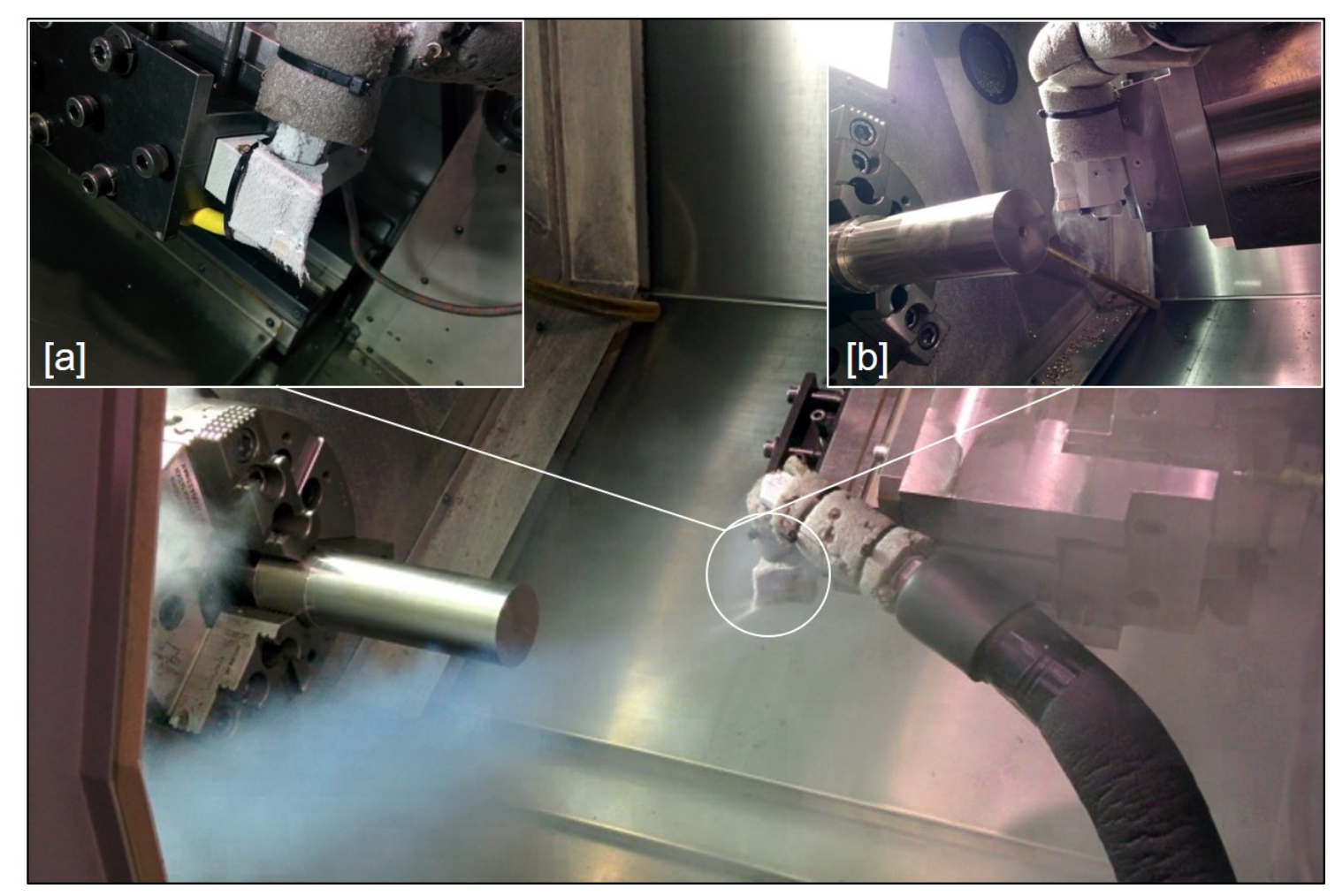

Figura 4.4: Montaje experimental para el torneado de AISI 304L [a] CryoMQL, [b] Criogénico 


\subsubsection{Resultados}

\section{Vida de herramienta}

Los resultados obtenidos en cuanto a vida de herramienta se han reflejado en la Figura 4.5. Bajo el mecanizado en seco se logró tornear $2500 \mathrm{~mm}$ utilizando las condiciones de corte descritas y aplicando la norma ISO 3685 como criterio de fin de ensayo. Estableciendo este valor como referencia, con las otra técnicas de refrigeración/lubricación se lograron mayores vidas de herramienta. En el caso del MQL se lograron mecanizar $2900 \mathrm{~mm}$ antes de llegar al fin de vida de herramienta. Este valor representa un aumento de vida de herramienta de alrededor del $20 \%$, como se muestra en la Figura 4.5. Utilizando LN2 y CO2, el aumento registrado fue de un $17 \%$ y $35 \%$, respectivamente. Finalmente, utilizando la tecnología CryoMQL los resultados fueron notablemente superiores. En el caso de combinar el MQL con el LN2 se logró aumentar un 55\% dicho valor y si es combinado con el CO2 se logró superar en un $100 \%$, es decir, se dobló la vida de herramienta.

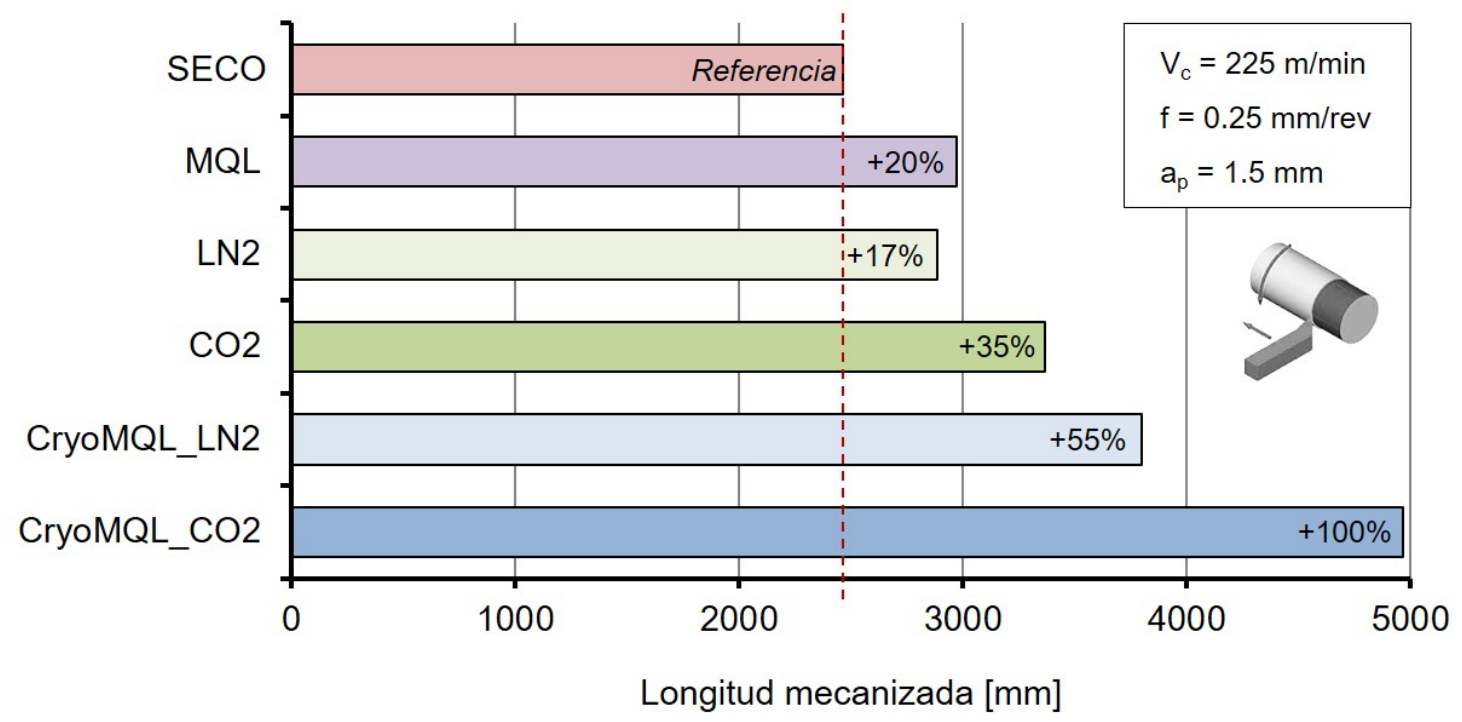

Figura 4.5: Vida de herramienta durante torneado de AISI 304L

Las altas temperaturas durante el mecanizado en seco implican una menor vida de herramienta debido principalmente al desgaste derivado de los efectos térmicos generados. Al utilizar MQL, el efecto lubricante derivado de la inyección de micropartículas de aceite implica un aumento de vida de herramienta. Sin embargo, la 
capacidad refrigerante del MQL no es suficiente para lograr un proceso viable. En el caso del mecanizado asistido con gases criogénicos, tanto al utilizar LN2 como $\mathrm{CO} 2$, la vida de herramienta aumenta debido a su capacidad refrigerante la cual disminuye el desgaste derivado por efectos térmicos. Por lo tanto, la utilización de estas tecnologías en modo "stand alone" no es suficiente para tratar con este material en estas condiciones. Por ello, para poder alcanzar una solución viable se hace necesario combinar los efectos lubricante y refrigerante de cada una de las tecnologías expuestas. De hecho, los resultados muestran que con la combinación de MQL y CO2 se consigue doblar la vida de herramienta.

\section{Fuerzas de corte}

Las fuerzas de corte obtenidas son reflejadas en la Figura 4.6 a lo largo de las diferentes etapas de desgaste de la herramienta. Las fuerzas mostradas en dicha figura son las tres componentes de las que está compuesta la fuerza total de corte, es decir, la fuerza de corte $\left(F_{c}\right)$, la fuerza de avance $\left(F_{f}\right)$ y la fuerza radial $\left(F_{r}\right)$. Además, se muestra el valor del módulo de la fuerza total de corte $(F)$. El efecto del desgaste de herramienta puede ser despreciado cuando la herramienta es nueva, y por lo tanto el efecto de los fluidos de corte son los que marcan la diferencia en las fuerzas de corte. En esta etapa, las fuerzas radiales son pequeñas y bastante similares debido a que la herramienta no está desgastada. Además, tanto las fuerzas de corte como de avance sólo presentan ligeras diferencias, alcanzando valores alrededor de $800 \mathrm{~N}$ y $325 \mathrm{~N}$, respectivamente. Tomando las fuerzas de corte durante el mecanizado en seco como referencia, el resto de valores obtenidos con las otras técnicas de lubricaciónrefrigeración son inferiores entre un $0.05 \%$ y $6 \%$ para la componentes de la fuerza de corte y varían entre un $-4 \%$ y $+6.5 \%$ para las componentes de la fuerza de avance. Estas pequeñas variaciones indican la viabilidad de las alternativas estudiadas.

Por otra parte, los valores de las fuerzas de corte también están relacionados con el desgaste de la herramienta y aumentan con éste. Sin embargo, aunque el CryoMQL_LN2 presenta durante todo el proceso un módulo de fuerza total de corte $(F)$ menor que el del CryoMQL_CO2, su componente de fuerza de corte $\left(F_{c}\right)$ es mayor. Este comportamiento se acentúa cuando el desgaste del flanco está cercano a 0,3 mm. Por lo tanto, con el fin de validar los resultados obtenidos en estos casos, se ha realizado un análisis estadístico basado en la distribución de T-student estableciendo un intervalo de confianza para las 3 componentes de las fuerzas de corte a 

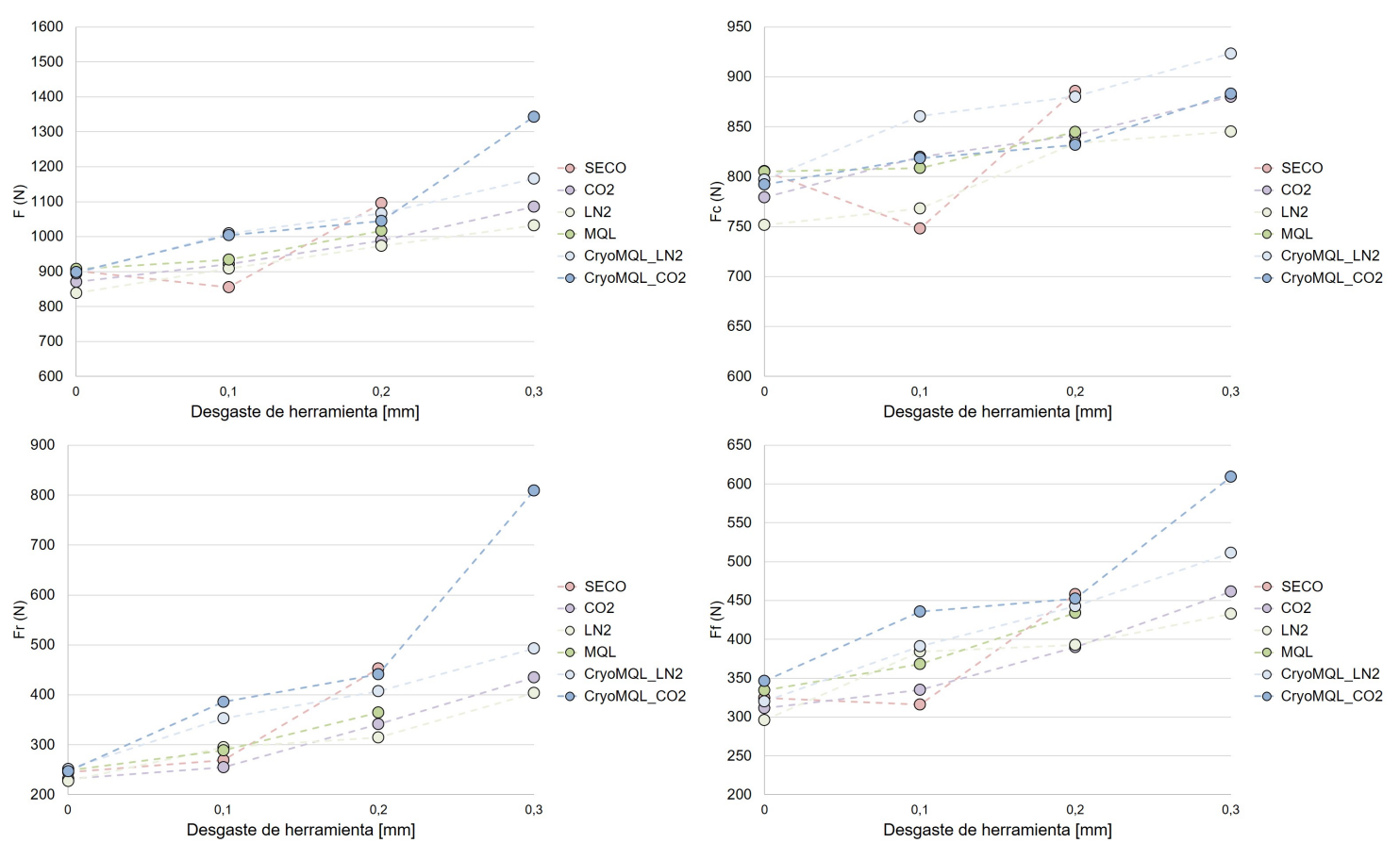

Figura 4.6: Fuerzas de corte en torneado de AISI 304L

lo largo del proceso de mecanizado con ambas técnicas CryoMQL. El nivel del intervalo de confianza fue establecido en un $90 \%$; se utilizaron 6 y 9 grados de libertad para el CryoMQL_CO2 y CryoMQL_LN2, respectivamente; y se utilizó la media aritmética obtenida durante todo el proceso para cada una de las componentes de las fuerzas de corte. En la tabla 4.10 se muestran lo resultados obtenidos.

En ellos se observa que cuando se utiliza el CryoMQL_CO2 como fluido de corte los valores de las fuerzas de corte se encuentran dentro del intervalo de confianza para cada etapa del desgaste de herramienta analizado con un nivel del $90 \%$. Sin embargo, en el caso del CryoMQL_LN2, las fuerzas de corte están fuera de dicho intervalo cuando el desgaste de flanco alcanza $0,3 \mathrm{~mm}$. Este fenómeno inestabiliza el proceso de corte en dicha etapa causando un posible fallo incontrolado de la herramienta. Esto es acorde con el valor del desgaste de flanco especificado en la norma ISO 3685. Por lo tanto, las fuerzas de corte obtenidas con ambas técnicas de refrigeración-lubricación CryoMQL no afectan negativamente al proceso de corte. 


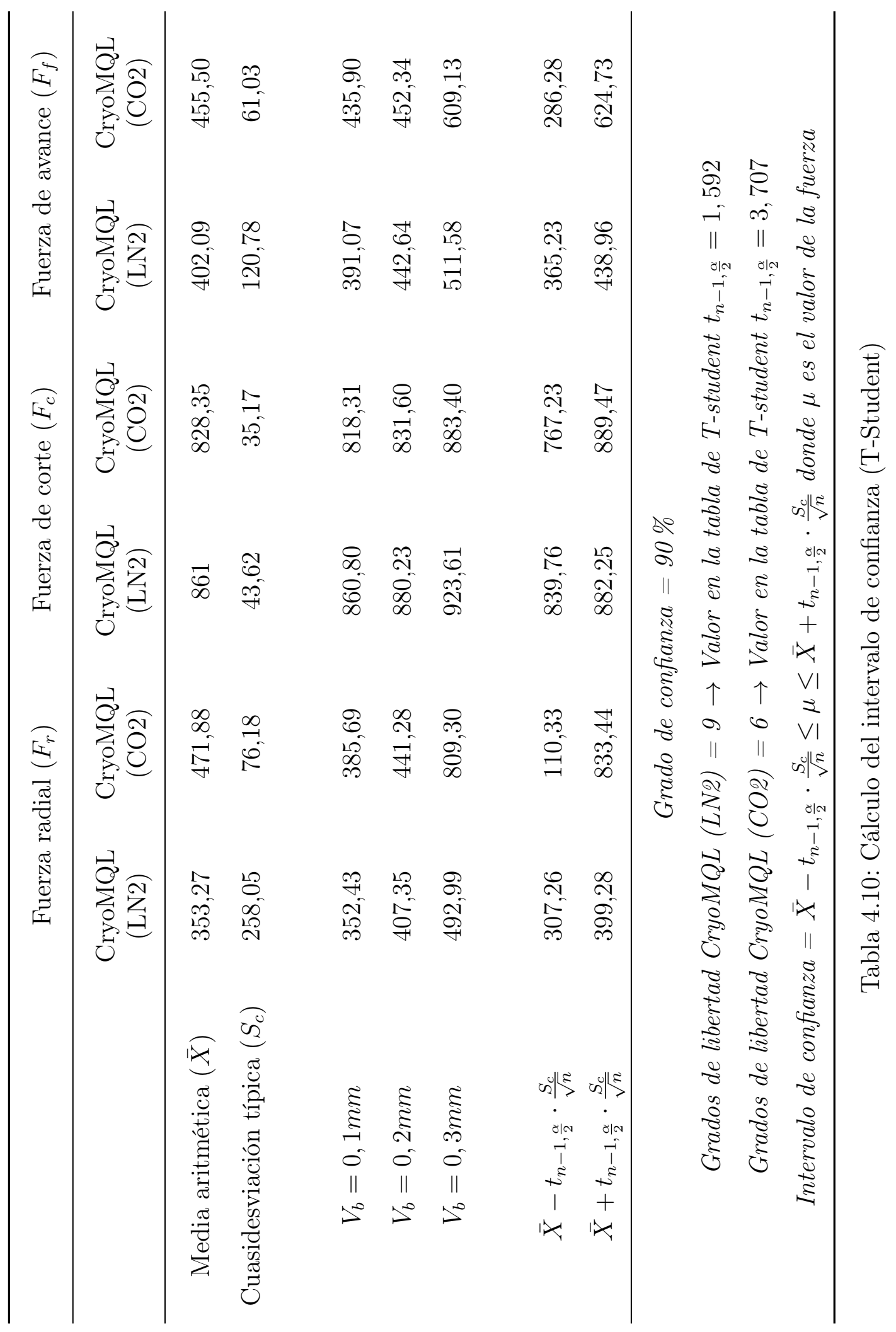




\section{Integridad superficial}

La integridad superficial en componentes mecanizados es de gran importancia para poder validar una tecnología de corte. De hecho, para que una mejora en los procesos de mecanizado sea implementada la integridad superficial debe ser mantenida o mejorada. Uno de los indicadores más comunes para analizar la integridad superficial son los parámetros de rugosidad, la topología superficial, el análisis de microestructura y las durezas superficiales y subsuperficiales.

En cuanto a rugosidad superficial, los resultados obtenidos durante el torneado con las diferentes tecnologías de refrigeración/lubricación son mostrados en la Figura 4.7. En ella se representan los valores obtenidos en las diferentes etapas de desgaste de la herramienta. Cuando el inserto es nuevo la influencia del desgaste de herramienta en la rugosidad superficial puede ser despreciado. Teniendo en cuenta los valores teóricos obtenidos de las ecuaciones 4.1 y 4.2 [Kant and Sangwan, 2014] [Shaw, 1984] , sólo al utilizar el MQL como técnica de lubricación y con el mecanizado en seco la rugosidad medida $\left(R_{a}\right)$ se encuentra por debajo de su valor teórico. Sin embargo, sus valores medios de cinco alturas máximas entre pico y valle $\left(R_{z}\right)$ se encuentran por encima de dicho valor teórico. Estos valores disminuyen a lo largo del mecanizado y por lo tanto con el desgaste de herramienta. Este fenómeno es habitual en este tipo de insertos donde la zona estable de mecanizado es obtenida en valores alrededor de $0,2 \mathrm{~mm}$ de desgaste de incidencia y por lo tanto los parámetros de rugosidad superficial alcanzan sus valores mínimos [Fernández-Valdivielso et al., 2015]. En esta etapa $\left(V_{b}=0,2 \mathrm{~mm}\right)$, tanto $R_{a}$ como $R_{z}$ se encuentran por debajo de sus valores teóricos. Únicamente $R_{z}$ al mecanizar con LN2 se encuentra por encima del valor teórico. Los mejores resultados son obtenidos al utilizar MQL y el CryoMQL_CO2 con una mejora del 40,6\%, situándose $R_{a}$ para ambas técnicas en $1,45 \mu \mathrm{m}$ en la zona estable. En cuanto a $R_{z}$, los valores obtenidos en esta etapa son similares con las tecnologías de lubricación/refrigeración estudiadas en este caso, obteniendo una mejora del $\simeq 18 \%$.

$$
\begin{gathered}
R_{z}=\frac{f_{r}{ }^{2}}{8 \cdot r_{\text {inserto }}} \\
R_{a}=\frac{R_{z}}{4}
\end{gathered}
$$



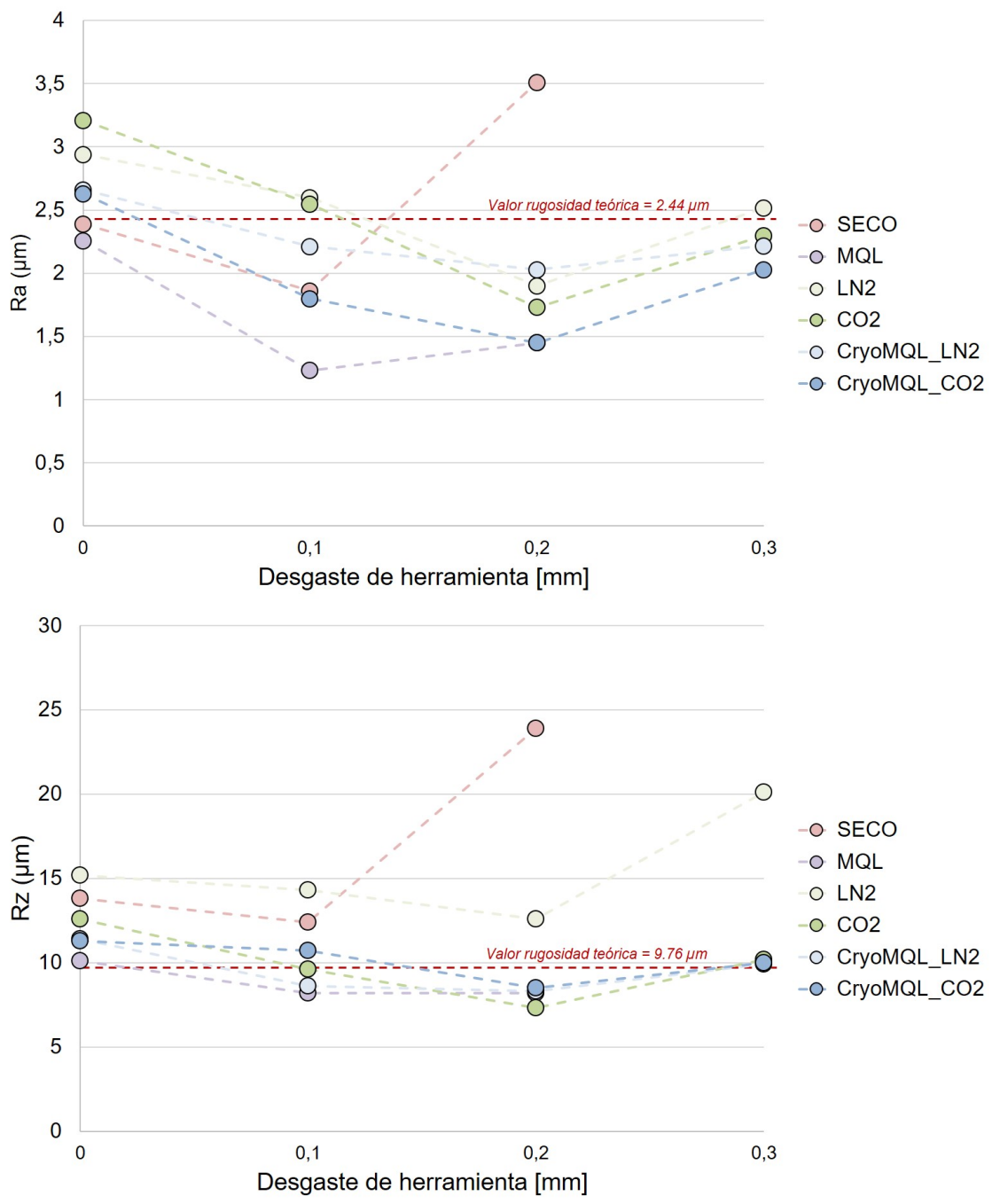

Figura 4.7: Rugosidad obtenida durante el torneado de AISI 304L

Además de los parámetros de rugosidad, también es importante analizar la topografía superficial. En la Figura 4.8 se muestran las topografías después de mecanizar en seco y con CryoMQL_CO2 cuando el desgaste de la herramienta $\left(V_{b}\right)$ se encuentra con un valor de $0,2 \mathrm{~mm}$. Los resultados obtenidos muestran que al utilizar CryoMQL se genera la típica superficie patrón de torneado de forma inequívoca. Esto implica un proceso de corte estable además de controlable. Para el mecanizado en seco, los resultados muestran un proceso de deformación de los picos y valles en el perfil de rugosidad. Este hecho implica aspectos negativos como una capa deformada mayor, una rugosidad superficial no uniforme y probablemente una menor vida de herramienta. 

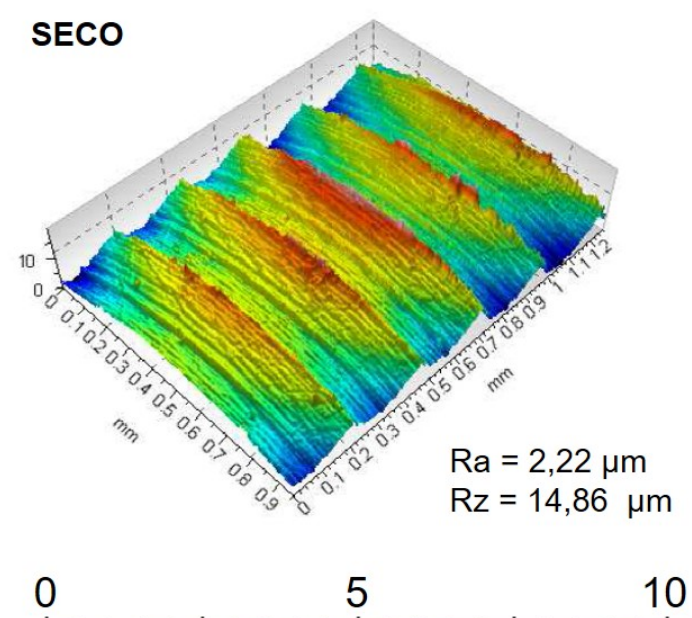

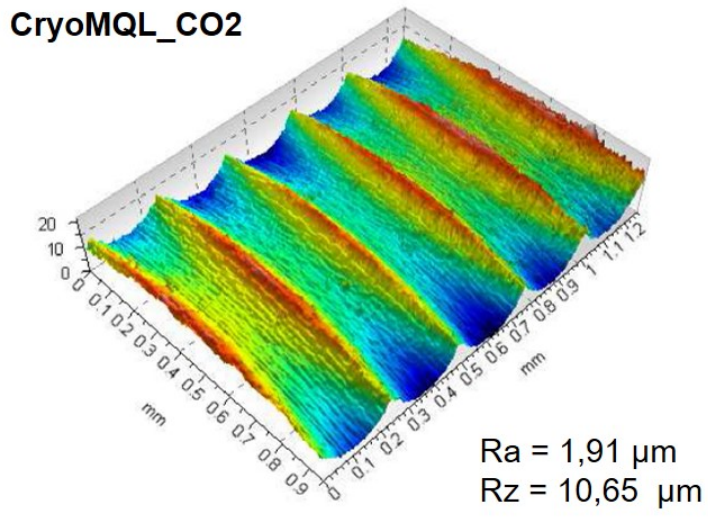

15

$20 \mu \mathrm{m}$

Figura 4.8: Topología superficial obtenida durante el torneado de AISI 304L

El análisis de la microestructura del material es esencial para determinar la zona afectada durante el mecanizado en caso de existir. En la Figura 4.9 se muestran las microestructuras de dos muestras de material en las que se ha mecanizado en seco y con CryoMQL_CO2. Las muestras fueron obtenidas de las piezas mecanizadas cuando la herramienta se encontraba aproximadamente a mitad de vida de herramienta $\left(V_{b} \approx 0,15-0,2 \mathrm{~mm}\right)$. Los resultados muestran que mecanizando en seco, el espesor de la capa deformada es notablemente mayor que utilizando CryoMQL. Concretamente, con el mecanizado en seco se encuentran afectadas $\approx 30 \mu \mathrm{m}$, mientras que utilizando CryoMQL_CO2 se encuentra en $10 \mu \mathrm{m}$. Este hecho es extremadamente importante cuando se trata de componentes de alto valor añadido como componentes de turbomaquinaria aeronáutica o similares.
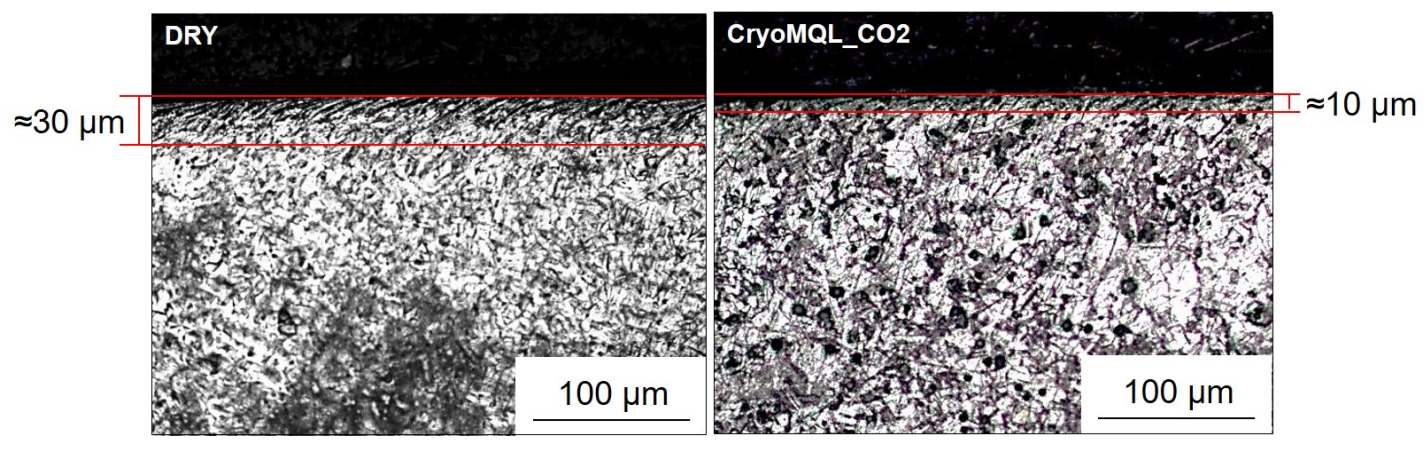

Figura 4.9: Capa deformada en microestructura de AISI 304L 
Por otra parte, la capa deformada puede afectar notablemente a la dureza superficial y subsuperficial, como se muestra en la Figura 4.10. Los valores fueron tomados cada $40 \mu \mathrm{m}$ hasta una profundidad de $200 \mu \mathrm{m}$. Con el fin de eliminar cualquier tipo de distorsión proveniente de medidas previas, entre medidas hubo un desplazamiento lateral de $30 \mu m$. La dureza del material base suele estar entre los 200-210 HBN. Sin embargo, al mecanizar con las diferentes tecnologías de refrigeración/lubricación, los valores de la dureza varían. Los aceros austeníticos tienden al endurecimiento en frío después de cada pasada de mecanizado, lo que aumenta el desgaste de herramienta si no se utiliza la tecnología de refrigeración/lubricación apropiada. Los resultados muestran que los valores más altos de dureza aparecen en la superficie al mecanizar en seco. Esto es coherente con los resultados anteriores del espesor de la capa deformada en el análisis microestructural. Por otra parte, a $200 \mu m$ la dureza del material base sólo se alcanza cuando se aplica MQL o LN2 como fluido de corte. Sin embargo, a pesar de que las microdurezas subsuperficiales obtenidas a esta profundidad con ambas técnicas CryoMQL está por encima de dicho valor, si se toma como referencia el mecanizado en seco, hay una mejora del $11 \%$.

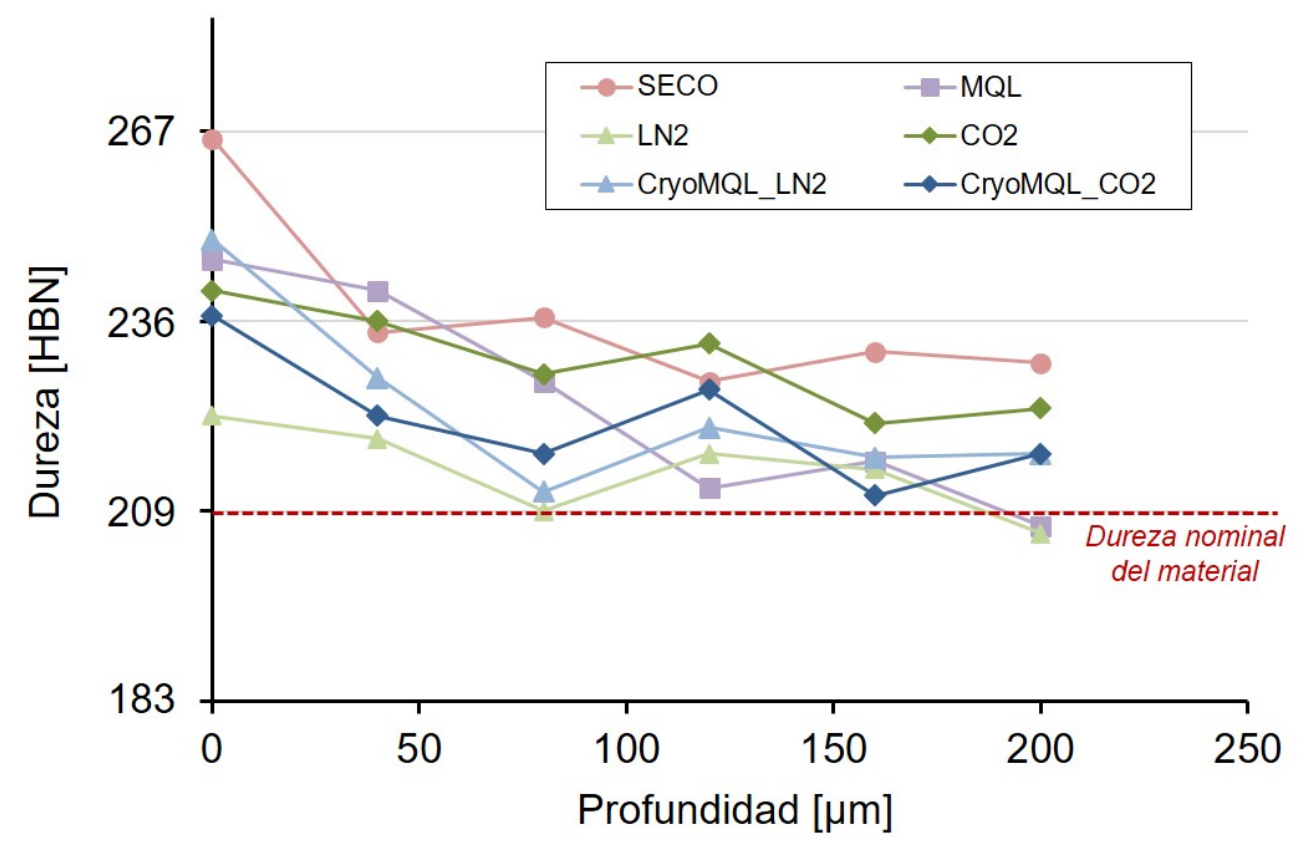

Figura 4.10: Dureza de AISI 304L después del torneado 


\subsubsection{Discusión de los resultados - AISI 304L}

De los resultados mostrados en esta sección referente al torneado de AISI 304L se derivan las siguientes conclusiones:

- Se hace necesario la utilización de técnicas avanzadas de refrigeración/lubricación para eliminar o minimizar la utilización de fluidos de corte convencionales durante el mecanizado de aceros inoxidables. En este caso, el mecanizado en seco no se presenta como una solución factible debido a la poca duración de la vida de herramienta.

- En lo que se refiere a aspectos técnicos, se han obtenido resultados similares durante la ejecución de los ensayos al utilizar las diferentes alternativas al uso de emulsiones de aceite. Sin embargo, a pesar de que con todas las técnicas de refrigeración/lubricación estudiadas las rugosidades medias se encuentran por debajo del valor teórico, al mecanizar con MQL y CryoMQL_CO2 se obtuvieron los mejores resultados cuando la herramienta alcanza los $0,2 \mathrm{~mm}$ de desgaste de flanco. De hecho, en este punto con ambas tecnologías se logra una mejora del $40 \%$.

- La utilización de alternativas en modo "stand alone", como la refrigeración criogénica con LN2 o CO2 y el MQL, no ofrecen una solución completa. Para el mecanizado de este tipo de materiales de difícil maquinabilidad se hace necesario refrigerar y lubricar simultáneamente. La vida de herramienta en estos casos no es lo suficientemente alta como para sustituir las emulsiones de aceite tradicionales.

- La utilización de CO2 como gas criogénico en el CryoMQL se presenta como una alternativa viable para minimizar la utilización de fluidos de corte convencionales. En comparación con la lubricación MQL, esta alternativa provoca un aumento de la vida de herramienta en un $30 \%$ y la dobla en comparación con el mecanizado en seco. Además, con esta técnica se obtienen otras ventajas como la generación de virutas totalmente limpias, un descenso del gasto en fluidos de corte y un aumento de la higiene en los talleres mecánicos. 


\subsection{Torneado en duro de ASP23}

\subsubsection{Introducción}

Tras la evaluación de las diferentes tecnologías de refrigeración/lubricación durante el torneado de AISI 304L, se procedió a evaluar el comportamiento de la refrigeración criogénica en el torneado en duro. Este proceso de mecanizado se viene aplicando a materiales de extrema dureza (generalmente por encima de 45HRc) donde tradicionalmente se han mecanizado mediante procesos de rectificado. El auge de este proceso de mecanizado en entornos industriales se debe a que al utilizar el torneado en duro se eliminan las restricciones geométricas asociadas a los procesos de rectificado a la vez que se reducen los tiempos de mecanizado hasta un $60 \%$ [Tönshoff et al., 2000]. Por ello, este proceso tiene gran interés principalmente en operaciones de desbaste para la fabricación de herramientas HSS.

Generalmente este tipo de torneado se realiza con herramientas de nitruro de boro cúbico policristalino (PCBN) con el fin de eliminar posibles daños superficiales y reducir los problemas de tolerancias geométricas y dimensionales. Esto implica que se tenga que mecanizar en seco debido a que el PCBN no presenta buena resistencia a la fatiga térmica. Por ello, se debe tener en cuenta que en este tipo de procesos se alcanzan altas temperaturas de corte que pueden modificar la integridad superficial de la pieza. Concretamente en materiales ferrosos se produce una capa superficial endurecida conocida como capa blanca. Esta capa, que debe su nombre a su aspecto en el microscopio, es producida principalmente por el rápido aumento de la temperatura del material por encima de la temperatura de austenización seguida por un rápido enfriamiento debido a los fluidos de corte o la simple convección con el aire atmosférico durante el mecanizado. La formación de la capa blanca influye de forma drástica en el comportamiento de los componentes a fatiga. De hecho, según [Guo et al., 2010] en el AISI 52100 la resistencia a fatiga del material se reduce hasta 8 veces su valor inicial. Por otra parte, según [Smith et al., 2007] una capa blanca menor a $2 \mu \mathrm{m}$ implica que no haya evidencias concluyentes de que la capa blanca tenga impacto alguno en la fatiga axial del componente.

Por ello, con el fin de mantener el espesor de la capa blanca por debajo de dicho umbral a la vez que se consigue un aumento de la vida de herramienta, en esta tesis se decidió utilizar la refrigeración criogénica con $\mathrm{CO} 2$ como alternativa al mecani- 
zado en seco durante el proceso de torneado en duro. La elección en este caso de la utilización de CO2 en vez de LN2, aparte de las razones ya dadas anteriormente, es debido a que el CO2 presenta una capacidad de refrigeración menor que la del LN2 lo que implica una menor dureza por sobreenfriamiento del material, haciendo que éste siga siendo factible de ser mecanizado mediante torneado.

\subsubsection{Montaje y metodología experimental}

Con el fin de llevar a cabo la evaluación del uso de la refrigeración criogénica en esta dirección se ha procedido al cilindrado de ASP23 (64HRc) en seco y utilizando CO2 como fluido de corte con condiciones de corte constantes. En cada uno de los ensayos se utilizaron dos tipos de insertos con diferentes ángulos de incidencia. Hay que tener en cuenta que un aumento en el ángulo de incidencia implica una disminución del desgaste de flanco a costa de reducir la tenacidad del filo. Sin embargo, éste se hace necesario para que el filo de corte trabaje libremente sin rozamiento. Por ello, el primer inserto utilizado fue uno negativo VNGA160408, con $0^{\circ}$ de ángulo de incidencia, montado sobre un portaherramientas DVVN2525M16 y el otro inserto utilizado fue uno positivo VCGW160408, con un ángulo de incidencia de $7^{\circ}$, que se montó en un portaherramientas SVVCN2525M16. De este modo se puede evaluar el ángulo de incidencia más apropiado para la refrigeración criogénica con el fin de alargar la vida de herramienta lo máximo posible. En la Tabla 4.11 se resumen las características técnicas de los insertos y las condiciones de corte utilizadas.

\begin{tabular}{ccc}
\hline Inserto & VNGA160408 & VCGW160408 \\
\hline Material & CBN & CBN \\
Forma & Rómbica $35^{\circ}$ & Rómbica $35^{\circ}$ \\
Ángulo de incidencia & $0^{\circ}$ & $7^{\circ}$ \\
Diámetro & 9,525 & 9,525 \\
circunferencia & 4,76 & 4,76 \\
Espesor & 0,8 & 0,8 \\
Radio de punta & & \\
\hline Condiciones de corte & Avance & Prof. de pasada \\
\hline Velocidad de corte & $0,05 \mathrm{~mm} / \mathrm{rev}$ & $0,05 \mathrm{~mm}$ \\
\hline $160 \mathrm{~m} / \mathrm{min}$ & &
\end{tabular}

Tabla 4.11: Características técnicas de insertos y condiciones de corte 
Con el propósito de reproducir unas condiciones industriales, se utilizaron piezas esbeltas con una longitud de $290 \mathrm{~mm}$ entre las garras y el contrapunto. Durante los ensayos se realizaron diversas paradas con el fin de medir la evolución del desgaste de herramienta con el microscopio Nikon SMZ-2T y medir la rugosidad superficial (Ra y Rz) con el rugosímetro Taylor Hobson. En este caso, en cada ensayo se llevó el inserto hasta el fallo catastrófico. Una vez terminados los ensayos a pie de máquina, se procedió a analizar la microestructura del material con el fin de medir el espesor de la capa blanca con el microscopio Nikon Optiphot 100. En la Figura 4.11 se muestra el montaje experimental realizado para la ejecución de estos ensayos.

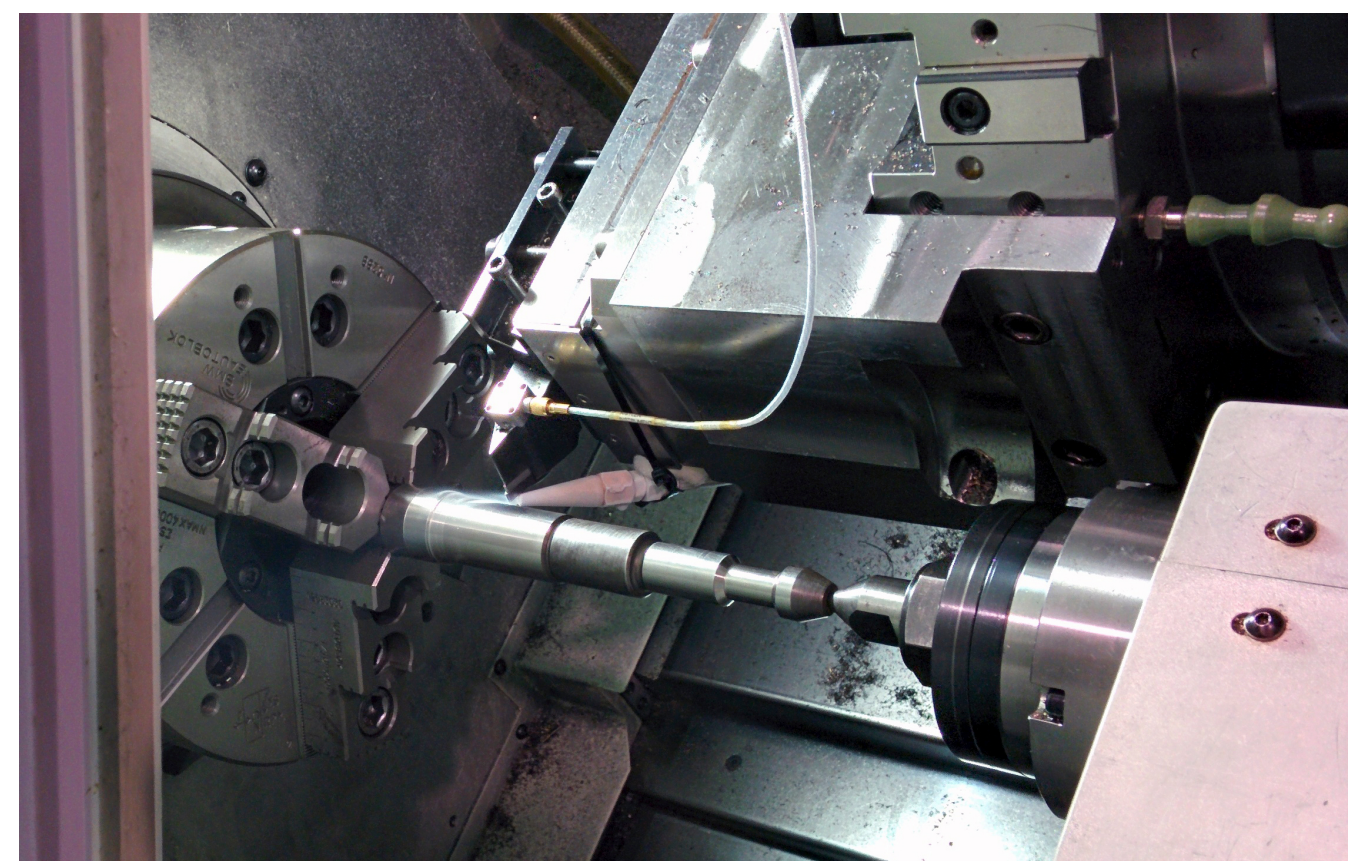

Figura 4.11: Montaje experimental para el torneado en duro de ASP23

\subsubsection{Resultados}

\section{Vida de herramienta}

En cuanto a la vida de herramienta, en la Figura 4.12 se muestran las evoluciones obtenidas en cada uno de los ensayos realizados con los insertos propuestos. En ambos casos al utilizar CO2 como fluido de corte se obtuvieron mayores vidas de herramienta. Asociando un valor del $100 \%$ al mecanizado en seco, se aprecia como con el inserto VNGA160408 la vida de herramienta aumenta en un $18.96 \%$ y como 
con la VCGW160408 se llega hasta un 69.5\%. Sin embargo, con el fin de anticipar la rotura del inserto es conveniente que se obtenga una zona estable durante el mecanizado. Dicha zona se observa claramente al combinar el inserto VNGA160408 y la refrigeración criogénica con CO2. En cambio, con el inserto VCGW160408 esto sólo ocurre durante un corto espacio al mecanizar en seco.
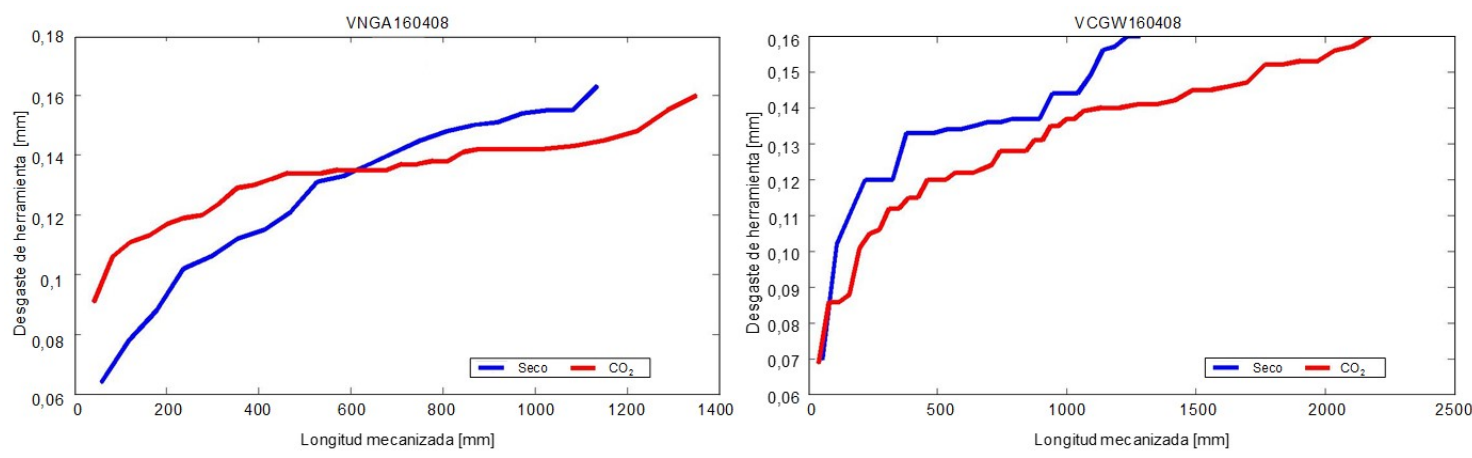

Figura 4.12: Evolución del desgaste de herramienta al tornear en duro ASP23

\section{Integridad superficial}

Con el fin de comprobar si la integridad superficial se mantiene o incluso si ésta mejora al mecanizar criogénicamente con $\mathrm{CO} 2$, se han analizado tanto las rugosidades superficiales como las microestructuras obtenidas con ambos insertos en cada uno de los ensayos planteados.

En cuanto a rugosidad superficial se refiere, como se observa en la Figura 4.13, en el caso de utilizar el inserto negativo VNGA160408 tanto la rugosidad media $\left(R_{a}\right)$ como la rugosidad media entre 5 valles-picos $\left(R_{z}\right)$ son claramente inferiores al mecanizar criogénicamente. Análogamente, al utilizar el inserto VCGW160408 se da una situación similar además de observarse una mayor estabilidad en $R_{z}$ a lo largo de la vida útil de la herramienta que si se mecanizase en seco. Cabe destacar, que en ambos casos, al mecanizar con CO2 se consiguen superficies con menor rozamiento que al hacerlo en seco. De hecho, si se toman como referencia los requisitos mínimos de rugosidad media superficial en los procesos de desbaste de los mangos de herramientas HSS, situados por debajo de $0.8 \mu \mathrm{m}$, se puede apreciar que con ambos insertos la rugosidad media está por debajo de dicho valor. Incluso en el peor de los casos no se excede el $90 \%$ del valor de referencia. 
Si se compara la influencia del uso de un inserto u otro al mecanizar criogénicamente, se observa como con el VNGA16408, a pesar de tener una menor vida de herramienta, presenta una $R_{a}$ con un crecimiento más estable donde su valor máximo se da al final de su vida útil, al contrario que ocurre con el VCGW160408, donde su valor máximo se da cuando se alcanza la zona estable de vida de herramienta. A pesar de que estos valores se dan en etapas distintas de la duración del inserto, estos fenómenos están ligados al desgaste del radio de éste. Si se observan las gráficas detenidamente, en ambos casos se alcanzan los valores máximos con una longitud de corte mecanizada similar. Sin embargo el inserto VCGW160408, al presentar un desgaste incremental a lo largo de su mayor vida útil provoca que la rugosidad media vaya descendiendo a partir de este punto. Por otro lado, al analizar $R_{z}$ se observa en ambos casos unas evoluciones muy estables, obteniendo menores valores durante el mecanizado con el inserto VNGA160408.
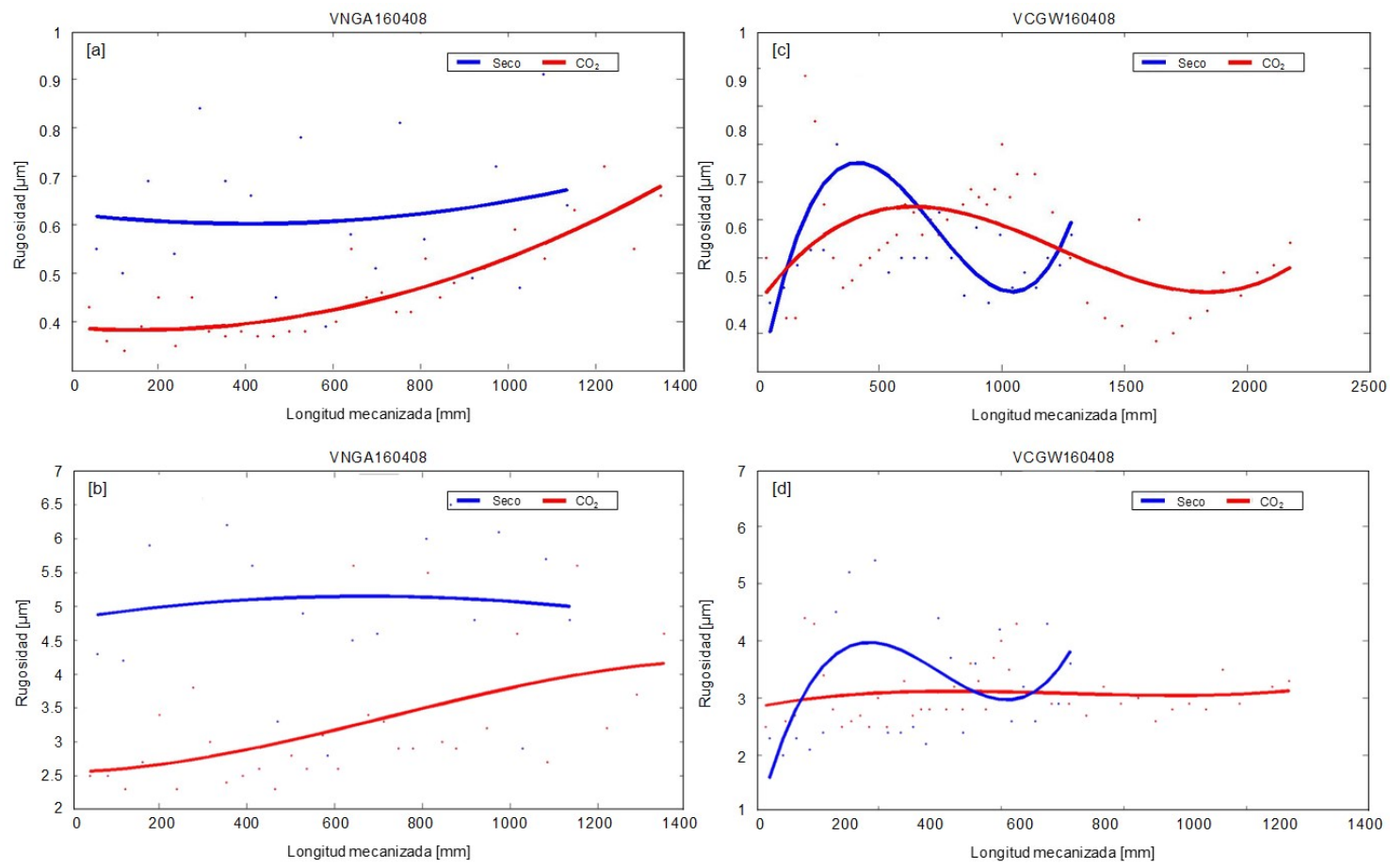

Figura 4.13: Evolución de la rugosidad al tornear en duro ASP23 VNGA 160408: [a] $R_{a}$ [b] $R_{z}$ VCGW160408: [c] $R_{a}[d] R_{z}$

Finalmente para completar el análisis de la integridad superficial se ha analizado la microestructura del material mecanizado en cada uno de los ensayos realizados 
con el fin de buscar la formación de la capa blanca en la subsuperficie de las probetas. El agente utilizado para obtener el grano fue Nital 4. Las microestructuras obtenidas con cada un de los insertos son mostradas en la Figura 4.14. En ambos casos, en el lado izquierdo se muestran las probetas obtenidas durante el mecanizado en seco. Como se puede observar, en ambos casos no hay presencia de capa blanca. Análogamente, en el lado derecho de la figura se muestran las microestructuras obtenidas durante el mecanizado criogénico con cada uno de los insertos, respectivamente. En este caso, al mecanizar con el inserto VCGW16408 no existe la formación de capa blanca. Sin embargo, al mecanizar con el inserto VNGA160408 se observa la presencia de la capa blanca con un espesor de $2 \mu \mathrm{m}$, lo que supone el valor máximo antes de que la capa blanca presente evidencias de afectar a la fatiga del componente mecanizado. Por otra parte, cabe destacar que en todos los casos, con la salvedad de éste último, la distribución de los carburos se mantiene constante sin la presencia de deformación en las capas superficiales.
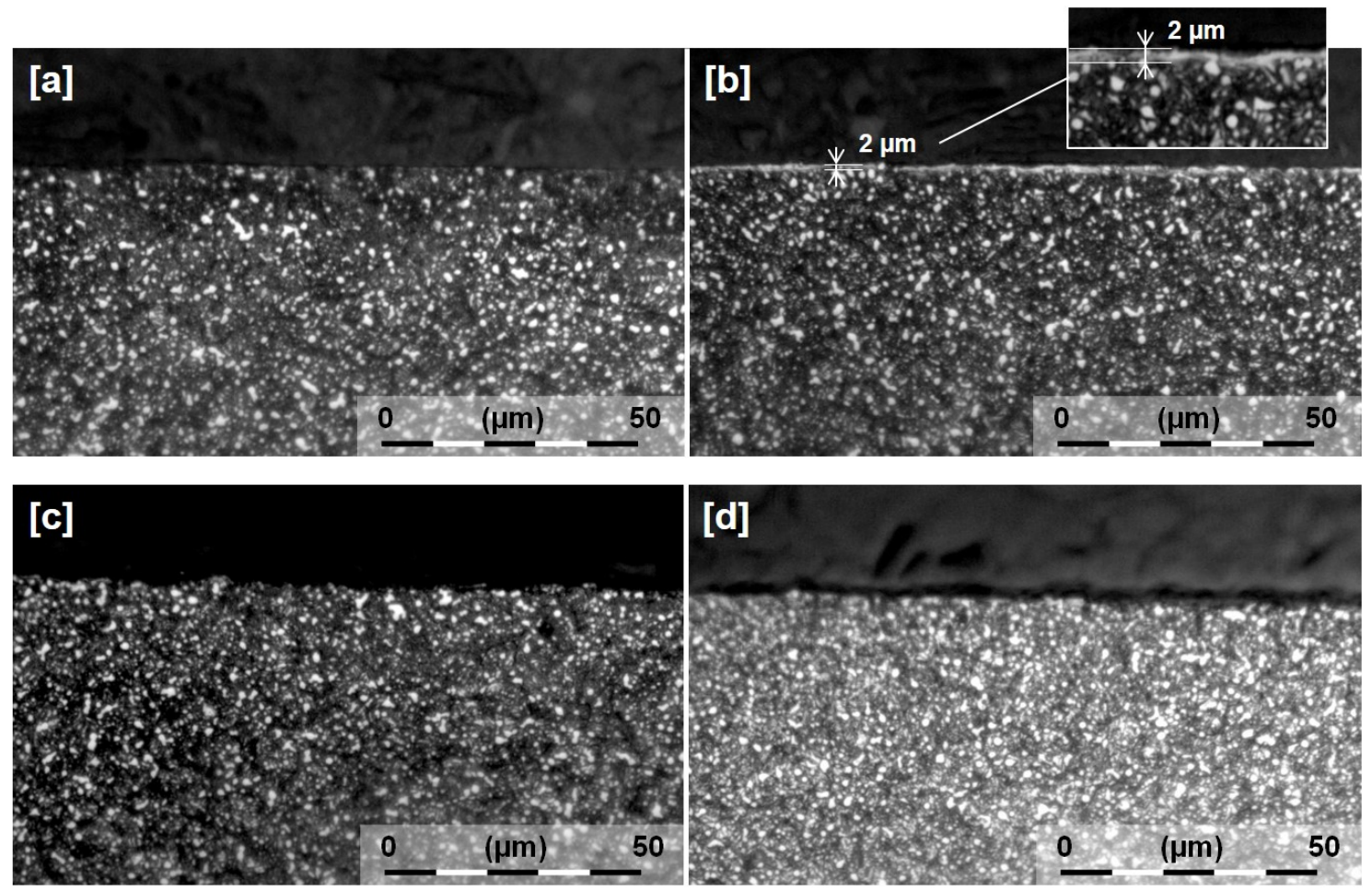

Figura 4.14: Microestructuras obtenidas al tornear en duro ASP23

VNGA 160408: (a) Seco (b) CO2 VCGW160408: (c) Seco (d) CO2 


\subsubsection{Discusión de los resultados - ASP23}

De los resultados mostrados en esta sección referente al torneado en duro de ASP23 se derivan las siguientes conclusiones:

- Se ha demostrado la efectividad de la utilización de la refrigeración criogénica con $\mathrm{CO} 2$ durante el torneado en duro con insertos de CBN en cuanto a vida de herramienta se refiere. Al utilizar insertos negativos, el aumento de vida de herramienta se sitúa en el $\approx 20 \%$ frente al torneado en seco convencional. En caso de utilizar insertos positivos, este valor aumenta hasta el $\approx 70 \%$.

- En cuanto a rugosidad superficial, se han obtenido valores similares en los cuatro ensayos realizados. Cabe destacar que a pesar de que el inserto negativo ofrece una menor vida de herramienta, éste presenta un crecimiento de la rugosidad media más estable cuyo valor máximo se da al final de su vida útil. Sin embargo, con el inserto positivo el valor máximo se alcanza en la zona estable de la vida de herramienta. No obstante, tomando como referencia la rugosidad superficial requerida en el desbaste de los mangos de herramientas HSS $(0,8 \mu m)$, incluso en el peor de los casos no se excede el $90 \%$ del valor de referencia.

- En lo que a microestructura se refiere, con el torneado en duro convencional no se observa la formación de capa blanca, es decir, no se alcanza la temperatura de austenización con ninguno de los insertos estudiados. Sin embargo, al utilizar la refrigeración criogénica, únicamente la utilización del inserto positivo presenta ausencia de dicha capa. En el caso de utilizar el inserto negativo, ésta aparece con un valor que no excede los $2 \mu m$ debido a la presión aplicada por el inserto desgastado. 


\subsection{Fresado Inconel 718}

\subsubsection{Introducción}

Con el fin de evaluar las diferentes tecnologías ecológicas de refrigeración/lubricación durante los procesos de fresado se ha procedido a la realización de planeados en la aleación de níquel Inconel 718. La razón por la que se seleccionó esta operación es debido a la frecuencia con que es utilizada durante los procesos de fabricación de componentes de alto valor añadido presentes en la turbomaquinaria aeronáutica. Este tipo de aleaciones, además de presentar una alta ductilidad, tienden al endurecimiento superficial durante su mecanizado debido a su matriz austenítica. Esto se traduce en un desgaste prematuro de la herramienta principalmente debido a la entalla generada en su filo entre pasadas. Por todo ello, se ha considerado este tipo de operación como la más representativa a la hora de evaluar el impacto producido por las diferentes técnicas de refrigeración/lubricación evaluadas.

\subsubsection{Montaje y metodología experimental}

El montaje experimental se muestra en la Figura 4.15. Se ha realizado un mecanizado de planeado siguiendo una trayectoria helicoidal manteniendo la profundidad radial $\left(a_{e}\right)$ constante (exceptuando la entrada y salida). Tras cada espiral completa mecanizada se ha medido el desgaste de la herramienta con el microscopio Nikon SMZ-2T. Las condiciones de corte se muestran en la Tabla 4.12. En relación a la velocidad de corte, se ha optado por condiciones agresivas para dotar al proceso de una mayor carga térmica y amplificar los efectos y la importancia de las diferentes técnicas de lubricación-refrigeración.

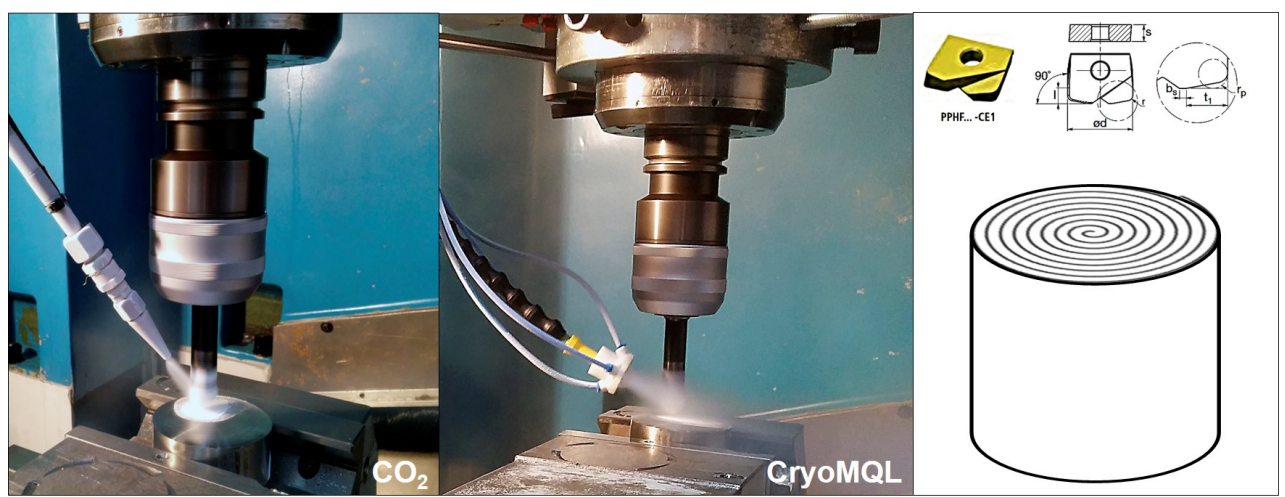

Figura 4.15: Montaje experimental y geometría de la herramienta 


\begin{tabular}{cc}
\hline Herramienta & $\begin{array}{c}\text { ARAF- Ball nose finishing } \\
\text { endmill }\end{array}$ \\
\hline Referencia & PPHF 1600 08-CE1 \\
$\varnothing[\mathrm{mm}]$ & 16 \\
Calidad & 2003 \\
Filos & 2 \\
$V c_{e f}[\mathrm{~mm} / \mathrm{min}]$ & 120 \\
$a_{p}[\mathrm{~mm}]$ & 0,2 \\
$\varnothing_{e f}[\mathrm{~mm}]$ & 7,8 \\
$a_{e}[\mathrm{~mm}]$ & 3 \\
$f_{z}[\mathrm{~mm}]$ & 0,06 \\
$\mathrm{~S}[\mathrm{rpm}]$ & 4897 \\
$\mathrm{~F}[\mathrm{~mm} / \mathrm{min}]$ & 588 \\
\hline
\end{tabular}

Tabla 4.12: Condiciones de corte para el fresado de Inconel 718

Los ensayos se han realizado para cinco condiciones diferentes de lubricaciónrefrigeración, las cuales se muestran en la Tabla 4.13.

\begin{tabular}{cc}
\hline $\begin{array}{c}\text { Técnicas de } \\
\text { Refrigeración/Lubricación }\end{array}$ & Características y descripción \\
\hline Mecanizado en seco & No hay lubricantes \\
MQL & Aceite de colza $\left(0,92 \mathrm{~g} / \mathrm{cm}^{3}\right)$, \\
& Caudal $=100 \mathrm{ml} / \mathrm{h}$, \\
CO2 & Presión neumática $=6$ bares \\
& Dióxido de carbono \\
& $\left(15\right.$ bares, $\left.-78^{\circ} \mathrm{C}\right)$ \\
CryoMQL $(\mathrm{CO} 2)$ & MQL $+\mathrm{CO} 2$ \\
Taladrina & $\left(100 \mathrm{ml} / \mathrm{h}+14 \mathrm{bar},-78^{\circ} \mathrm{C}\right)$ \\
& Emulsión al $10 \%, 6$ bares \\
\hline
\end{tabular}

Tabla 4.13: Técnicas de lubricación evaluadas en torneado 


\subsubsection{Resultados}

\section{Vida de herramienta}

Los resultados de vida de herramienta se muestran en la Figura 4.16. El valor representado corresponde a la media del valor de desgaste de flanco máximo en los dos filos del inserto. En la gráfica se representa el valor del desgaste en función del volumen $\left(\mathrm{mm}^{3}\right)$ de viruta desalojado, en función de la longitud (mm) mecanizada y en función del tiempo (min). Se ha tomado como referencia un valor de 0,2 $\mathrm{mm}$ de desgaste máximo de flanco como consideración para fin de vida de la herramienta. Experiencias previas han demostrado que por encima de este valor de desgaste, la integridad superficial no está garantizada en componentes críticos de Inconel 718 [Fernández-Valdivielso et al., 2015].

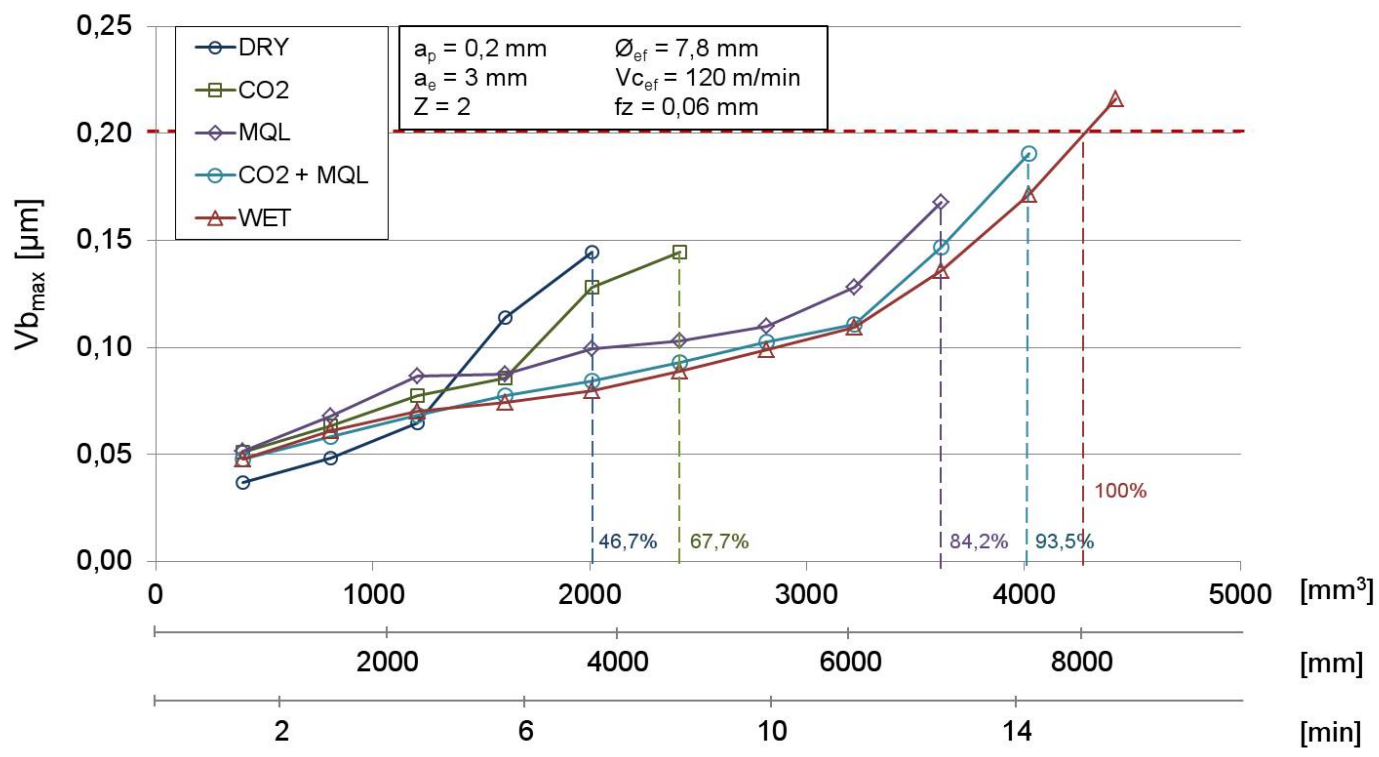

Figura 4.16: Evolución de vida de herramienta durante el fresado de Inconel 718

Se ha asignado el valor de vida de la herramienta para el mecanizado con taladrina como el $100 \%$. Los resultados muestran que con el mecanizado en seco el rendimiento de la herramienta es inferior respecto al uso de taladrina, siendo su duración del 46,7\%. El mecanizado con CO2, mejora los valores del mecanizado en seco, alcanzando un $67.7 \%$. Utilizando MQL con un caudal de $100 \mathrm{ml} / \mathrm{h}$, se consiguen valores del $84.2 \%$, y complementado con el uso de CO2 (CryoMQL) se alcanzan valores de $93.5 \%$ respecto al uso de taladrinas. 
En la Figura 4.17 se muestran imágenes de la evolución del desgaste para cada una de las condiciones de refrigeración-lubricación estudiadas. En el mecanizado en seco se aprecian valores muy bajos de desgaste en los primeros minutos. Sin embargo, a partir de los 4 minutos el filo de corte presenta un cráter que deriva en rotura después de 7 minutos de corte. Como se muestra en la Figura 4.18, en este punto el mecanizado con CO2 muestra una entalla en la zona cercana a la unión de las dos facetas de corte que tiene cada filo, además de múltiples micro-roturas a lo largo del filo. Alrededor del minuto 9 se produce la rotura, posiblemente causada por el aumento de fragilidad del conjunto herramienta-pieza y el consiguiente aumento de las fuerzas de corte. Por otra parte, al mecanizar con MQL, con CryoMQL y con taladrina, se obtiene un desgaste homogéneo hasta rotura.

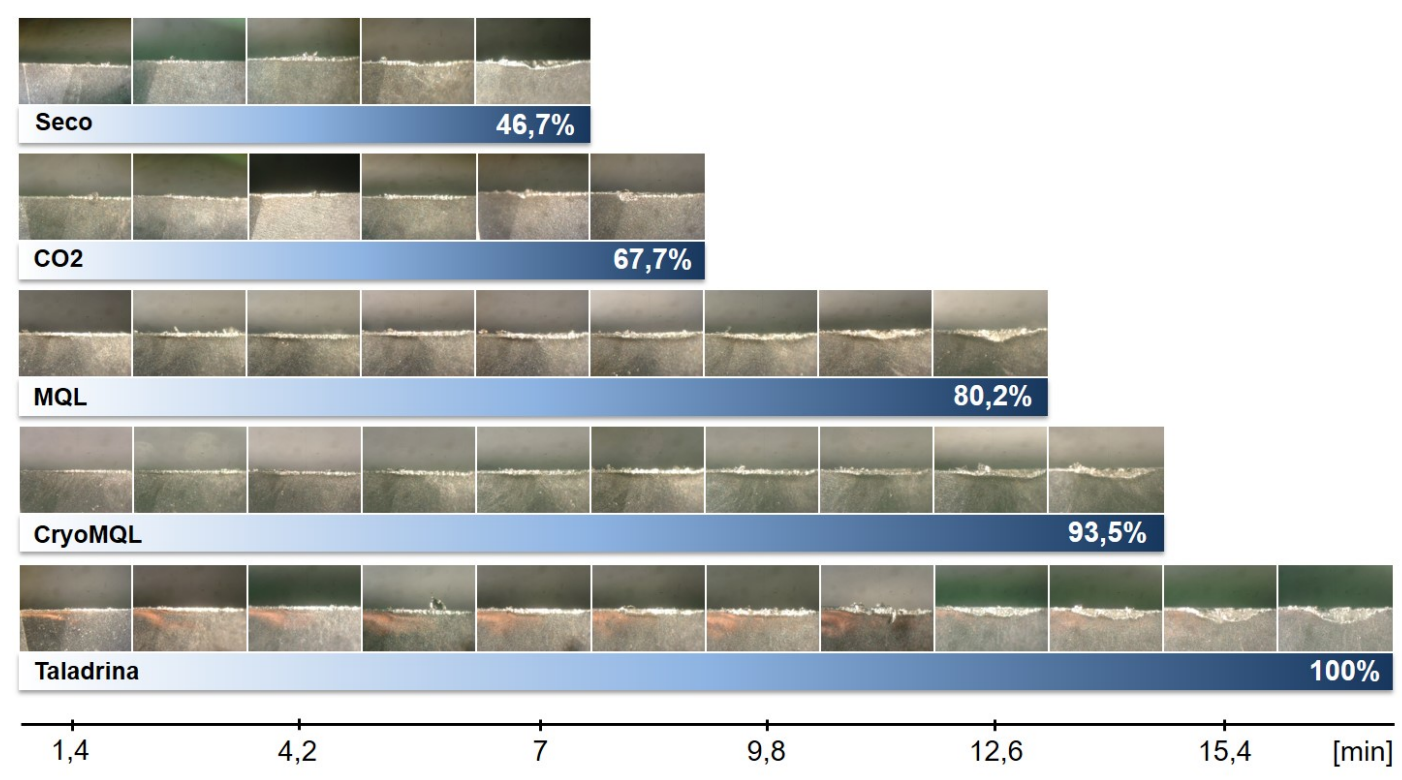

Figura 4.17: Evolución del desgaste de la herramientas en la cara de incidencia
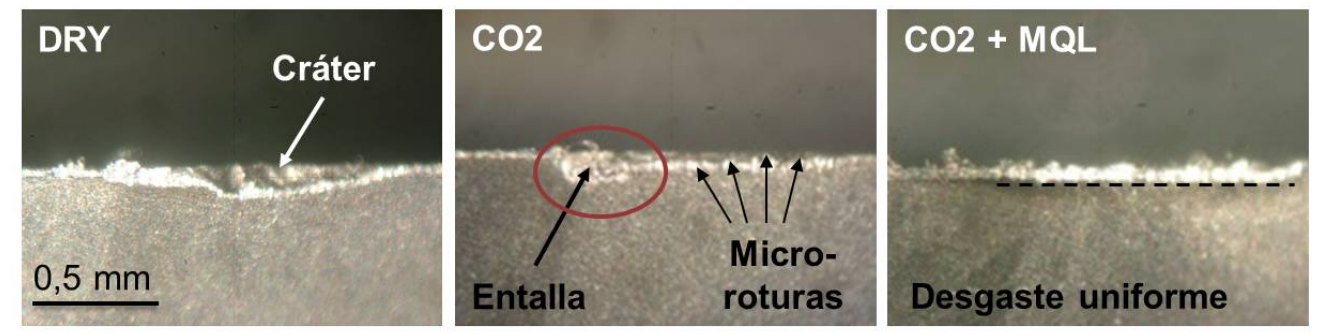

Figura 4.18: Estado de los insertos después de 7 minutos mecanizados 
Los resultados muestran cómo aplicando CO2 frente al mecanizado en seco la vida de la herramienta aumenta ligeramente, posiblemente debido a la disminución de la temperatura durante el proceso de corte. Sin embargo, esta disminución de la carga térmica no es suficiente para conseguir valores aceptables de vida de herramienta utilizando solamente CO2. De este modo el uso de CO2 como único medio de refrigeración se presenta insuficiente en este caso, ya que por una parte disminuye la carga térmica, pero por otra aumenta considerablemente la carga mecánica debido al aumento de la fragilidad tanto del material como de la herramienta. Por otra parte, los ensayos muestran cómo utilizando MQL y CryoMQL se consiguen desgastes más uniformes con vidas de herramienta en torno al $85 \%$ y $90 \%$ respectivamente ya que con la lubricación aportada se consiguen paliar las cargas mecánicas a las que la herramienta es sometida, las cuales son las principales causas de desgaste en este tipo de materiales.

\subsubsection{Discusión de los resultados - Inconel 718}

De los resultados mostrados en esta sección referente al fresado de Inconel 718 se derivan las siguientes conclusiones:

- El mecanizado convencional utilizando taladrina es la alternativa con la que se consigue un mayor rendimiento a vida de los insertos de corte. Sin embargo, el objetivo es minimizar o eliminar el uso de éstas con el fin de conseguir un proceso más ecológico y rentable.

- El uso exclusivo de CO2 como refrigerante no es suficiente en procesos donde la carga mecánica predomina sobre la térmica en el desgaste de herramienta.

- De las alternativas estudiadas, la técnica de CryoMQL es la que mejores resultados presenta, alcanzando la herramienta una duración del $90 \%$ respecto al mecanizado con taladrina. 


\subsection{Taladrado Stacks Ti6Al4V-CFRP}

\subsubsection{Introducción}

Finalmente, se ha procedido a validar la refrigeración criogénica en procesos de taladrado. Para ello, en este caso se ha optado por el mecanizado de composites formados por stacks de fibra de carbono (CFRP) y la aleación de titanio Ti6Al4V. Hay que destacar que desde 2010 el uso de composites en el sector aeronáutico está sufriendo un crecimiento exponencial con el fin de hacer estructuras más ligeras y resistentes con el fin de conseguir aeronaves más eficientes. De hecho, actualmente este tipo de materiales ya suponen alrededor del $50 \%$ del peso total de éstas. Este tipo de materiales se comportan de forma distinta a los materiales metálicos debido a que no son homogéneos y dependiendo de qué materiales compongan su matriz y refuerzo, su mecanizado puede resultar un reto importante debido a que las herramientas alternan el corte entre un tipo de material y otro. Concretamente, durante el taladrado de stacks de CFRP-Ti6Al4V se generan grandes temperaturas de corte ya que la fibra de carbono debe de ser mecanizada en seco. Como consecuencia se producen adhesiones de titanio en el filo de la broca debido a la gran afinidad que éste presenta a altas temperaturas con los materiales de la herramienta de corte. Por esto, la utilización de la refrigeración criogénica puede abarcar un nicho de mercado en el cual optimizar este tipo de procesos.

\subsubsection{Montaje y metodología experimental}

En estos ensayos se realizaron pruebas en seco y utilizando CO2 como fluido de corte. Como se indicó anteriormente, la razón por la cual no se utilizó ni taladrina ni MQL fue debido a la necesidad de mecanizar en seco la fibra de carbono con el fin de no contaminarla con el fluido de corte y además no formar una "pasta" compuesta con éste y el polvo generado que embote la herramienta. Las brocas utilizadas fueron de metal duro recubiertas de diamante con un diámetro de 7,6 mm, un ángulo de posición de filo $\left(2 K_{r}\right)$ de $135^{\circ}$ y refrigeración interna. El montaje experimental se muestra en la Figura 4.19. Los ensayos fueron realizados en el centro de mecanizado Kondia A6 al cual se acopló un sistema de aspiración con el fin de absorber toda la viruta y polvo generado durante los taladrados. Para la inyección del CO2 se dispuso de un portaherramientas giratorio, el cual permite la entrada del $\mathrm{CO} 2$ axialmente en 
su interior para así poder conducirlo consecuentemente por los conductos internos de los que la herramienta está provista. Las características del material y condiciones de corte utilizadas se reflejan en la Tabla 4.14. Como objetivo se estableció la realización de 160 agujeros consecutivos. Durante su ejecución se capturó la temperatura de la punta de la herramienta con una cámara de infrarrojos Impac justo al finalizar el agujero y se monitorizó el consumo de potencia del husillo con el potenciómetro Vydas UPC-E-12V. Además cada 40 agujeros se obtuvieron imágenes de la evolución de la adhesión de Ti6Al4V al filo de la herramienta con el microscopio Nikon SMZ2T y cada 10 agujeros se procedió a la medida de los diámetros obtenidos con un micrómetro de interiores. Una vez finalizados los ensayos, se procedió a la medida de la altura de la rebaba formada en el stack de CFRP con el microscopio confocal Leica DCM-3D y se obtuvieron imágenes más representativas en busca de quemados en los bordes de los agujeros del CFRP con el microscopio Nikon SMZ-2T.

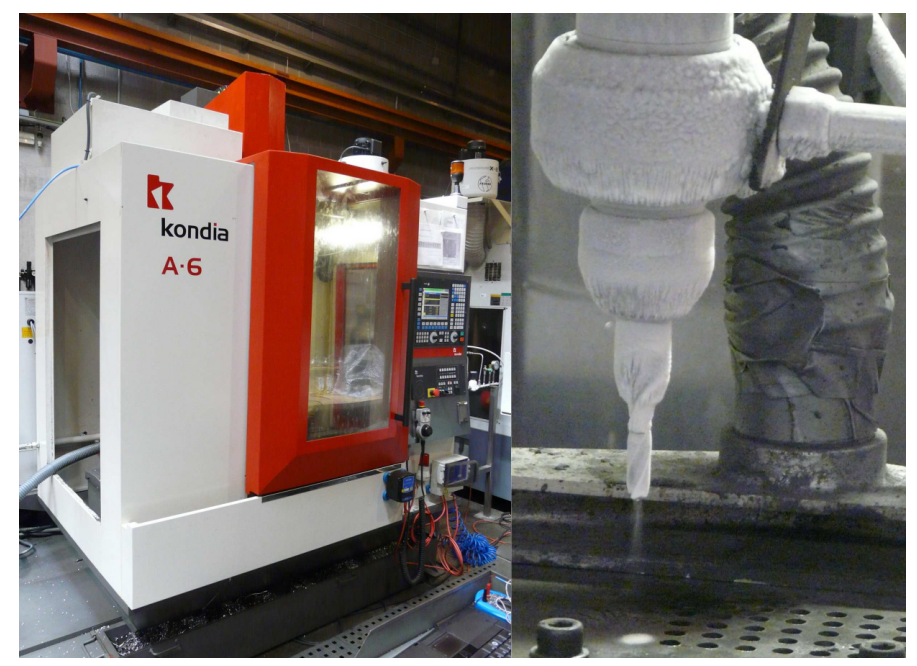

Figura 4.19: Montaje experimental para el taladrado de composite CFRP-Ti6Al4V

\begin{tabular}{ccccc}
\hline Material & $\begin{array}{c}\text { Espesor } \\
{[\mathbf{m m}]}\end{array}$ & $f_{z}[\mathbf{m m}]$ & $V_{c}[\mathbf{m} / \mathbf{m i n}]$ & Estrategia \\
\hline CFRP & 8 & 0,025 & 70 & $\begin{array}{c}\text { Taladro } \\
\text { continuo }\end{array}$ \\
Ti6Al4V & 10,4 & 0,025 & 15 & $\begin{array}{c}\text { Peck drilling } \\
0,5 \mathrm{~mm}\end{array}$ \\
\hline
\end{tabular}

Tabla 4.14: Características del composite y condiciones de corte utilizadas 


\subsubsection{Resultados}

\section{Diámetros y temperaturas obtenidos}

En la Figura 4.20 se muestran los diámetros obtenidos a lo largo del mecanizado de los 160 agujeros. En ella están representados los valores obtenidos en cada uno de los materiales al mecanizar en seco y con CO2, respectivamente. Como se puede apreciar, en ambos materiales, al utilizar el CO2 como fluido de corte los diámetros que se alcanzan son cercanos al valor nominal a lo largo de todo el ensayo. Sin embargo esto no ocurre al mecanizar en seco, dándose el caso más acusado en el taladrado del CFRP.

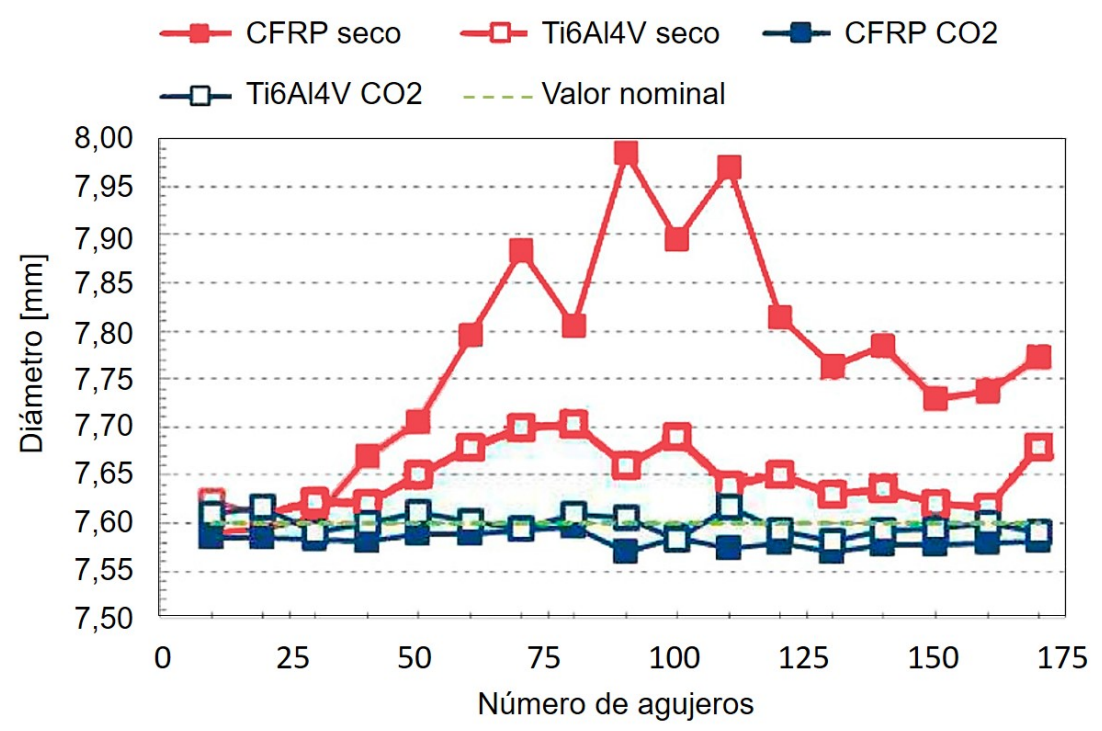

Figura 4.20: Diámetros obtenidos durante el taladrado de stacks CFRP-Ti6Al4V

Además como se observa en la Figura 4.21, al utilizar CO2 la temperatura de la punta de la herramienta se mantiene constante, cercana a los $0^{\circ} \mathrm{C}$. Sin embargo al taladrar en seco, ésta crece exponencialmente durante los primeros 80 agujeros hasta estabilizarse alrededor de $\operatorname{los} 325^{\circ} \mathrm{C}$. Cabe destacar que este fenómeno de crecimiento y posterior estabilización se da también en menor medida durante la utilización de CO2 como fluido de corte. Esto es debido principalmente a que el recubrimiento desaparece y se dan los primeros casos de material adherido a la herramienta. Este fenómeno es mostrado en la Figura 4.22 donde además se aprecia cómo al mecanizar con $\mathrm{CO} 2$, el filo de la herramienta permanece más afilado frente al mecanizado en seco. 


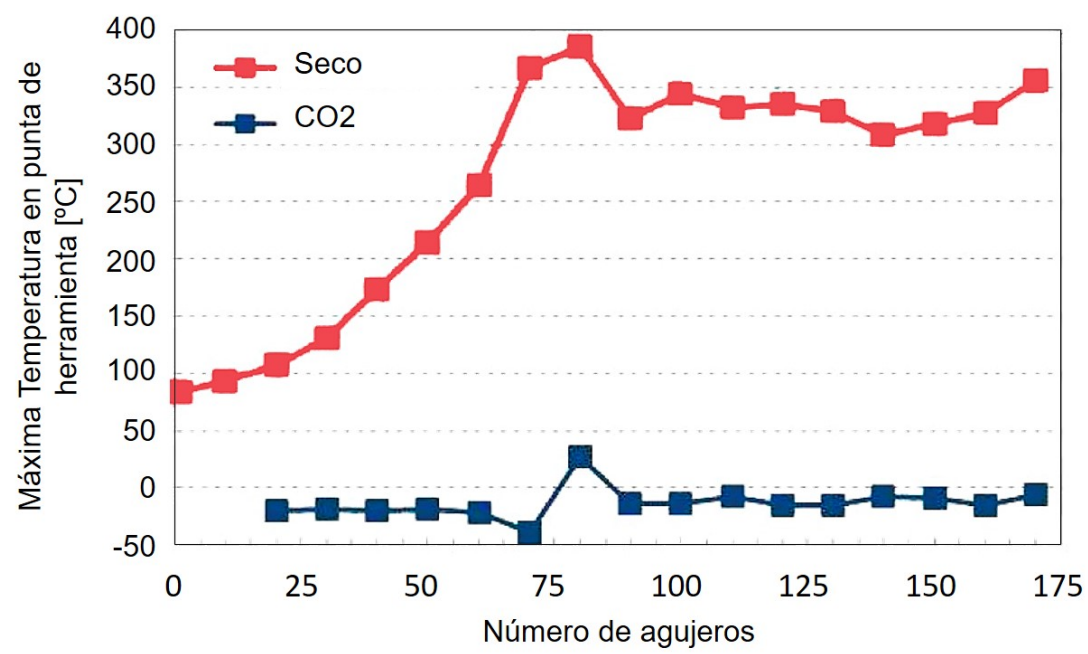

Figura 4.21: Temperatura de herramienta al taladrar stacks CFRP-Ti6Al4V

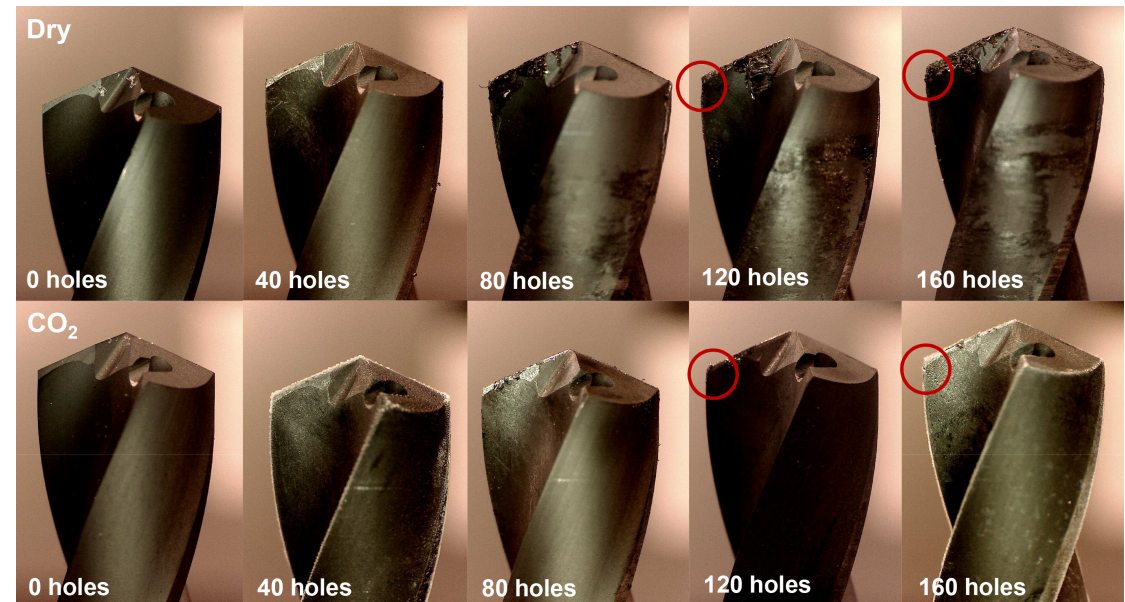

Figura 4.22: Imágenes de las brocas al taladrar stacks CFRP-Ti6Al4V

\section{Altura de rebaba}

Por otra parte, en cuanto a la altura de rebaba derivada de la entrada de la broca en la primera capa de CFRP, como se muestra en la Figura 4.23, tanto al mecanizar en seco como con $\mathrm{CO} 2$ las altura obtenidas exceden la tolerancia de diseño de la broca, siendo el caso más desfavorable para el mecanizado en seco donde se saturan las medidas obtenidas por el microscopio confocal Leica. 


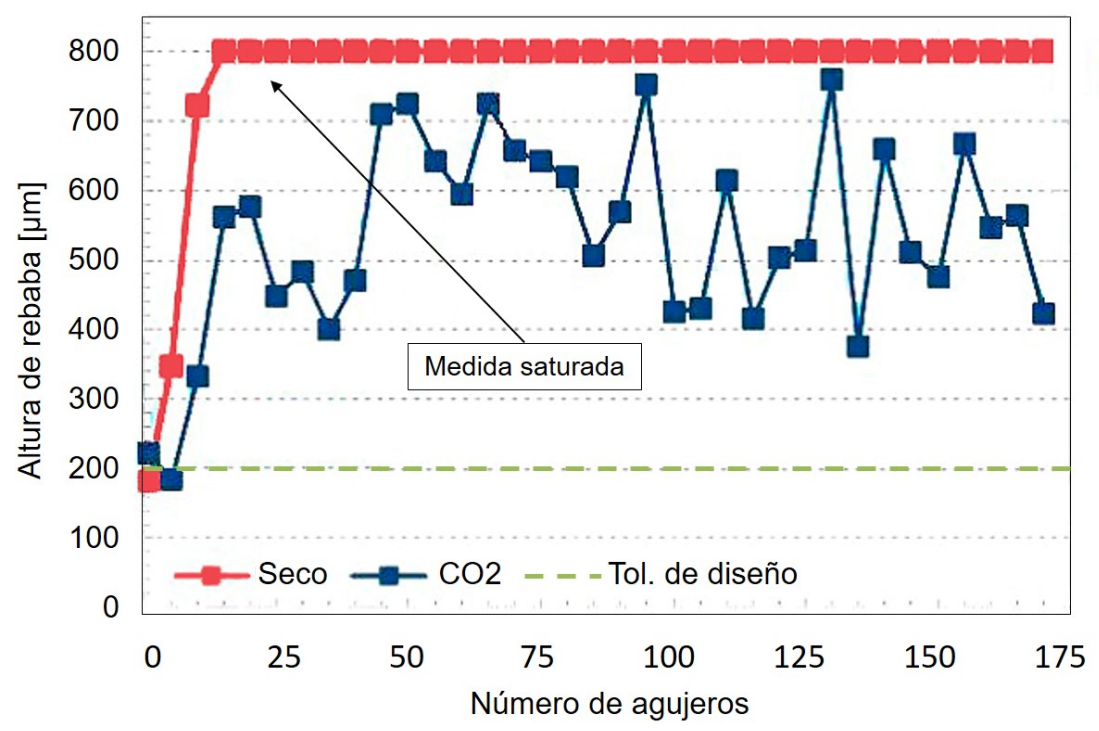

Figura 4.23: Altura de rebaba al taladrar stacks CFRP-Ti6Al4V

\section{Potencia consumida e integridad del material y herramienta}

En cuanto al consumo de potencia por el husillo, en la Figura 4.24 se muestran las potencias consumidas durante el primer agujero, el agujero número 100 (intermedio) y el agujero 160 (último) de los ensayos realizados. Como se observa, al mecanizar el CFRP con CO2 hay una gran diferencia de consumo de potencia debido a la gran variación de temperatura de corte existente entre el mecanizado en seco y con CO2. Sin embargo, a pesar de este mayor consumo de potencia, como se muestra en la Figura 4.25, después de terminar los ensayos la herramienta con la que se ha mecanizado criogénicamente apenas presenta daños y contiene menor cantidad de Ti6Al4V adherido. Además, el CFRP no presenta rebabas ni presencia de quemados.
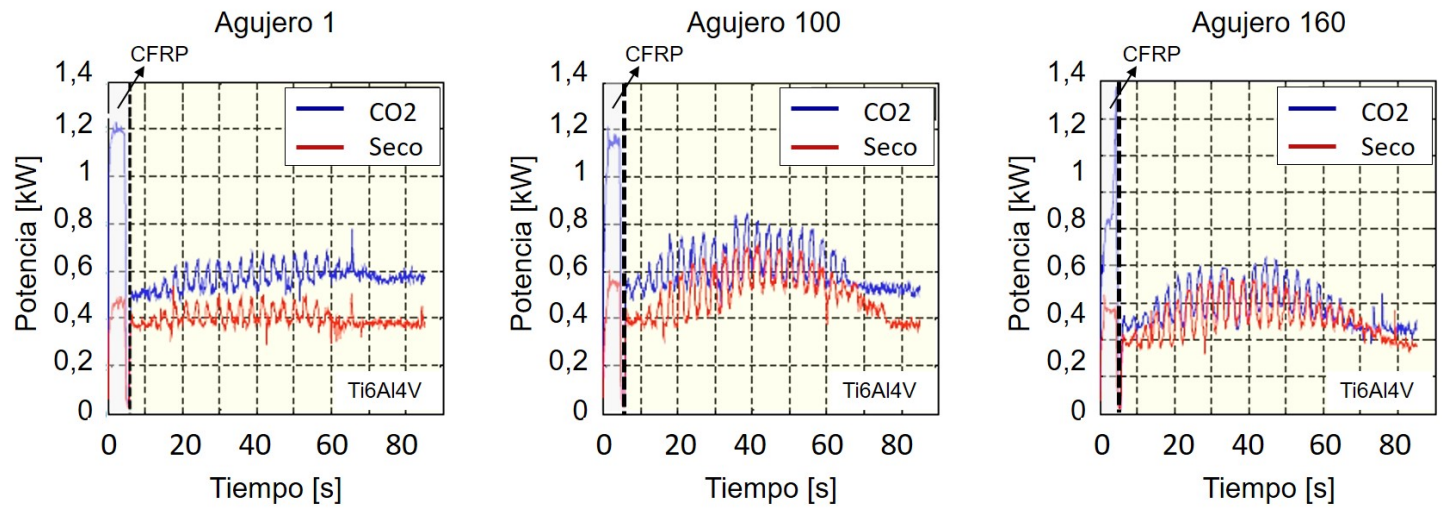

Figura 4.24: Potencia consumida por el husillo al taladrar stacks CFRP-Ti6Al4V 

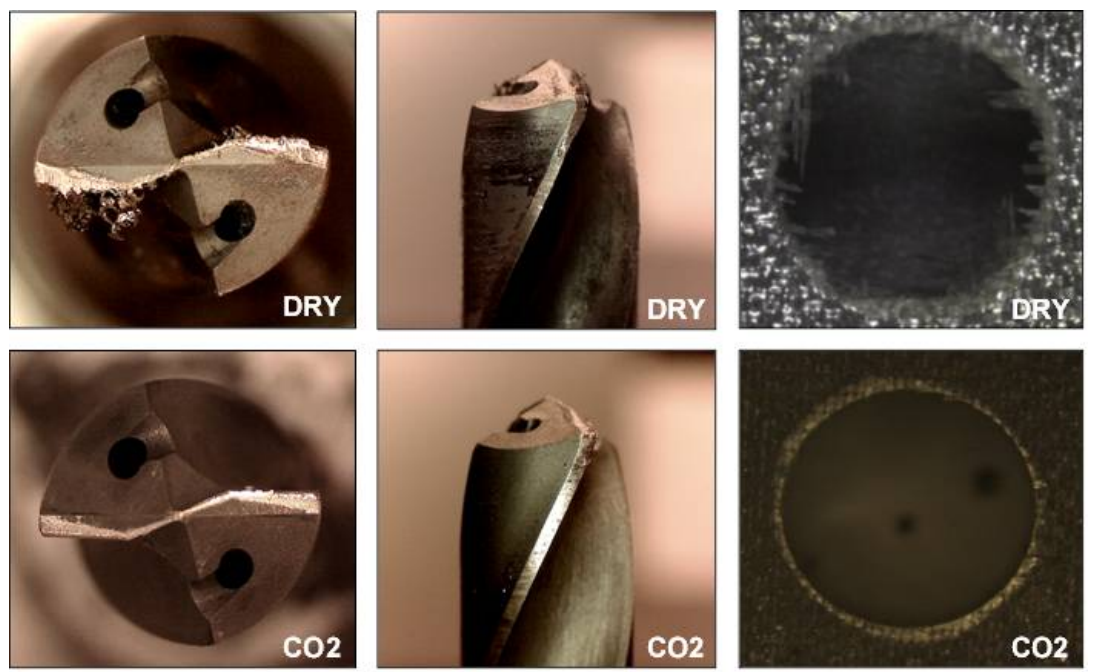

Figura 4.25: Estado de la herramienta y el CFRP tras el taladrado de 160 agujeros

\subsubsection{Discusión de los resultados - Ti6Al4V-CFRP}

De los resultados mostrados en esta sección referente al taladrado de stacks de Ti6Al4V-CFRP se derivan las siguientes conclusiones:

- La utilización de refrigeración interna con CO2 tiene un efecto positivo durante el taladrado de stacks de Ti6Al4V-CFRP. Concretamente, se alcanzan en los taladros realizados unos valores diametrales cercanos al valor nominal, particularmente en la zona de CFRP.

- Además, debido al control de la temperatura de corte, no se observan daños térmicos en el CFRP a la vez que no se produce la adhesión del Ti6Al4V al filo de la broca, incluso una vez llegado al criterio de parada de ensayo (160 taladros).

- Sin embargo, hay que tener en cuenta que al utilizar la refrigeración criogénica se genera un mayor consumo de potencia (asociado al par de la herramienta) debido al descenso de la temperatura de corte. Este efecto es producido principalmente durante el taladrado del CFRP. 


\subsection{Conclusiones}

En este capítulo se han expuesto los diferentes ensayos realizados en esta tesis con el fin de validar tanto la refrigeración criogénica como la tecnología CryoMQL en diferentes situaciones. Para ello se han aplicado estas tecnologías a operaciones de fresado, torneado y taladrado en diferentes entornos. Concretamente se han identificado diversos nichos de mercado en sectores estratégicos en el ámbito industrial como es el de la turbomaquinaria aeronáutica. Los materiales seleccionados para llevar a cabo los ensayos en todos los casos han sido materiales de difícil maquinabilidad con el fin de buscar los entornos más agresivos.

En el caso del torneado de AISI 304L se ha analizado tanto la vida de herramienta como la integridad superficial de la pieza en profundidad con el objetivo de observar el comportamiento de cada una de las alternativas de refrigeración/lubricación estudiadas. Gracias a ello se ha concluido que el uso de las tecnologías consideradas ecológicas no afectan a la integridad estructural de la pieza.

Posteriormente se ha aplicado la refrigeración criogénica con CO2 al torneado en duro de ASP23 (HSS-64HRc). Gracias a ello se logró un aumento de vida de herramienta de hasta el 69,5\% sin superar un espesor de capa blanca de $2 \mu \mathrm{m}$. Dado el alto coste que suponen los insertos en este tipo de operación supone una optimización considerable sin afectar a la resistencia a fatiga del componente mecanizado.

En cuanto a fresado se ha realizado el planeado de Inconel 718 en el cual se ha comparado la tecnología CryoMQL frente al uso de taladrina tradicional. Los resultados mostraron que tecnológicamente la taladrina es la mejor opción. Sin embargo, la utilización del CryoMQL presenta una vida de herramienta menor en un 6,5\%; no obstante, si se consideran otras ventajas, como la obtención de la viruta totalmente limpia, hace que su uso sea factible en un entorno industrial.

Por último se ha llevado a cabo la validación de la refrigeración criogénica en materiales compuestos durante el proceso de taladrado. En este caso se ha seleccionado el composite formado por stacks de CFRP-Ti6Al4V debido al gran uso que se hace de este material en las estructuras de las aeronaves actualmente. En este caso al utilizar $\mathrm{CO} 2$ no sólo se consigue un aumento de vida de herramienta sino que 
el diámetro nominal de los agujeros se mantiene constante a la vez que se evitan los quemados en la zona de CFRP. Por ello, esta tecnología se presenta como una alternativa con la cual abordar la problemática existente en cierto tipo de materiales compuestos donde la utilización de fluidos de corte líquidos se hace imposible.

En definitiva, desde un punto de vista tecnológico el uso de la refrigeración criogénica con CO2 así como la tecnlogía CryoMQL se presentan como alternativas aplicables en entornos industriales agresivos donde no sólo la integridad superficial de la pieza mecanizada es de vital importancia sino también la vida de herramienta juega un papel crucial para determinar la viabilidad del proceso. 

CAPÍTULO 5

Análisis de ciclo de vida 



\section{Análisis de ciclo de vida (ACV)}

\subsection{Introducción}

En el capítulo anterior se ha validado el uso de la refrigeración criogénica y su combinación con la lubricación MQL (CryoMQL) desde un punto de vista tecnológico. Sin embargo, se hace necesario cuantificar su huella ambiental con el fin de poder valorar de forma objetiva la sostenibilidad ecológica que se le presupone a estas tecnologías. Por ello, en el presente capítulo se pasará a validarlas desde un punto de vista medioambiental. Para ello se ha realizado un exhaustivo análisis de ciclo de vida $(\mathrm{ACV})$ en el cual se hace un estudio medioambiental de las principales técnicas de refrigeración/lubricación conocidas hasta la fecha. Concretamente se han analizado el mecanizado en seco; el mecanizado con emulsiones de aceite; la refrigeración criogénica con $\mathrm{CO} 2$ y LN2, respectivamente; la lubricación mediante MQL; y la combinación de estas dos últimas en modo CryoMQL. Para una mejor comprensión del capítulo, las tablas derivadas del análisis de inventario y la realización de la evaluación del impacto ambiental se han dispuesto en un anexo al final del presente capítulo.

\subsection{Definición y objetivo del alcance del ACV}

Para la realización de este ACV se han tenido en cuenta los principios de la norma ISO14040:2006 y se han seguido los requisitos y directrices dictados por la norma ISO14044:2006. Específicamente se ha comparado el mecanizado con emulsiones de aceite, el mecanizado criogénico (CO2 y LN2) y la lubricación mediante MQL. En el caso particular de la refrigeración/lubricación mediante CryoMQL al ser la combinación de la refrigeración criogénica y la lubricación mediante MQL, su impacto se ha calculado como la suma de los impactos ambientales de las dos 
tecnologías en modo "stand alone".

Este ACV es aplicado concretamente al proceso de torneado de acero inoxidable AISI 304L. La razón que ha llevado a realizar este ACV es poder analizar de forma cuantitativa el impacto ambiental que tiene cada una de las técnicas de refrigeración. Consecuentemente, los resultados obtenidos serán de utilidad a la hora de esclarecer las diferencias entre las distintas técnicas de refrigeración/lubricación.

El sistema bajo estudio es un torno CMZ modelo TC25BTY con una potencia instalada de $45 \mathrm{KVA}$ y $35 \mathrm{~kW}$ de potencia en el motor de plato. En este caso la función del sistema es tornear barras de acero AISI-304L con una velocidad de corte de $225 \mathrm{~m} / \mathrm{min}$ con una profundidad de pasada de $1,5 \mathrm{~mm}$, un avance de $0,25 \mathrm{~mm} / \mathrm{rev}$ y una longitud de corte de $150 \mathrm{~mm}$. En cada sistema analizado se ha utilizado una técnica de refrigeración/lubricación diferente para su posterior análisis y comparación.

La unidad funcional en este caso se ha considerado el volumen de viruta desalojado por barra mecanizada. Barra mecanizada es equivalente al cilindrado desde un diámetro inicial de $59 \mathrm{~mm}$ hasta un diámetro de $32 \mathrm{~mm}$ en una longitud de 150 $\mathrm{mm}$; por lo tanto el flujo de referencia son 290.094,67 $\mathrm{mm}^{3}$ de viruta desalojada.

Los limites del sistema son los mostrados en la Figura 5.1 para el mecanizado convencional con taladrina y para sus alternativas "near-to-dry", respectivamente. El criterio de selección de los procesos unitarios se ha basado en la importancia que tienen éstos en el propio mecanizado de la pieza y para que a su vez muestren de forma objetiva las diferencias entre la utilización de una técnica de refrigeración/lubricación y otra. Dentro de los límites del sistema se ha establecido la producción, uso y tratamiento, si fuese necesario, del fluido de corte utilizado para refrigerar/lubricar la herramienta durante el torneado; el consumo eléctrico utilizado durante el mecanizado por el torno; y la limpieza de las virutas de AISI-304L generadas. La razón de su selección es debida a que estos son los procesos que realmente marcan la diferencia entre las distintas tecnologías de lubricación/refrigeración en cuanto a sostenibilidad medioambiental se refiere.

Los procedimientos de asignación de cada proceso unitario del sistema, tanto dentro como fuera de sus límites, han sido establecidos según el origen de éste. 


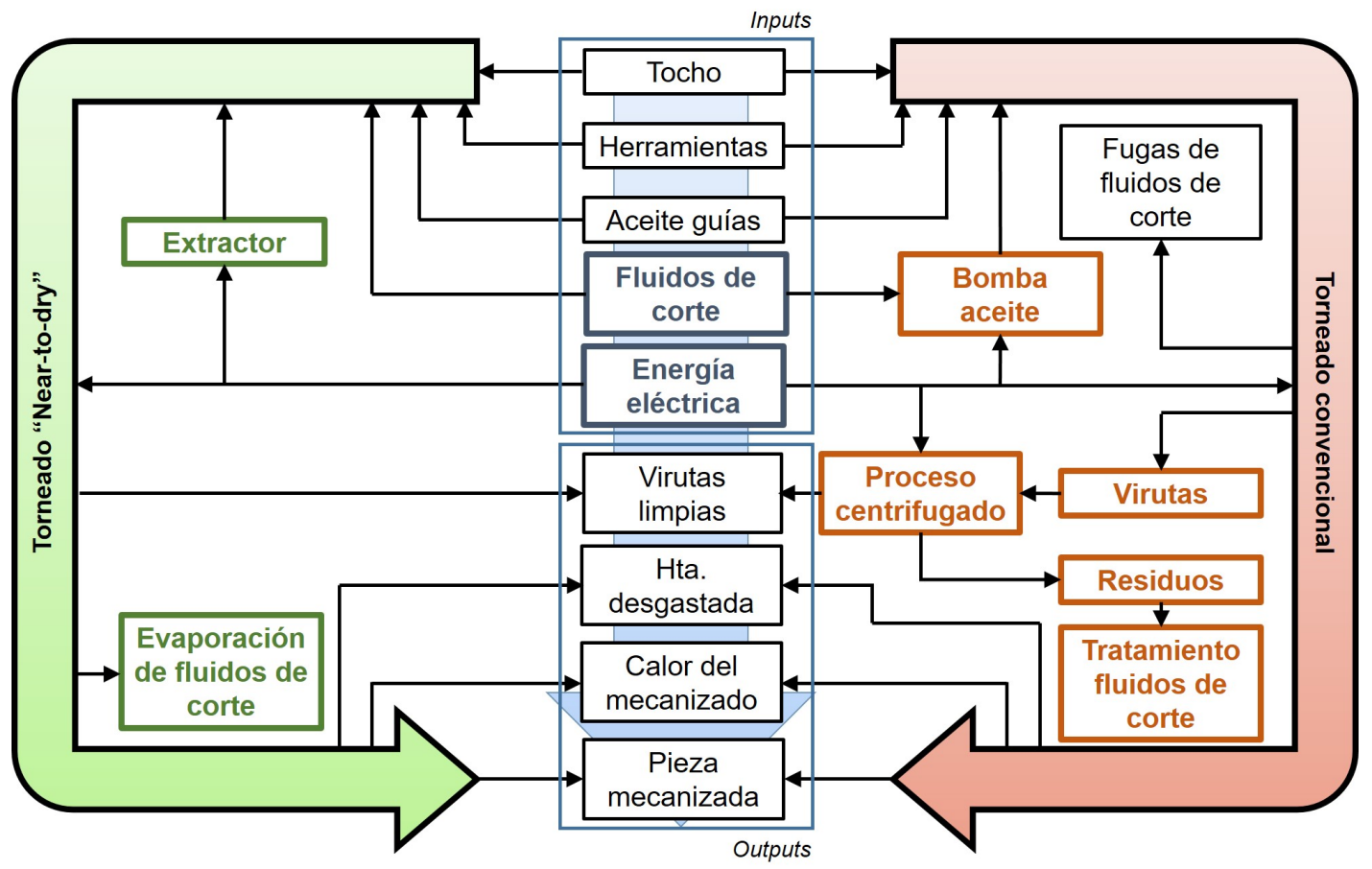

Figura 5.1: Límites del sistema

Por un lado se encuentran los de origen material como son el material a mecanizar, las herramientas, las piezas, las virutas y los fluidos de corte utilizados en cada sistema. Por otra parte se encuentra un proceso unitario de origen energético, que en este caso es la electricidad consumida por el torno. Y finalmente se han asignado aquellos de importancia medioambiental que no están englobados dentro de los dos procedimientos anteriores, es decir, el tratamiento posterior de los fluidos de corte, en caso de que sea necesario, y la limpieza de las virutas mecanizadas.

Aunque la selección de las categorías de impacto se ha basado en las propuestas por la norma ISO14047:2003 y de éstas se han seleccionado las que directamente están relacionadas con el proceso de torneado estudiado, para el análisis de estas categorías se ha utilizado la metodología de análisis de ciclo de vida $\boldsymbol{T R} \boldsymbol{A C I}$. Consecuentemente, los indicadores de resultados y los factores de caracterización seleccionados son los utilizados por esta metodología. Esta selección se debe a que con este método se hace mayor hincapié en la toxicidad humana frente a otras metodologías. En la Tabla 5.1 se pueden observar con detalle las categorías seleccionadas así como los indicadores de resultados y factores de caracterización.

Los datos obtenidos han sido interpretados, como se indicó anteriormente, de 


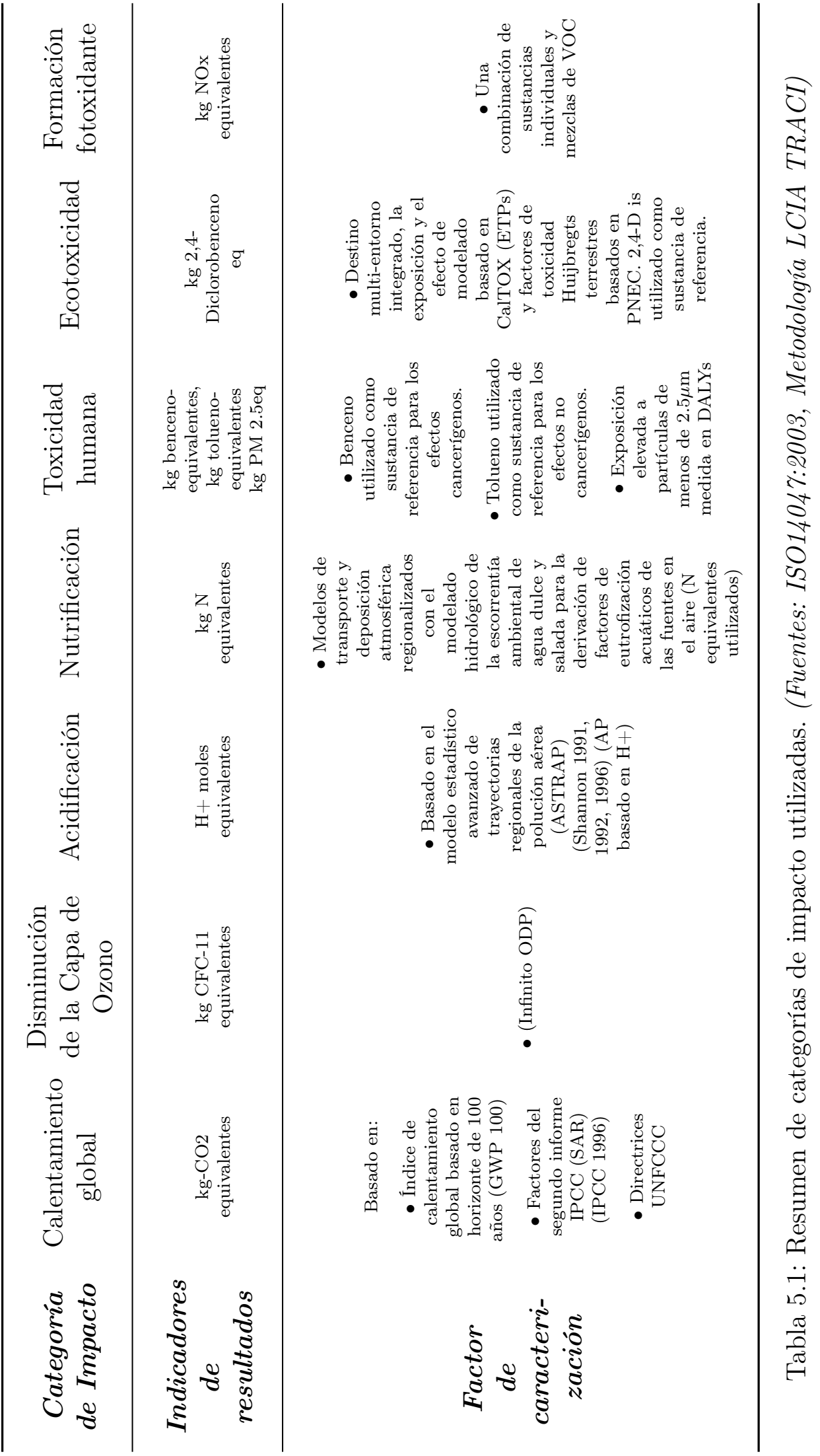


forma cuantitativa para la comparación del impacto ambiental entre las diferentes técnicas de refrigeración/lubricación estudiadas. El requisito principal en relación a la toma de datos es que deben ser tomados de forma directa cuando sea posible o en su lugar ser buscados en fuentes fidedignas con el fin de obtener unos valores apropiados para el estudio realizado. Consecuentemente, las suposiciones y requisitos de las que parte este ACV se basan principalmente en 6 puntos:

- En cuanto a herramientas se refiere, su desgaste al utilizar las diferentes técnicas de refrigeración/lubricación, al igual que hiciera [Pusavec et al., 2010], se ha considerado el mismo. En cuanto a su fabricación, basándose en [Fratila, 2010], se ha dejado fuera del ACV ya que a pesar de que generar sus recubrimientos tiene un alto impacto ambiental, éste es repartido a lo largo de toda su vida útil, lo que frente a los demás procesos unitarios es insignificante.

- En cuanto a las pérdidas de fluidos de corte sólo se han tenido en cuenta las pérdidas generadas por la utilización de taladrina. Esto es debido a que los refrigerantes criogénicos una vez inyectados en la zona de corte se evaporan sin causar residuo alguno y por otra parte, la cantidad de aceite utilizado en los sistemas MQL es ínfima además de ser biodegradables. En el caso de la taladrina, las pérdidas debidas a fugas, suciedad, procesos de limpieza, etc. sólo se han supuesto aquellas pérdidas debidas a su adhesión a las virutas evacuadas ya que las demás cantidades son ínfimas en comparación con ésta o incluso recuperables.

- Consecuentemente en cuanto al tratamiento de los fluidos de corte una vez terminada su vida útil sólo se han recogido los datos derivados del procesamiento de $1 \mathrm{~kg}$ de taladrina agotada. Hay que tener en cuenta que dependiendo de la región donde se genere el residuo su procesamiento es totalmente distinto (Fuentes consultadas: IHOBE, JCyL, Registro Estatal de Emisiones y Fuentes Contaminantes). Habitualmente lo que se hace una vez recibida la taladrina es ultrafiltrarla, someterla a osmosis inversa, diluirla y degradarla biológicamente para la eliminación de la materia orgánica existente. Finalmente, según el lugar donde sea procesada, se inertiza y se procede a su eliminación en un vertedero, o en otros casos se recicla y obtienen aceites base SN-80, hidrocarburos y naftas pesadas. Debido a esta diversidad, se ha optado por tomar los datos generalistas publicados por la Universidad de Chalmers. 
- En el caso del mecanizado con CO2 como refrigerante/lubricante, las emisiones derivadas de su propia inyección durante el torneado se consideran nulas debido a que éste es capturado de un proceso primario ya que si no se le diera este segundo uso sería vertido a la atmósfera como residuo. Por lo tanto, el vertido de un gas de efecto invernadero a la atmósfera no es producido directamente por el mecanizado, sino por el proceso primario. De este modo se mantiene el principio de "green machining" asociado a los procesos con refrigeración criogénica convencionales.

- El consumo energético ha sido analizado según el mix energético a nivel estatal ya que la electricidad proveniente de energías renovables tiene menor impacto ambiental que otras tecnologías convencionales y esta diferencia puede resultar significativa en el cómputo final al comparar una técnica de refrigeración/lubricación con el resto. Para saber el porcentaje proveniente de recursos renovables y no renovables se ha tenido en cuenta el informe anual de REE (Red Eléctrica Española) de 2013 en el que se refleja el origen de la energía consumida a nivel nacional.

- Como requisito general, los datos tomados de otras fuentes que no sean las propias no deben superar los 10 años de antigüedad y deben estar enmarcados dentro de los países de la Organización para la Cooperación y el Desarrollo Económicos (OCDE).

\subsection{Análisis de inventario (ICV)}

En esta fase se han recopilado tanto los datos cualitativos como cuantitativos para cada proceso unitario incluido dentro de los límites del sistema, el cálculo de los resultados derivados del mecanizado con cada técnica de refrigeración/lubricación, la validación de dichos resultados generados así como el ajuste de los límites del sistema en caso de ser necesario.

En las Tablas 5.2, 5.3, 5.4, 5.5, 5.6 se muestran los datos recopilados de las diferentes fuentes consultadas por la formación de un kilogramo de cada uno de los fluidos de corte utilizados para refrigerar/lubricar respectivamente.

En cuanto al tratamiento de los fluidos de corte una vez terminada su vida útil 
sólo se han recogido los datos derivados del tratamiento de $1 \mathrm{~kg}$ de taladrina agotada en la Tabla 5.7. Hay que destacar que los datos mostrados en dicha tabla son los referentes al propio proceso de tratamiento de $1 \mathrm{~kg}$ de taladrina agotada dejando fuera del análisis la posterior gestión de los residuos derivados del tratamiento.

Para la limpieza de viruta se ha tomado una centrifugadora HSZ650 de la compañía "Liquid Filter". Aunque esta centrifugadora es utilizada en los centros de reciclaje para la limpieza de la viruta, también es cierto que ya hay empresas que la incluyen en sus instalaciones con el fin de aumentar el beneficio económico resultante de la venta de viruta limpia a dichas plantas de reciclaje; por tanto se tiene en cuenta su consumo energético dentro del sistema en estudio. Dicha centrifugadora está dotada de una potencia de $4 \mathrm{~kW}$ y tiene una capacidad de secado de viruta de acero de $300-650 \mathrm{~kg} / \mathrm{h}$ dejando una humedad relativa del 1-4\%. Una vez limpia la viruta es almacenada para su posterior reciclaje y la taladrina rescatada se introduce en depósitos para su posterior eliminación. La estimación realizada empíricamente es que la taladrina perdida se sitúa en el 7,6\% del peso de viruta mecanizada, es decir, en el flujo de referencia tomado para este estudio se pierden 174,147 gramos de taladrina por cada barra mecanizada. En el caso de utilizar la refrigeración criogénica o el sistema de MQL como técnica de refrigeración/lubricación, la centrifugadora encargada de eliminar las virutas el fluido de corte adherido se hace innecesaria, ya que éstas salen completamente limpias. En cambio, sí se necesita a pie de máquina un ciclón que absorba y filtre la niebla flotante generada por el aerosol inyectado en la zona de corte y en caso de mecanizar criogénicamente que extraiga los gases criogénicos del interior del torno. El ciclón utilizado en este estudio es de la compañía "Filtermist", modelo FX3000. Dicho ciclón tiene una potencia de 0,55 kW y filtra un caudal de $800 \mathrm{~m}^{3} / \mathrm{h}$.

Durante el mecanizado se ha medido el consumo de los 3 motores del torno utilizados (Cabezal, Eje X y Eje Z) y el consumo de la bomba de taladrina o ciclón en función de la técnica de refrigeración/lubricación utilizada con el fin de resaltar las diferencias entre éstas. En la Tabla 5.8 se adjuntan los resultados obtenidos.

Para el cálculo del impacto ambiental producido por la energía eléctrica consumida, como se ha indicado anteriormente, se ha tenido en cuenta el método de producción energética basado en los informes anuales de REE (Red Eléctrica Espa- 
ñola). En concreto, se ha utilizado el informe de 2013 (el más reciente) cuyos datos del mix energético a nivel estatal se reflejan en la Tabla 5.9. A partir de ellos se ha obtenido el impacto ambiental generado para producir un kilovatio, cuyos resultados se muestran en la Tabla 5.10.

\subsection{Evaluación del impacto ambiental}

Una vez inventariados todos los datos necesarios para llevar a buen término el $\mathrm{ACV}$, se ha procedido a la evaluación del impacto ambiental generado por el mecanizado con cada una de las diferentes técnicas de refrigeración/lubricación estudiadas. Para ello, de los datos inventariados se han seleccionado aquellos que están validados y son útiles para aplicar la metodología de análisis de ciclo de vida TRACI. Como se ha indicado en el apartado anterior, las categorías de impacto son seleccionadas en base a la norma ISO 14047:2003 teniendo en cuenta el objetivo y el alcance de este análisis de vida. Los factores de caracterización son los mostrados anteriormente en la Tabla 5.1.

Los datos utilizados en cuanto al impacto ambiental producido por las entradas al sistema sometido a estudio están resumidos en la Tabla 5.11. Por otra parte, a partir de los tiempos de mecanizado y potencias obtenidas en los ensayos realizados se ha calculado la energía consumida durante el mecanizado con las diferentes técnicas de refrigeración/lubricación. Los resultados obtenidos en este paso están expuestos en las Tablas 5.12 y 5.13, respectivamente.

Una vez se cuantificó la energía eléctrica consumida durante el mecanizado con las diferentes técnicas de refrigeración/lubricación, se procedió al cálculo del impacto ambiental derivado de dichos consumos. Los resultados obtenidos se reflejan en la Tabla 5.14.

Una vez calculado el impacto ambiental debido al consumo energético, se ha abordado el cálculo de los consumos de fluidos de corte utilizados con todas las técnicas de refrigeración estudiadas. Para ello se han medido los caudales de los fluidos de corte utilizados durante el mecanizado como se puede observar en la Tabla 5.15, con la excepción de la taladrina. En el caso de utilizar taladrina, debido a que está 
en constante recirculación, para poder relacionar el consumo asociado de ésta al flujo de referencia bajo estudio se tuvo en cuenta su vida útil así como las pérdidas derivadas de su arrastre con la viruta. Además, se ha tenido en consideración que la taladrina es una emulsión acuosa formada por un $20 \%$ de aceite mineral con el fin de calcular correctamente su impacto en su proceso de fabricación. La vida útil de la taladrina se estimó en 2016 horas, es decir, 2 turnos de trabajo de 8 horas durante 126 días (6 meses). Todos los resultados calculados respecto a la utilización de la taladrina se han plasmado en la Tabla 5.16. Una vez obtenidas todas las cantidades de fluidos de corte utilizados en función del flujo de referencia, se ha procedido al cálculo del impacto ambiental derivado de sus procesos de producción y tratamiento posterior, en caso de que sea necesario, como se muestran en la Tabla 5.17.

Por último, con los resultados generados se procede al cálculo total del impacto ambiental generado por cada fluido de corte desde su producción, pasando por su utilización, hasta su eliminación en función del flujo de referencia. Los resultados generados se pueden observar en la Tabla 5.18.

\subsection{Interpretación del ciclo de vida (ICV)}

Con los resultados generados en la evaluación del impacto ambiental, como se puede observar en la Figura 5.2, se ha elaborado un diagrama de red con el fin de tener una visión general del impacto ambiental generado por cada una de las técnicas de refrigeración/lubricación estudiadas.

A la luz de los resultados obtenidos, desde un punto de vista medioambiental se aprecia como las alternativas al uso de taladrina se agrupan en 3 parejas de similar huella ambiental. La pareja medioambientalmente más eficiente fue el mecanizado en seco junto con el sistema MQL; seguida por el mecanizado criogénico con LN2 o CO2; y finalmente, la combinación de la criogenia con el sistema MQL mediante CryoMQL con LN2 y CO2, respectivamente.

Concretamente, en la primera pareja, las pequeñas diferencias se encontraron en que al mecanizar en seco hay un consumo mayor de energía durante el mecanizado lo que provoca un aumento del vertido de kilogramos de tolueno equivalentes (kg tolueno-eq) en un 8.3\%. En cambio, derivado de la producción de los aceites 


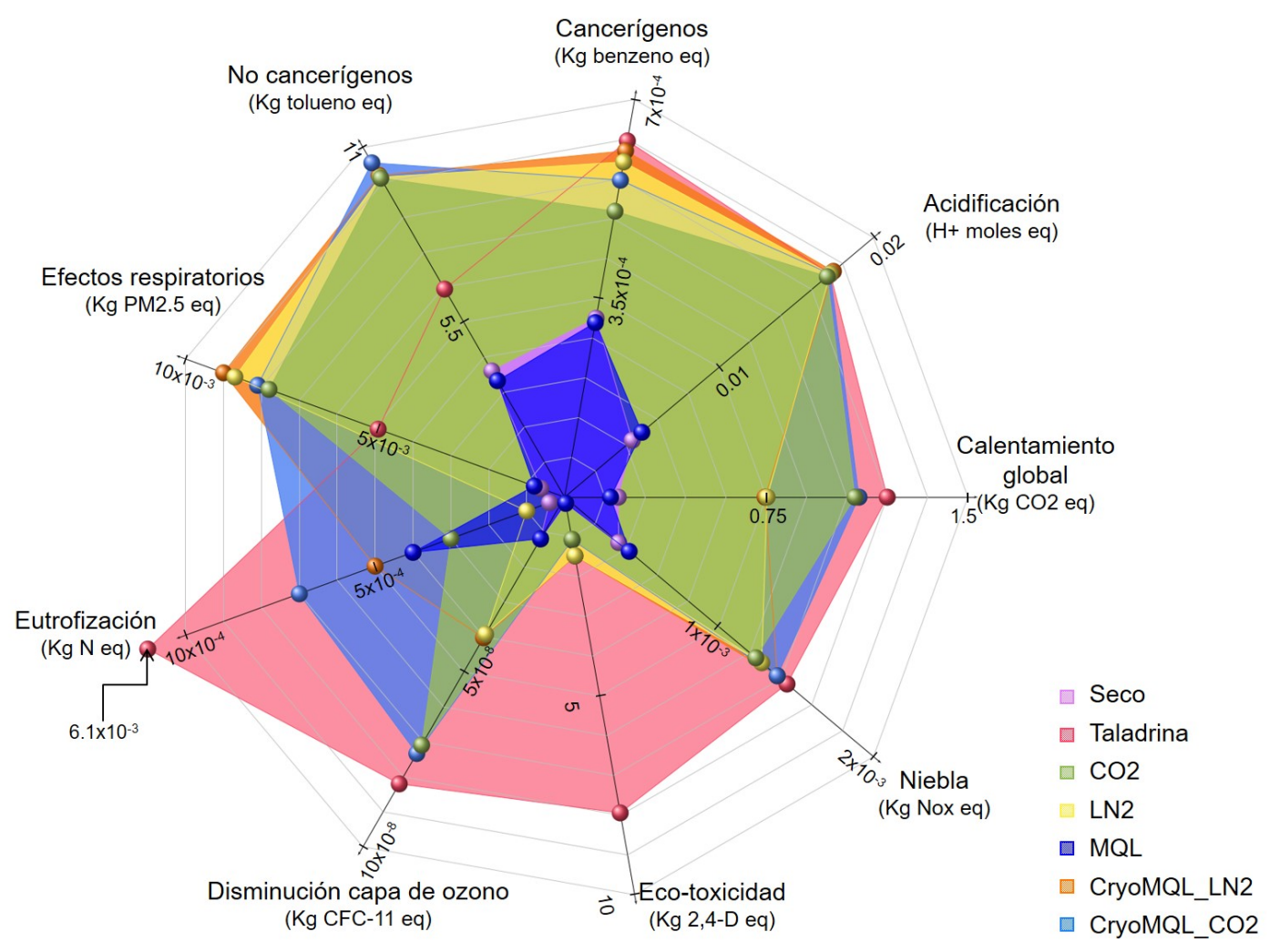

Figura 5.2: Diagrama de red resultados ACV

biodegradables, se obtuvo 8 veces más de kilogramos de nitrógeno equivalente (kg N-eq) al mecanizar con el sistema MQL. Cabe destacar también que gracias a que los aceites utilizados por los sistemas MQL son de origen vegetal, en este caso de colza, el indicador de calentamiento global en cuanto a su producción es negativo lo que provoca un vertido menor de kilogramos de $\mathrm{CO} 2$ equivalente (kg CO2-eq) al mecanizar con dicha tecnología frente al mecanizado en seco.

En cuanto al mecanizado criogénico se refiere, la diferencia entre la huella ambiental producida por el LN2 y CO2 viene dada principalmente por los procesos de obtención de éstos más que por su utilización durante el mecanizado donde la energía consumida fue similar. La máxima divergencia se ha obtenido en los indicadores de calentamiento global, cancerígenos, efectos respiratorios y disminución de la capa de ozono. En concreto, el CO2 provocó menos kilogramos de benceno equivalentes ( $\mathrm{kg}$ benceno-eq) que el LN2 en un $17 \%$ y un $11 \%$ en kilogramos de partículas menores a 2,5 micrómetros (kg PM 2.5-eq). Por contrapartida, debido mayormente al proceso 
de licuación del LN2 se observa cómo se ha vertido un $43 \%$ menos de $\mathrm{kg}$ CO2-eq a la atmósfera y que es más eficiente en cuanto a vertido de kilogramos de CFC-11 equivalentes (kg CFC-11-eq) en un $55 \%$.

En el uso de las tecnologías CryoMQL desde un punto vista medioambiental la utilización de CO2 o LN2 como líquido refrigerante presenta unas similitudes análogas al uso de estos gases en la refrigeración criogénica antes expuesta. Esto es debido a dos factores. El primero es que el impacto ambiental procedente de la producción de los fluidos de corte utilizados es la suma de los distintos indicadores de la producción de aceite biodegradable y el respectivo gas criogénico. El segundo se debe a que el impacto ambiental producido por la energía consumida durante la inyección de la tecnología CryoMQL con CO2 o LN2 también ha sido semejante.

Por último, con respecto a la taladrina se observa cómo fue la más ineficiente de todas las técnicas objeto de este estudio. Si se analizan los indicadores individualmente es cierto que en cuanto a efectos respiratorios y no cancerígenos es inferior que otras tecnologías de refrigeración/lubricación, lo que es importante desde un punto de vista de toxicidad humana, pero por contrapartida la ecotoxicidad generada y eutrofización aumentó en un $633 \%$ y $760 \%$, respectivamente, que unido a los demás marcadores en los que también resultó ser la más ineficiente, hacen de la taladrina una técnica de refrigeración/lubricación a evitar desde el punto de vista medioambiental.

\subsection{Conclusiones}

Con este capítulo se ha pretendido analizar el impacto ambiental generado por las principales técnicas de refrigeración/lubricación utilizadas en el ámbito industrial. Para ello se ha realizado un ACV del que cabe destacar que frente a los realizados hasta la fecha por otros autores amplía considerablemente los límites del sistema estudiado. En este análisis se ha recopilado información desde la producción de cada uno de los fluidos de corte, pasando por su propia utilización, hasta su tratamiento una vez acabada su vida útil. Además se ha tenido en cuenta el origen de la energía consumida durante el mecanizado. Esto se traduce en una minuciosa aproximación al impacto ambiental real generado por cada una de las técnicas de 
refrigeración/lubricación. A partir de él se ha observado cómo el MQL es la tecnología que medioambientalmente es más sostenible junto con el mecanizado en seco. En cuanto a la refrigeración criogénica y la tecnología CryoMQL los resultados son bastante similares. Finalmente, se ha cuantificado de forma objetiva la insalubridad presentada por la taladrina donde la eutrofización y ecotoxicidad alcanzan valores superiores en un $760 \%$ y $633 \%$, respectivamente.

Por todo ello, y teniendo en cuenta que se debe alcanzar un compromiso entre la viabilidad tecnológica y medioambiental durante los procesos de mecanizado, es necesario combinar estos resultados con los obtenidos de los ensayos realizados en el capítulo anterior. A raíz de ello, se concluye que en función del proceso de mecanizado realizado tanto la refrigeración criogénica como la tecnología CryoMQL en las que se utiliza el CO2 como fluido de corte presentan un equilibrio entre ambas cuestiones. 


\subsection{Anexo}

\begin{tabular}{ccccc}
\hline $\begin{array}{c}\text { Categoría de } \\
\text { Impacto }\end{array}$ & $\begin{array}{c}\text { Unidades de } \\
\text { impacto }\end{array}$ & $\begin{array}{c}\text { Aceite } \\
\text { mineral }\end{array}$ & $\begin{array}{c}\text { Sulfatantes } \\
\text { aniónicos }\end{array}$ & $\begin{array}{c}\text { Sulfatantes } \\
\text { no aniónicos }\end{array}$ \\
\hline $\begin{array}{c}\text { Energía } \\
\text { utilizada }\end{array}$ & MJ & 5,94 & 60,20 & 51,50 \\
$\begin{array}{c}\text { Calentamiento } \\
\text { global }\end{array}$ & $\mathrm{kg} \mathrm{CO} 2$-eq & 3,56 & 3,00 & 5,60 \\
$\begin{array}{c}\text { Acidificación } \\
\text { Uso del agua }\end{array}$ & $\mathrm{kg} \mathrm{SO}-\mathrm{eq}$ & 3,83 & 25,00 & 15,80 \\
Residuos sólidos & $\mathrm{kg}$ & 0,00 & 6,00 & 0,00 \\
\hline
\end{tabular}

Tabla 5.2: Datos recopilados por la formación de $1 \mathrm{~kg}$ de taladrina.

[Pusavec et al., 2010]

\begin{tabular}{ccc}
\hline Categoría de Impacto & Unidades de impacto & Nitrógeno Líquido \\
\hline Energía utilizada & MJ & 1,80 \\
Calentamiento global & $\mathrm{kg} \mathrm{CO} 2-\mathrm{eq}$ & 0,00 \\
Acidificación & $\mathrm{kg} \mathrm{SO} 2-\mathrm{eq}$ & 0,00 \\
Uso del agua & $\mathrm{kg}$ & 50,00 \\
Residuos sólidos & $\mathrm{kg}$ & 0,00 \\
\hline
\end{tabular}

Tabla 5.3: Datos recopilados por la formación de $1 \mathrm{~kg}$ de LN2 [Pusavec et al., 2010] 


\begin{tabular}{|c|c|c|c|c|}
\hline $\begin{array}{l}\text { Categoría de } \\
\text { Impacto }\end{array}$ & $\begin{array}{l}\text { Unidades de } \\
\text { impacto }\end{array}$ & $\begin{array}{l}\text { Aceite de } \\
\text { colza }\end{array}$ & $\begin{array}{l}\text { Aceite de } \\
\text { soja }\end{array}$ & $\begin{array}{l}\text { Aceite } \\
\text { mineral }\end{array}$ \\
\hline $\begin{array}{c}\text { Calentamiento } \\
\text { global }\end{array}$ & $\mathrm{kg} \mathrm{CO} 2-\mathrm{eq}$ & $-0,36$ & $-1,65$ & 1,07 \\
\hline Acidificación & $\mathrm{H}+$ moles-eq & 2,70 & 0,20 & 0,46 \\
\hline Cancerígenos & $\begin{array}{c}\mathrm{kg} \\
\text { benceno-eq }\end{array}$ & 0,006 & 0,001 & 0,003 \\
\hline No cancerígenos & $\mathrm{kg}$ tolueno-eq & 33,4 & 3,3 & 14,3 \\
\hline $\begin{array}{l}\text { Efectos } \\
\text { respiratorios }\end{array}$ & $\mathrm{kg}$ PM 2,5 eq & 0,005 & 0,001 & 0,002 \\
\hline Eutrofización & $\operatorname{kg~N-eq~}$ & 0,076 & 0,029 & 0,002 \\
\hline Capa de Ozono & kg CFC-11-eq & $2,8 \cdot 10^{-7}$ & $4,7 \cdot 10^{-8}$ & $6,5 \cdot 10^{-7}$ \\
\hline Ecotoxicidad & $\begin{array}{c}\operatorname{kg} 2,4- \\
\text { Diclorobenceno } \\
\text { eq }\end{array}$ & 1,78 & $-2,08$ & 1,22 \\
\hline $\begin{array}{l}\text { Niebla } \\
\text { fotoquímica }\end{array}$ & kg NOx eq & 0,023 & 0,004 & 0,003 \\
\hline
\end{tabular}

Tabla 5.4: Datos recopilados por la formación de $1 \mathrm{~kg}$ de diferentes aceites [Bart et al., 2013]

\begin{tabular}{cccc}
$\begin{array}{c}\text { Categoría de } \\
\text { Impacto }\end{array}$ & $\begin{array}{c}\text { Unidades de } \\
\text { impacto }\end{array}$ & $\begin{array}{c}\text { Nitrógeno } \\
\text { líquido }\end{array}$ & $\begin{array}{c}\text { Dióxido de } \\
\text { Carbono líquido }\end{array}$ \\
\hline $\begin{array}{c}\text { Calentamiento } \\
\text { global }\end{array}$ & $\mathrm{kg} \mathrm{CO} 2-\mathrm{eq}$ & 0,431 & 0,816 \\
$\begin{array}{c}\text { Acidificación } \\
\text { Cancerígenos }\end{array}$ & $\mathrm{H}+$ moles-eq & 0,101 & 0,106 \\
No cancerígenos & $\mathrm{kg}$ benceno-eq & 0,000226 & 0,000221 \\
Efectos & $\mathrm{kg}$ tolueno-eq & 4,86 & 6,07 \\
respiratorios & $\mathrm{kg} \mathrm{PM} \mathrm{2,5} \mathrm{eq}$ & 0,000623 & 0,000653 \\
Eutrofización & $\mathrm{kg} \mathrm{N}-\mathrm{eq}$ & $7,15 \cdot 10^{-5}$ & 0,00027 \\
Capa de Ozono & $\mathrm{kg} \mathrm{CFC-11-eq}$ & $2,13 \cdot 10^{-8}$ & $5,45 \cdot 10^{-8}$ \\
Ecotoxicidad & $\mathrm{kg} \mathrm{2,4-}$ & 1,01 & 0,828 \\
& Diclorobenceno & & 0,00085 \\
\hline
\end{tabular}

Tabla 5.5: Datos derivados de la formación de $1 \mathrm{~kg}$ de gases criogénicos licuados 


\begin{tabular}{cccc}
\hline $\begin{array}{c}\text { Categoría de } \\
\text { Impacto }\end{array}$ & $\begin{array}{c}\text { Unidades de } \\
\text { impacto }\end{array}$ & Aceite de colza & Aceite mineral \\
\hline Calentamiento & $\mathrm{kg} \mathrm{CO} 2$-eq & 0,3 & 3,56 \\
Global & $\mathrm{kg} \mathrm{CFC11}$ & $4.25 \cdot 10^{-10}$ & $8,9 \cdot 10^{-12}$ \\
Capa de Ozono & $\mathrm{kg} \mathrm{SO} 4$ & 0,00327 & 0,00383 \\
Acidificación & $\mathrm{kg} \mathrm{PO} 4$ & 0,00102 & 0,000378 \\
Eutrofización & $\mathrm{kg} \mathrm{Pb}$ & $3,75 \cdot 10^{-7}$ & $5,02 \cdot 10^{-7}$ \\
Metales Pesados & $\mathrm{kg} \mathrm{B}(\mathrm{a}) \mathrm{P}$ & $6,52 \cdot 10^{-11}$ & $1,62 \cdot 10^{-12}$ \\
Cancerígenos & $\mathrm{kg} \mathrm{SPM}$ & 0,000976 & 0,0018 \\
Niebla invernal & $\mathrm{kg} \mathrm{C} 2 \mathrm{H} 4$ & 0,000479 & $1,61 \cdot 10^{-8}$ \\
Niebla estival & $\mathrm{kg} \mathrm{act.s}$ & $1,43 \cdot 10^{-5}$ & 0,00 \\
Pesticidas & $\mathrm{MJ} \mathrm{LHV}$ & 6,18 & 5,94 \\
Energía & $\mathrm{kg}$ & 0,00773 & 0,00519 \\
Residuo sólidos & & & \\
\hline
\end{tabular}

Tabla 5.6: Datos recopilados por la formación de $1 \mathrm{~kg}$ de diferentes aceites [McManus, 2011]

\begin{tabular}{ccc}
\hline Categoría de Impacto & Unidades de impacto & $\begin{array}{c}\text { Tratamiento de 1 kg } \\
\text { de taladrina agotada }\end{array}$ \\
\hline Calentamiento global & $\mathrm{kg}$ CO2-eq & 4,52 \\
Acidificación & $\mathrm{H}+$ moles-eq & 0,602 \\
Cancerígenos & $\mathrm{kg}$ benceno-eq & 0,0011 \\
No cancerígenos & $\mathrm{kg}$ tolueno-eq & 11,5 \\
Efectos respiratorios & $\mathrm{kg}$ PM 2,5 eq & 0,00185 \\
Eutrofización & $\mathrm{kg}$ N-eq & 0,031148 \\
Capa de Ozono & $\mathrm{kg}$ CFC-11-eq & $2,37 \cdot 10^{-7}$ \\
Ecotoxicidad & $\mathrm{kg} 2,4$-Diclorobenceno eq & 40,23 \\
Niebla fotoquímica & $\mathrm{kg}$ NOx eq & 0,00519 \\
\hline
\end{tabular}

Tabla 5.7: Datos derivados del tratamiento de $1 \mathrm{~kg}$ de taladrina agotada 


\begin{tabular}{ccccc}
\hline $\begin{array}{c}\text { Técnica } \\
\text { utilizada }\end{array}$ & $\begin{array}{c}\text { Cabezal } \\
(\mathrm{kW})\end{array}$ & $\begin{array}{c}\text { Eje X } \\
(\mathrm{kW})\end{array}$ & $\begin{array}{c}\text { Eje Z } \\
(\mathrm{kW})\end{array}$ & $\begin{array}{c}\text { Bomba taladrina - } \\
\text { Centrifugadora virutas } \\
\text { Filtro de aire }(\mathrm{kW})\end{array}$ \\
\hline $\begin{array}{c}\text { Seco } \\
\text { Taladrina }\end{array}$ & 5,04 & 0,114 & 0,088 & \\
MQL & 3,669 & 0,126 & 0,095 & 1,1 \\
CO2 & 3,874 & 0,134 & 0,1 & 0,55 \\
LN2 & 3,522 & 0,122 & 0,091 & 0,55 \\
$\begin{array}{c}\text { CryoMQL } \\
\text { (CO2) }\end{array}$ & 3,136 & 0,142 & 0,107 & 0,55 \\
$\begin{array}{c}\text { CryoMQL } \\
(\mathrm{LN2})\end{array}$ & 3,935 & 0,136 & 0,102 & 0,55 \\
\hline
\end{tabular}

Tabla 5.8: Consumos medios eléctricos registrados durante el mecanizado

\begin{tabular}{cc}
\hline Tecnología de generación eléctrica & Porcentaje \\
\hline Ciclo combinado & $9,5 \%$ \\
Carbón & $14,6 \%$ \\
Nuclear & $21,2 \%$ \\
Hidráulica & $14,2 \%$ \\
Eólica & $21,2 \%$ \\
Solar fotovoltaica & $3,1 \%$ \\
Solar termoeléctrica & $1,7 \%$ \\
Térmica renovable & $2,0 \%$ \\
Cogeneración y resto (incluye térmica no renovable y & $12,5 \%$ \\
\hline
\end{tabular}

Tabla 5.9: Porcentaje de mix energético a nivel nacional [REE, 2013] 


\begin{tabular}{ccc}
\hline Categoría de Impacto & Unidades de impacto & $\begin{array}{c}\text { Generación de 1 kW } \\
\text { según el mix energético } \\
\text { estatal }\end{array}$ \\
\hline Calentamiento global & $\mathrm{kg} \mathrm{CO}$-eq & 0,632 \\
Acidificación & $\mathrm{H}+$ moles-eq & 0,137 \\
Cancerígenos & $\mathrm{kg}$ benceno-eq & 0,000984 \\
No cancerígenos & $\mathrm{kg}$ tolueno-eq & 12,4 \\
Efectos respiratorios & $\mathrm{kg}$ PM 2,5 eq & 0,000196 \\
Eutrofización & $\mathrm{kg}$ N-eq & 0,00014 \\
Capa de Ozono & $\mathrm{kg}$ CFC-11-eq & $3,77 \cdot 10^{-8}$ \\
Ecotoxicidad & $\mathrm{kg} 2,4$-Diclorobenceno eq & 0,507 \\
Niebla fotoquímica & $\mathrm{kg}$ NOx eq & 0,00109 \\
\hline
\end{tabular}

Tabla 5.10: Datos derivados de la generación de 1 kW de energía eléctrica 


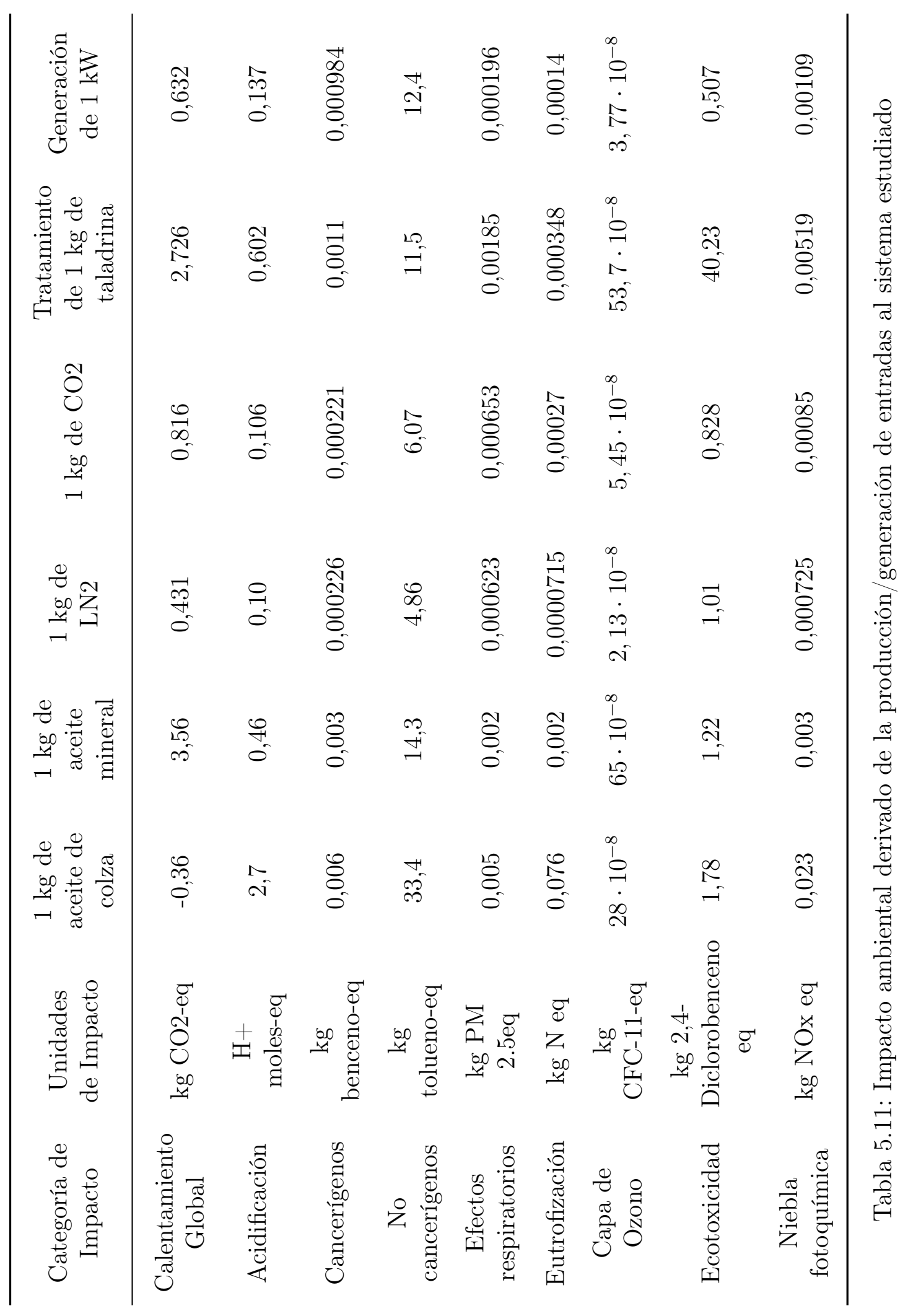




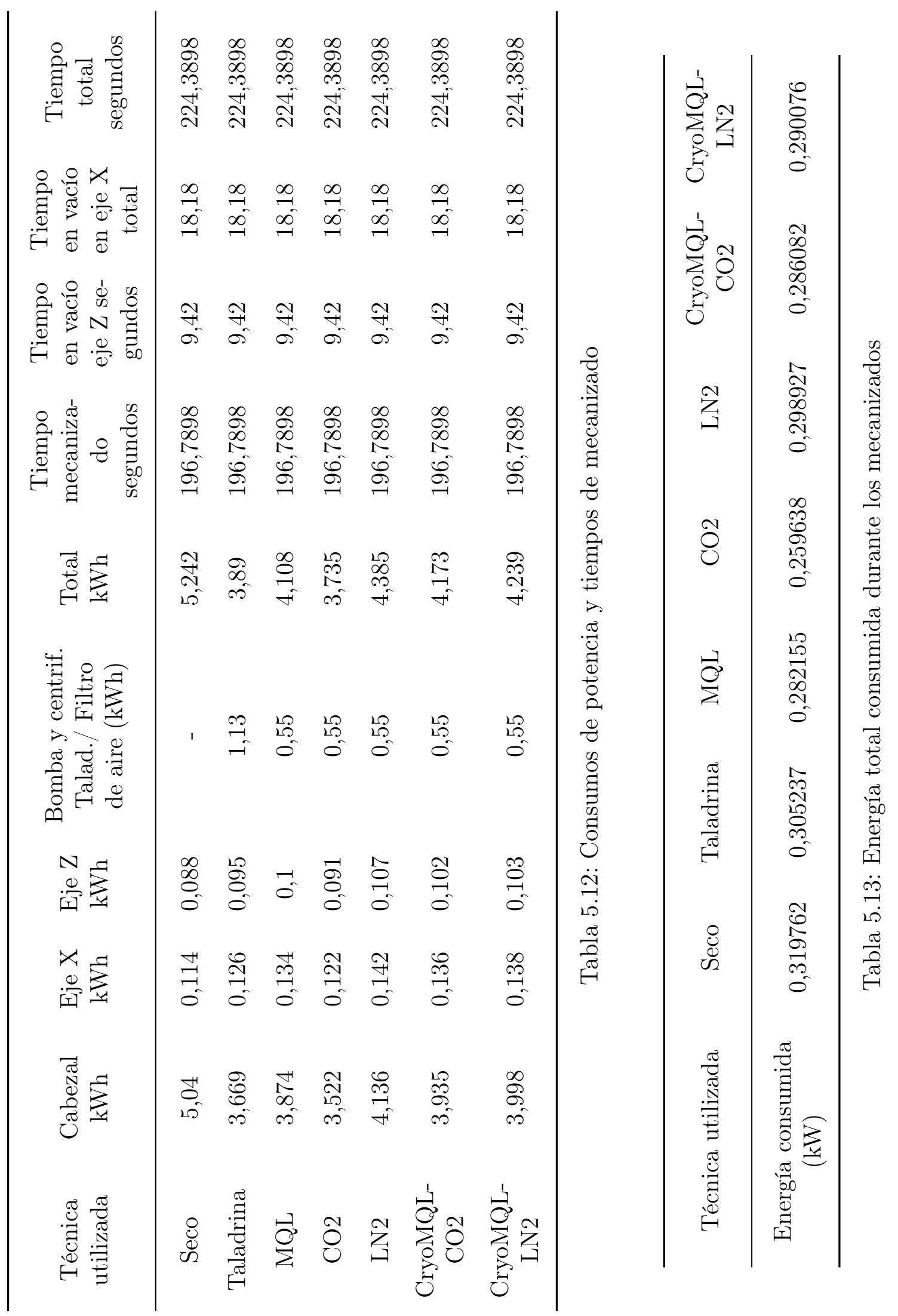




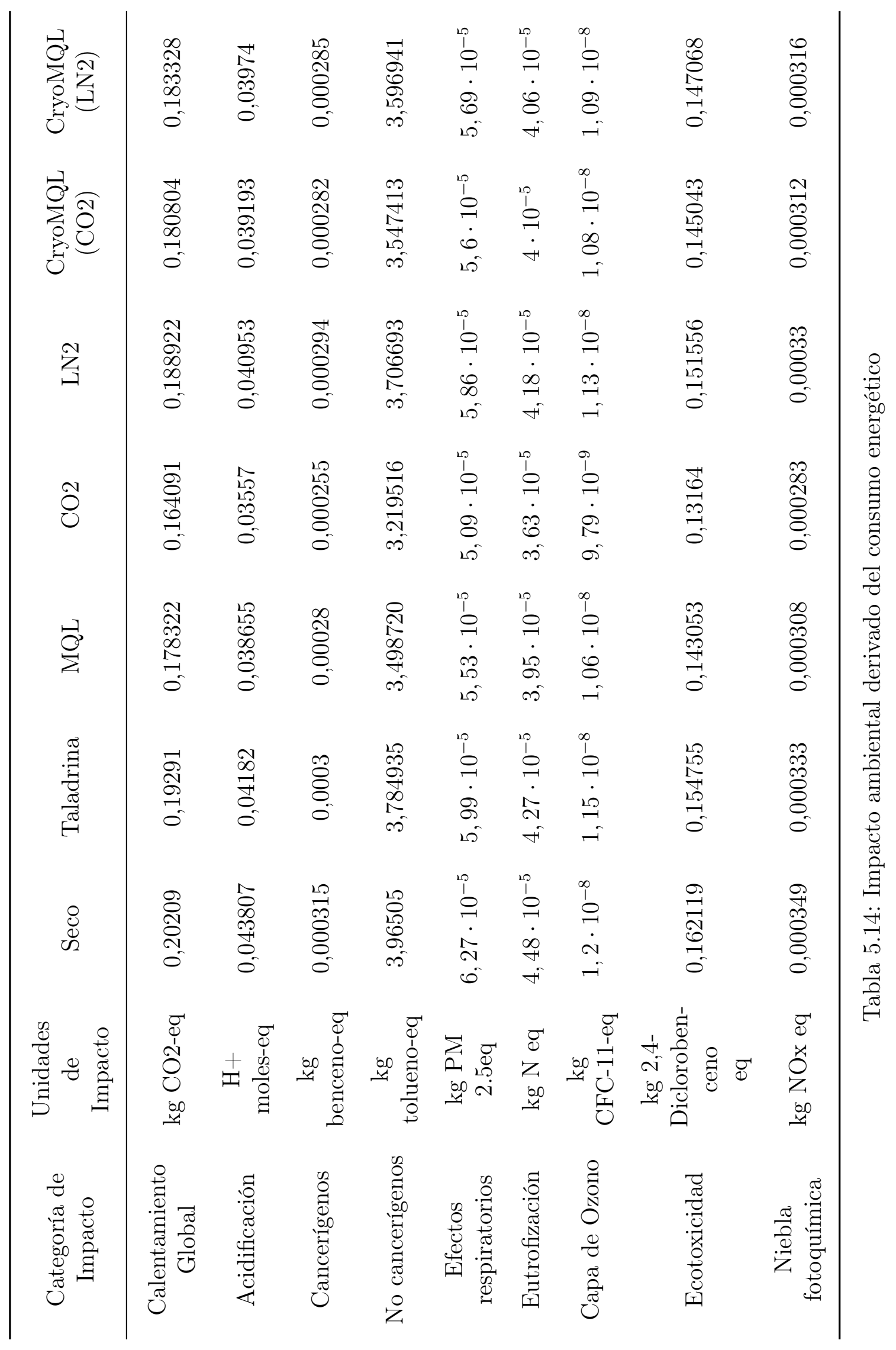




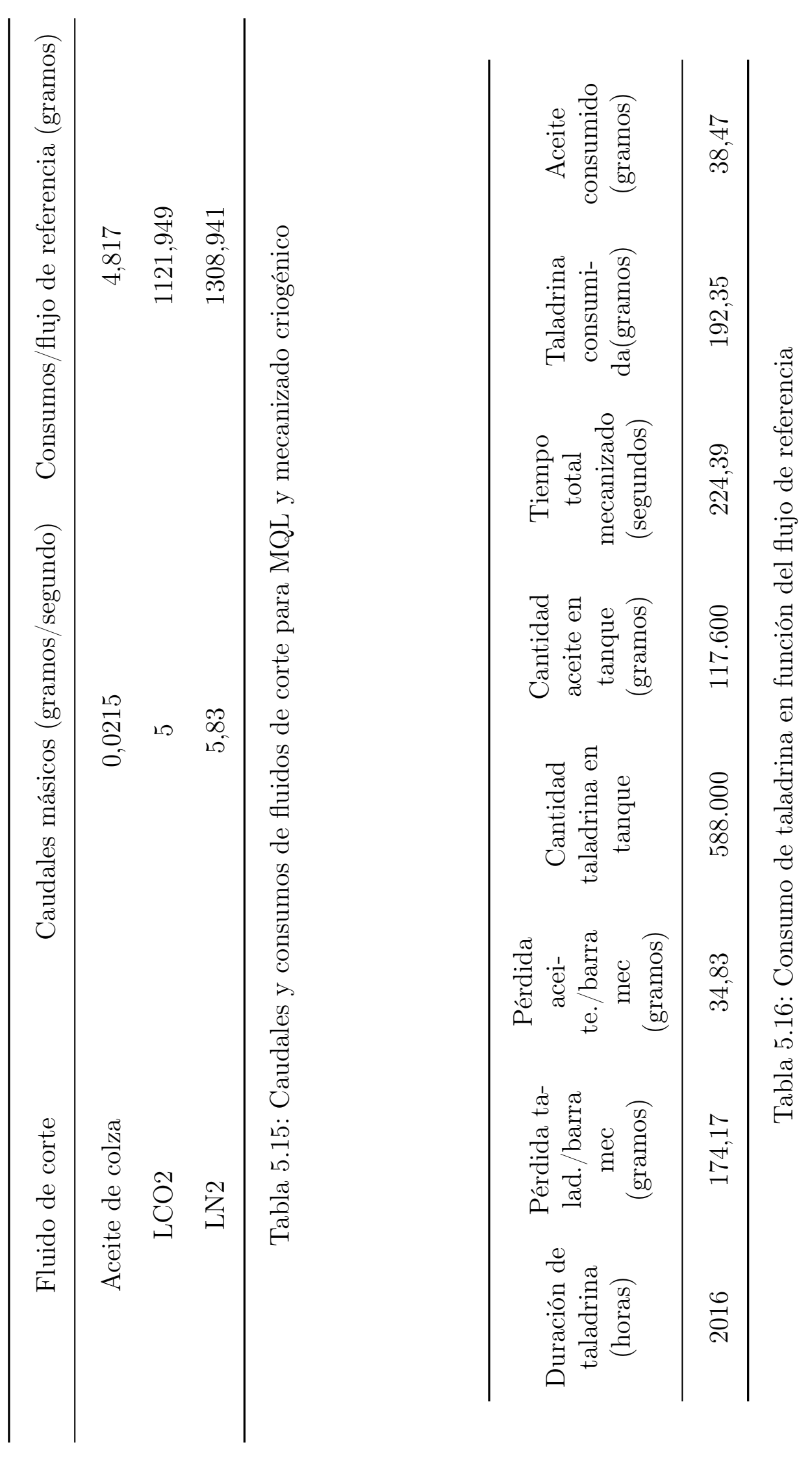




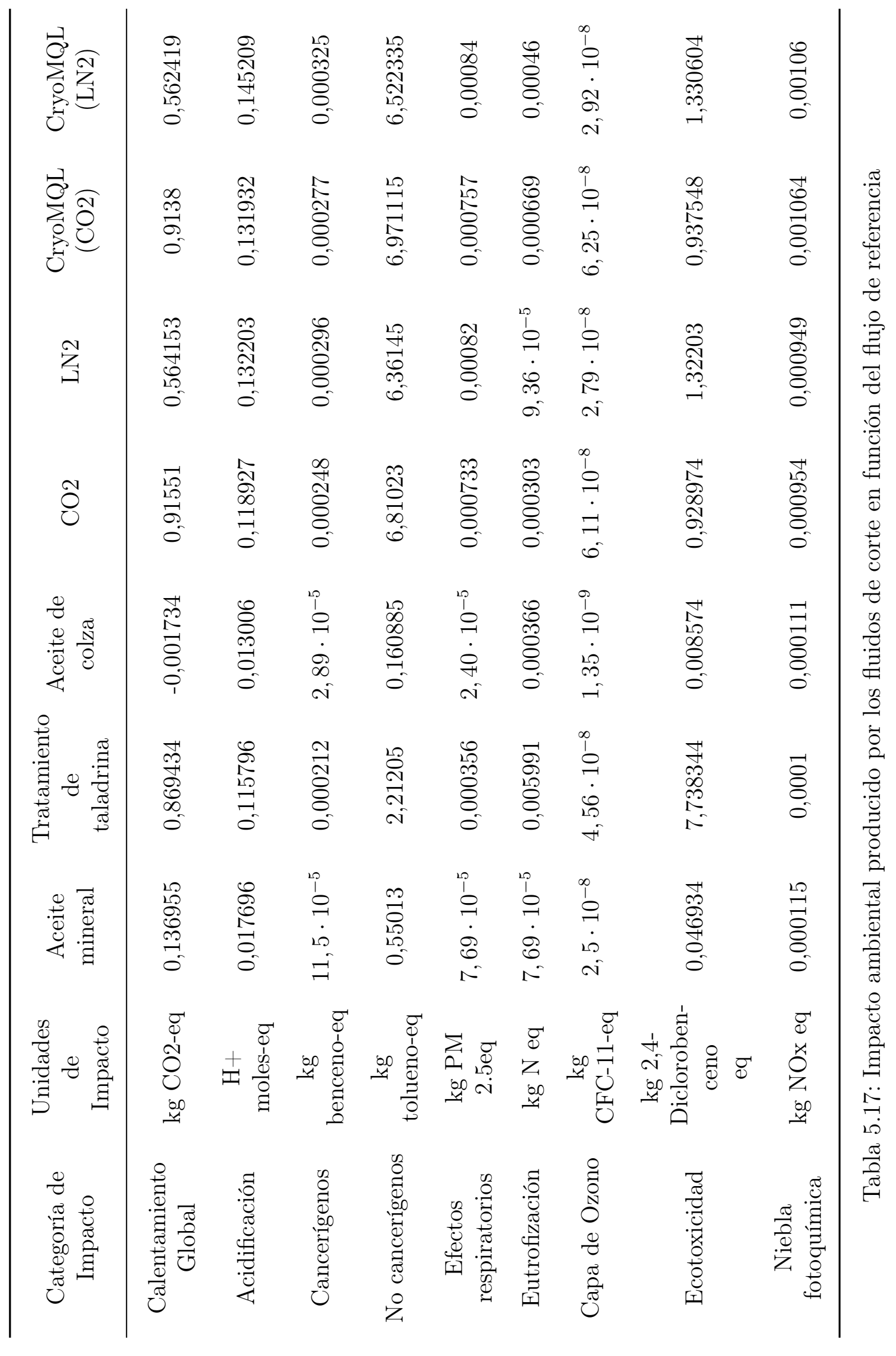




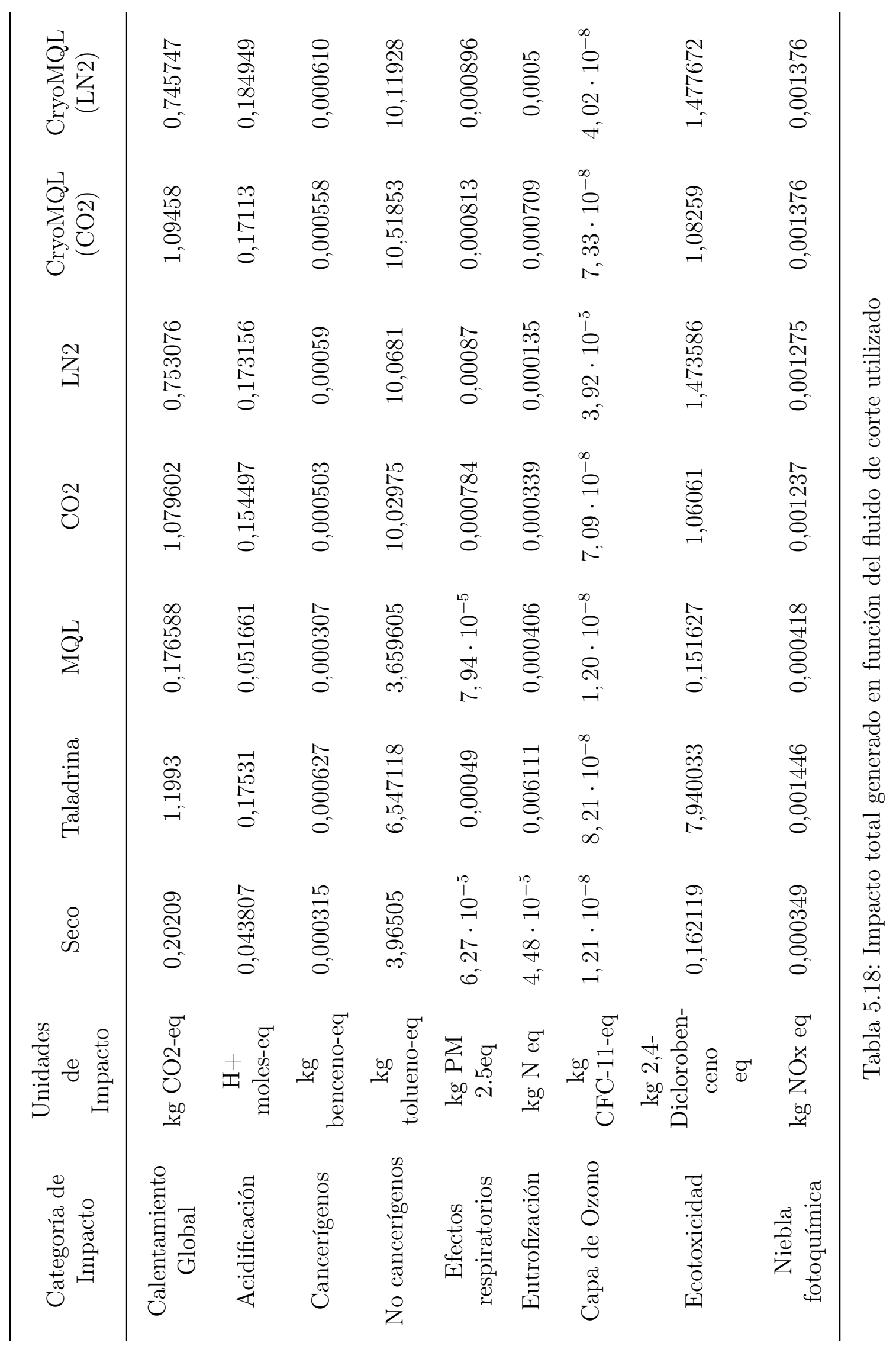


CAPÍTULO 6

Desarrollo y validación del equipo

CryoMQL propuesto 



\section{Desarrollo y validación del equipo CryoMQL propuesto}

\subsection{Introducción}

Una vez validadas las tecnologías objeto de esta tesis desde el punto de vista técnico y medioambiental, se ha procedido al desarrollo y validación de un equipo CryoMQL propio con el cual dar respuesta a las necesidades industriales del entorno. Este equipo permite no sólo la combinación de la lubricación MQL con la refrigeración criogénica sino también su uso en modo "stand alone". De este modo se puede optimizar el consumo de fluidos de corte en función de las necesidades del material a mecanizar. Este equipo es totalmente "Plug \& Play", es decir, ha sido diseñado de tal modo que la inversión inicial para su puesta en marcha sea lo mínima posible. Una vez desarrollado, el equipo ha sido validado mediante el recanteado de Inconel 718 utilizando varios de los sistemas de inyección propuestos en el capítulo 3.

\subsection{Finalidad del equipo CryoMQL}

Como se ha indicado en la introducción de este capítulo, con este equipo CryoMQL se pretende obtener un dispositivo de refrigeración y lubricación de herramientas para los principales procesos de mecanizado capaz de inyectar en la zona de corte tanto CO2 en estado líquido como micropartículas de aceite pulverizadas de forma independiente o combinada en función del material a mecanizar. Para ello, el equipo está compuesto por un sistema criogénico para la regulación de CO2 así como de un sistema MQL para la pulverización del aceite. Los dos sistemas que componen el equipo CryoMQL están gobernados electrónicamente por el mismo control. Concretamente se ha utilizado una tarjeta controladora Arduino®)con el fin de ahorrar 
costes así como facilitar la programación de éste. Asimismo, el dispositivo propuesto es totalmente portátil (Plug \& Play) de tal manera que puede ser utilizado en diferentes máquinas-herramienta sin la necesidad de realizar una instalación previa para su correcto funcionamiento, es decir, el equipo CryoMQL está desarrollado no sólo para un tipo de operación o máquina-herramienta específica, sino que el equipo es totalmente portátil e intercambiable pudiendo ser adaptado a cualquier máquinaherramienta de forma ágil y sencilla con el fin de ser utilizado en las principales operaciones de mecanizado. Asimismo, este sistema permite la utilización de la refrigeración criogénica no sólo de forma externa a la herramienta, sino también de forma interna. De hecho, en el caso del fresado cuando la refrigeración criogénica es utilizada de forma interna a la herramienta, ésta es utilizada como intercambiador de calor, lo que se traduce en un ahorro considerable de CO2 en estado líquido.

\subsection{Descripción de los sistemas que componen el equipo CryoMQL}

\subsubsection{El sistema criogénico}


Figura 6.1: Esquema de montaje del sistema criogénico 


\subsection{2. $\quad$ El sistema MQL}

El sistema MQL ha sido desarrollado como una técnica de mínima cantidad de lubricación (MQL) de dos canales, por lo que el aceite no es pulverizado hasta que no es inyectado mediante una tobera por efecto Venturi. De este modo se elimina la limitación de longitud de los canales que presentan los sistemas tradicionales de un solo canal derivado de la condensación de las micropartículas en las paredes de los conductos. El esquema de montaje se muestra en la Figura 6.2. Este sistema está formado por un regulador de presión que controla la presión a la que es alimentado de aire el sistema; un depósito el cual deberá contener aceite de corte; dos electroválvulas que controlan el paso de aire y aceite de corte, respectivamente; un acople que une axialmente los canales de aire y aceite; y una tobera al final del conducto coaxial la cual por efecto Venturi pulveriza el aceite transportado desde el depósito de aceite. Cuando este sistema entra en funcionamiento se abre la electroválvula del canal por el que circula aire e instantáneamente se abre también la electroválvula 
del canal por el que circula aceite. Sin embargo, esta última se abre de forma intermitente, es decir, está continuamente cambiando de estado con una frecuencia que determinará el caudal de aceite inyectado. Con este método de control por pulsos, se evita utilizar válvulas y frecuenciadores neumáticos que poseen los sistemas MQL tradicionales de dos canales de tal modo que el control del caudal de aceite utilizado es más exhaustivo.

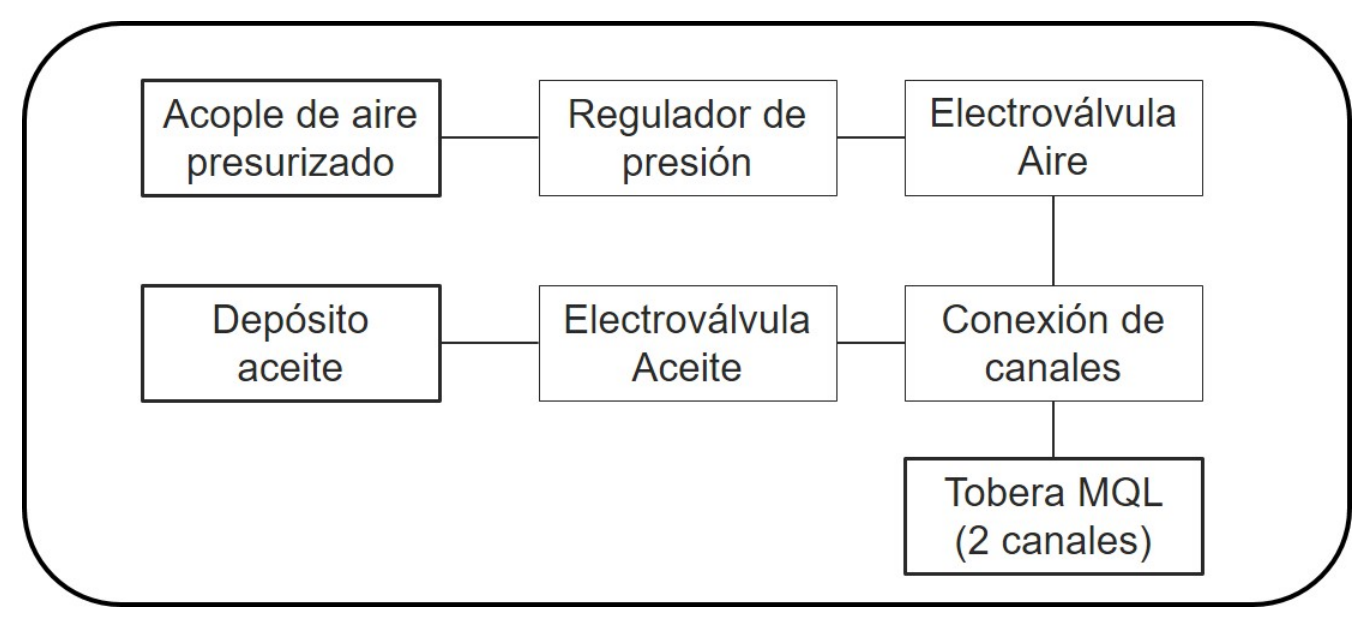

Figura 6.2: Esquema de montaje sistema MQL

\subsection{Composición y funcionamiento del Equipo}




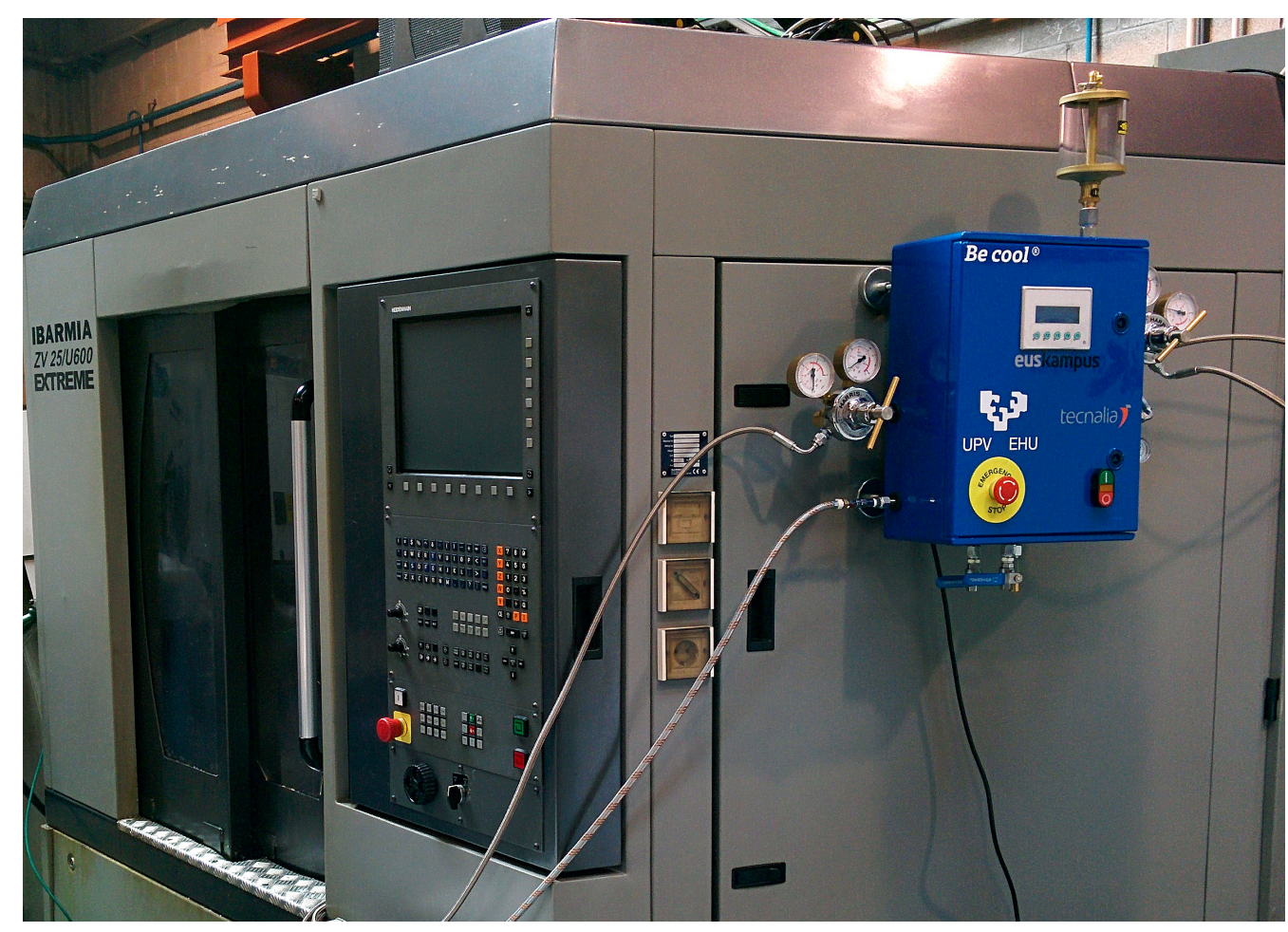

Figura 6.3: Equipo CryoMQL instalado en Ibarmia ZV-25

Figura 6.4: Componentes externos del equipo CryoMQL 
Figura 6.5: Componentes internos del equipo CryoMQL

Figura 6.6: Conexiones del equipo CryoMQL 
Figura 6.7: Algoritmo equipo CryoMQL 
Figura 6.8: Esquema de montaje del equipo CryoMQL

\subsection{Validación del equipo CryoMQL}

Una vez montado el equipo CryoMQL, con el fin de validar el funcionamiento del equipo durante los procesos de mecanizado, éste fue instalado en el centro de mecanizado de 3 ejes Kondia A6. Además de la validación, con estos ensayos se ha buscado comprobar la diferencia entre la utilización del CO2 como fluido de corte externo e interno a la herramienta de corte en procesos de fresado. Para ello además se han realizado simulaciones mediante elementos finitos (FEM) con el fin de observar de un modo gŕafico dichas diferencias.

\subsubsection{Montaje y metodología experimental}

El material seleccionado para la realización de las pruebas es la aleación de base hierro-níquel Inconel 718 debido a su gran demanda en el sector aeronáutico como se expuso en capítulos anteriores. Sin embargo, en este caso la operación a realizar ha 
sido el recanteado. Su elección se debe a que es la operación más simple de acabado realizada en álabes de turbina de turbopropulsores. De este modo se puede estudiar el impacto de cada una de las técnicas de lubricación/refrigeración utilizadas en el desgaste del filo de la herramienta de una forma sencilla.

La herramienta utilizada fue una fresa enteriza de carburo de tungsteno recubierta de TiAlN, diámetro $10 \mathrm{~mm}, 6$ labios y un ángulo de hélice de $45^{\circ}$. En cuanto a las condiciones de corte, se utilizaron las recomendadas por el fabricante, es decir, una velocidad de corte de $40 \mathrm{~m} / \mathrm{min}$, un avance por diente de $0,03 \mathrm{~mm} /$ diente, una profundidad de pasada de $10 \mathrm{~mm}$, y una profundidad radial de 0,2 $\mathrm{mm}$. El montaje experimental se muestra en la Figura 6.9. La longitud de los recanteados fue de $200 \mathrm{~mm}$. La entrada y salida de la herramienta se hizo tangencialmente al perfil con un radio de $15 \mathrm{~mm}$. Para medir el desgaste de herramienta con el microscopio (Nikon SMZ-2T) se realizaron paradas en diferentes etapas del ensayo. Como criterio de parada se utilizó un desgaste medio de flanco de 0,2 $\mathrm{mm}$. Este valor fue tomado porque existen ensayos que demuestran que un valor mayor puede afectar a la integridad superficial de la pieza [Fernández-Valdivielso et al., 2015]. Las técnicas de refrigeración/lubricación en este caso analizadas fueron: (1) Mecanizado con taladrina; (2) CO2 externo; (3) CO2 interno; (4) MQL; (5) CryoMQL externo; (6) CryoMQL interno.

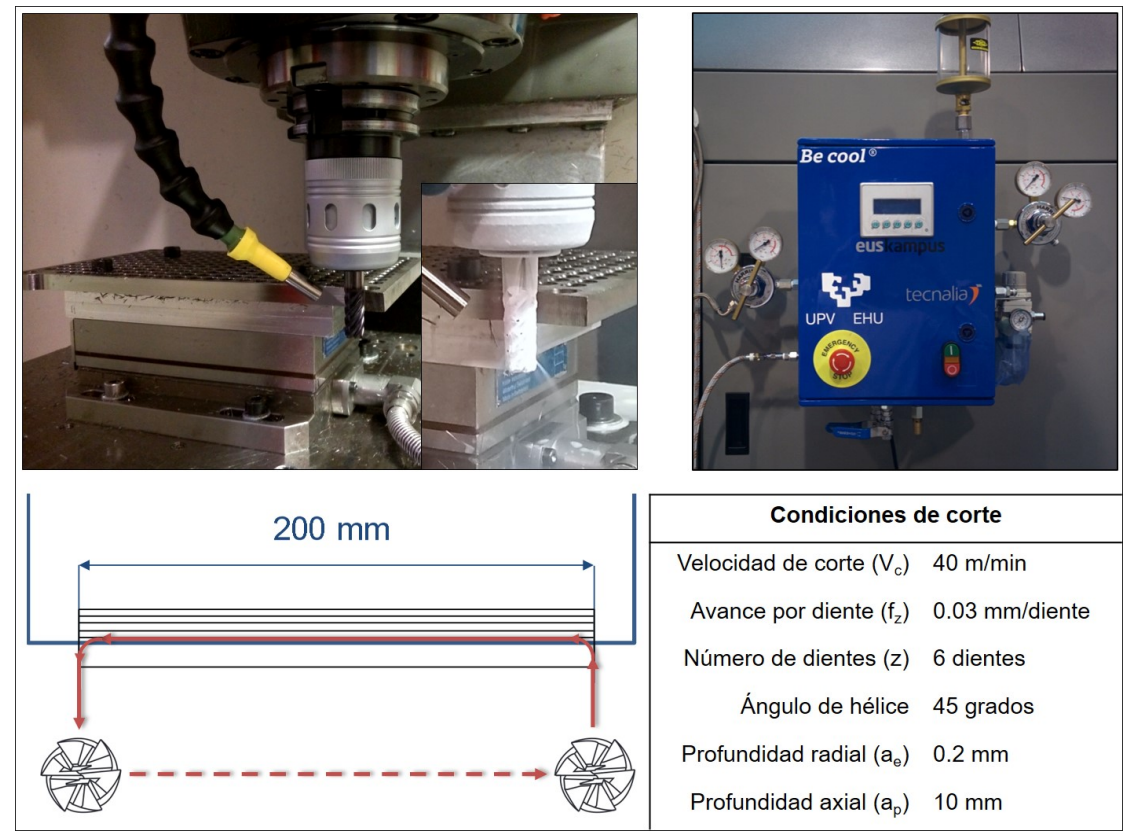

Figura 6.9: Esquema de montaje experimental 
En cuanto a la metodología seguida para la realización de las simulaciones, éstas fueron realizadas como corte ortogonal en 2D con un modelo de malla langrangiana adaptativa. En ellas se ha estudiado la influencia del CO2 al ser utilizado como fluido de corte interno y externo a la herramienta, respectivamente. Para ello se han calculado temperaturas de corte y tensiones de Von Mises para ambos casos. Además, con el fin de aproximar la simulación al montaje experimental se han utilizado las mismas condiciones de corte.

Con el fin de simular el comportamiento del CO2 durante las simulaciones, se ha aplicado la ecuación de transferencia de calor por convección como condición de frontera mostrada en la Figura 6.10. En el caso de la simulación para el CO2 como fluido de corte externo, esta condición fue aplicada tanto a la superficie de la herramienta como de la pieza. Además, se estableció que la temperatura superficial de ambas fuese $-78^{\circ} \mathrm{C}$. En la simulación de CO2 como fluido de corte interno, estas condiciones fueron sólo aplicadas a la herramienta. Sin embargo, en este caso, la temperatura interna de la herramienta se estableció en $-78^{\circ} \mathrm{C}$ a lo largo de toda la simulación con el fin de replicar el comportamiento del $\mathrm{CO} 2$ al ser introducido en el interior de ésta. Por otra parte, el coeficiente de transferencia de calor del CO2 se calculó en base al calor específico de absorción deducido en [Pusavec et al., 2014] $(347 \mathrm{~kJ} / \mathrm{kg})$; el caudal de CO2 calculado en el análisis de ciclo de vida ( $5 \mathrm{~g} / \mathrm{s}) ; \mathrm{y}$ una simulación previa bajo las condiciones de mecanizado en seco para conocer la temperatura de la superficie al ser mecanizada $\left(630^{\circ} \mathrm{C}\right)$. En la Figura 6.10 se resume el tipo de malla utilizada así como las condiciones de frontera utilizadas durante ambas simulaciones.
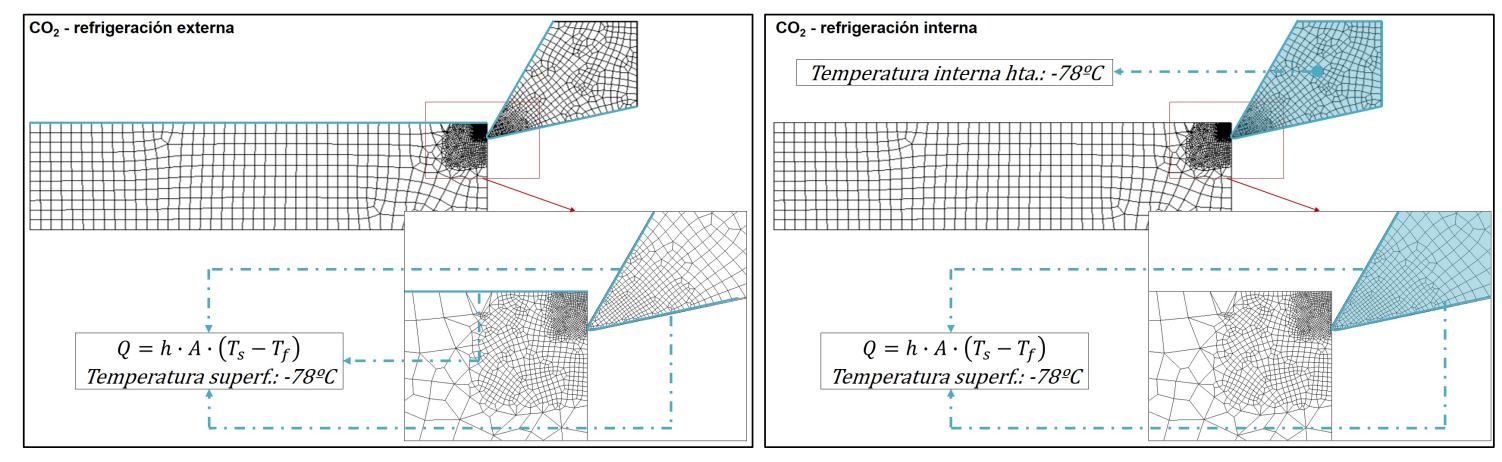

Figura 6.10: Características del mallado utilizado 


\subsubsection{Resultados}

En la Figura 6.11 se muestran la longitud mecanizada con cada una de las técnicas de lubricación/refrigeración analizadas.

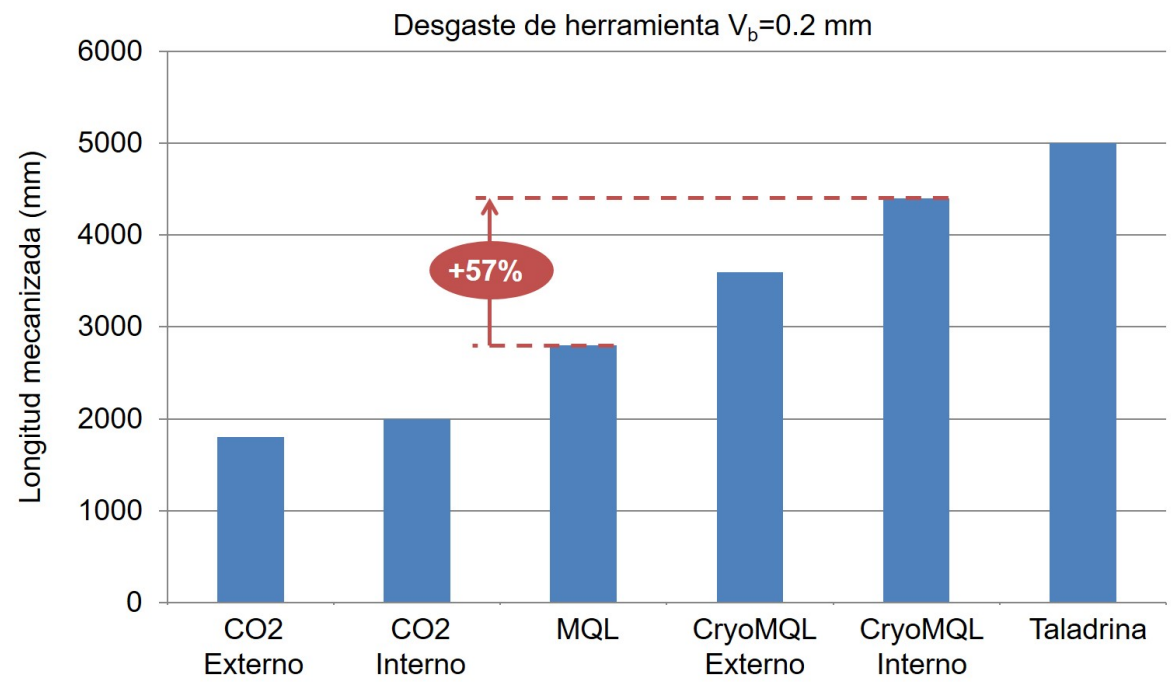

Figura 6.11: Longitudes mecanizadas

Los resultados muestran que utilizando el CO2 como fluido de corte externo, la herramienta es capaz de mecanizar $1800 \mathrm{~mm}$. Tomando este valor como referencia, las otras alternativas de refrigeración/lubricación estudiadas mejoran el comportamiento de la vida de herramienta. De hecho, si el CO2 es utilizado internamente, la longitud de mecanizado asciende hasta los 2000 mm. En la Figura 6.12 se muestran el estado de ambas herramientas una vez terminados los ensayos con ambas técnicas.
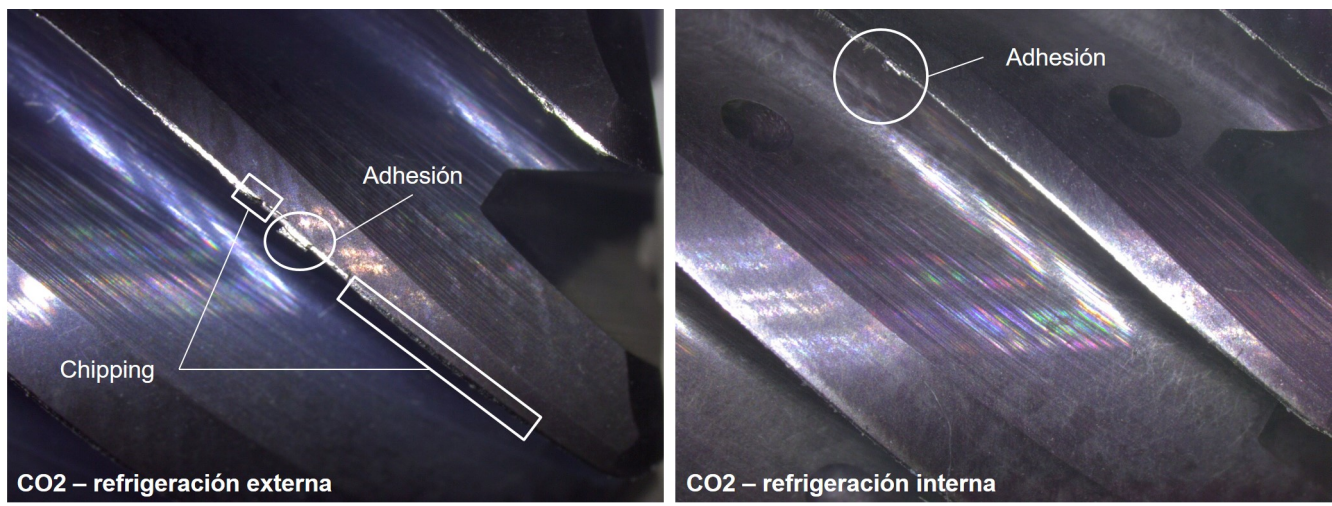

Figura 6.12: Imágenes de los filos en su final de vida 
Como se observa, si el CO2 es utilizado como fluido de corte externo, la herramienta no sólo no alcanza un desgaste de flanco de 0,2 $\mathrm{mm}$ sino que también presenta material adherido y un chipping generalizado. Esto se traduce en un mecanizado incontrolado que puede afectar a la integridad de la pieza. La diferencia de agresividad entre ambas técnicas radica no tanto por la reducción de la carga térmica en la herramienta sino por la reducción de los esfuerzos mecánicos derivado de utilizar el CO2 como refrigerante interno a la herramienta. En la Figura 6.13 se observan los resultados de las simulaciones realizadas con ambas técnicas en cuanto a temperatura y tensiones de Von-Misses se refiere. Estos resultados muestran de forma visual el origen de las diferencias entre la utilización del CO2 de forma externa o interna a la herramienta. En el caso de utilizar el CO2 internamente a la herramienta, éste es expandido en su interior y convierte a la herramienta en un intercambiador de calor sin llegar a afectar al material. Por tanto, la temperatura de corte del material es mayor que si se utilizase el CO2 de forma externa. Esto se traduce en que la dureza del material no se ve afectada por la capacidad refrigerante del CO2. De este modo, la tensión de fallo del material con la que se arranca la viruta es menor y consecuentemente también los esfuerzos mecánicos a los que es sometida la herramienta.

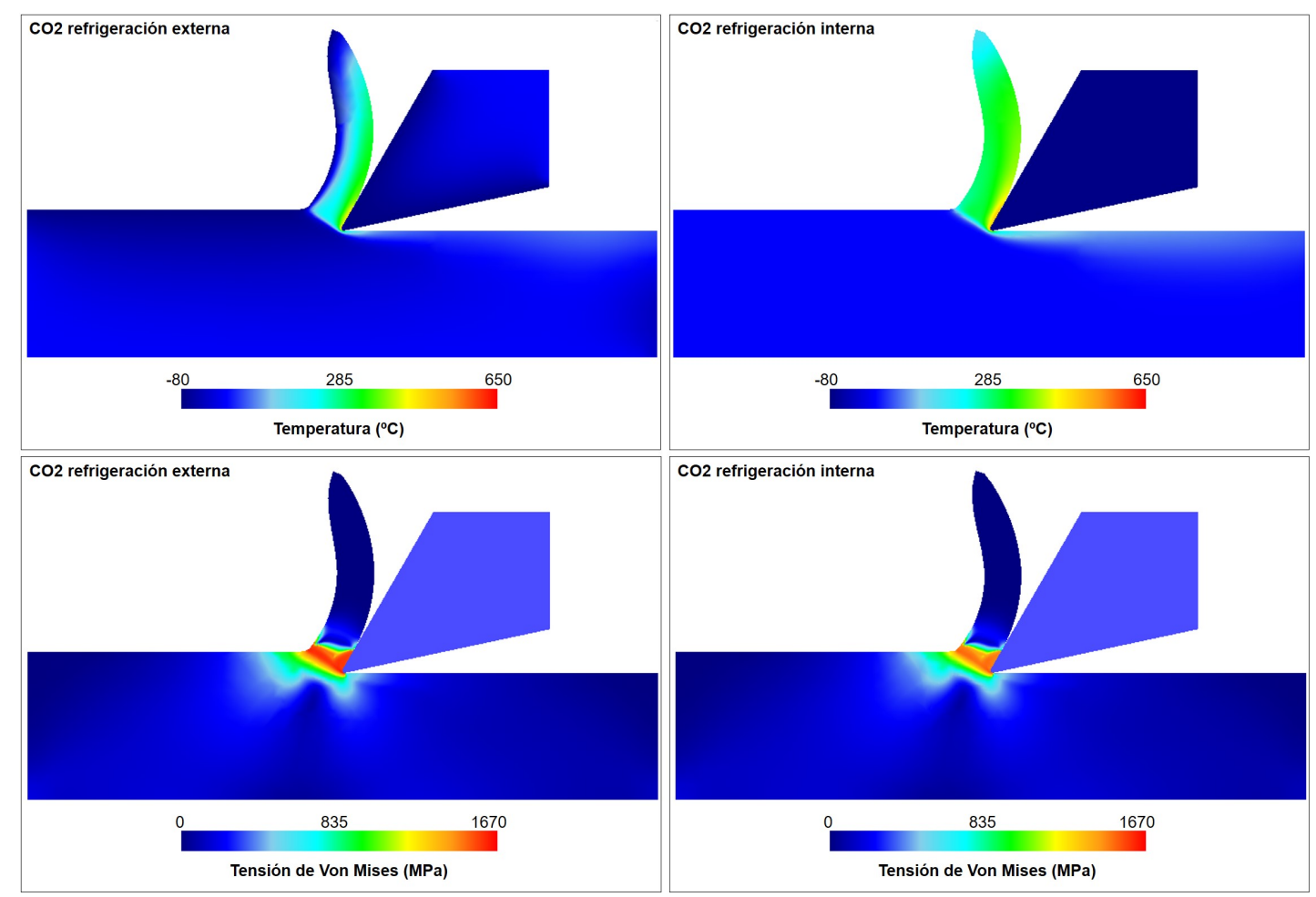

Figura 6.13: Resultados de las simulaciones 
Por otra parte, al utilizar MQL, el efecto de la lubricación provocado por el aceite implica un aumento de la longitud mecanizada, alcanzando $2800 \mathrm{~mm}$. Sin embargo, tanto con la refrigeración criogénica como la lubricación MQL utilizadas en modo "stand alone" no son suficientes para lograr un proceso viable. Concretamente, con la lubricación MQL no se reducen lo suficiente los efectos térmicos producidos sobre la herramienta, mientras que con la refrigeración criogénica no se lubrica lo suficiente la zona de corte para reducir los esfuerzos mecánicos.

En el caso del CryoMQL la vida de herramienta aumenta hasta los $3600 \mathrm{~mm}$ cuando el CO2 es utilizado de forma externa y alcanza los $4400 \mathrm{~mm}$ cuando éste es utilizado de forma interna a la herramienta. Este aumento de vida de herramienta se debe a que con esta tecnología se consigue hacer disminuir a la vez los efectos térmicos y esfuerzos mecánicos a los que es sometida la herramienta. De hecho, si se compara el CryoMQL interno con la lubricación MQL (la técnica en modo "stand alone") supone un aumento de vida de herramienta del $57 \%$. En la Figura 6.14 se muestra el desgaste de cada una de las herramientas en diferentes etapas al utilizar las técnicas CryoMQL y el MQL.
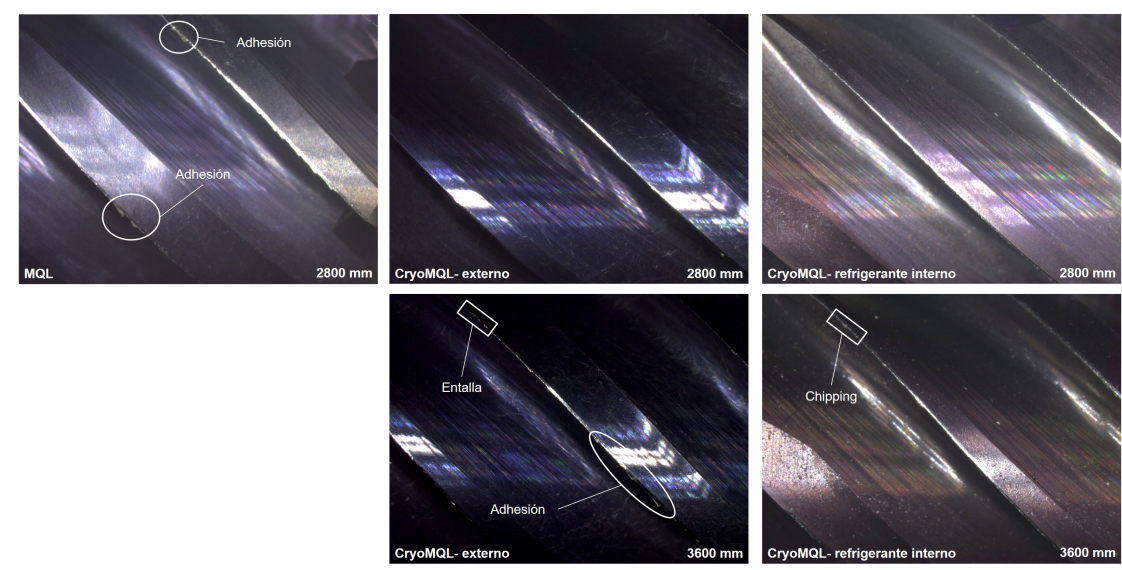

Figura 6.14: Imágenes de los filos en diferentes etapas de los ensayos

Finalmente, la longitud mecanizada al utilizar taladrina alcanza los $5000 \mathrm{~mm}$. Esto supone un aumento del $13,5 \%$ de la vida de herramienta si se compara con la tecnología CryoMQL interno. Sin embargo, el objetivo es conseguir minimizar el uso de fluidos de corte en el entorno industrial con el fin de alcanzar un proceso más limpio y medioambientalmente respetuoso. Por ello la combinación CryoMQL utilizando el CO2 internamente a la herramienta se presenta como la técnica de 
refrigeración/lubricación más atractiva ya que se alcanza un balance entre la capacidad de reducir el impacto ambiental y ser tecnológicamente viable.

\subsubsection{Discusión de los resultados - Inconel 718}

De los resultados mostrados en esta sección referente al recanteado de Inconel 718 se derivan las siguientes conclusiones:

- Aunque la mayor longitud de mecanizado se ha alcanzado con la taladrina, el objetivo es avanzar hacia procesos de mecanizado ecoeficientes. Por lo tanto, esta técnica debería ser eliminada de los entornos industriales a medio plazo.

- Las alternativas presentadas en modo "stand alone" (refrigeración criogénica con CO2 y MQL) no ofrecen una alternativa real para ser aplicada durante fresados de acabados en aleaciones termorresistentes como el Inconel 718 debido al desgaste prematuro de las herramientas utilizadas.

- En el caso de utilizar CO2 como fluido de corte, su aplicación de forma interna a la herramienta implica una optimización de la técnica debido a que la herramienta es refrigerada sin provocar un endurecimiento del material. De este modo el material no es endurecido por la acción refrigerante del CO2 provocando esfuerzos de corte menores.

- La utilización de la tecnología CryoMQL se presenta como la mejor alternativa al uso de emulsiones de aceite. En comparación con las otras alternativas estudiadas, si el CO2 es introducido en el interior de la herramienta, la longitud mecanizada aumenta hasta en un $57 \%$. En comparación con el uso de taladrina la vida útil de la herramienta se sitúa un 13,5\% por debajo de ésta. Sin embargo, cabe destacar que con la tecnología CryoMQL se alcanza un balance entre aspectos técnicos y medioambientales que no se obtiene ni con las emulsiones de aceite ni con las otras alternativas.

\subsection{Conclusiones}

En este capítulo se ha desarrollado un sistema de refrigeración y lubricación CryoMQL propio. Con él se ha dado respuesta a la problemática existente en equipos comerciales de similar índole. Concretamente, con este equipo se consigue uti- 
lizar la técnica CryoMQL o cualquiera de las técnicas que lo componen en modo "stand alone", en función del material a mecanizar. Por otra parte, el equipo no necesita de instalación previa para su correcto funcionamiento en cualquier máquinaherramienta. Por lo que unido a la primera premisa le concede una versatilidad de la que otros equipos no disponen.

Posteriormente el equipo ha sido validado mediante unos ensayos de fresado en Inconel 718 donde además se ha comprobado la ventaja de utilizar el CO2 como refrigerante interno a la herramienta en lugar de ser inyectado externamente. Con el fin de justificar este fenómeno, además de las pruebas empíricas, se han realizado unas simulaciones mediante FEM donde se aprecia cómo el utilizar la herramienta de corte como intercambiador de calor favorece el mecanizado. De hecho, al utilizar la tecnología CryoMQL con el CO2 a través de la herramienta se consigue un aumento de vida de herramienta del $57 \%$ frente a las otras alternativas a la taladrina.

Por lo tanto, con este capítulo se ha logrado optimizar la utilización del CO2 durante el proceso de fresado y alcanzar el último objetivo de esta tesis en el que se ha desarrollado y validado un equipo CryoMQL capaz de ser integrado en un entorno industrial. 

CAPÍTULO 7

Aportaciones y líneas futuras 



\section{Aportaciones y líneas futuras}

\subsection{Introducción}

En esta tesis se ha estudiado el uso de diferentes alternativas de refrigeración/lubricación para el mecanizado de materiales de difícil maquinabilidad con el fin de dar respuesta a las necesidades industriales en cuanto a optimización no sólo tecnológica sino medioambiental de los procesos de fresado, torneado y taladrado con el fin de alcanzar un balance entre ambos aspectos.

Debido a su versatilidad, principalmente se ha centrado el estudio en el uso de la refrigeración criogénica y la lubricación MQL en modo "stand alone" y combinado en función del tipo de operación a realizar y el material a optimizar.

Los materiales utilizados durante los ensayos han sido los comúnmente considerados de "difícil maquinabilidad". Este tipo de materiales y aleaciones generalmente combinan una alta dureza con gran ductilidad, lo que complica su mecanizado. Sin embargo, sus propiedades mecánicas apenas se ven afectadas a altas temperaturas, lo que hace que su uso se vea incrementado principalmente en componentes críticos presentes en la turbomaquinaria aeronáutica. En estos casos, además del alto valor del componente en cuestión hay que tener en cuenta el alto coste de las herramientas utilizadas para su mecanizado. Consecuentemente, por ello los ensayos realizados han estado principalmente enfocados a analizar la vida de herramienta y la conservación de la integridad de las piezas mecanizadas.

Además se han desarrollado no sólo diferentes sistemas de inyección que acerquen la refrigeración criogénica y la tecnología CryoMQL al entorno industrial sino un equipo propio con el que satisfacer las necesidades de refrigeración y/o lubrica- 
ción según el material y operación a tratar, avanzando así en la optimización de los parámetros de diseño y funcionamiento.

A continuación se plasman las principales aportaciones derivadas de la ejecución de esta tesis así como las principales líneas de desarrollo que quedan abiertas para futuras investigaciones.

\subsection{Aportaciones}

1. Se ha realizado un análisis del estado del arte en el que se han abarcado dos puntos de vista. Concretamente se ha realizado una revisión del estado de la técnica desde el punto de vista científico e industrial. Para ello se han resumido los últimos avances en cuanto a refrigeración criogénica y lubricación mediante MQL se refiere. Desde el punto de vista científico, en el caso de ésta última, principalmente se han plasmado los diferentes desarrollos con los que se ha tratado de suplir su bajo poder refrigerante para el mecanizado de materiales de difícil maquinabilidad. En el caso de la refrigeración criogénica y refrigeración/lubricación CryoMQL se ha ahondado en su aplicación en dicho tipo de materiales. Específicamente se ha recopilado información sobre su utilización en aceros inoxidables, aceros templados, aleaciones de titanio y aleaciones de níquel. Sin embargo, desde el punto de vista industrial, para ambas tecnologías se han analizado e identificado las debilidades de los diferentes equipos disponibles con los que se ha tratado de implementar estas tecnologías en entornos reales.

2. Se han desarrollado y adaptado diferentes sistemas de inyección criogénicos. Con ello se ha buscado el posibilitar el uso de la refrigeración criogénica y CryoMQL en máquinas-herramienta no sólo de nueva construcción, sino también en las ya existentes en el entorno industrial. Para ello, primeramente se ha calculado el diámetro óptimo de salida para la inyección de CO2 de tal modo que se asista de la forma más eficiente los procesos de mecanizado. Posteriormente, basándose en estos resultados se ha procedido al desarrollo y adaptación de diferentes sistemas de inyección de CO2 que posibiliten su utilización de forma externa e interna a la herramienta. Finalmente se 
ha desarrollado mediante "rapid prototyping" un adaptador con el que lograr aplicar la tecnología CryoMQL utilizando los equipos MQL ya existentes en la actualidad, ofreciendo así soluciones personalizadas de una forma sistemática.

3. Se ha validado la utilización de la refrigeración criogénica y su combinación con la lubricación MQL en diferentes situaciones durante el mecanizado de diferentes materiales de difícil maquinabilidad. Concretamente se ha evaluado la utilización de la refrigeración criogénica tanto con CO2 como LN2, la lubricación MQL y sus combinaciones durante el torneado del acero inoxidable austenítico AISI 304L. En estos ensayos se ha analizado en profundidad la vida de herramienta, los esfuerzos de corte y la integridad superficial de la pieza con cada una de las tecnologías analizadas. De dichos ensayos se desprende que la tecnología CryoMQL con CO2 es la alternativa con la que se obtiene una mayor vida de herramienta a la vez que se mantiene, incluso mejora en algunos aspectos, la integridad superficial de la pieza.

Posteriormente se ha aplicado la refrigeración criogénica con CO2 al torneado en duro del acero ASP23 (HSS-64HRc) con dos tipos de insertos. La aplicación de la refrigeración criogénica implica un aumento de vida de herramienta que oscila entre el $\approx 20 \%$ y el $\approx 70 \%$ en función de si el inserto tiene un ángulo de incidencia positivo o negativo, respectivamente.

En cuanto al fresado de Inconel 718, se han realizado dos tipos de operaciones. La primera de ellas ha sido una operación de planeado donde al aplicar la tecnología CryoMQL se lograba mayor vida de herramienta frente al uso de MQL o CO2 en modo "stand alone". Sin embargo, frente al uso de taladrina se obtenía una longitud mecanizada menor en un $6,5 \%$. Por otro lado, se han realizado recanteados con diferentes técnicas de refrigeración/lubricación donde se ha evaluado el comportamiento de la utilización del CO2 de forma interna y externa a la herramienta, respectivamente. De su análisis se ha obtenido que con la utilización de la tecnología CryoMQL con refrigeración interna de la herramienta mediante CO2 se logra un aumento de la vida de herramienta en un $\approx 20 \%$ frente a su utilización con refrigeración externa. 
En referencia al taladrado de stacks de Ti6Al4V-CFRP, con la refrigeración criogénica se ha conseguido optimizar el proceso de tal modo que se obtienen taladros homogéneos con valores diametrales cercanos al valor nominal de la broca, así como la eliminación de quemados del CFRP y adhesión de Ti6Al4V al filo de la broca.

4. Se ha realizado un exhaustivo análisis de ciclo de vida (huella ambiental) de las diferentes tecnologías de refrigeración y lubricación estudiadas en esta tesis. Frente a las limitaciones y simplificaciones realizadas en los ACV encontrados en la literatura, en éste se han tenido en cuenta escrupulosamente los principios de la norma ISO14040:2006 así como los requisitos y directrices dictados por la norma ISO14044:2006. Cabe destacar entre otros factores que se ha evaluado no sólo el coste ambiental derivado del uso de los fluidos de corte durante el mecanizado sino también de su obtención y disposición una vez terminada su vida útil en caso de ser necesaria. Además se ha tenido en cuenta el mix energético existente en el sistema eléctrico nacional. De este modo se logra ajustar el estudio realizado a la realidad proporcionando resultados robustos y fiables. Concretamente, en este análisis de ciclo de vida se ha analizado el impacto ambiental producido por el mecanizado en seco, lubricación MQL, refrigeración criogénica con CO2 y LN2, y las tecnologías CryoMQL con CO2 y LN2, respectivamente. De dicho análisis se desprende que la lubricación MQL es la alternativa medioambientalmente más sostenible junto con el mecanizado en seco. Además, gracias a este ACV se ha logrado cuantificar de forma objetiva la insalubridad presentada por la taladrina donde aspectos como la eutrofización y ecotoxicidad alcanzan valores superiores al $760 \%$ y $633 \%$ frente a las otras tecnologías estudiadas.

5. Se ha desarrollado y validado un equipo propio para la aplicación de la refrigeración criogénica y lubricación MQL en modo "stand alone" y combinado (CryoMQL). Con él se ha pretendido resolver las limitaciones de los equipos comerciales ya existentes. Este equipo posibilita su utilización en cualquier máquina-herramienta sin una instalación previa. Además, dispone de un display con el que seleccionar el tipo de fluido de corte a utilizar en cada caso y controlar de forma exhaustiva el caudal de aceite utilizado durante la lubricación MQL y la tecnología CryoMQL. 


\subsection{Publicaciones}

Durante la actividad investigadora que ha dado lugar a esta tesis se ha procedido a la publicación de los resultados obtenidos en diversos formatos y entornos.

Por un lado, con el fin de avanzar en el estado del arte se ha publicado en diversas revistas indexadas científicamente así como participado en múltiples congresos y conferencias. Por otra parte, aquellos datos susceptibles de ser protegidos industrialmente han sido registrados mediante patentes en la Oficina Española de Patentes y Marcas. Por último, con el objetivo de extender los resultados a un contexto industrial, se ha publicado en revistas divulgativas de carácter técnico de tal modo que se haga accesible la tecnología desarrollada en el trascurso de esta tesis a las empresas del entorno.

A continuación se indican las publicaciones realizadas en cada uno de los entornos indicados en orden cronológico inverso, es decir, desde los hitos más recientes a más antiguos:

\subsubsection{Revistas indexadas}

- Nozzle design for combined use of MQL and cryogenic gas in machining. O. Pereira, A. Rodríguez, J. Barreiro, A.I. Fernández-Abia, L.N. López de Lacalle. (2017) Int. J. of Precision Engineering and Manufacturing-Green Technology, Vol. 4, pp.87-95.

- Cryogenic and minimum quantity lubrication for an eco-efficiency turning of AISI 304. O. Pereira, A. Rodríguez, A.I. Fernández-Abia, J. Barreiro, L.N. López de Lacalle. (2016) J. of Cleaner Production, Vol. 139, pp.440-449.

- A Cryo Lubri-coolant approach for finish milling of aged Inconel 718. O. Pereira, A. Rodríguez, I. Ayesta, J. Barreiro, A.I. Fernández-Abia, L.N. López de Lacalle. (2016) Int. J. of Mechatronics and Manufacturing Systems, Vol. 9, pp.370-384. 


\subsubsection{Congresos y conferencias}

- Un sistema de micropulverizado de aceites vegetales en mecanizado por impulsión controlada de la dosificación. O. Pereira, R. Polvorosa, A. Rodríguez, A. Fernández-Valdivielso, J. Barreiro, A.I. Fernández-Abia, L.N. López de Lacalle. (2016) XXI Congreso Nacional de Ingeniería Mecánica. ISBN: 978-84-16024-37-7

- The use of hybrid CO2+MQL in machining operations. O. Pereira, P. Català, A. Rodríguez, T. Ostra, J. Vivancos, A. Rivero, L.N. López de Lacalle. (2015) 6 Manufacturing Engineering Society International Conference. ISBN: 978-84-1568863-1

- Cryogenic hard turning of ASP23 steel using carbon dioxide. O. Pereira, A. Rodríguez, A. Fernández-Valdivielso, J. Barreiro, A. Fernández-Abia, L.N. López de Lacalle. (2015) 6 Manufacturing Engineering Society International Conference. ISBN: 978-84-1568863-1

- Uso de la tecnología de refrigeración criogénica para operaciones de mecanizado de alto valor añadido. O. Pereira, A. Rodríguez, T. Ostra, A. Rubio, J. Barreiro, A.I. Fernández-Abia, A. Rivero, L.N. López de Lacalle. (2015) Congreso Máquina-Herramienta.

- Uso de gases criogénicos para un rendimiento ECO2 del mecanizado. A. Rodríguez, O. Pereira, J. Barreiro, A.I. Fernández-Abia, L.N.López de Lacalle. (2014) XX Congreso Nacional de Ingeniería Mecánica. ISSN: 0212-5071

- Las innovaciones en los sistemas MQL. O. Pereira, J. Paredes, N. Prego, Z. Prego. (2012) XXXIII Jornadas de automática. ISBN: 978-84-8158-583-4

\subsubsection{Patentes}

- EP16382239. Dispositivo y método para refrigeración y lubricación de herramientas en procesos de mecanizado. (2016)

- ES2517090-B1. Dispositivo y equipo de refrigeración y lubricación para operaciones de mecanizado de materiales (2013) 


\subsubsection{Revistas técnicas}

- Lo frío, lo limpio, llave para lo difícil. O. Pereira, A. Rodríguez, L.N. López de Lacalle, T. Ostra, A. Rivero, D. Martínez-Krahmer. (2016) MetalIndustria, Vol. 10, pp.10-19, ISSN:2340-194X.

- MQL y criogenia ¿Es esto una posibilidad? O. Pereira, A. Rodríguez, R. Polvorosa, A. Rubio, L.N. López de Lacalle. (2016) IMHE, Vol.418, pp.50-55, ISSN: 0210-1777.

- Refrigeración criogénica para operaciones de alto valor añadido. $O$. Pereira, A. Rodríguez, L.N. López de Lacalle, T. Ostra, A. Rivero, A. Rubio, J. Barreiro, A.I. Fernández-Abia. (2016) Técnica y Tecnología, Vol.38, ISSN: 2014-8305, pp.14-22.

- Mecanizado frío, el beneficio que surge del frío. A. Rubio, O. Pereira, F. Veiga, A. Rodríguez, A. Rivero, L.N. López de Lacalle. (2016) CiC-Network, Vol.6, pp.50-53, SS-1228-2006.

- Large spiral bevel gears on universal 5-axis milling machines: a complete process. A. Álvarez-Arregui, O. Pereira, L.N. López de Lacalle, A. Olaiz, A. Rivero. (2015) Técnica y Tecnología, Vol.33, pp.12-20, ISSN: 20148305 .

- Mecanizar sin defectos, visión global. A. Rodríguez, G. Urbikain, O. Pereira, R. Polvorosa, I. Cerrillo, L.N. López de Lacalle. (2015) Técnica y Tecnología, Vol.29, pp.12-26, ISSN: 2014-8305.

- Tecnologías novedosas en el mecanizado de superaleaciones. A. Rodríguez, O. Pereira, L.N. López de Lacalle, T. Ostra, A. Rivero. (2015) Técnica y Tecnología para la Industria Aeronáutica, Vol.1, pp.10-18, ISSN: 2014-8305.

- Tecnologías emergentes en fabricación. O. Pereira, A. Rodríguez, G. Urbikain, A. Fernández-Valdivielso, A. Calleja. (2014) IMHE, Vol.410, pp.22-28, ISSN: 0210-1777.

- Alternativas al mecanizado con taladrina. O. Pereira, A.I. FernándezAbia, J. Barreiro. (2013) Técnica y Tecnología, Vol.8, pp. 22-26, ISSN 20148305 . 
- Apostar por una fabricación limpia, la clave para el éxito. E. DíazTena, R. López-Blanco, A. Rodríguez, L. Gurtubay, A. Elías, O. Pereira. (2013) IMHE, Vol.397, pp.32-36, ISSN: 0210-1777.

\subsection{Líneas futuras}

Con esta tesis se ha contribuido a la aplicabilidad de la refrigeración criogénica y tecnología CryoMQL en materiales de difícil maquinabilidad de forma fehaciente de tal modo que puedan ser aplicadas en entornos industriales. No obstante, se abren diferentes caminos en los que será necesario trabajar de cara a una correcta implantación de dicha tecnología en los diferentes entorno productivos. Las principales líneas futuras se indican a continuación:

1. Optimizar la cantidad de CO2 utilizado. Uno de los parámetros que tienen gran influencia a la hora de implementar una tecnología industrialmente es el económico. Por ello, se hace necesario minimizar la cantidad de CO2 necesaria para ser utilizado como fluido de corte. Su inyección de forma interna a la herramienta hace descender su consumo de forma considerable. Sin embargo, las herramientas utilizadas durante el desarrollo de esta tesis fueron fresas con refrigeración interna para el uso de taladrina a alta presión. Por ello, sería interesante estudiar y desarrollar diferentes diseños de herramientas de tal modo que permita la expansión de CO2 en su interior de tal modo que se vierta a la atmósfera la menor cantidad de CO2 posible. De este modo, el gasto sería ínfimo pudiendo generalizarse su utilización no sólo a piezas de alto valor añadido.

2. Aplicar la tecnología CryoMQL al fresado trocoidal. Esta línea se está trabajando en la actualidad. El objetivo de esta línea es poder utilizar fresas de acabado con refrigeración interna para operaciones de desbaste. Gracias a ello, se podrá no sólo realizar procesos de acabado con CryoMQL asistido por el CO2 de forma interna a la herramienta, sino extrapolarlo a operaciones de desbaste. Consecuentemente, con dicha tecnología se podrá abarcar todo el proceso de mecanizado del componente de un modo más eficiente.

3. Estudiar la expansión del CO2 en el interior de la zona de trabajo de la máquina-herramienta. Un aspecto a tener en cuenta al utilizar el CO2 
como fluido de corte es el riesgo de asfixia intrínseco que conlleva. Por ello, a pesar de disponer de ciclones que absorban el gas del interior de la máquinaherramienta es de gran interés conocer la cantidad residual que se queda en su interior susceptible de fugarse al ambiente circundante a ésta después de largos tiempos de uso (16-24 horas).

\section{Introducir las micropartículas de aceite por el interior de la herra-} mienta. En el caso de utilizar CryoMQL con CO2 como refrigerante interno a la herramienta también sería de gran importancia introducir las micropartículas de aceite por el interior de la herramienta ya que actualmente existen dos métodos para poder hacerlo. El primero es utilizar el CO2 como refrigeración interna y el aerosol de micropartículas como fluido de corte externo. El segundo es utilizar los dos como fluidos de corte internos pero recorriendo la herramienta por canales separados hasta ser inyectados en la cara de desprendimiento de las herramientas. De este modo, se puede conseguir una mejor penetración de éstas en la zona de interacción herramienta-viruta, traduciéndose en un aumento de vida de herramienta.

\section{La aplicación de la refrigeración criogénica en pistolas neumáticas.} Este desarrollo es de gran interés debido a su aplicación directa en el sector aeronáutico. Actualmente se utilizan dichas pistolas para la realización de taladros de forma manual en stacks de Ti6Al4V-CFRP para anclar dichas planchas a las estructuras de las aeronaves. Gracias a ellas se podría optimizar la vida de las brocas, mejorando el proceso existente de forma considerable a raíz de los resultados obtenidos en los ensayos experimentales realizados en máquinaherramienta en esta tesis.

6. Estudio de diferentes aceites vegetales como fluidos de corte. En esta línea se está trabajando en la actualidad. El objetivo principal de este análisis es reducir aún más el impacto ambiental producido por la tecnología CryoMQL y MQL. Aunque la utilización de estas tecnologías implica la utilización de aceites biodegradables, hay que destacar que estos poseen aditivos de alta presión que dificultan dicha biodegradabilidad. Para ello se están estudiando diferentes aceites $100 \%$ vegetales los cuales eviten la utilización de 
dichos aditivos

7. Desarrollar toberas dirigibles. En esta línea se está investigando también actualmente. En el caso de utilizar refrigeración criogénica o CryoMQL de forma externa a la herramienta durante el fresado, se hace interesante que las toberas se posicionen en función de dos parámetros. El primero es la longitud de herramienta, cuyo valor debería ser tomado de la tabla de correctores del control de la máquina-herramienta y el segundo en función de la trayectoria seguida por la herramienta. De este modo se optimizaría la inyección del fluido de corte en la zona de corte, logrando por tanto un proceso de mecanizado más estable.

8. Elaboración de tablas o ventanas de proceso que caractericen los caudales de fluido de corte. La confección de esta tabla aplicada a los materiales y operaciones más comunes con el fin de optimizar el uso de gases criogénicos y aceite sería de gran interés. Gracias a ella se lograría incrementar la productividad de los procesos de mecanizado no sólo económicamente sino medioambientalmente. De este modo se avanzaría hacia la sistematización de los procesos de mecanizado que involucrasen el uso de la tecnología CryoMQL. 


\section{Bibliografía}

[Abele and Schramm, 2008] Abele, E. and Schramm, B. (2008). Using pcd for machining cgi with a co2 coolant system. Production Engineering, 2 (2):165-169.

[Astakhov, 2009] Astakhov, V. P. (2009). Ecological machining: near dry machining. Mechanics of machining: FEM simulation machining, pages 195-223.

[Attanasio et al., 2006] Attanasio, A., Gelfi, M., Giardini, C., and Remino, C. (2006). Minimal quantity lubrication in turning: Effect on tool wear. Wear, 260(3):333 - 338.

[Bart et al., 2013] Bart, J. C., Gucciardi, E., and Cavallaro, S. (2013). 11 - environmental life-cycle assessment (lca) of lubricants. In Bart, J. C., Gucciardi, E., and Cavallaro, S., editors, Biolubricants, Woodhead Publishing Series in Energy, pages 527 - 564. Woodhead Publishing.

[Benedetto and Klemeš, 2009] Benedetto, L. D. and Klemeš, J. (2009). The environmental performance strategy map: an integrated $\{\mathrm{LCA}\}$ approach to support the strategic decision-making process. Journal of Cleaner Production, 17(10):900 - 906. Early-Stage Energy Technologies for Sustainable Future: Assessment, Development, Application.

[Bicek et al., 2012] Bicek, M., Dumont, F., Courbon, C., Pusavec, F., Rech, J., and Kopac, J. (2012). Cryogenic machining as an alternative turning process of normalized and hardened aisi 52100 bearing steel. Journal of Materials Processing Technology, 212(12):2609 - 2618.

[Boelkins, 1971] Boelkins, W. (1971). US 3,618,709. Pressurized lubrication system.

[Bolz, 2005] Bolz, D. (2005). EP 1675688 B1. Method for producing an aerosol and injection unit. 
[Bonnarang and Guerardelle, 2011] Bonnarang, F. and Guerardelle, C. (2011). WO 2011/111035 A1. Rotary cutting tool having an adjustable cooling mechanism.

[Byrne et al., 2003] Byrne, G., Dornfeld, D., and Denkena, B. (2003). Advancing cutting technology. CIRP Annals - Manufacturing Technology, 52(2):483 - 507.

[Cetin et al., 2011] Cetin, M. H., Ozcelik, B., Kuram, E., and Demirbas, E. (2011). Evaluation of vegetable based cutting fluids with extreme pressure and cutting parameters in turning of aisi 3041 by taguchi method. Journal of Cleaner Production, 19(17-18):2049 - 2056.

[Chambers, 1995] Chambers, R. (1995). EP 0679971 A2. Lubricant nozzle positioning system and method.

[Chiffre et al., 2007] Chiffre, L. D., Andreasen, J., Lagerberg, S., and Thesken, I.B. (2007). Performance testing of cryogenic $\{\mathrm{CO} 2\}$ as cutting fluid in parting/grooving and threading austenitic stainless steel. CIRP Annals - Manufacturing Technology, 56(1):101-104.

[Cordes et al., 2014] Cordes, S., Hübner, F., and Schaarschmidt, T. (2014). Next generation high performance cutting by use of carbon dioxide as cryogenics. Procedia CIRP, 14:401 - 405. 6th \{CIRP $\}$ International Conference on High Performance Cutting, $\{$ HPC2014\}.

[Cotas et al., 2015] Cotas, C., Silva, R., Garcia, F., Faia, P., Asendrych, D., and Rasteiro, M. G. (2015). New paradigm of particle science and technology proceedings of the 7th world congress on particle technology. Procedia Engineering, $102: 1326-1335$.

[de Lacalle et al., 2006] de Lacalle, L. L., Angulo, C., Lamikiz, A., and SÃjinchez, J. (2006). Experimental and numerical investigation of the effect of spray cutting fluids in high speed milling. Journal of Materials Processing Technology, 172(1):11 -15 .

[Debnath et al., 2014] Debnath, S., Reddy, M. M., and Yi, Q. S. (2014). Environmental friendly cutting fluids and cooling techniques in machining: a review. Journal of Cleaner Production, 83:33 - 47. 
[Duchosal et al., 2015] Duchosal, A., Serra, R., Leroy, R., and Louste, C. (2015). Numerical steady state prediction of spitting effect for different internal canalization geometries used in $\{\mathrm{MQL}\}$ machining strategy. Journal of Manufacturing Processes, pages -.

[Eckardt and Stirling, 1969] Eckardt, F. and Stirling, N. J. (1969). US 3,478,843. Mist type coolant spray unit.

[Fernández-Valdivielso et al., 2015] Fernández-Valdivielso, A., López de Lacalle, L., Urbikain, G., and Rodriguez, A. (2015). Detecting the key geometrical features and grades of carbide inserts for the turning of nickel-based alloys concerning surface integrity. Proceedings of the Institution of Mechanical Engineers, Part C: Journal of Mechanical Engineering Science.

[Fratila, 2009] Fratila, D. (2009). Evaluation of near-dry machining effects on gear milling process efficiency. Journal of Cleaner Production, 17(9):839 - 845.

[Fratila, 2010] Fratila, D. (2010). Macro-level environmental comparison of near-dry machining and flood machining. Journal of Cleaner Production, 18(10-11):1031 -1039 .

[Guo et al., 2010] Guo, Y., Warren, A., and Hashimoto, F. (2010). The basic relationships between residual stress, white layer, and fatigue life of hard turned and ground surfaces in rolling contact. CIRP Journal of Manufacturing Science and Technology, 2(2):129 - 134 .

[Hong, 2007] Hong, S. Y. (2007). Lubrication mechanism of $\ln 2$ in ecological cryogenic machining. Machining Science and Technology, 10(1):133-155.

[Hong and Ding, 2001] Hong, S. Y. and Ding, Y. (2001). Cooling approaches and cutting temperatures in cryogenic machining of ti-6al-4v. International Journal of Machine Tools and Manufacture, 41(10):1417 - 1437.

[Hong et al., 1999] Hong, S. Y., Ding, Y., and Ekkens, R. G. (1999). Improving low carbon steel chip breakability by cryogenic chip cooling. International Journal of Machine Tools and Manufacture, 39(7):1065 - 1085.

[Hong et al., 2002] Hong, S. Y., Ding, Y., and Jeong, J. (2002). Experimental evaluation of friction coefficient and liqui nitrogen lubrication effect in cryogenic machining. Machining Science and Technology, 6(2):235-250. 
[Hong et al., 2001] Hong, S. Y., Markus, I., and cheol Jeong, W. (2001). New cooling approach and tool life improvement in cryogenic machining of titanium alloy ti6al-4v. International Journal of Machine Tools and Manufacture, 41(15):22452260 .

[Horn et al., 2011] Horn, W., Haus, W., and Shmalzried, S. (2011). US 2011/0166692 A1. Method for cooling and lublubricanting a tool and for cleaning the machined surface.

[Itoigawa et al., 2006] Itoigawa, F., Childs, T., Nakamura, T., and Belluco, W. (2006). Effects and mechanisms in minimal quantity lubrication machining of an aluminum alloy. Wear, 260(3):339 - 344 .

[Izumi and Katsushika-ku, 1973] Izumi, T. and Katsushika-ku (1973). US 3,756, 348. Machine tool lubricating device.

[Jackson, 2008] Jackson, D. P. (2008). US 7,389,941 B2. Fluid device and method for forming cryogenic composite fluid spray.

[Jackson, 2011] Jackson, D. P. (2011). US 8,048,830 B1. Method of forming and using carbcarbon machining fluid.

[Jerold and Kumar, 2012] Jerold, B. D. and Kumar, M. P. (2012). Machining of aisi 316 stainless steel under carbon-di-oxide cooling. Material and Manufacturing Processes, (27):1059-1065.

[Kant and Sangwan, 2014] Kant, G. and Sangwan, K. S. (2014). Prediction and optimization of machining parameters for minimizing power consumption and surface roughness in machining. Journal of Cleaner Production, 83:151-164.

[Khan and Ahmed, 2008] Khan, A. and Ahmed, M. (2008). Improving tool life using cryogenic cooling. Journal of Materials Processing Technology, 196(1-3):149-154. cited By (since 1996) 17.

[Khan et al., 2009] Khan, M., Mithu, M., and Dhar, N. (2009). Effects of minimum quantity lubrication on turning aisi 9310 alloy steel using vegetable oil-based cutting fluid. Journal of Materials Processing Technology, 209(1516):5573 - 5583.

[Klocke and Eisenblatter, 1997] Klocke, F. and Eisenblatter, G. (1997). Dry cutting. CIRP Annals - Manufacturing Technology, 46(2):519 - 526. 
[Klocke et al., 2012] Klocke, F., Krämer, A., Sangermann, H., and Lung, D. (2012). Thermo-mechanical tool load during high performance cutting of hard-to-cut materials. Procedia CIRP, 1(0):295 - 300. <ce:title $>$ Fifth $\{$ CIRP $\}$ Conference on High Performance Cutting $2012</$ ce:title $>$.

[Kopac, 2009] Kopac, J. (2009). Achivievements of sustainable manufacturing by machining. Journal of achievements in materials and manufacturing engineering, $34(2): 180-187$.

[Kramer et al., 2013] Kramer, A., Klocke, F., Sangermann, H., and Lung, D. (2013). Influence of the lubricoolant strategy on thermo-mechanical tool load. CIRP Journal of Manufacturing Science and Technology, 7(0):40-47. http://dx.doi.org/10.1016/j.cirpj.2013.09.001.

[Kuram et al., 2013] Kuram, E., Ozcelik, B., and Demirbas, E. (2013). Environmentally Friendly Machining: Vegetable Based Cutting Fluids, pages 23-47. Springer Berlin Heidelberg, Berlin, Heidelberg.

[Kwok, 1999] Kwok, K.-C. (1999). EP 0971 165 A2. Pumpless liquid dispensing system.

[Lawal et al., 2012] Lawal, S., Choudhury, I., and Nukman, Y. (2012). Application of vegetable oil-based metalworking fluids in machining ferrous metals. a review. International Journal of Machine Tools and Manufacture, 52(1):1 - 12.

[Lofton, 1990] Lofton, H. (1990). US 4919232. Cold lubricant misting device and method.

[Löfgren et al., 2011] Löfgren, B., Tillman, A.-M., and Rinde, B. (2011). Manufacturing actor's \{LCA\}. Journal of Cleaner Production, 19(17-18):2025 - 2033.

[Machai et al., 2013] Machai, C., Iqbal, A., Biermann, D., Upmeier, T., and Schumann, S. (2013). On the effects of cutting speed and cooling methodologies in grooving operation of various tempers of $\hat{\mathrm{I}}^{2}$-titanium alloy. Journal of Materials Processing Technology, 213(7):1027 - 1037.

[McManus, 2011] McManus, M. (2011). Life Cycle Assessment of Rapeseed and Mineral Oil Based Fluid Power Systems. PhD thesis, University of Barh. 
[Min et al., 2005] Min, S., Inasaki, I., Fujimura, S., Wada, T., Suda, S., and Wakabayashi, T. (2005). A study on tribology in minimal quantity lubrication cutting. CIRP Annals - Manufacturing Technology, 54(1):105 - 108.

[Obikawa et al., 2006] Obikawa, T., Kamata, Y., and Shinozuka, J. (2006). Highspeed grooving with applying mql. International Journal of Machine Tools and Manufacture, 46(14):1854 - 1861.

[Park et al., 2010] Park, K.-H., Olortegui-Yume, J., Yoon, M.-C., and Kwon, P. (2010). A study on droplets and their distribution for minimum quantity lubrication (mql). International Journal of Machine Tools and Manufacture, 50(9):824 $-833$.

[Pusavec et al., 2014] Pusavec, F., Deshpande, A., Yang, S., M'Saoubi, R., Kopac, J., Jr., O. W. D., and Jawahir, I. (2014). Sustainable machining of high temperature nickel alloy - inconel 718: part 1 - predictive performance models. Journal of Cleaner Production, 81(0):255 - 269.

[Pusavec et al., 2011] Pusavec, F., Hamdi, H., Kopac, J., and Jawahir, I. (2011). Surface integrity in cryogenic machining of nickel based alloy-inconel 718. Journal of Materials Processing Technology, 211(4):773 - 783.

[Pusavec et al., 2010] Pusavec, F., Krajnik, P., and Kopac, J. (2010). Transitioning to sustainable production - part i: application on machining technologies. Journal of Cleaner Production, 18(2):174 - 184.

[REE, 2013] REE (2013). El sistema eléctrico español, síntesis. Technical report, Red Eléctrica Española.

[Reynolds, 1987] Reynolds, W. C. (1987). Fundamentals of turbulence for turbulence modeling and simulation, pages 1-66. North Atlantic Treaty Organization (NATO-OTAN).

[Rother, 2010] Rother, R. (2010). EP 2338587 A1. Vorrichtung zur aerosolerzeugung.

[Rother, 2012a] Rother, R. (2012a). EP 2574423 A1. Verfahren zur kühlung von aerosolen.

[Rother, 2012b] Rother, R. (2012b). EP 2574424 A1. Verfahren zur kühlung von aerosolen. 
[Sadik et al., 2016] Sadik, M. I., Isakson, S., Malakizadi, A., and Nyborg, L. (2016). Influence of coolant flow rate on tool life and wear development in cryogenic and wet milling of ti-6al-4v. Procedia $\{C I R P\}, 46: 91-94$. 7th $\{$ HPC $\} 2016-\{\mathrm{CIRP}\}$ Conference on High Performance Cutting.

[Sharma et al., 2016] Sharma, A. K., Tiwari, A. K., and Dixit, A. R. (2016). Effects of minimum quantity lubrication $(\mathrm{mql})$ in machining processes using conventional and nanofluid based cutting fluids: A comprehensive review. Journal of Cleaner Production, 127:1 - 18 .

[Sharma and Sidhu, 2014] Sharma, J. and Sidhu, B. S. (2014). Investigation of effects of dry and near dry machining on $\{$ AISI $\}\{$ D2 $\}$ steel using vegetable oil. Journal of Cleaner Production, 66:619 - 623.

[Sharma et al., 2009] Sharma, V. S., Dogra, M., and Suri, N. (2009). Cooling techniques for improved productivity in turning. International Journal of Machine Tools and Manufacture, 49(6):435 - 453.

[Shaw, 1984] Shaw (1984). Metal Cutting Principles.

[Shaw and Smith, 1956] Shaw, M. and Smith, P. (1956). Methods of applying cutting fluids. American Society of Tool and Manufacturing Engineers (ASTME), Paper no. RR-3.

[Shih et al., 1995] Shih, T.-H., Liou, W. W., Shabbir, A., Yang, Z., and Zhu, J. (1995). A new k-e eddy viscosity model for high reynolds number turbulent flows. Computers \& Fluids, 24(3):227 - 238.

[Shih and Zhu, 1994] Shih, T.-H. and Zhu, J. (1994). A new reynolds stress algebraic equation model.

[Shokrani et al., 2012] Shokrani, A., Dhokia, V., and Newman, S. (2012). Environmentally conscious machining of difficult-to-machine materials with regard to cutting fluids. International Journal of Machine Tools and Manufacture, 57(0):83101.

[Shokrani et al., 2016] Shokrani, A., Dhokia, V., and Newman, S. T. (2016). Investigation of the effects of cryogenic machining on surface integrity in $\{\mathrm{CNC}\}$ end milling of ti-6al-4v titanium alloy. Journal of Manufacturing Processes, 21:172 179. 
[Siefen, 1959] Siefen, J. (1959). US 2,879,947. Spray gun.

[Smith et al., 2007] Smith, S., Melkote, S. N., Lara-Curzio, E., Watkins, T. R., Allard, L., and Riester, L. (2007). Effect of surface integrity of hard turned \{AISI\} 52100 steel on fatigue performance. Materials Science and Engineering: A, 459(1-2):337 - 346 .

[Spiess, 2003] Spiess, G. (2003). WO 03/070382 A1. Method and device for producing an aerosol.

[Stephenson et al., 2014] Stephenson, D., Skerlos, S., King, A., and Supekar, S. (2014). Rough turning inconel 750 with supercritical co2-based minimum quantity lubrication. Journal of Materials Processing Technology, 214(0):673-680.

[Strano et al., 2013] Strano, M., Chiappini, E., Tirelli, S., Albertelli, P., and Monn, M. (2013). Comparison of ti6al4v machining forces and tool life for cryogenic versus conventional cooling. Journal of Engineering Manufacture, 227(9):14031408.

[Su et al., 2007] Su, Y., He, N., Li, L., Iqbal, A., Xiao, M., Xu, S., and Qiu, B. (2007). Refrigerated cooling air cutting of difficult-to-cut materials. International Journal of Machine Tools and Manufacture, 47(6):927 - 933.

[Supekar et al., 2012] Supekar, S., Clarens, A., Stephenson, D., and Skerlos, S. (2012). Performance of supercritical carbon dioxide sprays as coolants and lubricants in representative metalworking operations. Journal of Materials Processing Technology, 212(12):2652 - 2658.

[Swift, 1991] Swift, S. (1991). EP 0458632 A1. A tool and workpiece mist lubrication system.

[Truesdale and Shin, 2009] Truesdale, S. L. and Shin, Y. C. (2009). Microstructural analysis and machinability improvement of udimet 720 via cryogenic milling. Machining Science and Technology, 13(1):1-19. Cited By (since 1996):4.

[Tönshoff et al., 2000] Tönshoff, H., Arendt, C., and Amor, R. B. (2000). Cutting of hardened steel. CIRP Annals - Manufacturing Technology, 49(2):547 - 566.

[Vega and Walker, 1964] Vega, S. and Walker, S. (1964). US 3,131,869. Coolant device for mahcine tools. 
[Visser, 1971] Visser, G. (1971). US 3,577,808. Sub-zero cutting fluid generator.

[Wakabayashi et al., 2007] Wakabayashi, T., Suda, S., Inasaki, I., Terasaka, K., Musha, Y., and Toda, Y. (2007). Tribological action and cutting performance of mql media in machining of aluminum. CIRP Annals - Manufacturing Technology, 56(1):97 - 100 .

[Weinert et al., 2004] Weinert, K., Inasaki, I., Sutherland, J., and Wakabayashi, T. (2004). Dry machining and minimum quantity lubrication. CIRP Annals - Manufacturing Technology, 53(2):511 - 537.

[Zurecki et al., 2003] Zurecki, Z., Herbert, J., and Trembley, J. (2003). US 6,513,336 B2. Apparatus and method for transferring a cryogenic fluid. 